\title{
Decadal climate oscillations, synoptic variability, and ice core climate proxy records in the Ross Sea region, Antarctica
}

\author{
Bradley Ross Markle
}

A thesis submitted in partial fulfillment of the requirements for the degree of Masters of Science in Geology, June 2011.

Resubmitted with revisions February 2012

Victoria University of Wellington

Wellington, New Zealand 



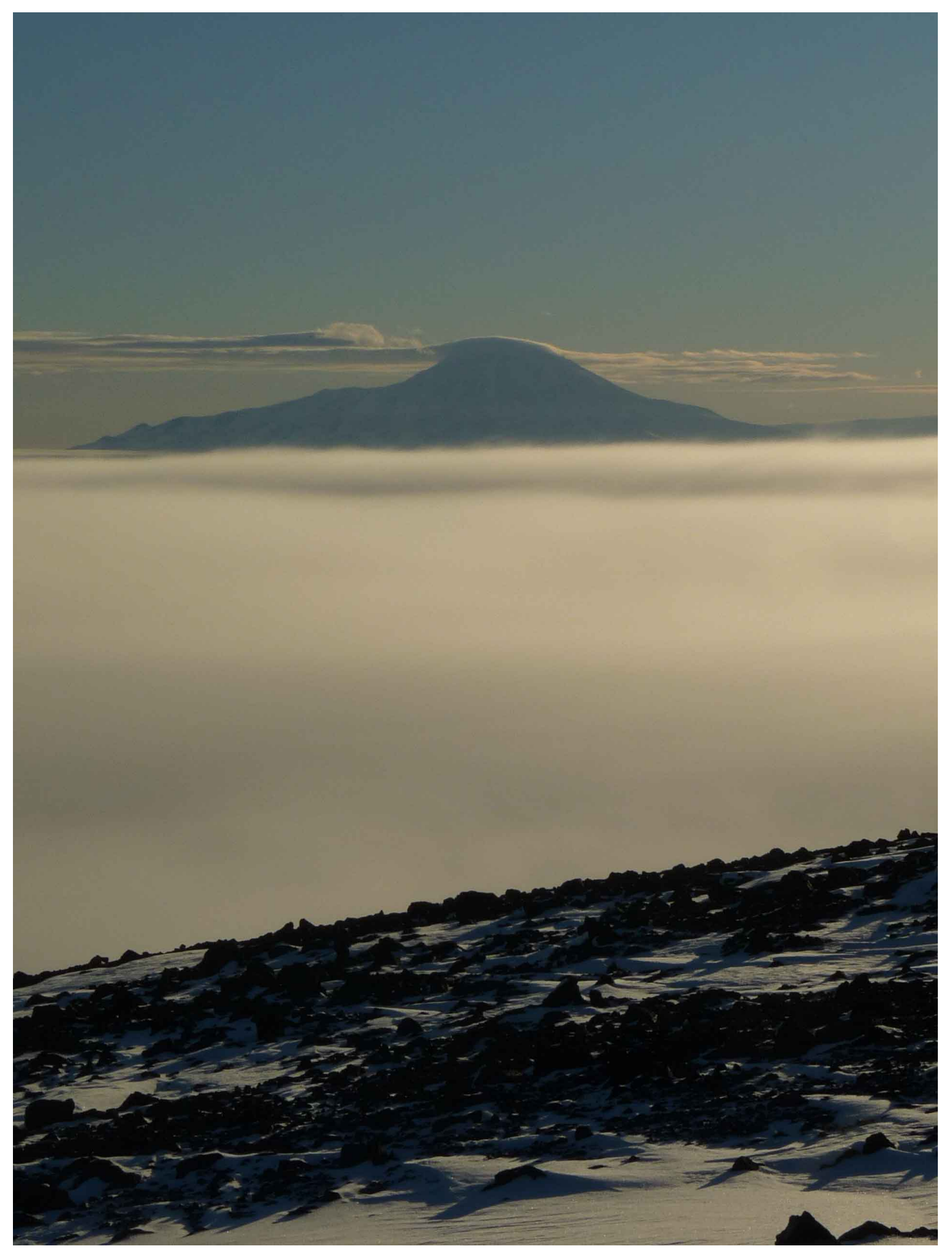


Reverse: Low clouds over the Ross Ice Shelf, Antarctica with Mt. Discovery in distance. Photo: Bradley Markle, 2011 


\section{Abstract}

This thesis investigates synoptic variability in the Ross Sea region, Antarctica and develops geochemical proxies of this variability from an ice core record in Southern Victoria Land. Particular focus is given to the influence of decadal climate oscillations on synoptic conditions and potential records of these oscillations in ice core proxy records as long-term records of these oscillations are important for understanding future climate change.

I present an investigation of the joint influence of the El Niño Southern Oscillation (ENSO) and the Southern Annular Mode (SAM) on variability in the Amundsen Sea Low (ASL), a dominant climatological feature that strongly influences the weather in the Ross Sea region. It is shown that the positive phase of each oscillation is associated with significant strengthening of the ASL, while negative phases are associated with a weakening. Through regression analysis I show that a simple linear combination of indices representing these oscillations can explain more than $40 \%$ of the geopotential height variance in the AS region at a seasonal scale and over $70 \%$ of the variance at an annual scale. These results are consistent with the known mechanisms of ENSO and SAM interaction in the region and show that while SAM is dominant hemispherically, ENSO is only influential in the Pacific Sector. Finally it is demonstrated that a simple model of linear reinforcement and interference between the oscillations describes their influence 
on the variability in the ASL better than models incorporating more complex interactions.

Atmospheric back-trajectory modeling and cluster analysis are used to investigate synoptic variability at the Gawn Ice Piedmont (GIP) ice core site in the Ross Sea Region, Antarctica. I identify two dominant air-mass trajectory clusters: oceanic - cyclonic and continental trajectories. My analysis shows that oceanic cyclonic trajectories peak during April (southern hemisphere winter), while continental trajectories reach their maximum during December (summer). A causal association is demonstrated between ENSO and the frequency of oceanic - cyclonic trajectories originating from the Ross Sea region. In contrast, it is shown that the Southern Annular Mode has little influence on the frequency of cyclonic clusters. I then develop proxy records for the synoptic variability using a shallow firn core from the GIP site containing 8 years of geochemical record. Continental trajectories correlate with concentrations of nitrate $\left(\mathrm{NO}_{3}\right)$, which is sourced from stratospheric air-masses descending over the Antarctic interior. Oceanic - cyclonic trajectory clusters strongly correlate with deuterium excess at seasonal and inter-annual scales, a proxy sensitive to changes in relative humidity and sea surface temperature (SST) in the in the Ross and Amundsen Seas. Decadal variability in the frequency of oceanic - cyclonic trajectories is discussed with respect to ENSO, SAM, and changes in SST and sea ice extent. 


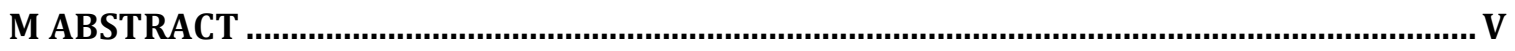

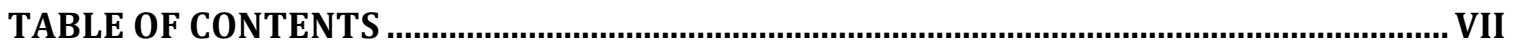

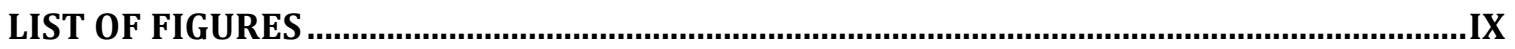

LIST OF TABLES

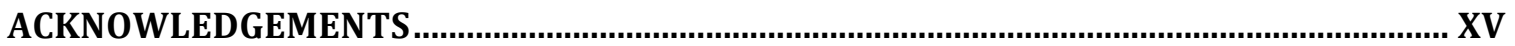

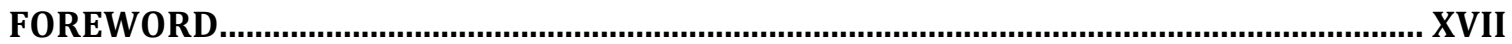

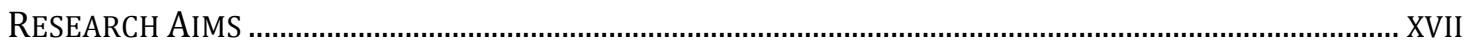

OUTLINE OF THESIS ................................................................................................................................. XVII

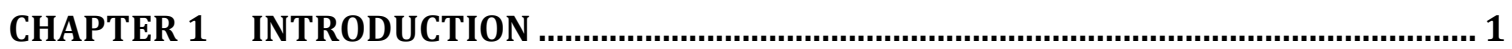

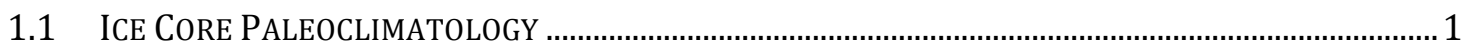

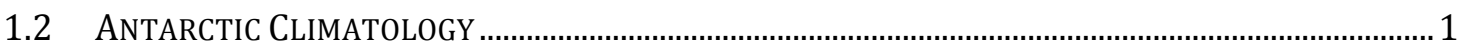

1.3 DECADAL CLIMATE OSCILLATIONS - ENSO AND SAM …............................................................. 5

1.4 GAWN ICE PIEDMONT ICE CORE AND STUDY SITE .......................................................................... 7

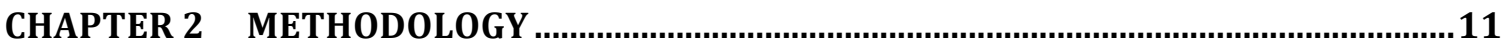

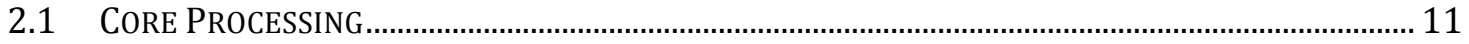

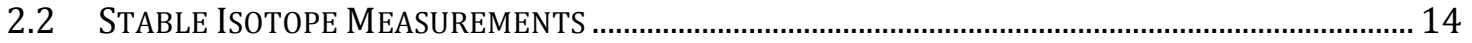

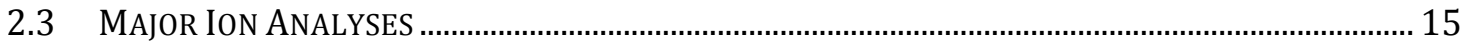

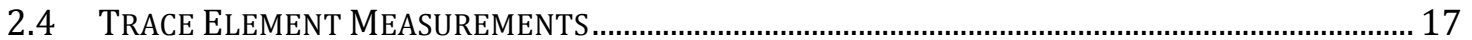

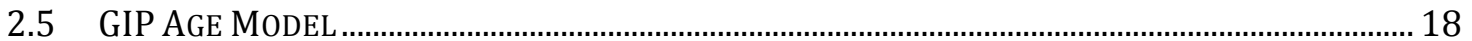

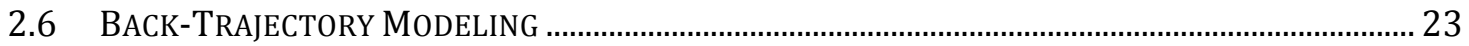

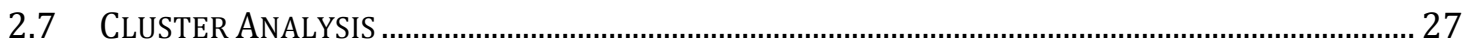

CHAPTER 3 THE JOINT INFLUENCE OF THE SOUTHERN ANNULAR MODE AND THE EL

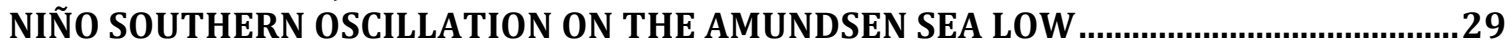

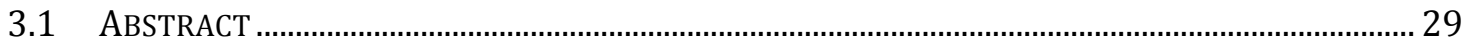

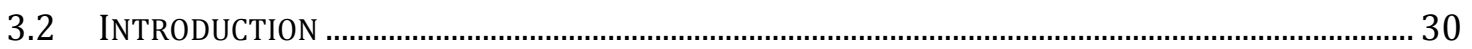

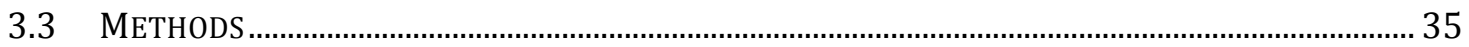

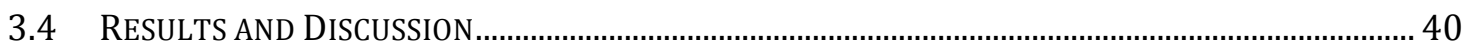

3.4.1 SOI-SAM Influence on Geopotential Height Variability ................................................. 40

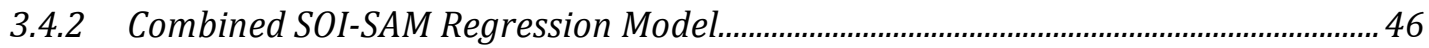

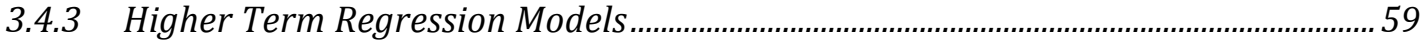

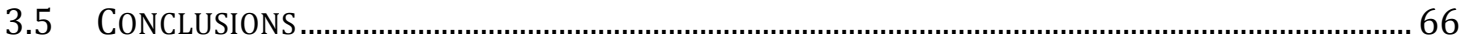

CHAPTER 4 SYNOPTIC VARIABILITY IN THE ROSS SEA REGION, ANTARCTICA AS SEEN FROM BACK-TRAJECTORY MODELING AND ICE CORE ANALYSIS..............................70

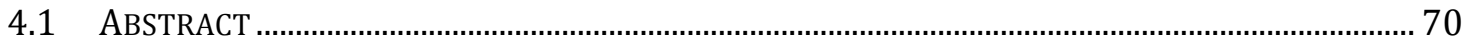

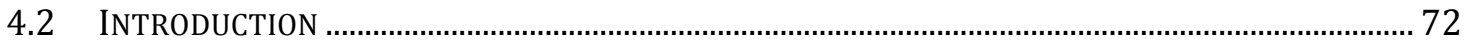

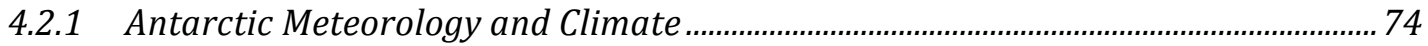

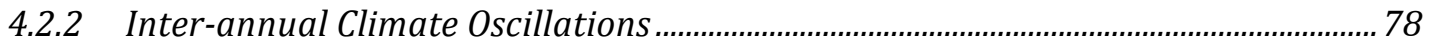

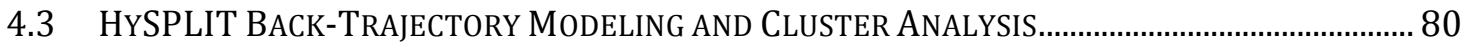

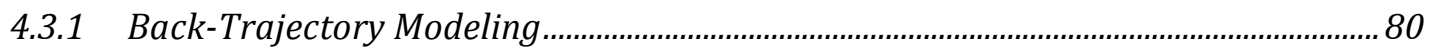

vii 


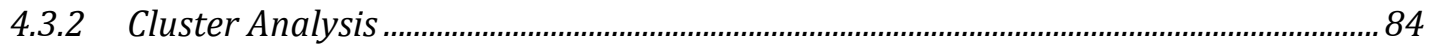

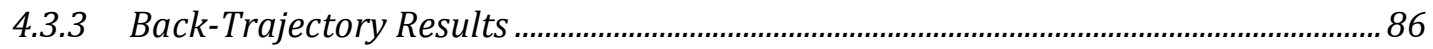

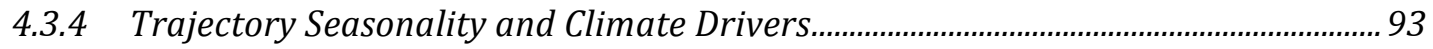

4.4 PROXY DEVELOPMENT FROM THE GIP FIRN CORE................................................................104

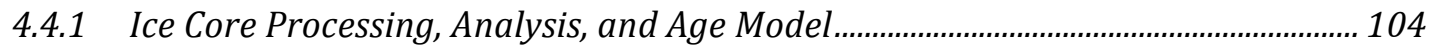

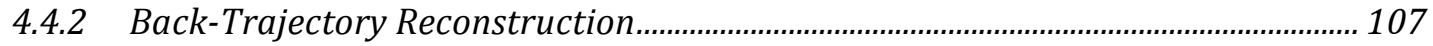

4.4.3 Proxy Development for Continental Trajectories...................................................... 113

4.4.4 Proxy Development for Oceanic Trajectories............................................................... 115

4.4.5 Possible Inter-annual Drivers of d Variability ................................................................ 120

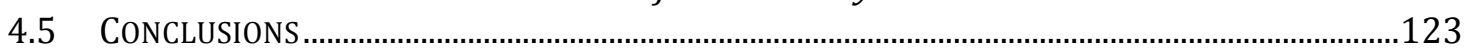

\section{CHAPTER 5 CORRELATIONS IN TRAJECTORY FREQUENCIES AND PRESSURE FIELDS} 126

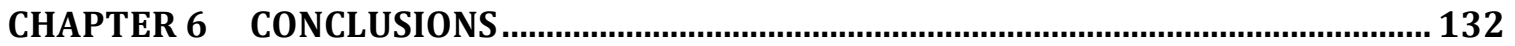

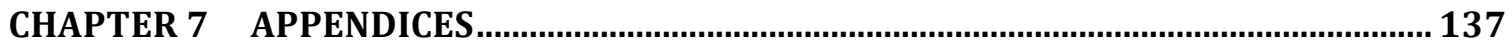

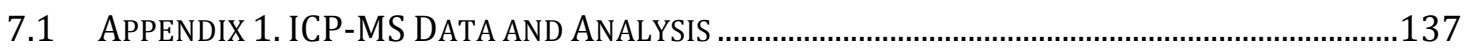

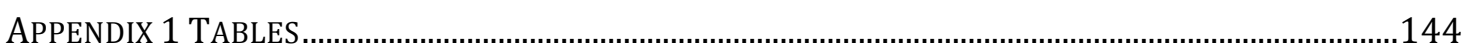

7.2 APPENDIX 2. COMPARISON OF WEATHER STATION AND REANALYSIS DATA IN THE ROSS SEA

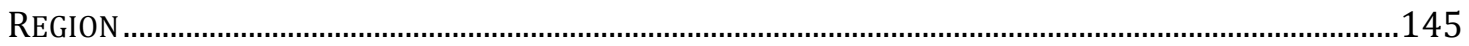

7.3 APPENDIX 3. COMPLETE TRAJECTORY AND CLUSTER ANALYSIS PLOTS ......................................148

7.4 APPENDIX 4. INTERCOMPARISON OF HYSPLIT RESULTS FROM DIFFERENT REANALYSIS

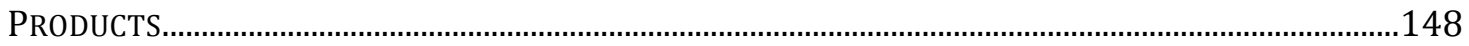

7.5 APPENDIX 5. MCMURDO SOUND DUST STORM EVENT AND POTENTIAL BIOGEOCHEMICAL LINKS

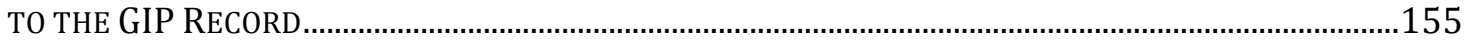

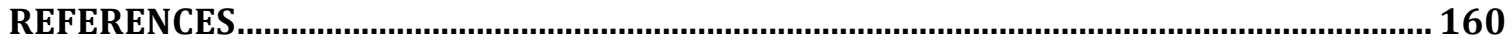




\section{List of Figures}

Figure 1.1 The mean annual $850 \mathrm{mb}$ geopotential heights are shown (in meters) from the 1980 to 2010 NCEP/NCAR reanalysis data set. The ASL feature is the dark purple center of low geopotential height in the upper right, centered in the Ross Sea, though extending across the entire Amundsen Sea region. Data available from http://www.esrl.noaa.gov/.

Figure 1.2 a) The Byrd Glacier drains from the East Antarctic Ice Sheet to the left, through the Transantarctic Mountains, to the Ross Ice Shelf on the right. The locations of the Gawn Ice Piedmont (GIP) and Skinner Saddle (SKS) ice core sites are shown in red. Image courtesy of NASA's Landsat Image Mosaic of Antarctica Project. North arrow indicates the grid north reference for the Landsat imagery; b) The Ross Sea region with surface wind fields plotted after Carrasco and Bromwich [1994]. The Byrd Glacier area is boxed in red; c) An overview of Antarctica with important features labeled with the Ross Sea area boxed in red.

Figure 1.3 Overview of ITASE science targets (yellow stars) in the Ross Sea region of Antarctica....... 8

Figure 1.4 ASTER satellite image of Gawn Ice Piedmont and vicinity. See Figure 1.2 for overview. Image from 08 January 2004. Yellow flag indicates location of camp and drill location of shallow firn core; red flag indicates proposed drilling location for deep core. B) Digital elevation model. $\mathrm{X} / \mathrm{Y} / \mathrm{Z}$ grid in meters (UTM zone 58). Red lines indicate location of ice penetrating radar survey lines [Bertler, 2008].

Figure 1.5 Collection of the GIP core on site in November 2007.

Figure 2.1 A section of GIP core during sampling on the discrete melter system in the clean laboratory at the New Zealand Ice Core Laboratory, GNS Science.

Figure 2.2 Peristaltic pump and automated fraction collector capturing samples for trace element analysis. This line was contained in a clean hood within the clean laboratory at the New Zealand Ice Core Laboratory, GNS Science.

Figure 2.3 $\delta D(d D)$ values are plotted against $\delta^{18} 0\left(\mathrm{~d}^{18} \mathrm{O}\right)$ values for all samples from the GIP core. The data consistently fall on a local water line with a slope of 7.8. Three data points (circled in red) plot off the mean water line and are suspected for contamination.

Figure 2.4 Composite monthly NNR surface temperature for the GIP site averaged for two periods: January 2000 to November 2007 (blue), the period spanned by the GIP core; and January 2000 to December 2010 (red), a 30-year climatology.

Figure 2.5 Select geochemistry data are shown from the GIP core plotted against the age model alongside NCEP/NCAR reanalysis (NNR) surface temperature data for the GIP site (red, at bottom). $\delta^{18} 0$ (dark blue) and MS (purple) peaks were used to distinguish annual cycles and matched to NNR temperature maxima. Geochemistry data are resampled at monthly resolution and many species (top) show distinct annual cycles by this age model. NNR data are available from http://www.esrl.noaa.gov/psd/data/reanalysis/.

Figure 3.1 Map of Antarctic showing locations of all NNR data points used in regression analysis (red stars). Note that the point at $70^{\circ} \mathrm{S}, 290^{\circ} \mathrm{E}$ (green star) on the Antarctic Peninsula is omitted from analysis so that all points used are over ocean to eliminate topographic effects. The Amundsen Sea Region is in the lower left. The point at $65^{\circ} \mathrm{S}, 240^{\circ} \mathrm{E}$, referenced throughout the text, is noted with a large orange star.

Figure 3.2 Correlation matrix of seasonally corrected NNR $850 \mathrm{mb}$ geopotential height anomalies. High spatial autocorrelation is observed in some areas such as between 0 and $160^{\circ} \mathrm{E}$, while lower spatial autocorrelation is seen in the AS region between 180 and $300^{\circ} \mathrm{E}$.

Figure 3.3 Composite anomaly maps of NNR $850 \mathrm{mb}$ geopotential heights, in meters, for a) $\mathrm{SAM}^{+}$ (September to August: 1982, '84, '93, '94, '97, '99, '00, '02, '08, '09); b) ENSO+ (May to April: 1982, '84, '85, '86, '89, ‘91, '96, ‘97, '99, '00, '01, '02, '04, '06, '08, '09); c) SAM- (September to August: 1980, '81, '83, '85, '88, '92, ‘01, '03, '07, '10); d) ENSO- (May to April: 1981, '83, '87, '92, '93, '94, '95, '98, '03, '05, '07, '10). Anomalies shown from the 1968-1996 climatological mean. Data obtained from the NOAA/ESRL Physical Sciences Division. .

Figure 3.4 Comparison of a) the SOI, b) SAM, and c) combined SOI-SAM regression model with NNR $850 \mathrm{mb}$ geopotential height anomalies for 1980 through 2009 from $65^{\circ} \mathrm{S}, 240^{\circ} \mathrm{E}$. All time series 
are shown with a 3-month mav smoothing. Correlations coefficients are shown at right. Note that the sign of the SOI and SAM have been flipped for plotting, a) and b), to more easily demonstrate the correlation, though r-values were calculated with the original sign..

Figure 3.5 Wavelet analysis is shown for a) the SOI, b) SAM, c) NNR $850 \mathrm{mb}$ geopotential height anomaly, d) our combined SOI-SAM regression model, and e) the model residuals. All time series are from 1980 through 2009, have been smoothed with a 3-month mav, and are for $65^{\circ}$, $240^{\circ} \mathrm{E}$ in the case of c), d), and e). Values outside dashed white lines may be influenced by edge effects with the ends of the time series while the solid black line denotes significance above a modeled red noise following Torrence and Compo [1998]. The color scale shows the square root of the ratio of power to total data variance and is thus relative for each time series. Period is plotted on a logarithmic scale.

Figure 3.6 a) Composite standardized $850 \mathrm{mb}$ geopotential height anomaly data with a 3 month moving averaging (red) and regression model results (blue) for 18 longitude points at $65^{\circ} \mathrm{S}$. b) Zonal mean for $850 \mathrm{mb}$ geopotential height anomaly and regression model results for $65^{\circ} \mathrm{S} . . .47$

Figure 3.7 a) Composite of residuals for the regression model at $65^{\circ} \mathrm{S}$. b) Zonal mean of the regression residuals at $65^{\circ}$. Scaling is identical to Figure 3.6 for comparison............................48

Figure 3.8 Spatial variability of the combined SOI-SAM regression model results with a 3-month mav smoothing is shown for a) Coefficients $b^{\text {SOI }}$ and $c^{\text {SAM }}$ represent the influence of the SOI and SAM, respectively; b) $\mathrm{R}^{2}$ values represent the percent variability of the NNR data captured by the model; c) The relative influence of SOI to SAM is represented by the ratio $b^{\mathrm{SOI}} / c^{\mathrm{SAM}}$. Values for $60^{\circ} \mathrm{S}$ are denoted with a smooth line, $65^{\circ} \mathrm{S}$ with open circles, and $70^{\circ} \mathrm{S}$ with a dashed line.... 49

Figure 3.9 The Combined SOI-SAM model (black) $\mathrm{R}^{2}$ values for $65^{\circ} \mathrm{S}$ with a 3-month mav smoothing are compared to those of SOI-only (dashed blue) and SAM-only models (red with open circles). The combined model significantly improves $\mathrm{R}^{2}$ over the SAM-only model only in the AS region where the influence of SOI becomes important.

Figure 3.10 The affect of 1, 3, 5, and 12-month average (av) and moving average (mav) smoothing on the regression model is shown for a) $b^{\text {SOI }} / c^{\text {SAM }}$, representing the relative influence of SOI to SAM and $\mathbf{b}) \mathrm{R}^{2}$, the percent variance in NNR geopotential explained by the combined SOI-SAM regression model at $65^{\circ} \mathrm{S}$. Note the difference in scales..

Figure 3.11 P-values are shown for a Breusch-Pagan test for the rejection of the null hypothesis of homoscedasticity for each longitude at $65^{\circ} \mathrm{S}$. The dashed red line denotes the $95 \%$ confidence limit; at sites with values above this line, the null hypothesis cannot be rejected........................53

Figure 3.12 Correlation matrix of the regression model residuals around $65^{\circ}$ S.................................54

Figure 3.13 Cross correlation matrix of regression model residuals and the $850 \mathrm{mb}$ geopotential

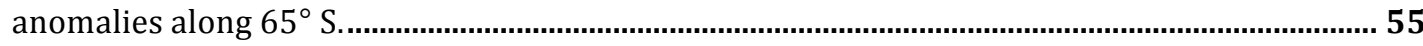

Figure 3.14 The combined SOI-SAM model for 1980 through 2009 (bold black) is compared to the individual decades: the 1980s (thin red line), 1990s (orange with open circles), and 2000s (dashed blue). a) The ratio $b^{\text {SOI }} / c^{\text {SAM }}$ represents the relative influence of SOI to SAM; b) and $\mathrm{R}^{2}$ represents the percent variance in NNR geopotential explained by the combined model. The results shown are for $65^{\circ} \mathrm{S}$ with a 3-month mav. Note the difference in scales.........................58

Figure 3.15 Here we compare a) the simple combined SOI-SAM model, with b) a model splitting the SOI and SAM into their positive and negative phases, and c) a model splitting the SOI into preand post-1990 indices. Where applicable, $\mathrm{R}^{2}$ values are shown in black, $a^{\text {const }}$ in green with crosses, $b^{\mathrm{SOI}}$ in blue with open circles, $c^{\mathrm{SAM}}$ in dashed red, and $b^{\mathrm{SOI}} / c^{\mathrm{SAM}}$ in purple. Note the nonzero values of $a^{\text {const }}$ in b) centered at $150^{\circ} \mathrm{E}$ and $300^{\circ} \mathrm{E}$. Note also the overall spatial similarity of $\mathrm{R}^{2}$ and $b^{\mathrm{SOI}} / c^{\mathrm{SAM}}$ between models.

Figure 4.1 a) The Byrd Glacier drains from the East Antarctic Ice Sheet to the left, through the Transantarctic Mountains, to the Ross Ice Shelf on the right. The locations of the Gawn Ice Piedmont (GIP) and Skinner Saddle (SKS) ice core sites are shown in red. Image courtesy of NASA's Landsat Image Mosaic of Antarctica Project. North arrow indicates the grid north reference for the Landsat imagery; b) The Ross Sea region with surface wind fields plotted after Carrasco and Bromwich [1994]. The Byrd Glacier area is boxed in red; c) An overview of Antarctica with important features labeled with the Ross Sea area boxed in red........................ 73 
Figure 4.2 Cluster mean trajectories for the 1980-2010 cluster analysis (top) color-coded by class and group. Blue shades represent Oceanic group clusters, while red shades show the Continental group. Mean trajectory altitudes over time are shown below.

Figure 4.3a) The 91-day moving average frequencies of cluster classes for the 1980 to 2010 period. Each color represents an individual cluster class as shown in Figure 4.2. Blue shades correspond to oceanic/West Antarctic group frequencies while red and orange shades correspond to continental/East Antarctic group frequencies. They are stacked from bottom, approximately clockwise (east) from the GIP site. Frequencies are shown in fractions of 1, i.e. a class with a frequency of 0.5 occurred on $50 \%$ of the days within a 91-day window centered on that day; b) The 5-month moving average time series of the SOI (red) and the non-seasonal AS sub-group (light blue); c) The 5-month moving average time series of the SOI (red) and the non-seasonal RS sub-group (dark blue). Note the reverse orientation of the RS frequency axis.

Figure 4.4 The seasonality of the Oceanic group frequency is shown (purple) as well as the constituent sub-groups: the Ross Sea (RS) sub-group (blue) and the Amundsen Sea (AS) subgroup (red). Note that the Continental group seasonality is simply opposite that of the Oceanic group, since at any point in time the sum of the two groups comprises all trajectories.............. 96

Figure $4.5850 \mathrm{mb}$ geopotential height anomalies associated with ENSO's a) positive phase (La Niña) and b) negative phase (El Niño). Anomalies are shown in meters from the 1981-2010 climatological mean. Positive ENSO (a) is associated with negative anomalies off West Antarctica and a deepening of the ASL which leads to increased frequency of trajectories sourced from the AS reaching the GIP site. Negative ENSO (b) is associated with positive anomalies off West Antarctica, a relative weakening of the ASL and a relative increase in RS sourced trajectories. Annual (Jan. to Dec.) $850 \mathrm{mb}$ geopotential height anomalies are plotted from the NCEP/NCAR reanalysis data (available at http://www.esrl.noaa.gov/psd/cgibin/data/composites/). Positive/negative ENSO years were determined by the sign of annual (Jan. to Dec.) sums of monthly SOI values. Positive SOI years: 1981, '85, '88, '96, '99, '00, '01, '07, '08. Negative years: 1980, '82, '83, '84, '86, '87, '90, '91, '92, '93, '94, '95, '97, '98, '02, '03, '04, '05, 09.

Figure 4.6 Annual (Jan. to Dec.) $850 \mathrm{mb}$ geopotential height anomalies associated with the a) positive and b) negative phase of SAM, shown in meters from the 1981-2010 climatological mean. Geopotential height anomalies are obtained from the NCEP/NCAR reanalysis data (available at http://www.esrl.noaa.gov/psd/cgi-bin/data/composites/). Positive/negative SAM years were determined from annual (Jan. to Dec.) sums of monthly Marshall [2003] SAM index values. Positive SAM years: 1982, '83, '85, '89, '93, '95, '97, '98, '99, '00, '01, '03, '04, '05, '06, '08, '09, '10. Negative years: 1980 , '81, '84, '86, '87, '88, '90, '91, '92, '94, '96, '02, '07. 103

Figure 4.7 Cluster mean trajectories for the 2000-2008 cluster analysis (top) color-coded by class and group. Blue shades represent Oceanic group clusters, while red shades show the Continental group. Mean trajectory altitudes over time are shown below.

Figure 4.8 a) The 91-day moving average frequencies of cluster classes, 2000-2008. Each color represents an individual cluster class as in Figure 4.7. Blue shades correspond to Oceanic group frequencies while red and orange shades correspond to Continental group frequencies. They are stacked, from bottom, clockwise (east) from the GIP site; b) Raw NO3 (orange) data are shown against the 91-day smoothed Continental group frequency (black). c) Raw d data (red) are shown against the 91-day smoothed Oceanic group frequency (blue).

Figure 4.9 Annual snow accumulation in $\mathrm{cm}$ of water equivalent (red) and average annual Oceanic group frequency (blue) for 2000-2008.

Figure 4.10 a) The mean resampled monthly values of NO3 (orange), SO4 (red), and MS (purple) concentrations from the GIP core; b) Seasonality of the mean resampled d (red) and $\partial 180$ (blue) values.

Figure 4.11 a) The non-seasonal, 5-month moving average Oceanic group frequency and resampled $\mathrm{d}$ record; b) the SOI; and c) NOAA's OI SST anomalies for the Ross and Amundsen Seas (orange) as well as the NSIDC sea Ice index for the Amundsen Sea (blue) (SST and SOI data available 
from http://www.esrl.noaa.gov/psd/data/climateindices/; and sea ice data is available from http://nsidc.colorado.edu/data/seaice_index/).

Figure 4.12 SST anomalies associated with a) positive ENSO years and b) negative ENSO years. Positive/negative ENSO years are identical to those described in Figure 4.5. Images created from NOAA's web plotting tool (available at http://www.esrl.noaa.gov/psd/cgibin/data/composites/printpage.pl).

Figure 5.1 Correlations between annual (Jan-Dec) NNR $850 \mathrm{mb}$ geopotential height from 1980 through 2009 are shown for monthly a) Oceanic group, b) Amundsen Sea sub group, and c) Ross Sea sub group trajectories frequencies. Data are available at http://www.esrl.noaa.gov/psd/data/correlation/. Note the difference in scales.

Figure 5.2 Oceanic group frequency correlations with NNR $850 \mathrm{mb}$ geopotential height from 1980 through 2009 are shown for a) summer (D J F), b) fall (M A M), c) winter (J J A), and d) spring (S O N) Data are available at http://www.esrl.noaa.gov/psd/data/correlation/. Note the difference in scales.

Figure 5.3 AS subgroup frequency correlations with NNR $850 \mathrm{mb}$ geopotential height from 1980 through 2009 are shown for a) summer (D J F), b) fall (M A M), c) winter (J J A), and d) spring (S ON ) Data are available at http://www.esrl.noaa.gov/psd/data/correlation/. Note the difference in scales.

Figure 5.4 RS subgroup frequency correlations with NNR $850 \mathrm{mb}$ geopotential height from 1980 through 2009 are shown for a) summer (D J F), b) fall (M A M), c) winter (J J A), and d) spring (S O N) Data are available at http://www.esrl.noaa.gov/psd/data/correlation/. Note the difference in scales.

Figure 7.1 Concentrations of Mg are plotted against $\mathrm{Na}$, as measured by ICP-MS, for all data. The blue line indicates the mean seawater ratio of $\mathrm{Mg}$ to $\mathrm{Na}$. Data samples suspected of contamination are shown as black dots surrounded by red circles, plotting well off the mean seawater line. Samples neighboring the suspected samples were then measured ("New Data", shown in red dots) and are shown to plot closer to the mean water line, similar to the rest of the data.......138

Figure 7.2 Values of $\mathrm{Ca}, \mathrm{Mg}$, and Na measured by both ICP-MS (red) and IC (blue) for identical samples are plotted against core depth (meters of water equivalent). Concentrations are plotted on a log scale, to highlight outliers.

Figure 7.3 A cross correlation matrix is shown of all geochemistry concentrations. "NA", "MG", "CA" are concentrations measured by IC, as opposed to "Na" "Mg" and "Ca" measured by ICP-MS. Correlations along the $\mathrm{Y}$-axis are read in the rows below the labels, $\mathrm{X}$-axis correlations in the column to the right of the labels.

Figure 7.4 Loadings, by element, are shown for the first four principle components, representing in total $77 \%$ of the total variance.

Figure 7.5 The loadings of PC 2 against PC 1 are shown for all elements. Note the distinct clustering of species into coherent groups.

Figure 7.6 Comparison of AWS and NCEP temperature for the SKS and EPG ice core sites. NCEP data are available from NASA's Earth System Research Laboratory, Physical Sciences Division (http://www.esrl.noaa.gov/psd/data).

Figure 7.7 Comparison of $\delta^{18} 0$, NCEP temperature, and AWS temperature (where applicable) between the EPG, GIP, and SKS ice core site in the Ross Sea Region Antarctica. The data show an acceptable agreement between recorded temperature and $\delta^{18} 0$, suggestive that a longer record from GIP could be used to reconstruct the temperature history of the region.

Figure 7.8 Comparison of cluster means for cluster analysis of daily back-trajectories for 1990 and 2000 based on NCEP/NCAR, ERA-40, and ERA-Interim reanalysis data.

Figure 7.9 Graphs showing the Oceanic Group, and RS and AS sub-group monthly frequencies for each reanalysis product for 2000 . Y-axis shows frequency from 0 to $100 \%$, and X-axis shows the numerical month (i.e. January $=1$ ).

Figure 7.10 Graphs showing the Oceanic Group, and RS and AS sub-group monthly frequencies for each reanalysis product for the year 1990 The average of all three reanalyses for 1990 is also 
shown. Y-axis shows frequency from 0 to $100 \%$, and $\mathrm{X}$-axis shows the numerical month (i.e. January =1)

Figure 7.11 From top to bottom: A comparison of Ross Sea sea ice extent (from the NSIDC sea ice index data base), Chlorophyll- $\alpha$ concentration from the McMurdo Sound polynya region from the SEA-WiFS program, McMurdo Sound dust flux concentration [Winton, personal communication], GIP nss $\mathrm{SO}_{4}$, and GIP MS records 


\section{List of Tables}

Table 3-1 Values of $\mathrm{R}^{2}, b^{\mathrm{SOI}} / c^{\mathrm{SAM}}$, and the percent significance level of the F statistic above a SAM-only model for 1, 3, 5, and 12-month average (av) and moving average (mav) smoothing methods.

Values are shown for two points $\left(65^{\circ} \mathrm{S}, 240^{\circ} \mathrm{E}\right.$ and $\left.65^{\circ} \mathrm{S}, 260^{\circ} \mathrm{E}\right)$ in the AS region. ...................52

Table 3-2 Terms used in each regression model, the corresponding $\mathrm{R}^{2}$ value at $65^{\circ} \mathrm{S}, 240^{\circ} \mathrm{E}$ (the peak in the AS region), and the percent significance level. All models use time series with 3month mav smoothing and include a constant term, $a^{\text {const, not shown }}$

Table 4-1 Cluster Classification 1980-2010. Cluster groups and classes for the 1980-2010 classification arranged approximately clockwise from the GIP site. The approximate source region and/or general pathway is given (WKL=Wilkes Land and VCL= Victoria Land), along with a qualitative indication of relative speed. "Var." is used to denote classes containing trajectories with variable lengths.

Table 4-2 Reanalysis Inter-comparison. Percent differences in annual cluster class or group frequency between three reanalysis products, NCEP/NCAR, ERA-40, and ERA-Interim. Bold italic numbers indicate differences greater than $10 \%$.

Table 4-3 Cluster Classification 2000-2008. Cluster groups and classes for the 2000-2008 classification arranged approximately clockwise from the GIP site. The approximate source region and/or general pathway is given $(\mathrm{QML}=\mathrm{Queen}$ Maud Land, WKL= Wilkes Land, and VCL= Victoria Land), along with a qualitative indication of relative speed. "Var." is used to denote classes containing trajectories with variable lengths.

Table 7-1 Geochemistry data. All chemistry data is shown by sample. Age is based on the age model described in Chapter 2.

Table 7-2 Detection Limits. ICP-MS detection limits are shown for all species in all samples.......144

Table 7-3 Melter Blanks. Background concentrations are presented for MilliQ blanks that were passed through the entire core sampling process and melter system 


\section{Acknowledgements}

I'd first like to thank my supervisor, Dr. Nancy Bertler for the tremendous support, encouragement, and unfailing enthusiasm throughout this project. I owe a very special thanks to Holly Winton, Kate Sinclair, Rachael Rhodes, and Lana Cohen for immeasurable help at every stage of this thesis. Thanks to Dr. Melissa Bowen for instruction with wavelet analysis, Dr. Euan Smith for his statistical expertise, and Dr. Marc Millet for his geochemical assistance. I'd like to express my deep gratitude to the entire Antarctic Research Center at Victoria University of Wellington, for the tremendous support, opportunities, and friendship. I would like to thank Antarctica New Zealand and Scott Base for logistical support in Antarctica. Thanks to Sharon Sneed at the Climate Change Institute at the University of Maine and the GNS Stable Isotope Lab for geochemical measurements. Thank you very much to my thesis examiners Dr. Dan Zwartz and Dr. Sam Dean as well as 3 anonymous reviewers from the Journal of Geophysical Research - Atmospheres. Their thoughtful comments and suggestions have greatly improved the quality of this work. Finally, thanks to the Fulbright New Zealand Association for making this extraordinary experience possible.

This work was funded by the New Zealand Foundation of Research, Science, and Technology via contracts awarded to Victoria University of Wellington and GNS Science (contracts VICX0704, COX0202, and C05X0902) and by a Fulbright Fellowship from the U.S. State Department. NCEP/NCAR re-analysis time series 
were obtained from NOAA Earth System Research Laboratory, as were all climate indices (http://www.esrl.noaa.gov/psd/data/). Sea ice data was obtained from the National Snow and Ice Data Center (http://nsidc.colorado.edu/data/seaice index/). The Marshall SAM index was obtained from G. Marshall at http://www.antarctica.ac.uk/met/gjma/sam.html. 


\section{Foreword}

\section{Research Aims}

This thesis contributes to the New Zealand International Trans-Antarctic Scientific Expedition by studying the climate history at the Gawn Ice Piedmont Glacier using re-analysis data and a shallow firn core. The research presented here aims

i. To quantify the relative influence of decadal climate oscillations, such as the El Niño Southern Oscillation and the Southern Annular Mode on climate variability in the Ross Sea Region, Antarctica

ii. To reconstruct past climate and develop a proxy records of synoptic variability as captured in a firn core from the Gawn Ice Piedmont, a high accumulation ice core site in the southern Ross Sea Region, Antarctica

\section{Outline of Thesis}

This thesis is comprised of 6 chapters. Chapters 3 and 4 are manuscripts that have been prepared for submission to scientific journals. Due to their stand-alone nature, pertinent elements of background information (Chapter 1) and methodologies (Chapter 2) are restated within these manuscripts. However, an effort has been made to avoid excessive repetition, thus some relevant information may only be found in the manuscripts. 
Chapter 1: 'Introduction' provides an overview of important aspects of Antarctic climate, the importance of the Ross Sea Region in the global climate system, and the relevance of the Gawn Ice Piedmont study site.

Chapter 2: 'Methodology' discusses the analytical procedures of the ice core analyses conducted (sample processing, analytical measurements, and the determination of the age model), and the methods used in back-trajectory modeling and cluster analyses are outlined.

Chapter 3: 'The joint influence of the Southern Annular Mode and the El Niño Southern Oscillation on the Amundsen Sea Low' is prepared as a manuscript for submission to the International Journal of Climatology. This paper investigates the joint influence of ENSO and SAM on the pressure systems of the high latitude southern hemisphere through a simple regression model. In addition, higher order relationships are also tested but do not improve the correlation. Understanding the influence of these oscillations on pressure systems in the region is key to understanding how they may be recorded in ice cores.

Chapter 4: 'Synoptic variability in the Ross Sea region, Antarctica as seen from back-trajectory modeling and ice core analysis' is a manuscript now published the Journal of Geophysical Research - Atmospheres. The study uses back-trajectory modeling and cluster analysis to i) identify modes of synoptic variability at Gawn Piedmont ice core site and ii) to reconstruct a 30-year record of synoptic variability. The influence of the ENSO and SAM on the modulation of this synoptic variability is investigated and the geochemical records derived from the Gawn Ice Piedmont firn core are interpreted in light of the synoptic reconstruction. Finally, proxies for xviii 
cyclonic frequency and continental air-mass input to the site are developed and their relationship to decadal climate oscillations is examined.

Chapter 5: 'Correlations in Trajectory Frequencies and Pressure Fields' briefly explores the correlations of trajectory frequencies created in Chapter 4 to reanalysis pressure fields. This work informs the overall context of this thesis but was not possible to include in the manuscript representing Chapter 4.

Chapter 6: 'Conclusion' summarizes the finding of this thesis and proposes future work.

Chapter 7: 'Appendices' includes data, results, and analyses not presented elsewhere in the text.

In completion of this thesis I conducted the following work:

i. I completed processing and stratigraphical logging of the Gawn Ice Piedmont (GIP) firn core

ii. I sampled the GIP ice core for stable isotope, major ion, and trace element analysis using a continuous melter system at the National Ice Core Laboratory, GNS Science with the assistance of Drs. Bertler and Sinclair.

iii. I prepared 495 samples for geochemistry analysis, a subset of which I measured using inductively coupled plasma mass spectrometry (ICPMS) analysis with the assistance of Dr. Marc-Alban Millet and Dr. Rachael Rhodes.

iv. I prepared 495 samples for stable isotope analysis, which were measured at the National Isotope Centre, GNS Science. 
v. I prepared 495 samples for major ion analysis using Ion

Chromatography, a subset of which was measured by Mrs Sharon Sneed at the Climate Change Institute, University of Maine.

vi. I conducted all data processing and quality control analysis of the geochemistry data, as well as the calculation of secondary parameters such as deuterium excess, and non-sea salt and sea salt contributions to major ion concentrations.

vii. I conducted statistical modeling and tests on reanalysis data and climate indices with the assistance of Prof. Euan Smith.

viii. I modelled 11,131 back trajectories for the GIP site from NCEP/NCAR re-analysis data and the HySPLIT trajectory model.

ix. I developed and tested a method of creating synoptic reconstructions and timeseries from back-trajectory cluster analysis.

x. I conducted all statistical analyses of back-trajectory and chemistry data timeseries.

xi. I conducted all comparisons and analyses of the data collected in this study with other published climate data sets and indices. 


\section{Chapter 1 Introduction}

\subsection{Ice Core Paleoclimatology}

Ice cores can provide near instrumental-quality records of past climate variability [Legrand and Mayewski, 1997; Mayewski and White, 2002] and are particularly important in Antarctica where meteorological data are sparse and short in duration [Jouzel et al., 2007; Mayewski et al., 2005]. While Antarctica is an excellent repository of past climate history, it is also a dominant driver of the global system and will both respond to and influence future climate change [Mayewski et al., 2009]. Ice core records from high accumulation, coastal Antarctic sites are a focus of the New Zealand contribution to the International Trans-Antarctic Scientific Expedition (ITASE) [Mayewski et al., 2005]. Due to their high resolution, coastal ice cores can help to reconstruct and understand recent climate variability, including decadal scale oscillations, an essential component to understanding future environmental change [IPCC, 2007; Mayewski et al., 2005]. Here a shallow firn core from the Gawn Ice Piedmont is analyzed to investigate synoptic variability and the influence of decadal climate oscillations in the Ross Sea Region.

\subsection{Antarctic Climatology}

Antarctica plays a unique and critical role in the global climate system [Mayewski et al., 2009]. The Antarctic landmass is the highest, driest, coldest and windiest continent on Earth. Between its two ice sheets, Antarctica holds the 
equivalent of $57 \mathrm{~m}$ in global sea level rise [Lythe et al., 2001]. Isolated from the rest of the globe by the Southern Ocean, Antarctica is surrounded by the Antarctic Circumpolar Current, the largest on the planet, and the only current to connect all major ocean basins [Boning et al., 2008].

The temperature gradient between the tropical and polar regions drives global atmospheric circulation and ocean currents. While the solar energy received in the Tropics is almost constant throughout the year, the poles experience profound seasonality. Antarctica receives more solar radiation than any other region on the planet during the Southern Hemisphere summer. However, during the austral winter, Antarctica experiences a polar night creating the coldest temperatures on Earth. This seasonality causes the development of the Polar Vortex [King and Turner, 1997] and the annual growth of sea ice which effectively doubles the area of the continent in winter [Fetterer et al., 2002].

Competing influences of the cold continent and the relatively warm Southern Ocean characterize the meteorology of Antarctica. The dry continental interior is dominated by a high-pressure anticyclone and gravity-driven drainage of cold katabatic winds [King and Turner, 1997; Parish and Bromwich, 1987]. These surface winds are caused by radiative cooling of the above-ice air layer, which then flows down the major glacier outlets from the continent [Carrasco and Bromwich, 1994; King and Turner, 1997]. In contrast, a low-pressure belt, the Antarctic Circumpolar Trough (CPT), surrounds the Antarctic continent at an average position of $66^{\circ} \mathrm{S}$ and is a zone of intense cyclonic activity. Asymmetry in the CPT gives rise to three 
distinct climatological low pressure centers including the Amundsen Sea Low (ASL)

(Figure 1.1), which brings synoptic-scale cyclones to the Ross Sea region and West

Antarctica [King and Turner, 1997; Simmonds et al., 2003].
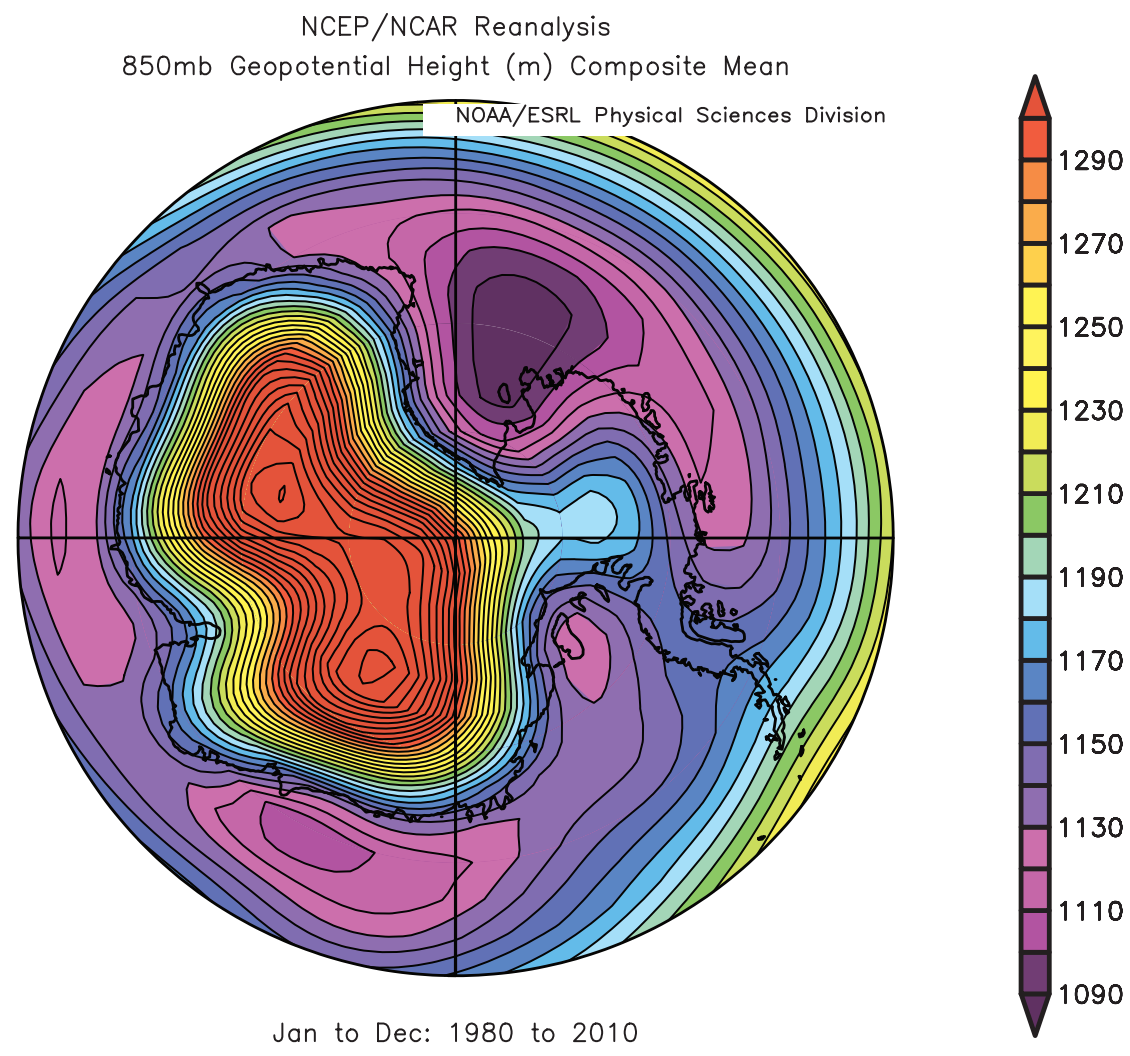

Figure 1.1 The mean annual $850 \mathrm{mb}$ geopotential heights are shown (in meters) from the 1980 to 2010 NCEP/NCAR reanalysis data set. The ASL feature is the dark purple center of low geopotential height in the upper right, centered in the Ross Sea, though extending across the entire Amundsen Sea region. Data available from http://www.esrl.noaa.gov/.

The Ross Sea region lies in the New Zealand sector of Antarctica (See Figure 1.2) and has been visited every year for over 50 years for scientific studies. The climate of the region is dominated by the dichotomy outlined above: drainage of cold air from the continental interior and oceanic cyclones from the Ross and Amundsen Seas [King and Turner, 1997; Parish and Bromwich, 1987; Simmonds et al., 2003]. The Ross Sea is also an important area of Antarctic Bottom Water 
formation, an important aspect of the global thermohaline circulation, an

instrumental moderator and driver of the global climate system [Broecker, 1997;

Jacobs et al., 1970].

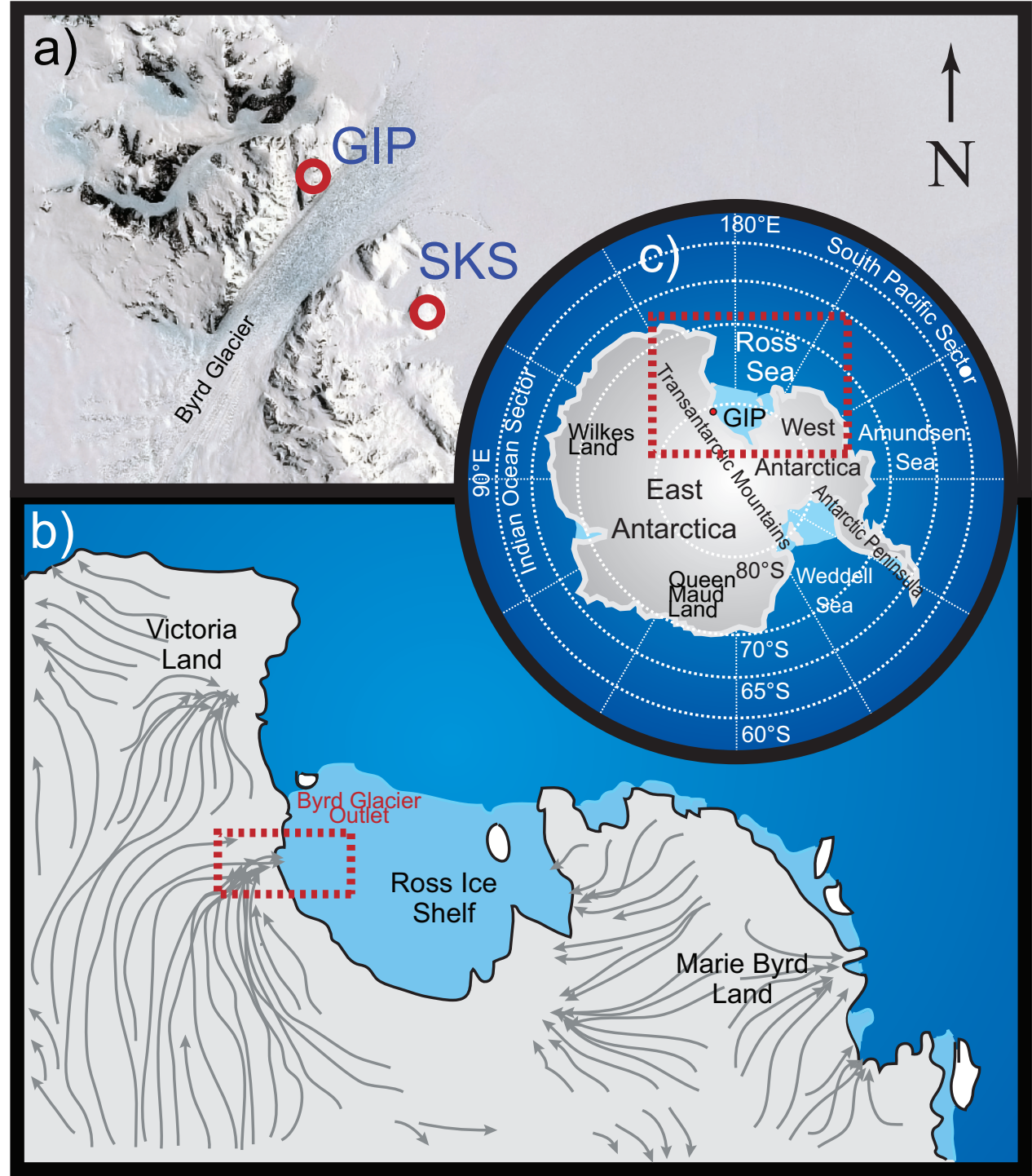

Figure 1.2 a) The Byrd Glacier drains from the East Antarctic Ice Sheet to the left, through the Transantarctic Mountains, to the Ross Ice Shelf on the right. The locations of the Gawn Ice Piedmont (GIP) and Skinner Saddle (SKS) ice core sites are shown in red. Image courtesy of NASA's Landsat Image Mosaic of Antarctica Project. North arrow indicates the grid north reference for the Landsat imagery; b) The Ross Sea region with surface wind fields plotted after Carrasco and Bromwich [1994]. The Byrd Glacier area is boxed in red; c) An overview of Antarctica with important features labeled with the Ross Sea area boxed in red. 
Katabatic flow down major outlet glaciers and onto the Ross Ice Shelf contributes to instability in the atmosphere and mesoscale cyclone formation [Bromwich, 1991; Carrasco and Bromwich, 1994; Carrasco et al., 2003]. The Byrd Glacier (Figure 1.2) is one of the primary drainages of surface wind from East Antarctica and is identified as a major source of mescocyclogenesis [Bromwich, 1991]. Although mesocyclones form at an average rate of one per week in the area, there is a distinct seasonal cycle of summer maxima and winter minima in mesocyclonic frequency [Carrasco and Bromwich, 1994].

\subsection{Decadal Climate Oscillations - ENSO and SAM}

The El Niño Southern Oscillation (ENSO) and the Southern Annular Mode (SAM) are dominant modes of decadal climate variability. First recognized in coastal Peru, El Niño is the quasi-periodic movement of anomalously warm water eastwards across the Pacific Basin [Trenberth, 1997]. This phenomenon was later recognized as a part of a large-scale ocean-atmosphere interaction, now known as the El Niño Southern Oscillation, that links anomalous climate events around the globe through changes in ocean and atmosphere circulation [Neelin et al., 1998; Trenberth, 1997], from failure of the tropical Indian Monsoon [Grove, 1998] to variability in Antarctic sea ice [Yuan, 2004]. The 1982/83 El Niño event (positive ENSO phase) is estimated to have caused over $\$ 8 \mathrm{~B}$ in damages and been responsible for up to 2000 deaths worldwide [Basher, 1998]. In the United States, the positive phase of ENSO has been linked to significantly more frequent and more destructive hurricanes, with mean damages of $\$ 5.8 \mathrm{~B}$ per event [Pielke and Landsea, 1999]. The 
Ministry of Agriculture and Forestry estimated the impact of droughts associated with just the 1997-99 ENSO event in New Zealand, at over \$1B [Basher, 1998].

Although tropical in origin, the ENSO signal has been detected throughout the Antarctic in fluctuations of sea ice extent [Yuan, 2004], Antarctic precipitation [Bromwich et al., 2000], SSTs [Kwok and Comiso, 2002], and changes in pressure fields and circulation patterns [Chen et al., 1996; John Turner, 2004]. In the Ross Sea Region, ENSO has been linked to observed temperature trends through changes in atmospheric circulation and the suppression of the otherwise expected warming at terrestrial stations [Bertler et al., 2004]. The region is the terminus of the Pacific South American wave train, thought to be the teleconnection mechanism for ENSO to the high southern latitudes [Houseago et al., 1998; Mo and Higgins, 1998].

The Southern Annular Mode is the dominant mode of climate variability in the Southern Hemisphere and operates at a range of time scales from daily to decadal [Fogt et al., 2009a; Marshall, 2003; Mo, 2000; Thompson and Solomon, 2002]. Fundamentally, the SAM is a symmetric (annular) oscillation in the strength and position of the circumpolar westerly winds and is related to the contraction and expansion of the polar vortex [Jones et al., 2009; Thompson and Solomon, 2002]. It has been shown to influence temperatures and precipitation on every continent in the Southern Hemisphere [Gillett et al., 2006] including significant influence on the climate variability of New Zealand [Kidston et al., 2009].

Modeling studies suggest that SAM is an inherent mode of atmospheric dynamics and, unlike ENSO, does not require ocean-atmosphere interactions [Cai and Watterson, 2002]. The SAM has shown a significant positive trend since the 6 
1960s, increasing intensity and southward movement of the westerly winds [Mo, 2000; Thompson and Solomon, 2002]. Possible explanations for this trend include anthropogenic ozone depletion and greenhouse gas emissions [Arblaster and Meehl, 2006; Fogt et al., 2009b; Jones et al., 2009]. It has been suggested that this positive trend is at least in part responsible for the observed warming in the Antarctic Peninsula and cooling over East Antarctica [Marshall, 2007; Thompson and Solomon, 2002].

The Ross Sea region is strongly influenced by both ENSO and SAM, in particular through their modulation of the Amundsen Sea Low (ASL), a center of cyclogenic activity [Fogt and Bromwich, 2006; King and Turner, 1997; Mo, 2000]. Both oscillations show significant loading centers in the area of the ASL [Mo, 2000]. The interactions and joint forcing of ENSO and SAM can significantly impact the climate of Antarctica, particularly where they intersect in the Pacific sector. High accumulation sites, which are influenced by air masses from the South Pacific, have the potential to record the interactions and influences of these important oscillations in snow chemistry climate proxies and could provide insights into the past variability of ENSO and SAM beyond the instrumental record.

\subsection{Gawn Ice Piedmont Ice Core and Study Site}

A shallow core was retrieved from the Gawn Ice Piedmont (GIP) as part of the New Zealand ITASE project to assess recent climate variability in the Ross Sea Region, of Antarctica (Figure 1.3). GIP is a small, locally accumulating piedmont glacier at the northern edge of the Byrd Glacier, the largest outlet glacier in the 
Transantarctic Mountains (Figure 1.2). The GIP site is located at $80^{\circ} 05^{\prime} 58.15^{\prime \prime}$, $159^{\circ} 16^{\prime} 37.60^{\prime \prime} \mathrm{E}$, and lies at an elevation of 1,221 m above sea level (Figure 1.4). During the 2007/08 field season the NZ ITASE team conducted a site survey which included ice penetrating radar imaging (red lines in Figure 1.4) and the collection of a $12 \mathrm{~m}$ deep firn core (yellow flag). The core was drilled using a lightweight, 3-inch powered, mechanical drill provided by the Alfred Wegner Institute (Figure 1.5).

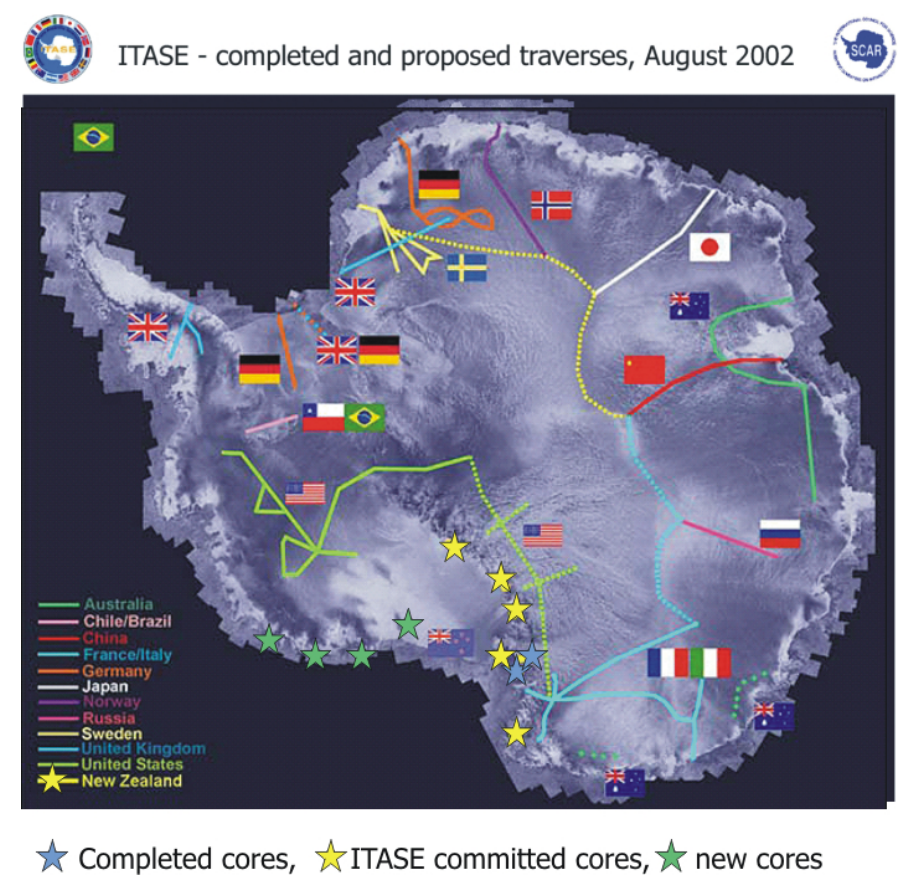

Figure 1.3 Overview of ITASE science targets (yellow stars) in the Ross Sea region of Antarctica. 


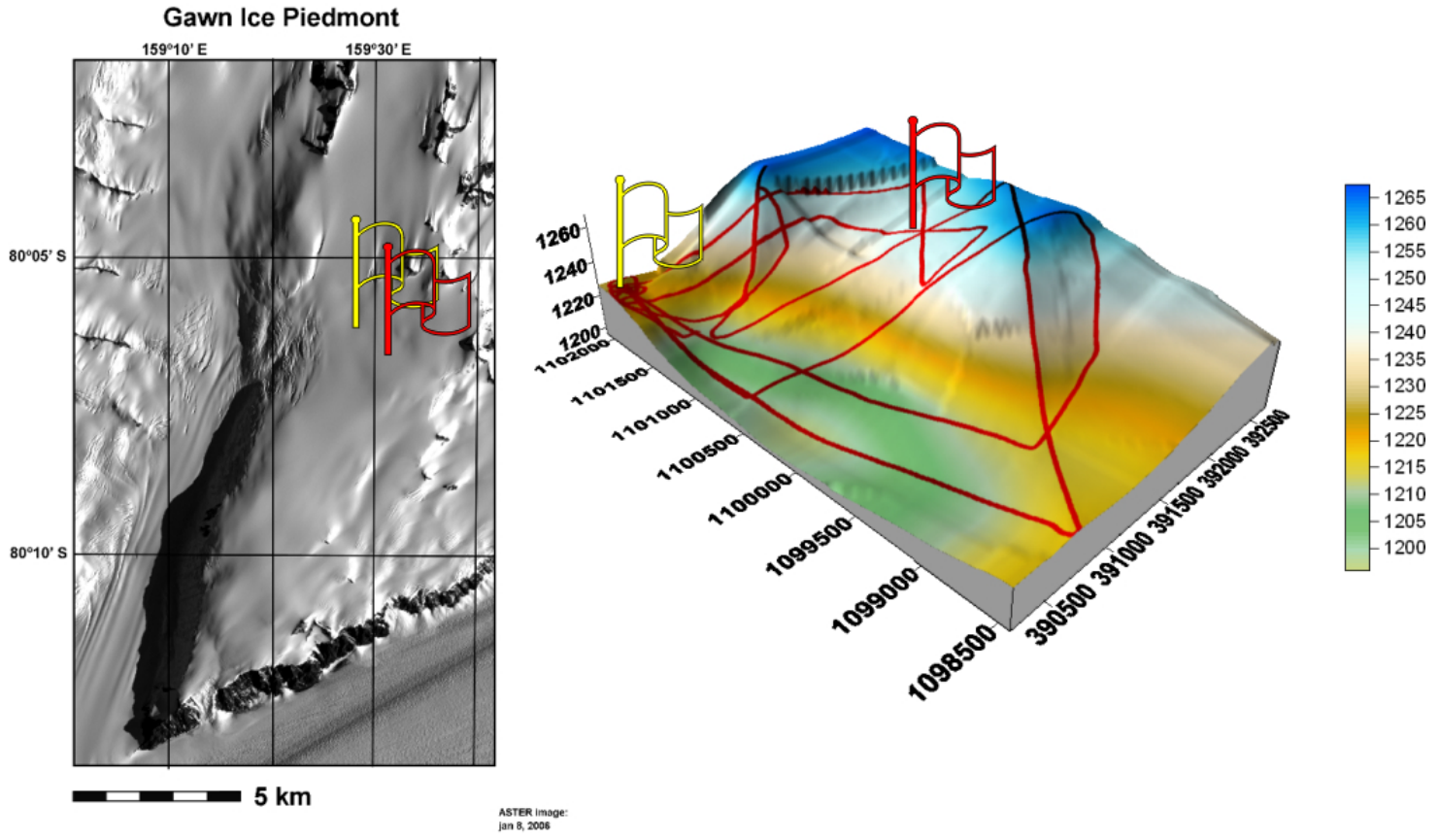

Figure 1.4 ASTER satellite image of Gawn Ice Piedmont and vicinity. See Figure 1.2 for overview. Image from 08 January 2004. Yellow flag indicates location of camp and drill location of shallow firn core; red flag indicates proposed drilling location for deep core. B) Digital elevation model. X/Y/Z grid in meters (UTM zone 58). Red lines indicate location of ice penetrating radar survey lines [Bertler, 2008].

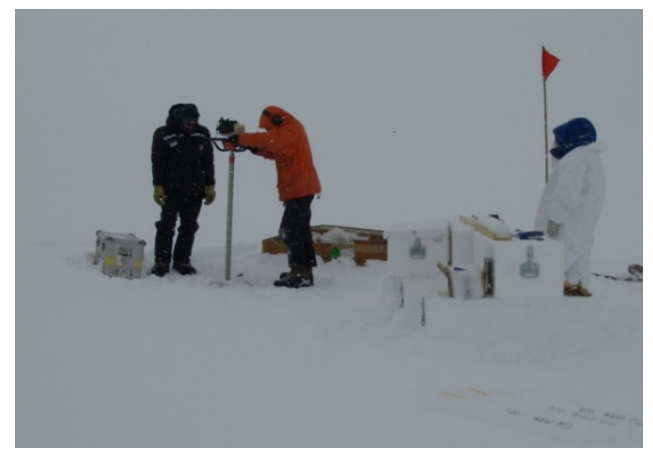

Figure 1.5 Collection of the GIP core on site in November 2007.

The GIP site was chosen by the NZ ITASE project as it lies at the boundary between katabatic winds descending from both East and West Antarctica (Figure 1.2). In conjunction with other NZ ITASE study sites, a record from GIP was thought 
to provide an opportunity to study the relative influence of West and East Antarctica air masses on the Ross Ice Shelf (Bertler, pers. communication). This is particularly important, as West Antarctica has been shown to have warmed over the past 50 years [O'Donnell et al., 2010; Steig et al., 2009] and to have experienced accelerated ice loss [Rignot et al., 2008]. In contrast, it has been suggested that the Ross Sea Region is cooling [Doran et al., 2002; O'Donnell et al., 2010] and that it is an area of ice sheet growth [Rignot et al., 2008]. Bertler et al. [2004] showed that the cooling of the Ross Sea is a short term trend, initiated by an ENSO driven change in atmospheric circulation that promotes cooler air masses from West Antarctica to dominate of cyclonic activity derived from the Ross Sea.

This thesis investigates synoptic variability at the GIP site through back trajectory modeling and analysis of the GIP ice core record to quantify the relative importance of katabatic and cyclonic activity and the influence of ENSO and SAM on the atmospheric circulation pattern of the Ross Sea Region. Owing to exceptionally high and continuous snow accumulation at the area [Sinclair et al., 2010], the record achieves sub-seasonal resolution. 


\section{Chapter 2 Methodology}

In this chapter I outline the main research methodologies employed in this study. I give particular focus to those methods that were not possible to present in full detail within the manuscripts comprising Chapters 3 and 4 due to journal length restrictions. Namely the core processing, details of the geochemical analyses, quality control, and age model construction are discussed. I also outline back-trajectory and cluster analysis methods as some novel additions to this technique were developed as part of this study.

\subsection{Core Processing}

As discussed above, a $12 \mathrm{~m}$ reconnaissance firn core was recovered from the Gawn Ice Piedmont in the Ross Sea Region, Antarctica in November 2007 as part of New Zealand's contribution to the International Transantarctic Scientific Expedition. The core was processed in a cold laboratory $\left(-18^{\circ} \mathrm{C}\right)$ at the New Zealand Ice Core Laboratory, National Isotope Center, GNS Science. Twelve $1 \mathrm{~m}$ sections of core were weighed and logged for breaks, ice and dust layers, and crystal structure. The core was then quartered with a band saw and an archival section was stored for possible future analyses. The outside surfaces of the quarter selected for immediate analysis was cleaned with a pre-washed ceramic knife to remove any possible contamination from the processing procedure. During the procedure Tyvek® clean suits, surgical masks, and disposable, low contaminant gloves were worn. Individual sections of cores were then moved into pre-cleaned plexi-glass $®$ holders in preparation for 
melting the core with the continuous melter. The core sections were stored in a clean working lab at $-20^{\circ} \mathrm{C}$ for no longer than 8 hours prior to sampling to prevent possible contamination.

The core was melted into 495 discrete samples using an ultra clean continuous melter system designed by the University of Maine [Osterberg et al., 2006] in the class 100 clean room of the GNS Science Ice Core Research Laboratory. An ultra pure nickel melt disc (99.9999\% nickel) seated on an aluminum head, which is heated to $14^{\circ} \mathrm{C}$, was used to melt the cores (Figure 2.1). The disk consists of two rings, an inner ring, which collects material from the center of the ice core, and an outer section, which collects the remaining material, including the outer surfaces of the core. The melted sample from the inner nickel ring travels through an acidcleaned Teflon ${ }^{\circledR}$ funnel into cleaned Teflon tubing and pumped with peristaltic pumps into two fraction collectors (Figure 2.2). The first fraction collects $12 \mathrm{ml}$ for trace element analysis; the second fraction collector collects $4 \mathrm{ml}$ for major ion analysis. The melted sample collected in the outer section $(\sim 25 \mathrm{ml})$ travels through the aluminum head into Teflon tubing to a third fraction collector and aliquots of this sample are taken for stable isotope analysis $(4 \mathrm{ml})$. The remainder is archived for possible future analyses. It is important to note that samples from the three fraction collectors are taken from the same depth in the core and hence represent samples of identical age. For this reason, it is possible to investigate leads and lags between different proxies even if the absolute age might not be known with the same precision. All samples were re-frozen for storage after collection. 


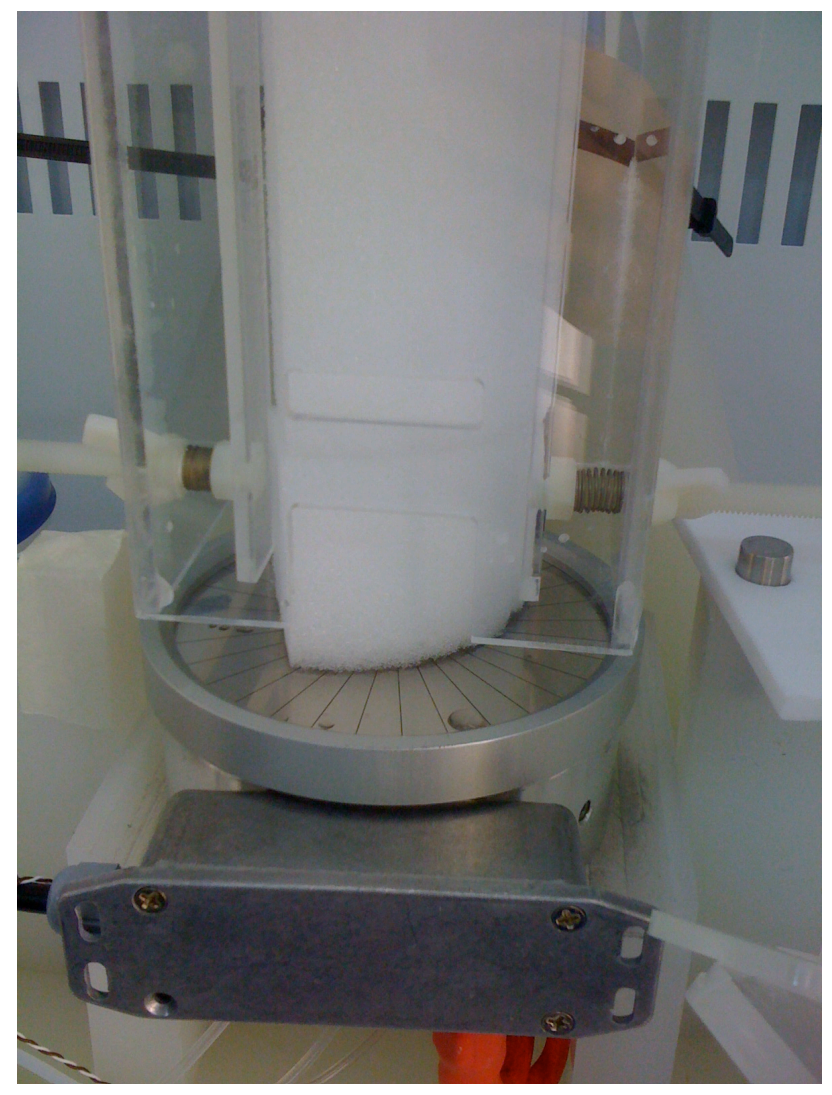

Figure 2.1 A section of GIP core during sampling on the discrete melter system in the clean laboratory at the New Zealand Ice Core Laboratory, GNS Science.

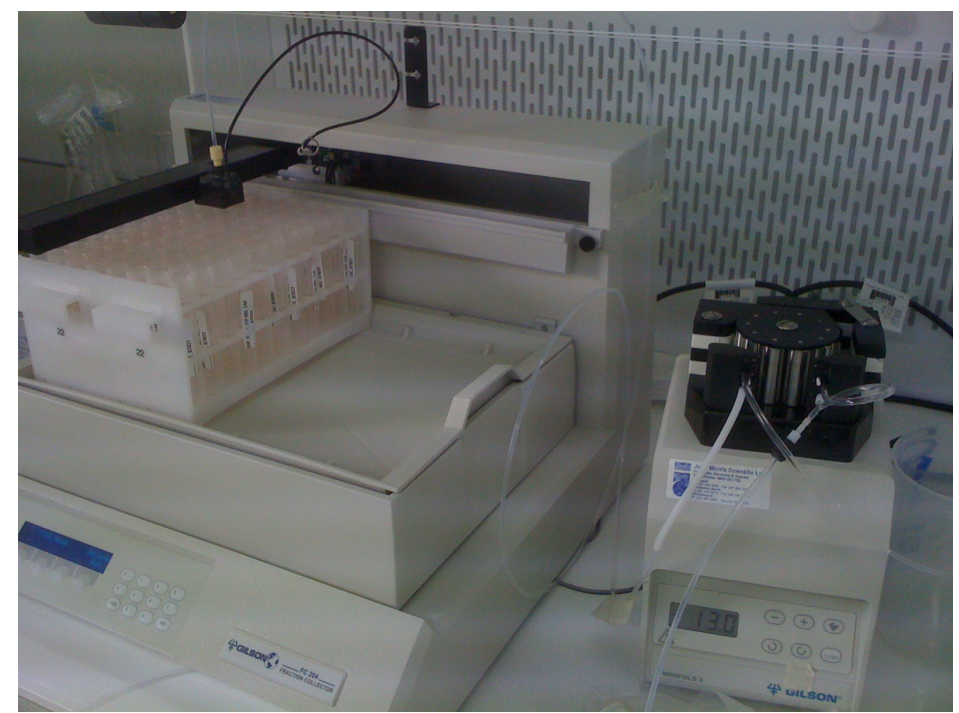

Figure 2.2 Peristaltic pump and automated fraction collector capturing samples for trace element analysis. This line was contained in a clean hood within the clean laboratory at the New Zealand Ice Core Laboratory, GNS Science. 


\subsection{Stable Isotope Measurements}

In total, 495 samples were measured for stable isotopic ratios at the National Isotope Centre, GNS Science. Oxygen stable isotope ratios $\left(\delta^{18} 0\right)$ were analyzed on a GVI AquaPrep attached to a GVI IsoPrime mass spectrometer by the equilibration method. $400 \mu \mathrm{l}$ of water is equilibrated with $3 \mathrm{ml}$ of headspace flushed with $\mathrm{CO}_{2}$ for 24 hours at $25.5{ }^{\circ} \mathrm{C}$. The $\mathrm{CO}_{2}$ is extracted and analyzed by dual inlet on the IsoPrime. All oxygen results are reported with respect to VSMOW, normalized to our internal standards: INS11, INS9 and MM1 with reported values of $-0.3 \% 0,-17.3 \%$, and $29.4 \%$ respectively. The analytical precision for these measurements is $0.1 \%$. Hydrogen (Deuterium) stable isotope ratios $(\delta D)$ were analyzed on a GVI PyrOH attached to a GVI IsoPrime mass spectrometer by direct injection over hot chromium. $5 \mu$ l of water is injected into a helium stream through a quartz reactor filled with chromium granules and quartz chips held at $1050{ }^{\circ} \mathrm{C}$ where it is reduced to $\mathrm{H}_{2}$ gas. The $\mathrm{H}_{2}$ is then analysed by continuous flow mode on the IsoPrime. All hydrogen results are reported with respect to VSMOW, normalized to our internal standards: INS11, INS9 and MM1 with reported values of -3.3\%, -136.5 \%o, and $231.5 \%$ respectively. The analytical precision for these measurements is $1.0 \%$.

For quality control all $\delta^{18} \mathrm{O}$ values were plotted against $\delta \mathrm{D}$. The data fell consistently on a local water line with a slope of 7.8, demonstrating a linear relationship between $\delta^{18} 0$ and $\delta \mathrm{D}$ (Figure 2.3). Three samples were identified as potentially contaminated due to strong deviation from this mean line. As these 
samples came from locations of breaks within the core or at the end of a core section where contamination is likely, they were removed from further analysis.

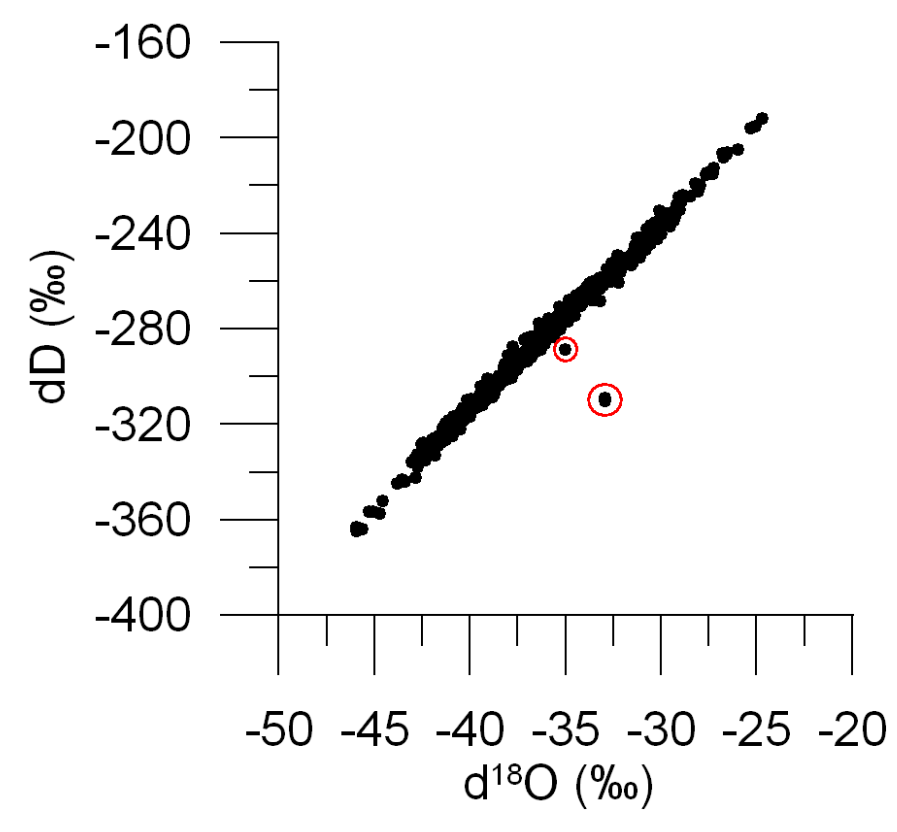

Figure 2.3 $\delta D(d D)$ values are plotted against $\delta^{18} 0\left(d^{18} 0\right)$ values for all samples from the GIP core. The data consistently fall on a local water line with a slope of 7.8. Three data points (circled in red) plot off the mean water line and are suspected for contamination.

\subsection{Major Ion Analyses}

Every $5^{\text {th }}$ sample (99 in total) of the GIP core was measured for major and trace element concentrations. Ion chromatography (IC) analyses of major ion concentrations $\left(\mathrm{Na}^{+}, \mathrm{K}^{+}, \mathrm{Mg}^{2+}, \mathrm{Ca}^{2+}, \mathrm{MS}^{-}, \mathrm{Cl}^{-}, \mathrm{NO}_{3}{ }^{-}, \mathrm{SO}_{4}{ }^{2-}\right)$ were carried out at the Climate Change Institute, University of Maine. Major cation concentrations were measured using ion chromatography with a Dionex IonPac CS12 column and a 20 mM methanesulphonic acid eluent. Major anion concentrations were measured with a Dionex AS11 column and $6.0 \mathrm{mM} \mathrm{NaOH}$ eluent. External quality control samples were run approximately every tenth sample. Control samples of frozen ultrapure 
water (18 M $\Omega$ MilliQ) were measured with both systems and show that no significant contamination occurred during sampling and processing stages. 


\subsection{Trace Element Measurements}

Due to the extremely low concentrations (parts per billion to parts per trillion), samples for trace element analysis were carried out using an Inductively Coupled Plasma Mass Spectrometry (ICP-MS). The samples were collected into acidwashed vials through the continuous melter system described in Section 2.1. To prevent contamination, prior to analysis vials were washed with $18 \mathrm{M} \Omega \mathrm{MilliQ}$, then soaked in $5 \% \mathrm{HNO}_{3}$ for no less than 2 weeks, then rinsed and soaked in $18 \mathrm{M} \Omega$ MilliQ for $24 \mathrm{hrs}$ in the ultra-clean laboratory at Victoria University of Wellington.

Ninety-nine samples from the GIP core (identical intervals to the IC analyses) were analyzed for major and trace element concentrations ( $\mathrm{Li}, \mathrm{Na}, \mathrm{Mg}, \mathrm{Al}, \mathrm{Ca}, \mathrm{Ti}, \mathrm{V}$, Mn, As, Rb, Sr, Y, Zr, Cr, Ba, La, Ce, Pr, Tl, Pb, Bi, Th, U) at the Geochemistry Laboratory in the School of Geography, Environment and Earth Sciences, Victoria University of Wellington. Analyses were made on an Agilent 7500cs series ICP-MS following the method of Rhodes [2011], outlined below. Samples were defrosted and acidified to $1 \mathrm{wt}$.\% HNO at least $12 \mathrm{hrs}$ before measurement. Measurement was made without the octopole collision cell, the use of which diminishes the ability to measure extremely low trace element concentrations, the main aim in this investigation. However, Fe cannot be measured without this collision cell and so is absent from this study. Between each sample and standard the system was flushed with $\mathrm{H}_{2} \mathrm{O}$ for 10 seconds, 5 wt. $\% \mathrm{HNO}_{3}$ for 200 seconds, and finally 1 wt. $\% \mathrm{HNO}_{3}$ for 220 seconds. 
Acid blanks were run between every 5 th sample to quantify background noise and alkaline and lithophile standards were run between every 10 samples for calibration. An external standard, SLRS-4 (National Research Council, Canada), was run each day of measurement to test reproducibility and accuracy. The blanks and standards were used to calculate detection limits for each element. Additionally, 11 MilliQ $\mathrm{H}_{2} \mathrm{O}$ blanks were run through the continuous melter system and analyzed to quantify background contamination.

Concentrations of Na were plotted against Mg for all data (see Appendix 1, Figure 7.1). Samples that strongly deviated from the mean ocean water line were examined for possible contamination. Comparison of $\mathrm{Ca}, \mathrm{Na}$, and $\mathrm{Mg}$ measurements made on both the IC and ICP-MS also helped to identify possibly contaminated samples. Four samples with anomalously high, single-point, values in many major and trace element concentrations were identified as outliers. Neighboring archived samples were measured and confirmed the single-point nature of these anomalous

peaks, suggesting either contamination or the presence of particles not fully dissolved during acidification. Further analysis of ICP-MS results and the above quality control methods are discussed in Appendix 1.

\subsection{GIP Age Model}

Because of a high, and continuous snow accumulation observed in automatic weather station data from the nearby Skinner Saddle site [Sinclair et al., 2010] (see Figure 1.2 for area overview), the GIP record provides a unique opportunity to study sub-annual and possibly even event driven climate variability. To distinguish the 
seasonal signal from individual events, a multi-proxy approach was employed to create an age model. Maxima in methylsulphonate (MS) concentrations and $\delta^{18} \mathrm{O}$ maxima were used to identify summer peaks in the annual cycles.

While many sites experience seasonal biased snow precipitation [Bertler, 2011], the automatic weather station deployed at nearby Skinner Saddle suggests that the site receives precipitation year round with only a slight decrease during the months of April and May [Sinclair et al., 2010] during the single year of observation. The stable isotope ratios of water, $\delta^{18} 0$ and $\delta D$, are linearly related to site temperature [Dansgaard, 1964; Jouzel et al., 1997] enabling their use as records of annual temperature change. Because of the likely continuous snow precipitation at GIP, it is reasonable to assume that highest $\delta^{18} 0$ and $\delta D$ values correspond to summer precipitation, while low $\delta^{18} 0$ and $\delta \mathrm{D}$ values are likely to represent winter.

MS is a secondary bi-product of primary production by phytoplankton and diatoms and is produced locally in the Ross Sea during the summer months [Legrand and Mayewski, 1997; Saltzman et al., 1983]. Rhodes et al. [2009] demonstrate a causal link between the MS record in precipitation and the seasonal cycle of sea ice cover and primary production in the Ross Sea region. MS has strong cyclicity in the GIP record; cross-correlation and principal component analysis (PCA) show strong independence of the MS record from other measurements making its use in this context appropriate (see Appendix 1, Figures 7.3, 4, and 5). A monthly NCEP/NCAR reanalysis (NNR) surface temperate composite shows that December and January are the months of average peak annual surface 
temperature at the GIP site for an average of the last 30 years as well as for the shorter period likely spanned by the GIP record (Figure 2.4). Comparison of NNR data to local weather station data is discussed in more depth in Appendix 2. Counting back from the known core-top age tie-point (November 2007), $\delta^{18} \mathrm{O} / \mathrm{MS}$ maxima were tied to the summer peaks, establishing the scale of each year. Since average temperatures for December $\left(-8.49^{\circ} \mathrm{C}\right.$, for the period spanned by the core) and January $\left(-8.59^{\circ} \mathrm{C}\right)$ are extremely similar and likely indistinguishable in this context, $\delta^{18} 0$ maxima coinciding with MS peaks were assigned to the 1st of January of each year to be centered in this period of peak warmth. In years where a single oxygen minimum was unambiguous, 2001, 2003, and 2004, sample depths were tied to August $1^{\text {st }}$, August $1^{\text {st }}$, and July $1^{\text {st }}$, respectively, based on temperature minima from monthly reanalysis data (Figure 2.5). Ages for all samples were then linearly interpolated between tie points giving an average of 41 samples per year and no less than 12 samples per year. For the purpose of correlation with trajectory classes and meteorologic fields, all ice core data were also re-sampled to monthly resolution through linear interpolation. Based on this age model, the GIP record spans almost 8 years, from summer 2000 to recovery in November 2007. 


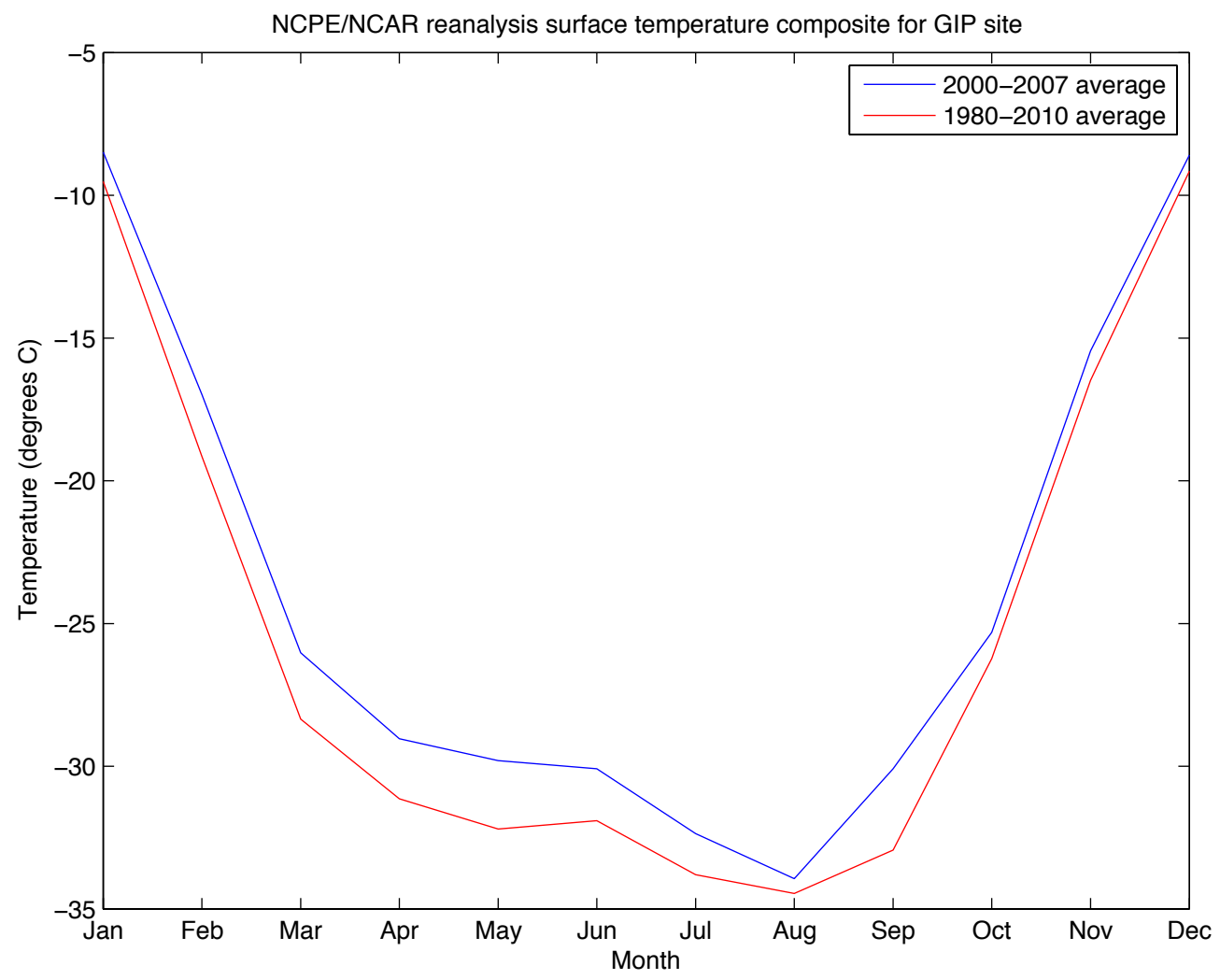

Figure 2.4 Composite monthly NNR surface temperature for the GIP site averaged for two periods: January 2000 to November 2007 (blue), the period spanned by the GIP core; and January 2000 to December 2010 (red), a 30-year climatology. 


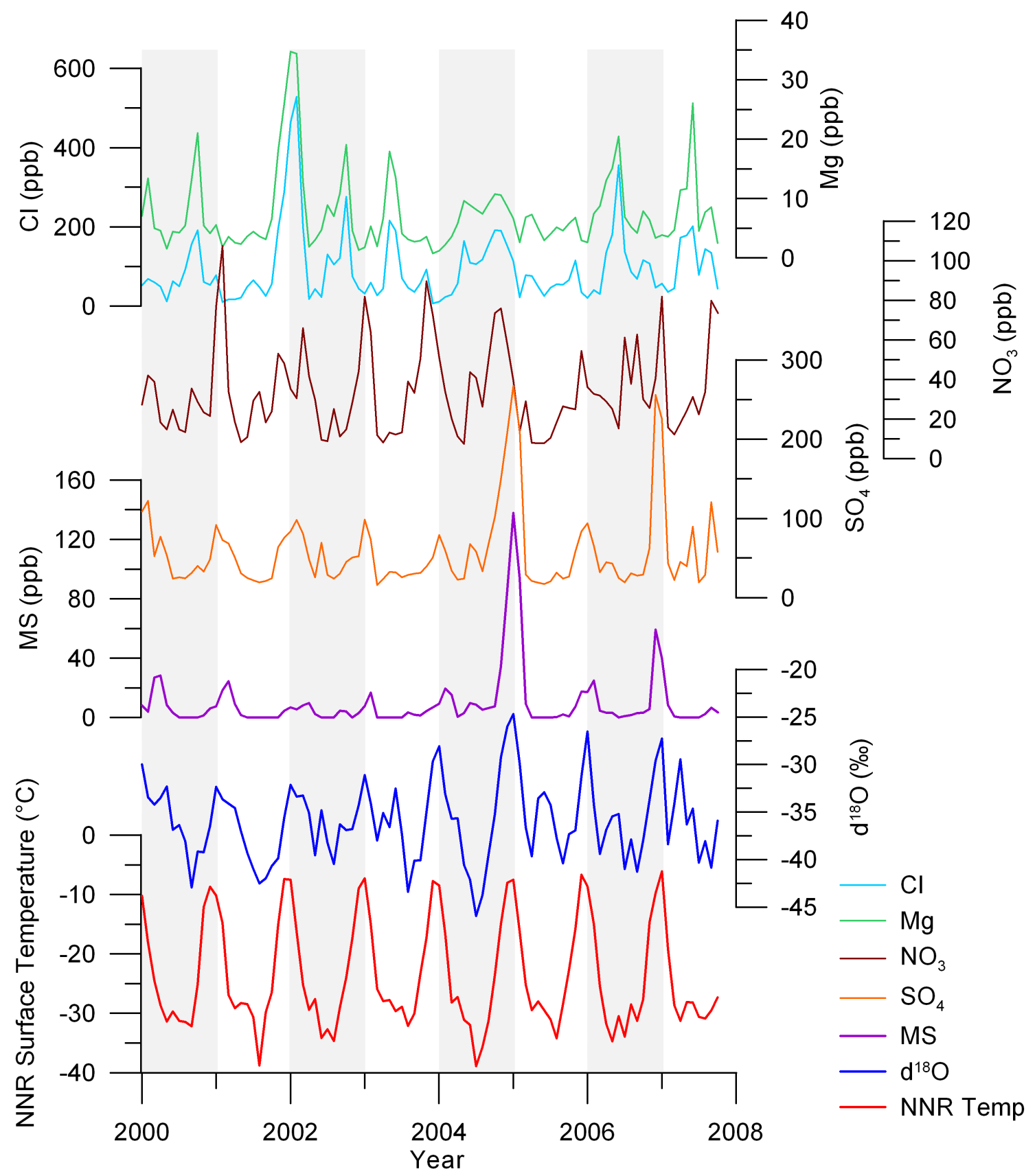

Figure 2.5 Select geochemistry data are shown from the GIP core plotted against the age model alongside NCEP/NCAR reanalysis (NNR) surface temperature data for the GIP site (red, at bottom). $\delta^{18} \mathrm{O}$ (dark blue) and MS (purple) peaks were used to distinguish annual cycles and matched to NNR temperature maxima. Geochemistry data are resampled at monthly resolution and many species (top) show distinct annual cycles by this age model. NNR data are available from http://www.esrl.noaa.gov/psd/data/reanalysis/.

An average accumulation of 1.12 meters of water equivalent per year is calculated for the GIP site, an exceptionally high rate for Antarctica, but in 
agreement with AWS data from the nearby SKS site [Sinclair et al., 2010].

Additionally concentrations of $\mathrm{Mg}, \mathrm{Cl}, \mathrm{SO}_{4}$, and $\mathrm{NO}_{3}$ each show eight distinct peaks in the record suggesting some amount of annual variability in their sources (Figure 2.5). The potential sources of $\mathrm{SO}_{4}$, and $\mathrm{NO}_{3}$ are discussed below and in detail in Chapter 4. Concentrations of $\mathrm{Mg}$ and $\mathrm{Cl}$ are not necessarily expected to follow an annual cycle and indeed their seasonal variability is inconsistent. Potentially of marine origin, their relationship to other marine species is discussed in Appendix 1.

An independent tie point is provided by a large dust storm event that affected the Ross Sea region in spring of 2004 [Steinhoff et al., 2008]. The least accumulation of the record is observed during this year, perhaps suggesting some wind scour occurred at the site. Interestingly, our core shows the largest $\mathrm{MS}$ and $\mathrm{SO}_{4}$ peaks of the record during the following summer, 2004/05. Like MS, $\mathrm{SO}_{4}$ in Antarctic snow can be sourced from the oxidation of dimethlysulphide, a product of primary production [Saltzman et al., 1983]. The synchrony of the MS and $\mathrm{SO}_{4}$ records, particularly in summer 2004/05 may suggest that an unusually large algae bloom was present due to enhanced iron fertilization from the dust delivered into the Ross Sea during the event. This connection is explored further in Appendix 5.

\subsection{Back-Trajectory Modeling}

Back-trajectory modeling, particularly in conjunction with cluster analysis, can be used to understand the synoptic controls on precipitation at a study site [e.g. Dorling and Davies, 1995; Helsen et al., 2006; Schlosser et al., 2008; Sinclair et al., 2010]. Cluster analysis is a statistical method of grouping related sub-sets within a 
larger data set. By simultaneously accounting for the curvature and length of air parcel trajectories, cluster analysis allows us to identify characteristic atmospheric trajectory groups, which can represent distinct synoptic patterns [Dorling and Davies, 1995; Dorling et al., 1992; Scarchilli et al., 2010; Sinclair et al., 2010]. In combination with ice-core measurements, back-trajectory analysis can be used to directly relate synoptic conditions to precipitation and geochemical records [e.g. Helsen et al., 2006; Schlosser et al., 2008; Sinclair et al., 2010] which may greatly improve our understanding of past climate variability and future change.

Three-dimensional back-trajectories were constructed using the Hybrid Single-Particle Lagrangian Integrated Trajectory (HySPLIT) model from NOAA's Air Research Laboratory [Draxler and Hess, 1998]. Five-day (120 hr) back-trajectories were calculated from NCEP/NCAR reanalysis input data [Kalnay et al., 1996] arriving at 12:00 UTC daily from October 1979 through March 2010, resulting in a total of 11,131 trajectories. An in-depth justification of the use of the NCEP/NCAR reanalysis data in this context is given in Chapter 4 and Appendices 2 and 4 . I use a starting point $1500 \mathrm{~m}$ above ground level at the closest reanalysis grid point to the GIP ice core site $\left(79.95^{\circ} \mathrm{S}, 159.99^{\circ} \mathrm{E}\right)$ and employ a model upper boundary height of $20 \mathrm{~km}$ and a data-based vertical motion method. Following Sinclair et al. [2010] initial heights of $500 \mathrm{~m}, 1000 \mathrm{~m}$, and $1500 \mathrm{~m}$ were tested for trajectories to the GIP site using a trajectory matrix. Spatially consistent flow paths were generally observed for all initial heights, though $1500 \mathrm{~m}$ is chosen to best capture synopticscale conditions while minimizing the obscuring influence of underlying terrain. 
Spatial sensitivity of the area is also tested using a $1^{\circ} \mathrm{x} 1^{\circ}$ matrix of 100 starting points. The results show generally consistent flow paths for a number of trajectory pathway types in the area surrounding the Byrd Glacier outlet.

Scarchilli et al. [2010] found spatial uncertainties in 5-day back-trajectories of $15-30 \%$ of total distance and attributed these to numerical truncations within the model as well as limited resolution in the reanalysis data. Similarly, Schlosser et al. [2008] suggest that mean errors of $20 \%$ may be typical of 5-day back-trajectories due largely to errors in the input wind data fields. It is reasonable to anticipate uncertainties on the same order as the above studies, though they are not quantified in this study as the analysis concerns the broad classification of trajectories rather than precise starting points.

Although reanalysis precipitation data are available from the ERA-40 project, I do not apply a precipitation filter (i.e. only model trajectories arriving at days with precipitation above a certain threshold) to our back-trajectory analysis for several reasons. First, this study aims to understand the synoptic conditions generally at the site and not just those resulting in precipitation. Second, the influence of dry deposition of chemical species at the site should not be excluded, since it is likely an important factor in Victoria Land [Bertler et al., 2005]. A precipitation filter would limit the utility of the back-trajectory analysis in interpreting those species. Finally, significant testing against AWS data would be desirable to test the suitability of reanalysis precipitation fields in the region, which is beyond the scope of this study. 
However, such improvements to back-trajectory analysis will certainly be foci of future work. 


\subsection{Cluster Analysis}

The HySPLIT model's cluster analysis algorithm groups trajectories by minimizing the spatial variability between trajectories within some defined number of clusters [Draxler, 1999]. The choice of cluster number should balance intracluster variability and interpretability with respect to synoptic conditions and is somewhat subjective in practice [Scarchilli et al., 2010]. Empirical tests on the effect of cluster number on the GIP trajectories showed that too few clusters resulted in the grouping of spatially similar but meteorologically different trajectories (e.g. slow-moving cyclonic and anti-cyclonic trajectories originating from opposite sides of the Transantarctic Mountains). By retaining a greater number of clusters it is possible to reduce the data set to a manageable size yet divide the clusters into synoptically distinct classes and groups. Specifically 15 to 20 clusters were found desirable for large, multi-year data sets, to balance the separation of local (slower) clusters into distinct groups while maintaining an interpretable number of total clusters. An in-depth explanation of the choice of cluster number and its implications is given in Chapter 4.

Cluster analysis was performed on subsets of the entire data set $(11,131$ daily trajectories) to test the consistency of results and the classification scheme. Decades (1980's, 1990's, and 2000's) were individually clustered at daily resolution using points at $4 \mathrm{hr}$ intervals along each trajectory. Due to computational limitations, the entire 1980-2010 period was clustered at a reduced resolution; 2 
day (5,565 trajectories) and 3 day resolution (3,711 trajectories) with $12 \mathrm{hr}$ and $6 \mathrm{hr}$ trajectory intervals, respectively.

The smoothed time series of the two primary synoptic groups (see Chapter 4) from the entire 30-year period (at 2-day resolution) and decade-long sub-sets (at daily resolution) are correlated at $r=0.9(p=0.00)$, suggesting little information is lost in a reduction to 2-day resolution. However the 3-day resolved cluster analysis showed significant differences to the higher resolution, shorter duration sampling periods and lower correlation coefficients. This suggests that important variability was lost at this resolution and that a minimum of two-day resolution is desirable. Clustering all trajectories together, rather than individual decades, allows a cohesive analysis and classification of the dominant patterns of the entire period. To balance computational limits with high temporal resolution, the 2-day dataset was analyzed for the 1980 to 2010 period. Classifications of back-trajectory clusters are discussed in Chapter 4. 


\section{Chapter 3 The joint influence of the Southern Annular Mode and the El Niño Southern Oscillation on the Amundsen Sea Low}

This chapter constitutes a manuscript prepared for submission to the International Journal of Climatology.

\subsection{Abstract}

Here we present an investigation of the joint influence of the El Niño Southern Oscillation (ENSO) and the Southern Annular Mode (SAM) on the climate variability of the Amundsen Sea (AS) region of Antarctica, particularly in modulating the Amundsen Sea Low (ASL). We show that the positive phase of each oscillation is associated with significant strengthening of the ASL, while the negative phases are associated with weakening of the low in the eastern AS. Through regression analysis we show that a simple linear combination of indices representing these oscillations can explain more than $40 \%$ of the geopotential height variance in the AS region at a seasonal scale and over $70 \%$ of the variance at an annual scale. Our results are consistent with the known mechanisms of ENSO and SAM interaction in the region. We quantify the ratio of relative ENSO to SAM influence in governing the geopotential height variance in the Southern Hemisphere, which is uniformly small except in the AS region where it approaches unity. Finally we show that a simple model of linear reinforcement and interference describes the oscillations' influence better than models incorporating more complex interactions. 


\subsection{Introduction}

The El Niño Southern Oscillation is the principle driver of decadal climate variability globally [Diaz and Markgraf, 1992; Trenberth, 1997]. Although it originates in the tropical Pacific it has been shown to exert significant influence world wide, including in the high southern latitudes [John Turner, 2004]. However, the dominant mode of climate variability in the southern hemisphere ( $\mathrm{SH}$ ) is the Southern Annular Mode and feedbacks associated with the SAM have been connected to observed climatic changes in Antarctica [Marshall, 2003; Thompson and Solomon, 2002]. The interaction of these two climate oscillations can potentially explain a substantial portion of climate variability in the Antarctic, particularly in the Amundsen Sea (AS) region of the South Pacific (Figure 3.1).

The ENSO is a coupled ocean-atmosphere phenomenon that operates at decadal and sub-decadal time scales, with a periodicity of roughly 3 to 7 years [Trenberth, 1997; John Turner, 2004]. Originating in the tropics, ENSO is an oscillation in sea surface temperature (SST) anomalies and dominant circulation patterns across the Pacific basin with two alternating phases known as El Niño and La Niña [Trenberth, 1997; John Turner, 2004; Yuan, 2004]. In Antarctica, the ENSO signal has been detected in fluctuations of sea ice extent [Yuan, 2004], Antarctic precipitation [Bromwich et al., 2000], SSTs [Kwok and Comiso, 2002], and changes in pressure fields and circulation patterns [Chen et al., 1996; John Turner, 2004]. In the Ross Sea Region, ENSO has been linked to observed temperature trends through 
changes in atmospheric circulation and the suppression of the otherwise expected warming at terrestrial stations [Bertler et al., 2004].

The mechanism of this tropical-polar teleconnection is rooted in ENSOdriven changes to tropical circulation and convection. These changes, such as weakening or strengthening of Hadley and Ferrell cells, zonal shifts in circulation centers, and associated changes to upper level convergence have been shown to be responsible for the modulation of the split polar jet stream which in turn guides pressure fields and storm trajectories [Chen et al., 1996; Yuan, 2004]. These ENSOdriven changes are propagated pole-wards from the tropics via the Pacific South American (PSA) Pattern, a wave train of positive/negative geopotential height anomalies extending across the Pacific [Fogt and Bromwich, 2006; Houseago et al., 1998; Mo and Higgins, 1998; Mo et al., 1987; Thompson and Solomon, 2002].

One of the most significant impacts of ENSO on the climate of the Antarctic is ENSO's modulation of the position and strength of the Amundsen Sea Low. The ASL is a climatological low-pressure feature located in the AS Region, an important center of cyclonic activity [King and Turner, 1997]. Multiple analyses suggest that La Niña (El Niño) events cause a relative strengthening (weakening) of the low [Bertler et al., 2004; Chen et al., 1996; John Turner, 2004; Yuan, 2004]. Moreover, this sector of the Pacific experiences the most significant inter-annual variability of the split jet stream [Chen et al., 1996] and changes associated with the PSA wave train [Houseago et al., 1998; Mo and Higgins, 1998].

The Southern Annular Mode, also known as the Antarctic Oscillation (AAO), is the dominant mode of climate variability in the SH [Jones et al., 2009; Marshall, 
2003; Thompson and Solomon, 2002]. The SAM is an approximately zonally symmetric oscillation in the strength and position of the circumpolar westerly winds and is related to the contraction and expansion of the polar vortex and the meridional pressure gradient [Jones et al., 2009; Thompson and Solomon, 2002]. Atmospheric modeling suggests that SAM as well as the PSA are inherent modes of atmospheric dynamics and, unlike ENSO, do not require ocean-atmosphere interactions [Cai and Watterson, 2002]. The SAM operates at a range of time scales from sub-seasonal to decadal [Fogt et al., 2009b; Thompson and Solomon, 2002] and has shown a significant positive trend since the 1960s, that is an increase in intensity and a southward movement of the average position of the westerly winds [Fogt et al., 2009b; Mo, 2000; Thompson and Solomon, 2002]. Many studies have investigated possible causes for this trend including ozone depletion and greenhouse gas concentrations [Arblaster and Meehl, 2006; Fogt et al., 2009b; Jones et al., 2009]. It has been suggested that the SAM's positive trend is at least in part responsible for the observed warming on the Antarctic Peninsula and cooling over East Antarctica [Marshall, 2007; Thompson and Solomon, 2002].

The SAM is revealed as the leading empirical orthogonal function (EOF) of a range of fields of atmospheric variability in the Southern Hemisphere [Marshall, 2003]. Mo [2000] showed that the SAM is the leading EOF of reanalysis geopotential height anomalies in the SH and can account for 20 to $27 \%$ of the annual variance based on NCEP/NCAR or ECMWF reanalysis data set, respectively. The Climate Prediction Center of the National Oceanic and Atmospheric Administration defines 
the AAO index of SAM as the projection of hemispheric $700 \mathrm{hPa}$ height anomalies on to the loading pattern of this leading EOF.

Mo [2000] found that the subsequent two most important modes of variability from EOF analysis represent the PSA patterns and account for $\sim 13 \%$ and $\sim 11 \%$ of the total variance in the NCEP/NCAR and ECMWF reanalysis, respectively. The first of these exhibits a high correlation with the Southern Oscillation Index (SOI), which describes the evolution of ENSO based on the twice-standardized pressure difference between Tahiti and Darwin [Trenberth, 1997]. The analyses by Mo [2000] show that both the SAM and the PSA have significant loading centers in the Amundsen Sea indicating that SAM as well as ENSO (via the PSA) play a role in governing the pressure fields in this region [Fogt and Bromwich, 2006; Mo, 2000].

Several studies have investigated the interaction of ENSO and SAM and their combined forcing on the Antarctic [Bertler et al., 2006a; Bertler et al., 2006b; Fogt and Bromwich, 2006]. Fogt and Bromwich [2006] suggest that the SAM modulates the strength of the ENSO teleconnection to the high southern latitudes such that when the two oscillations are in-phase (out of phase), ENSO's influence in the Antarctic is strengthened (weakened), due to the reinforcing/interfering nature of SAM and the PSA patterns.

Fogt and Bromwich [2006] identify a significant shift in the nature of the ENSO-SAM relationship between the 1980's and 1990's in the form of a shift in phase of maximum cross-correlation. Other studies independently identify an approximately synchronous shift in the sign of correlation between ENSO and 
Antarctic precipitation [Bromwich et al., 2000], as well as ENSO, SAM, and sea level pressure records [Bertler et al., 2006a; Bertler et al., 2004].

While the importance of ENSO and SAM as drivers of Southern Hemisphere climate variability has been demonstrated, questions remain, particularly about the interactions between these two oscillations. Here we investigate: a) the individual effect of SAM or ENSO on the ASL, b) the quantitative, relative, and combined effect of these two oscillations on high southern latitude geopotential fields, c) the spatial and temporal variability of this relationship, and d) the representation of their interactions and combined influence.

The relative importance of these oscillations has been examined to some extent by the decomposition of reanalysis fields into EOF modes [Fogt et al., 2009b; Jones et al., 2009; Marshall, 2003; Thompson and Solomon, 2002]. We motivate this study by first noting some potential difficulties in interpreting EOF modes of variability, such as the EOF based indices used to described SAM and ENSO. Rather than employ these indices, we use independent station record based indices of ENSO and SAM to examine their relative importance. As reviewed by Monahan et al. [2009], EOF decomposition applied to geophysical data sets does not generally produce individual modes of variability that are dynamically, kinematically, or statistically independent. For example the asymmetry of the SST anomalies defining ENSO result in EOFs that cannot be statistically independent [Monahan et al., 2009]. Moreover, they show that the geometry of the analysis can impose itself on the geometry of the resultant modes such as the EOFs of reanalysis geopotential describing SAM. These can arise from zonally localized variability coupled with 34 
zonally symmetric statistics rather than cohesive hemispheric-scale phenomena [Monahan et al., 2009]. However, we also note that indices of SAM based on observational station pressure records, and radiosonde data are generally well correlated with the leading mode of reanalysis based EOFs [Fogt et al., 2009b; Jones et al., 2009; Marshall, 2003; Thompson and Solomon, 2002] and that the station based SOI is well correlated with the $2^{\text {nd }}$ leading mode of EOF analysis [Mo, 2000]. Thus while EOF modes are demonstrably useful, there are limitations to their statistical use.

In this study, we first investigate the individual affects of the SAM and ENSO on the ASL using NCEP/NCAR reanalysis data. Through linear regression of station record-based indices onto reanalysis geopotential fields, we explore the relative influence and interaction of these two oscillations in governing SH pressure systems, particularly the ASL. With this approach we avoid EOF-based oscillation indices and instead employ indices based on observational station pressure records. We describe and quantify the complexity of the ENSO/SAM relationship through our regression model.

\subsection{Methods}

Many studies have investigated the suitability and shortcomings of the NCEP/NCAR Reanalysis data set (hereafter NNR) in the Antarctic. For the region, the data are of high quality after the start of the modern satellite era in 1979 [Fogt and Bromwich, 2006; Fogt et al., 2009b; Jones et al., 2009; Kalnay et al., 1996; Marshall, 
2003]. This study examines monthly reanalysis time series data for the 30 -year period 1980 through the end of 2009.

We use monthly SOI and the monthly Marshall SAM index for time series representations of ENSO and SAM, respectively. The SOI is a station pressure based index, calculated as the twice-standardized pressure difference between Tahiti and Darwin, Australia (available from NOAA at

\section{http://www.esrl.noaa.gov/psd/data/climateindices/) [Trenberth, 1997]. The}

Marshall SAM index is a station-based reconstruction of zonal pressure differences between $40^{\circ} \mathrm{S}$ and $65^{\circ} \mathrm{S}$, following the numerical definition of SAM from Gong and Wang [1999] and is available from Marshall at

\section{http://www.antarctica.ac.uk/met/gjma/sam.html [Marshall, 2003]. Constructed}

from 12 station pressure records, the Marshall SAM index is advantageous due to its simplicity and temporal consistency. This has to be balanced with the fact that it cannot capture the non-zonal SAM variability seen in EOF based indices.

Furthermore, a lack of station pressure records from the Southern Pacific region, owing to a lack of landmasses, may bias the index in a manner that is hard to quantify [Marshall, 2003]. Therefore we test our results using additional ENSO and SAM indices including the Niño 3, BEST, and AAO (all indices are available at http://www.esrl.noaa.gov/psd/data/climateindices/list/] [Smith and Sardeshmukh, 2000; Trenberth, 1997].

Composite maps for the phases of ENSO and SAM were created using continuous NNR 850 mb geopotential height data (available at http://www.esrl.noaa.gov/psd). 
Geopotential height means and anomalies were mapped for the AS region between $60^{\circ} \mathrm{S}$ and $90^{\circ} \mathrm{S}$ (Figure 3.3). Composites were created using positive and negative years of each index. Anomalies were created by subtracting the 1968-1996 climatological mean from the composite mean. To best capture the variability of each index and to eliminate seasonal bias, a May to April centered year was used for the phases of SOI and a September to August centered year for SAM.

Linear regression was used to model NNR $850 \mathrm{mb}$ geopotential height anomalies as linear combinations of the SOI and SAM indices. Discrete NNR time series of 850 $\mathrm{mb}$ geopotential heights are used from points at $20^{\circ}$ of longitude intervals around the Southern Ocean at $60^{\circ} \mathrm{S}$ and $65^{\circ} \mathrm{S}(18$ points each $)$ and at $10^{\circ}$ intervals at $70^{\circ} \mathrm{S}$ in the Amundsen Sea Region between $170^{\circ} \mathrm{E}$ and $350^{\circ} \mathrm{E}$ (18 points) for a total of 54 points (see Figure 3.1). Note that point $70^{\circ} \mathrm{S}, 290^{\circ}$ E, over the Antarctic Peninsula (marked in green in Figure 3.1), is omitted for consistency so that all points used are over ocean. All NNR and oscillation index time series were normalized over the 1980 through 2009 period by subtracting the period mean and dividing by the standard deviation, hence all time series represent anomalies in units of one standard deviation. The NNR data were corrected for the seasonal cycle by subtracting the monthly mean values for each gripoint. 


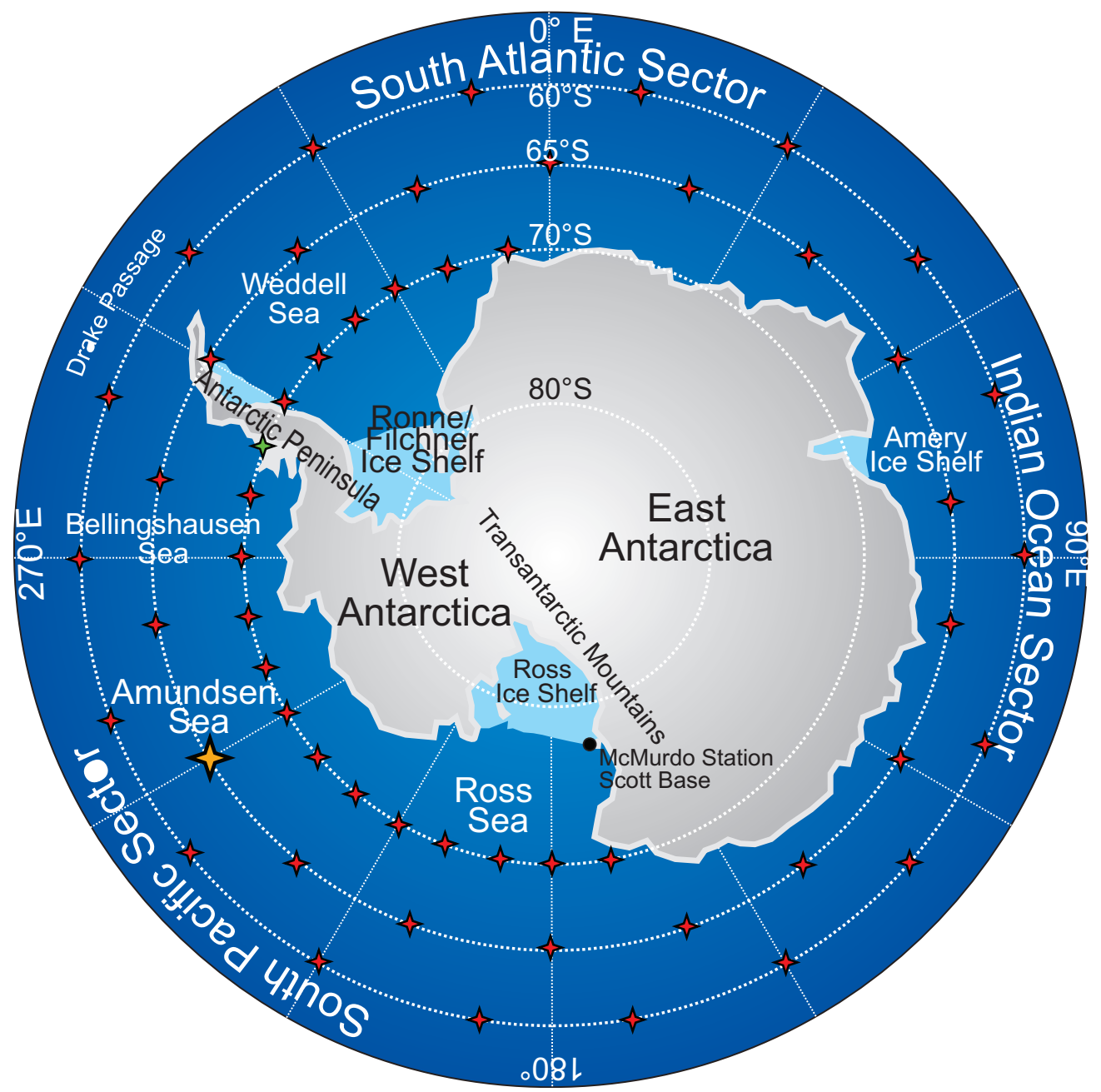

Figure 3.1 Map of Antarctic showing locations of all NNR data points used in regression analysis (red stars). Note that the point at $70^{\circ} \mathrm{S}, 290^{\circ} \mathrm{E}$ (green star) on the Antarctic Peninsula is omitted from analysis so that all points used are over ocean to eliminate topographic effects. The Amundsen Sea Region is in the lower left. The point at $65^{\circ} \mathrm{S}, 240^{\circ} \mathrm{E}$, referenced throughout the text, is noted with a large orange star.

To filter the data for high frequency noise we applied 1, 3, 5, and 12-monthly averages (av) and moving averages (mav). All results are presented using a seasonal 3-month mav smoothing unless otherwise noted. The influence of the choice of smoothing factor is discussed below. 
For gridpoints along each longitude, geopotential heights were linearly regressed against SOI alone, SAM alone, and SOI and SAM together, i.e. for the last, a linear model

$$
\mathbf{P}_{j}=a^{c o n s t}+b^{S O I} \mathbf{S O I}_{j}+c^{S A M} \mathbf{S A M}_{j}
$$

was fitted by least squares to the geopotential time series at each site. No adjustment is made for the non-independence of the moving average filtered data. Significance levels of F values are calculated for the combined SOI-SAM model against a model incorporating SAM only using the combined residual variance of the region that saw greatest improvement in $\mathrm{R}^{2}$ of the combined model over the SAMonly model.

Wavelet analysis, following the method of Torrence and Compo [1998], was performed on the monthly and 3-month mav SOI and SAM indices, as well as the NNR $850 \mathrm{mb}$ geopotential, the regression model, and the model residuals (the difference between the model and the NNR data) from $65^{\circ} \mathrm{S}, 240^{\circ} \mathrm{E}$. Analysis was conducted using a Morlet wavelet and significance above a modeled red noise was calculated following Torrence and Compo [1998]. 


\subsection{Results and Discussion}

\subsubsection{SOI-SAM Influence on Geopotential Height Variability}

Spatial auto correlation in the seasonally corrected NNR $850 \mathrm{mb}$ geopotential height anomalies is examined in Figure 3.2. Immediately adjacent points show high correlation and some broad regions of high spatial autocorrelation are observed, particularly between 0 and $160^{\circ} \mathrm{E}$. In the AS region, however, spatial autocorrelation is relatively lower and tails off to very low values much quicker. The correlation matrix for the raw geopotential heights without the seasonal cycle removed (not shown) is very similar to Figure 3.2, as one would expect. 


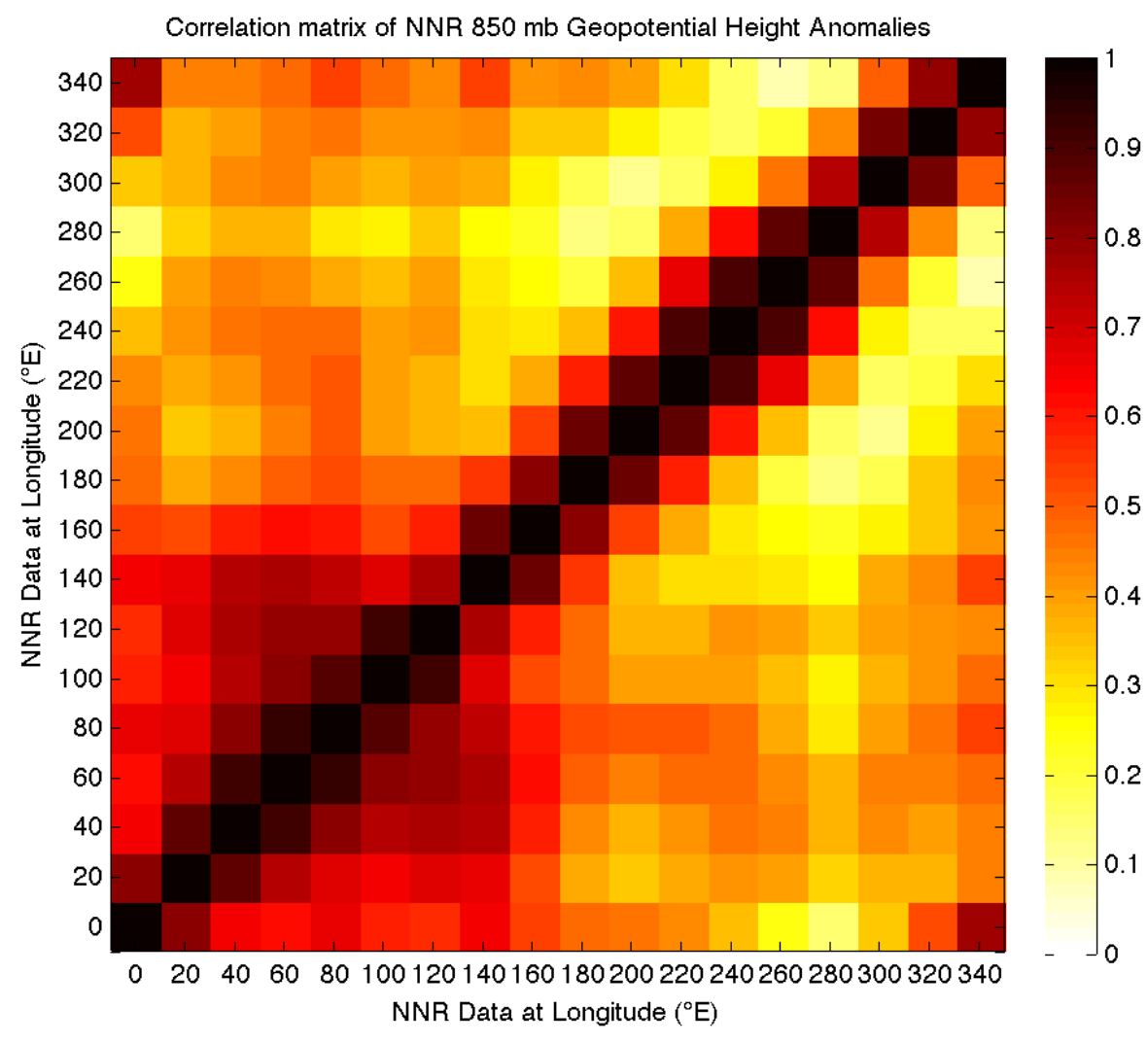

Figure 3.2 Correlation matrix of seasonally corrected NNR $850 \mathrm{mb}$ geopotential height anomalies. High spatial autocorrelation is observed in some areas such as between 0 and $160^{\circ} \mathrm{E}$, while lower spatial autocorrelation is seen in the AS region between 180 and $300^{\circ} \mathrm{E}$.

Composite $850 \mathrm{mb}$ geopotential anomaly maps for the phases of ENSO and SAM are shown in Figure 3.3. The effects of both oscillations on the region are similar. Significant deepening of the ASL (negative anomaly) is seen during the positive phases of both SOI and SAM. Alternatively, during both negative phases, positive anomalies are seen in the eastern Amundsen Sea, indicating a relative weakening of the low, while deepening is observed west of the Ross Sea. 
SAM

a)
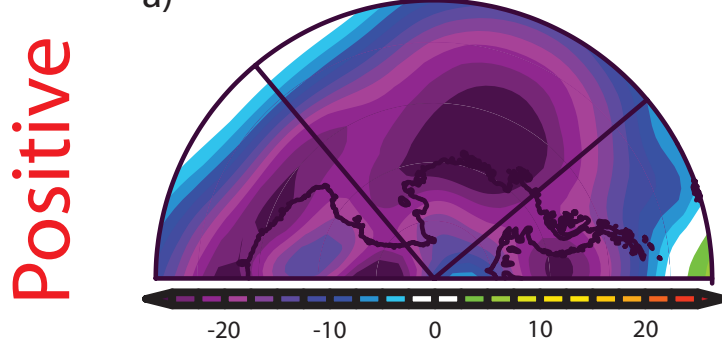

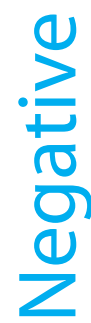

c)

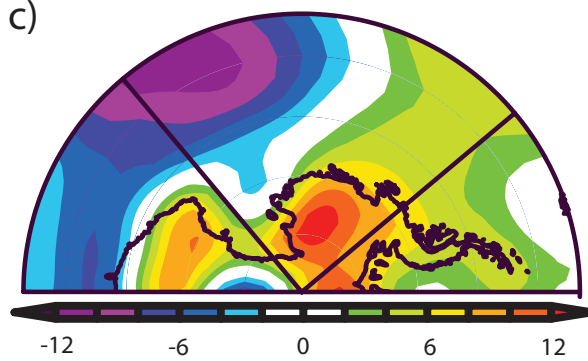

ENSO

b)

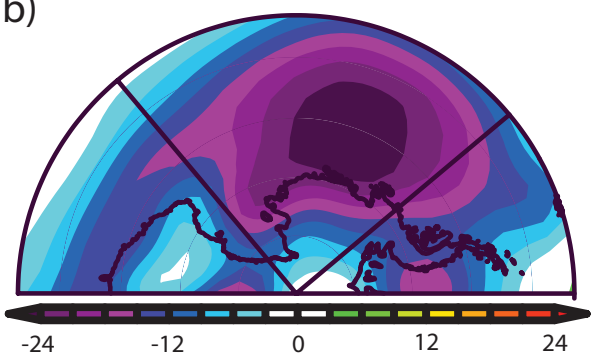

d)

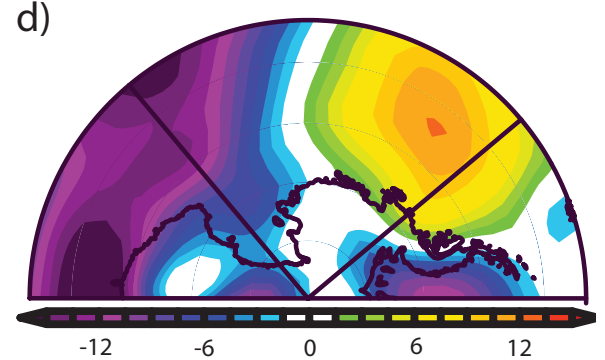

Figure 3.3 Composite anomaly maps of NNR $850 \mathrm{mb}$ geopotential heights, in meters, for a) $\mathrm{SAM}^{+}$ (September to August: 1982, '84, '93, '94, '97, '99, '00, '02, '08, '09); b) ENSO+(May to April: 1982, '84, '85, '86, '89, '91, '96, '97, ‘99, '00, '01, '02, '04, '06, '08, '09); c) SAM- (September to August: 1980, '81, '83, '85, '88, '92, '01, '03, '07, '10); d) ENSO- (May to April: 1981, '83, '87, '92, '93, '94, '95, '98, '03, ’05, '07, '10). Anomalies shown from the 1968-1996 climatological mean. Data obtained from the NOAA/ESRL Physical Sciences Division. 
Comparison of SOI, SAM, and the NNR $850 \mathrm{mb}$ geopotential height time series from $65^{\circ} \mathrm{S}, 240^{\circ} \mathrm{E}$ (a point in the ASL) is shown in Figure 3.4a and 3.4b. Strong anticorrelation is observed between the geopotential height and both SOI and SAM with correlation coefficients of -0.44 and -0.56 with SOI and SAM, respectively. It is important to note that although ENSO and SAM are shown to have similar influences on the ASL, as seen in Figure 3.3, they operate at different frequencies and are at times in-phase and at times out of phase, particularly at higher frequencies (i.e. inphase, 1983; out of phase, 1996-1997).

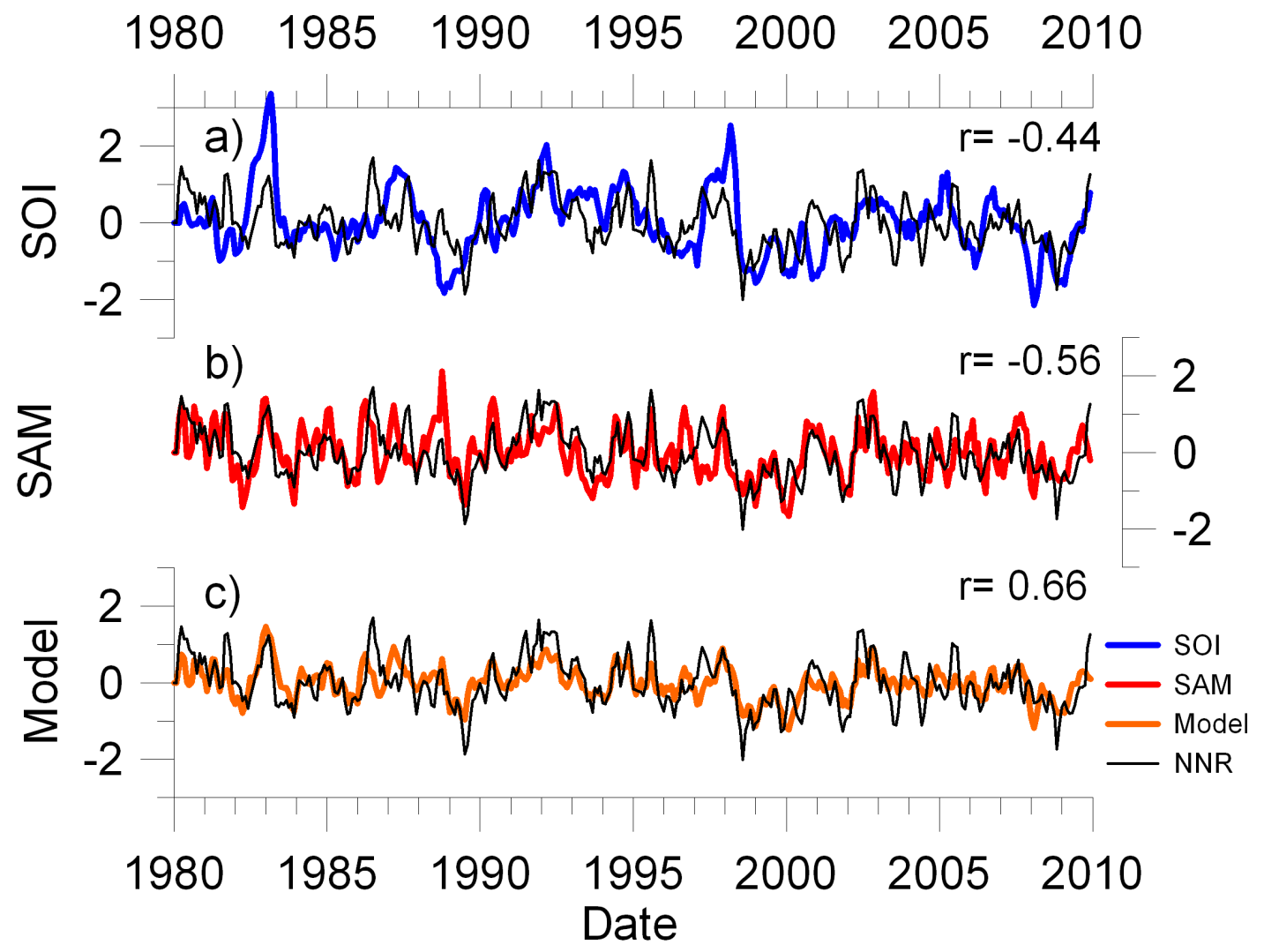

Figure 3.4 Comparison of a) the SOI, b) SAM, and c) combined SOI-SAM regression model with NNR $850 \mathrm{mb}$ geopotential height anomalies for 1980 through 2009 from $65^{\circ} \mathrm{S}, 240^{\circ} \mathrm{E}$. All time series are shown with a 3-month mav smoothing. Correlations coefficients are shown at right. Note that the sign of the SOI and SAM have been flipped for plotting, a) and b), to more easily demonstrate the correlation, though r-values were calculated with the original sign. 
Results of Fourier and wavelet analyses further accentuate the distinctly different power spectra of the two oscillations (Figure 3.5a and 3.5b). The SAM shows variability across a range of time scales but is particularly strong at periods less than two years. Like the SAM, the SOI shows strong variability at 1 to 2 year periods. However, it also exhibits greater power at longer periods, particularly 2 to 6 years. Furthermore analysis of the NNR $850 \mathrm{mb}$ geopotential time series from $240^{\circ} \mathrm{E}, 65^{\circ} \mathrm{S}$ (Figure $3.5 \mathrm{c}$ ) clearly shows variability in the data at a range of periods associated with both oscillations. It is thus reasonable to conclude that the advantage of the combined SOI/SAM regression model lies in the combination of these scales of variability; the SOI dominating longer period variation and the SAM contributing to shorter period variability. While some of the features discussed here may be influenced by edge affects at the start of the time series (values to the left of the leftmost white dashed line, Figure 3.5a and b), wavelet analysis of longer time series (from 1951 for SOI and 1957 for SAM) finds the same features and suggests edge effects are minimal. 
a)

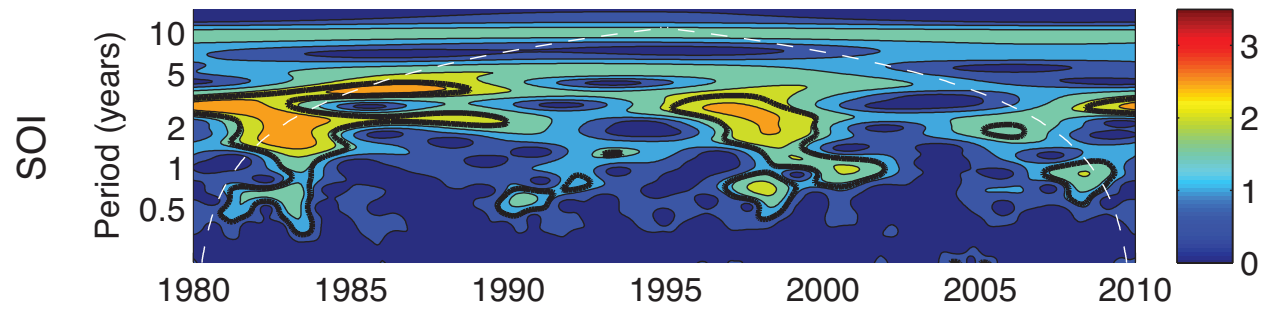

b)

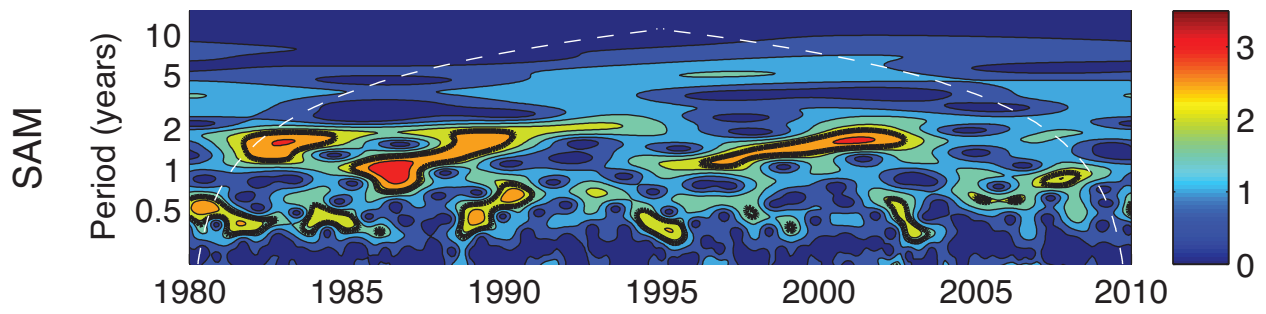

c)

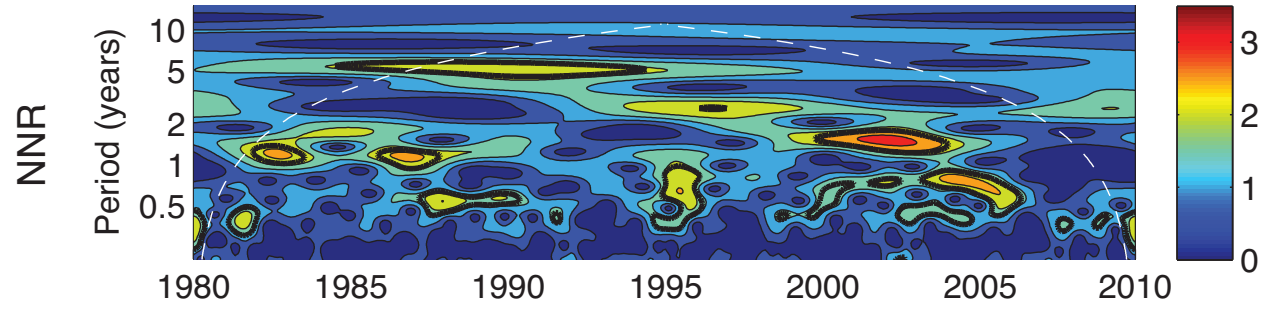

d)

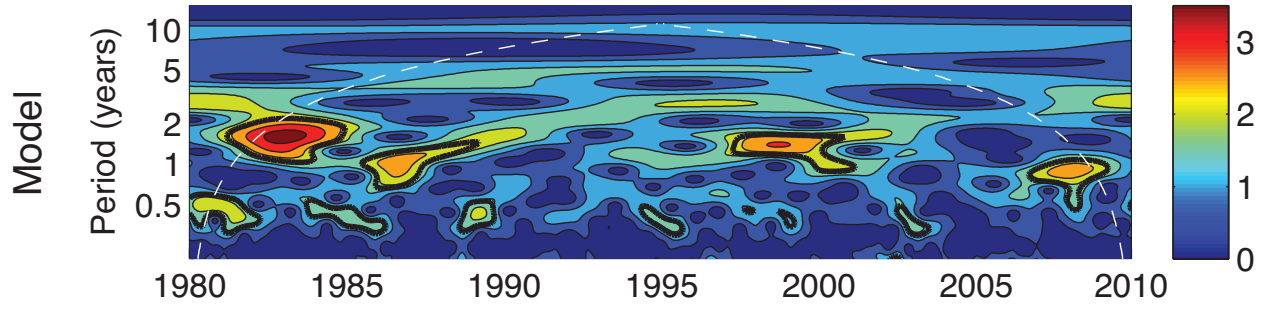

e)

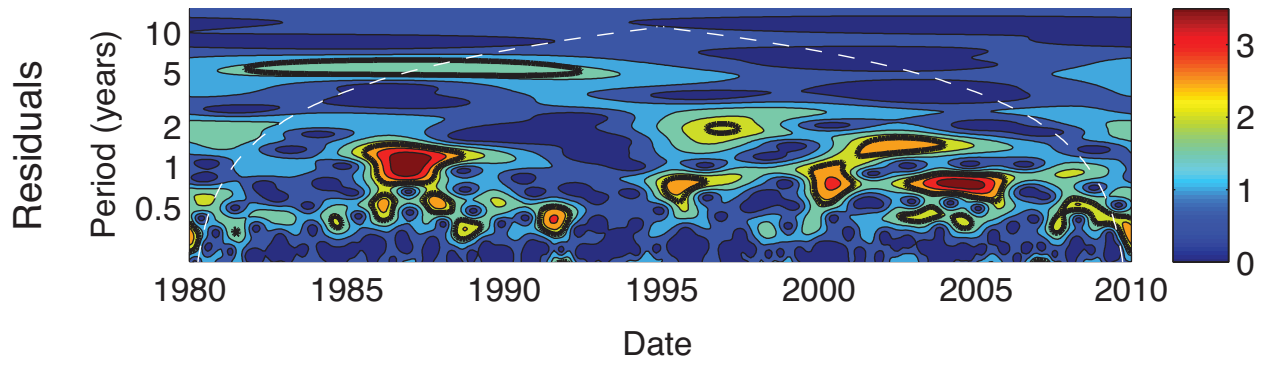

Figure 3.5 Wavelet analysis is shown for a) the SOI, b) SAM, c) NNR $850 \mathrm{mb}$ geopotential height anomaly, d) our combined SOI-SAM regression model, and e) the model residuals. All time series are from 1980 through 2009 , have been smoothed with a 3-month mav, and are for $65^{\circ} \mathrm{S}, 240^{\circ} \mathrm{E}$ in the case of c), d), and e). Values outside dashed white lines may be influenced by edge effects with the ends of the time series while the solid black line denotes significance above a modeled red noise following Torrence and Compo [1998]. The color scale shows the square root of the ratio of power to total data variance and is thus relative for each time series. Period is plotted on a logarithmic scale. 


\subsubsection{Combined SOI-SAM Regression Model}

Our regression analysis reveals the ability of simple linear combinations of SOI and SAM to model the NNR $850 \mathrm{mb}$ geopotential height around the Antarctic between 1980 and 2009. Figure 3.4c shows the combined SOI-SAM model against the NNR data at $240^{\circ} \mathrm{E}, 65^{\circ} \mathrm{S}$ in the Amundsen Sea Region (correlation coefficient = 0.66). A composite of the regression results and the standardized geopotential height anomaly timeseries at all longitude points around $65^{\circ} \mathrm{S}$ (with a 3 mav) are shown in Figure 3.6a, while the zonal means for $65^{\circ} \mathrm{S}$ for both the geopotential and model are shown in Figure 3.6b. A composite of the regression residuals are shown at all longitude points around $65^{\circ} \mathrm{S}$ are shown in Figure 3.7.a, while the residual zonal mean is shown in Figure 3.7b. Mean residuals are relatively small compared to amplitudes in the model and there is considerable variance across sites. 

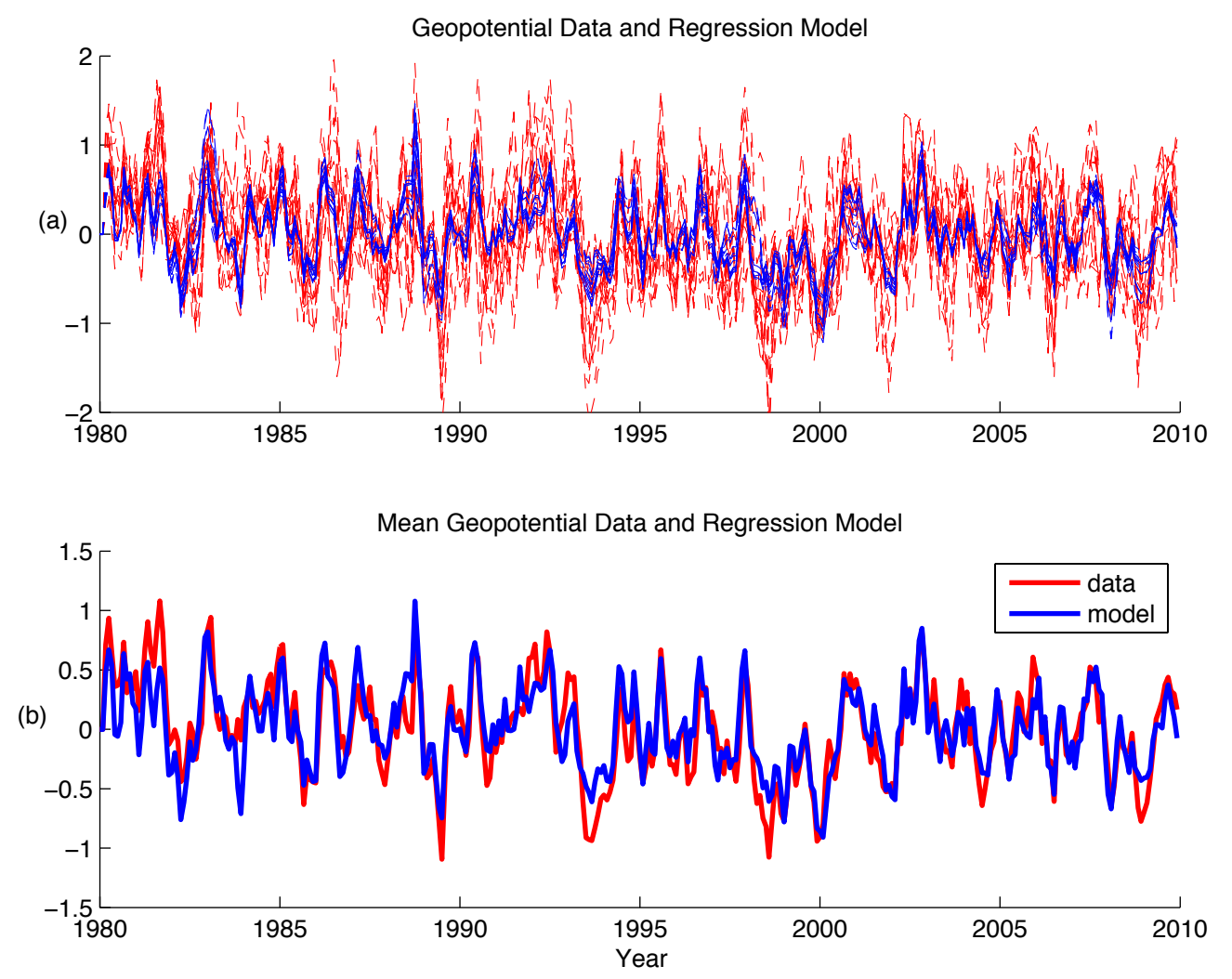

Figure 3.6 a) Composite standardized $850 \mathrm{mb}$ geopotential height anomaly data with a 3 month moving averaging (red) and regression model results (blue) for 18 longitude points at $65^{\circ} \mathrm{S}$. b) Zonal mean for $850 \mathrm{mb}$ geopotential height anomaly and regression model results for $65^{\circ} \mathrm{S}$. 

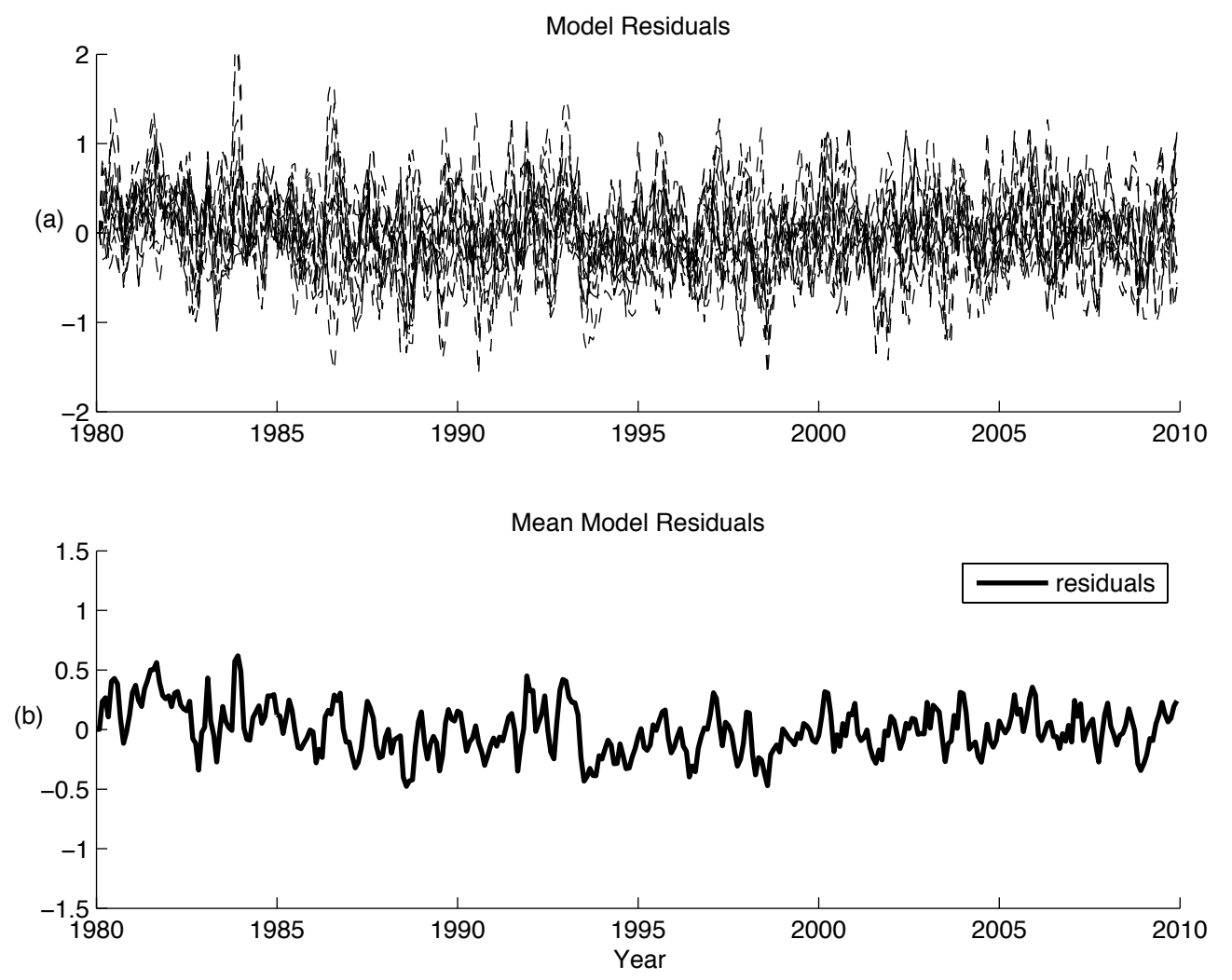

Figure 3.7 a) Composite of residuals for the regression model at $65^{\circ} \mathrm{S}$. b) Zonal mean of the regression residuals at $65^{\circ} \mathrm{S}$. Scaling is identical to Figure 3.6 for comparison.

The spatial variability in the relative weighting of SOI and SAM by our regression analysis is shown in Figure 3.8a. The influence of SAM, coefficient $c^{\mathrm{SAM}}$, is consistently negative (anti-correlated) across all longitudes and latitudes. The influence of SOI, coefficient $b^{\text {SOI }}$, however, is weak except in the Amundsen Sea region $\left(180^{\circ} \mathrm{E}\right.$ to $\left.310^{\circ} \mathrm{E}\right)$ where it is strong and negative. Values of $c^{\mathrm{SAM}}$ generally decrease northward while the magnitude of $b^{\text {SOI }}$ remains essentially constant across latitude. The constant term, $a^{\text {const, }}$ is found to be essentially zero across all latitudes and longitudes. As all time series were normalized for the period, the constant's zero value verifies our method. The relative importance of SOI compared to SAM, the 48 
ratio $b^{\mathrm{SOI}} / c^{\mathrm{SAM}}$ (Figure 3.8c), increases dramatically in the AS region, peaking between $240^{\circ} \mathrm{E}$ and $260^{\circ} \mathrm{E}$. This peak generally increases northward, $b^{\mathrm{SOI}} / c^{\mathrm{SAM}} \approx 0.4$ at $70^{\circ} \mathrm{S}$ and $b^{\mathrm{SOI}} / c^{\mathrm{SAM}} \approx 0.8$ at $60^{\circ} \mathrm{S}$. We show that the SAM alone represents much of the geopotential variability around the southern ocean except in the AS region, where the SOI becomes almost equally important.

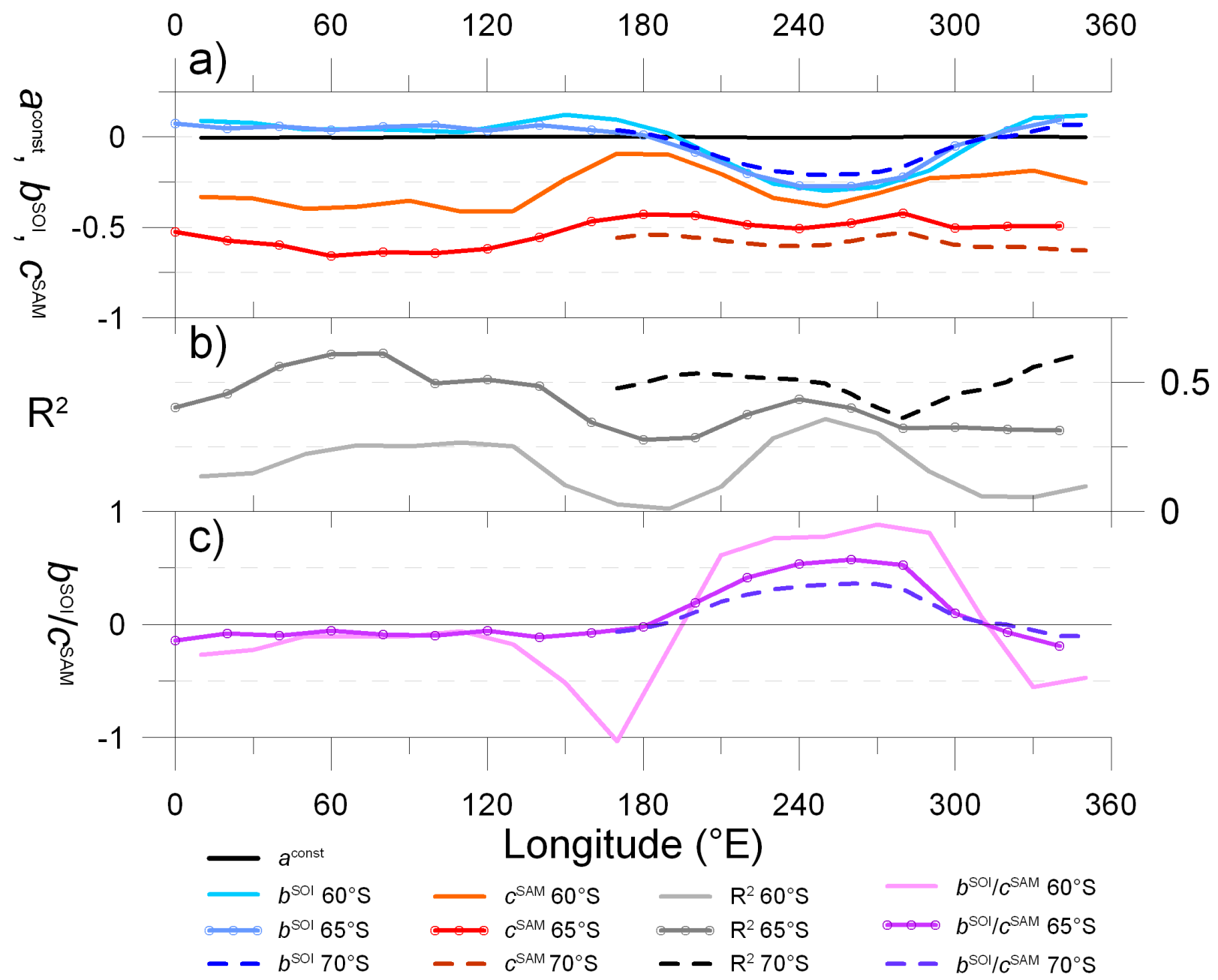

Figure 3.8 Spatial variability of the combined SOI-SAM regression model results with a 3-month mav smoothing is shown for a) Coefficients $b^{\text {SOI }}$ and $c^{\text {SAM }}$ represent the influence of the SOI and SAM, respectively; b) $\mathrm{R}^{2}$ values represent the percent variability of the NNR data captured by the model; $\mathbf{c}$ ) The relative influence of SOI to SAM is represented by the ratio $b^{\mathrm{SOI}} / c^{\mathrm{SAM}}$. Values for $60^{\circ} \mathrm{S}$ are denoted with a smooth line, $65^{\circ} \mathrm{S}$ with open circles, and $70^{\circ} \mathrm{S}$ with a dashed line. 
The regression $\mathrm{R}^{2}$ values, shown in Figure $3.8 \mathrm{~b}$ and Figure 3.9, represent the percent variance of geopotential height anomaly explained by the regression model. We note that $\mathrm{R}^{2}$ generally decreases northward (slightly in the AS region and more markedly elsewhere) suggesting the greater influence of other variables in guiding mid latitude pressure systems. The longitudinal change in $\mathrm{R}^{2}$ co-varies with $-c^{\mathrm{SAM}}$, as $b^{\text {SOI }}$ remains relatively consistent across latitude except in the AS region (Figure 3.8). The combined SOI-SAM model's $\mathrm{R}^{2}$ is significantly higher than SOI-only or SAMonly models in the AS region (Figure 3.9). Outside this region, the combined model is essentially a SAM-only model as the SOI regression coefficient, $b^{\text {SOI }}$, is close to zero (Figure 3.8).

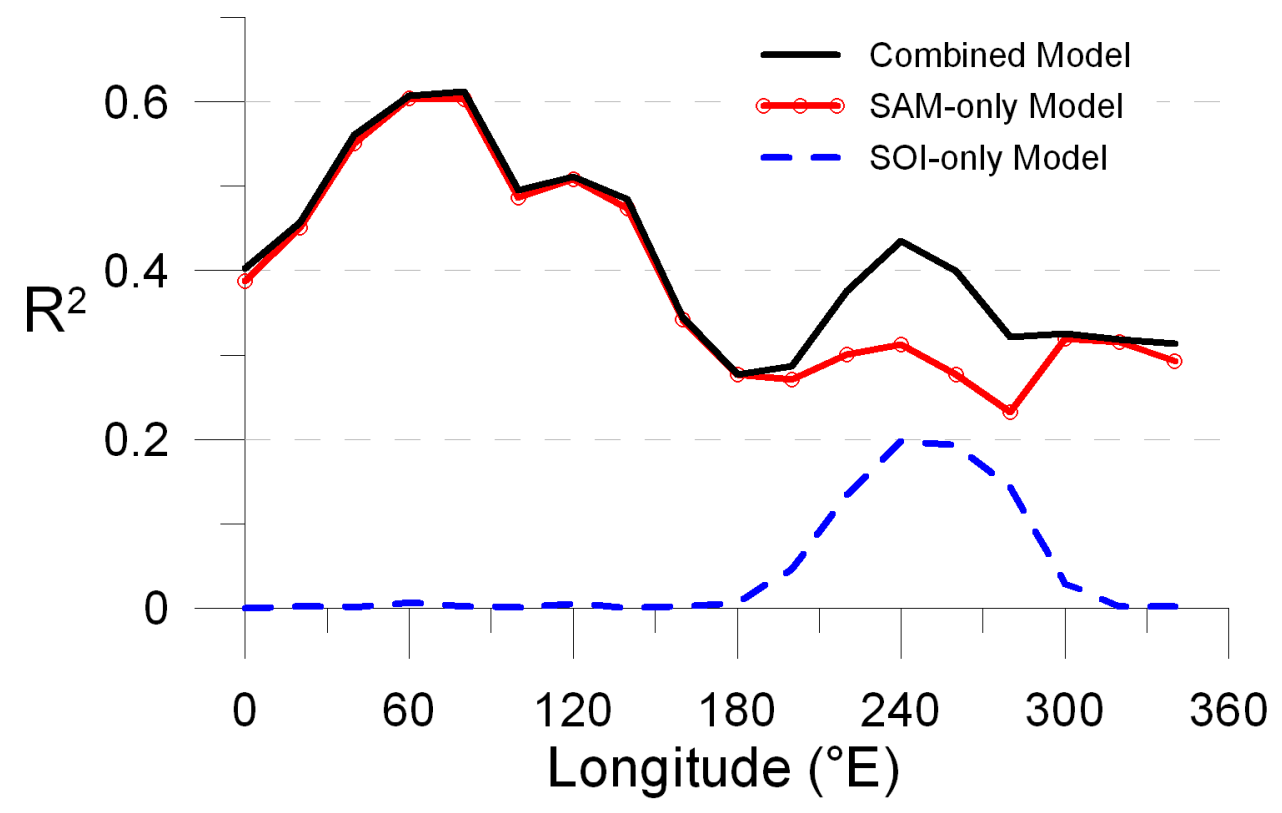

Figure 3.9 The Combined SOI-SAM model (black) $\mathrm{R}^{2}$ values for $65^{\circ} \mathrm{S}$ with a 3-month mav smoothing are compared to those of SOI-only (dashed blue) and SAM-only models (red with open circles). The combined model significantly improves $\mathrm{R}^{2}$ over the SAM-only model only in the AS region where the influence of SOI becomes important.

Results of regression analysis using raw monthly values of the SOI, SAM, and NNR geopotential heights, as well as 3, 5, and 12-month averages and moving 
averages all reveal qualitatively similar patterns. The choice of smoothing has slight affects on the values of $b^{\mathrm{SOI}}$, and $c^{\mathrm{SAM}}$, however the ratio $b^{\mathrm{SOI}} / c^{\mathrm{SAM}}$ remains relatively consistent with only some spread of values observed in the AS region as shown in Figure 3.10a. We show that increased smoothing increases the model's $\mathrm{R}^{2}$ values, particularly in the AS region (Figure 3.10b). Table 3-1 summarizes the relationship between smoothing choice, $\mathrm{R}^{2}$, and $b^{\mathrm{SOI}} / c^{\mathrm{SAM}}$ for two points at the peak of SOI influence in the AS region. It is plausible that high frequency variation, which may be masked by increased smoothing, may govern the divergence of the model from the data.

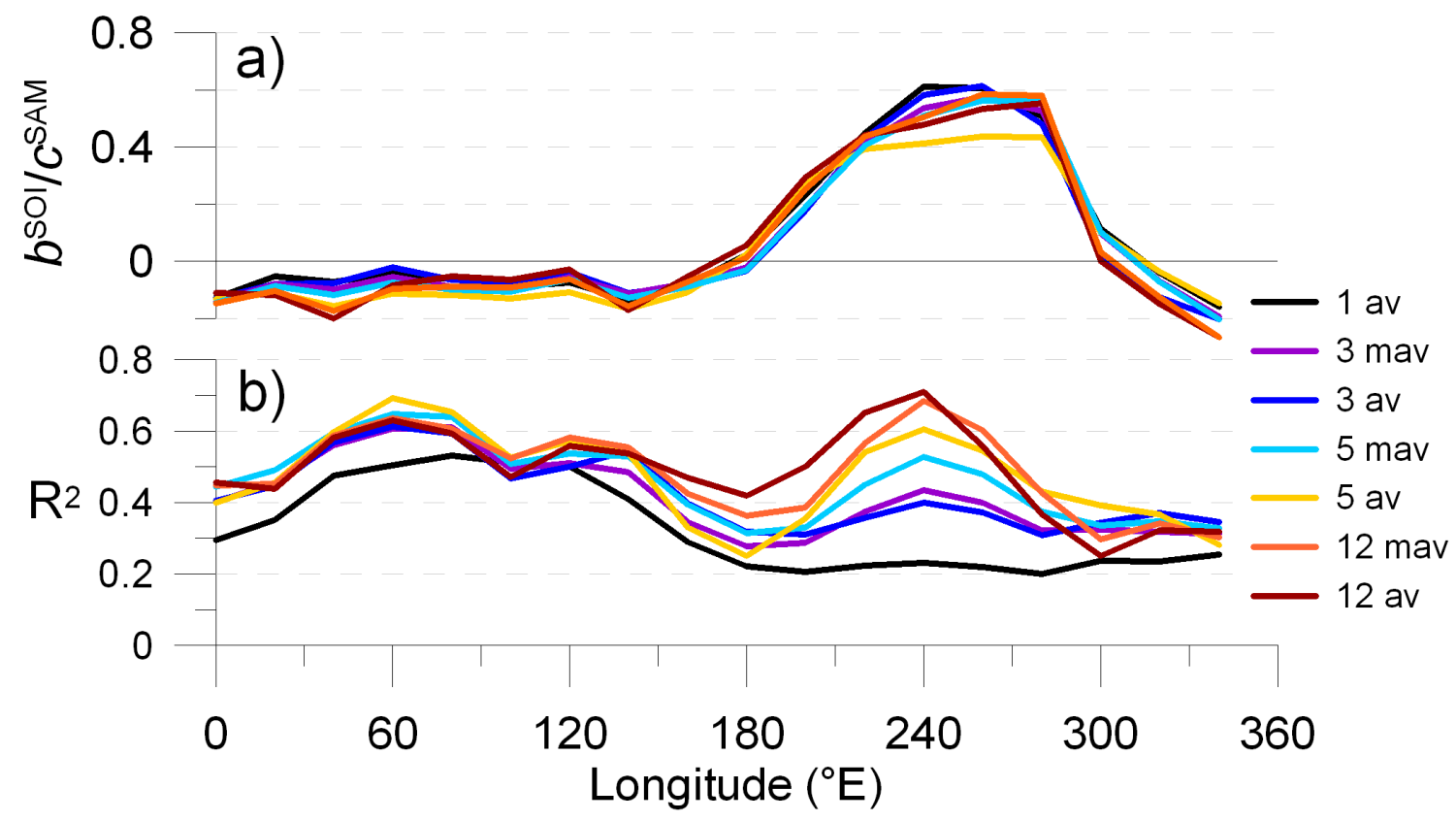

Figure 3.10 The affect of 1, 3, 5, and 12-month average (av) and moving average (mav) smoothing on the regression model is shown for a) $b^{\mathrm{SOI}} / c^{\mathrm{SAM}}$, representing the relative influence of SOI to SAM and b) $\mathrm{R}^{2}$, the percent variance in NNR geopotential explained by the combined SOI-SAM regression model at $65^{\circ} \mathrm{S}$. Note the difference in scales.

The 3-month mav combined SOI-SAM model produced an improved $\mathrm{R}^{2}$ between longitudes $200^{\circ}$ and $280^{\circ} \mathrm{E}$ over the SAM-only model, with a maximum 
improvement of $\mathrm{R}^{2}$ at $240^{\circ} \mathrm{E}$, from 0.31 for the SAM-only model to 0.44 for the combined model (Equation 1). Since only every $3^{\text {rd }}$ data point is independent, we count $360 / 3=120$ degrees of freedom for each longitude. The combined residual variance for the five longitude sets is 0.8723 for SAM alone and 0.7707 for the combined model. The ratio $0.8723 / 0.7707=1.132$ should have an $\mathrm{F}$ distribution with $5 \times(120-2), 3 \times(120-3)$ degrees of freedom. An $F$ value of 1.132 is significant at the $93 \%$ level $(95 \% \mathrm{~F}$ value $=1.146)$. Analogously, the 5-month mav smoothed model has an $\mathrm{R}^{2}$ value of 0.53 with an $\mathrm{F}$ value of 1.196 and is significant at the $95 \%$ level $($ critical $F$ value $=1.193$ ). Table 3-1 summarises these findings.

Table 3-1 Values of $\mathrm{R}^{2}, b^{\mathrm{SOI}} / c^{\mathrm{SAM}}$, and the percent significance level of the $\mathrm{F}$ statistic above a SAM-only model for 1, 3, 5, and 12-month average (av) and moving average (mav) smoothing methods. Values are shown for two points $\left(65^{\circ} \mathrm{S}, 240^{\circ} \mathrm{E}\right.$ and $\left.65^{\circ} \mathrm{S}, 260^{\circ} \mathrm{E}\right)$ in the AS region.

\begin{tabular}{|c|c|c|c|c|c|}
\hline & $65^{\circ} \mathrm{S}, 240$ & & $65^{\circ} \mathrm{S}, 260^{\circ}$ & & \\
\hline Smoothing & $b^{\mathrm{SOI}} / c^{\mathrm{SAM}}$ & $\mathbf{R}^{2}$ & $b^{\mathrm{SOI}} / c^{\mathrm{SAM}}$ & $\mathbf{R}^{2}$ & Significance Level \\
\hline 1-month av & 0.61 & 0.23 & 0.61 & 0.22 & $84 \%$ \\
\hline 3-month av & 0.58 & 0.40 & 0.61 & 0.37 & $92 \%$ \\
\hline 3-month mav & 0.54 & 0.44 & 0.58 & 0.40 & $93 \%$ \\
\hline 5-month av & 0.41 & 0.61 & 0.44 & 0.55 & $97 \%$ \\
\hline 5-month mav & 0.51 & 0.53 & 0.56 & 0.48 & $95 \%$ \\
\hline 12-month av & 0.48 & 0.71 & 0.53 & 0.56 & $97 \%$ \\
\hline 12-month mav & 0.50 & 0.68 & 0.59 & 0.60 & $97 \%$ \\
\hline
\end{tabular}

We present a minimum smoothing choice of 3-month mav for consistency, unless otherwise noted. This smoothing preserves seasonal variation in the model while still explaining more than $40 \%$ of the variance in the ASL region. We note that 52 
our model explains over $70 \%$ of the geopotential variance in the AS region at an annual scale (12 month av smoothing).

Model residuals were examined for heteroscedasticity, an assumption of linear regression, using a Breusch-Pagan test [Breusch and Pagan, 1979] with the Koenker modification [Koenker, 1981]. We find that we cannot reject the null hypothesis of homoscedasticity (uniformity in the variances of the residuals) at $95 \%$ confidence for 13 of 18 longitudes at $65^{\circ} \mathrm{S}$ as shown in Figure 3.11. Critically, we find homoscedasticity at all sites in the ASL region, the focus of this study.

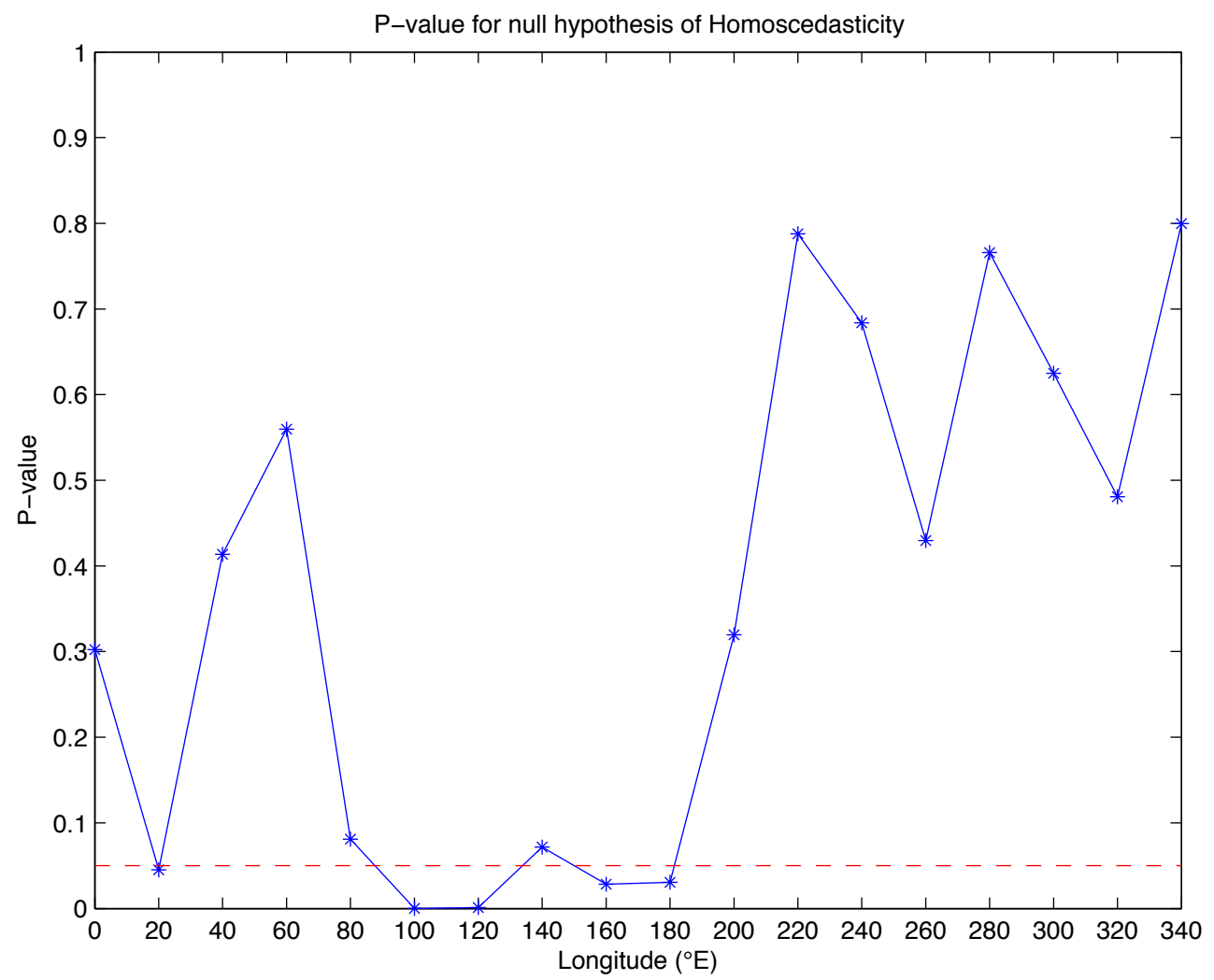

Figure 3.11 P-values are shown for a Breusch-Pagan test for the rejection of the null hypothesis of homoscedasticity for each longitude at $65^{\circ} \mathrm{S}$. The dashed red line denotes the $95 \%$ confidence limit; at sites with values above this line, the null hypothesis cannot be rejected. 
We examine the spatial correlations in the model residuals in Figure 3.12. In agreement with the results of the Breusch-Pagan test shown in Figure 3.11 we find very little broad spatial correlation between model residuals, except in the small region between 80 and $160^{\circ}$ E. Spatial correlation between the residuals is particularly low in the AS region.

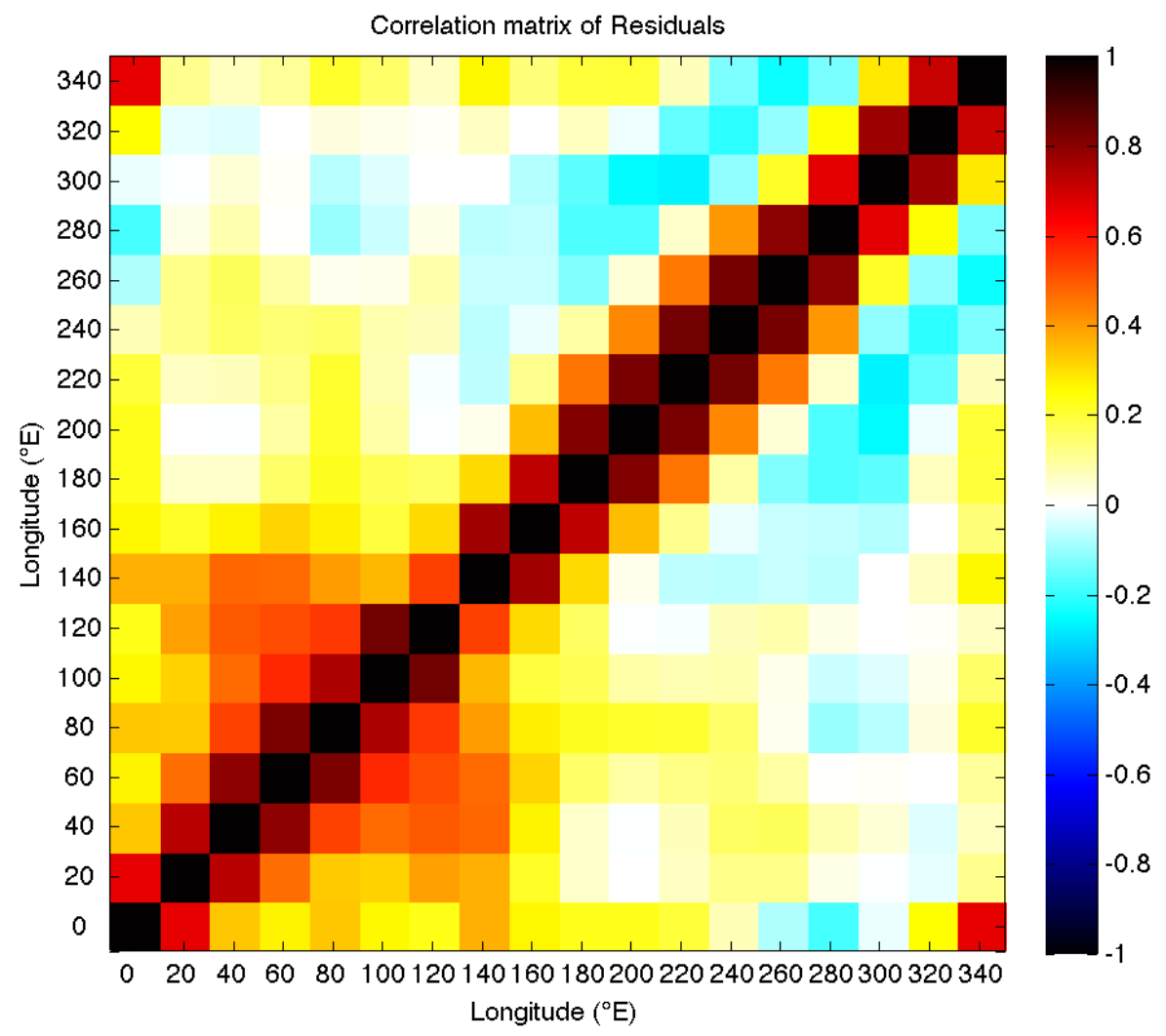

Figure 3.12 Correlation matrix of the regression model residuals around $65^{\circ} \mathrm{S}$.

The above pattern is very similar to that shown in a cross-correlation matrix of the model residuals and the NNR data timeseries (Figure 3.13). The affect of the spatial auto correlation can be seen in the higher correlation coefficients along and near the diagonal. However, in general, correlation coefficients are low, particularly in the AS region. 


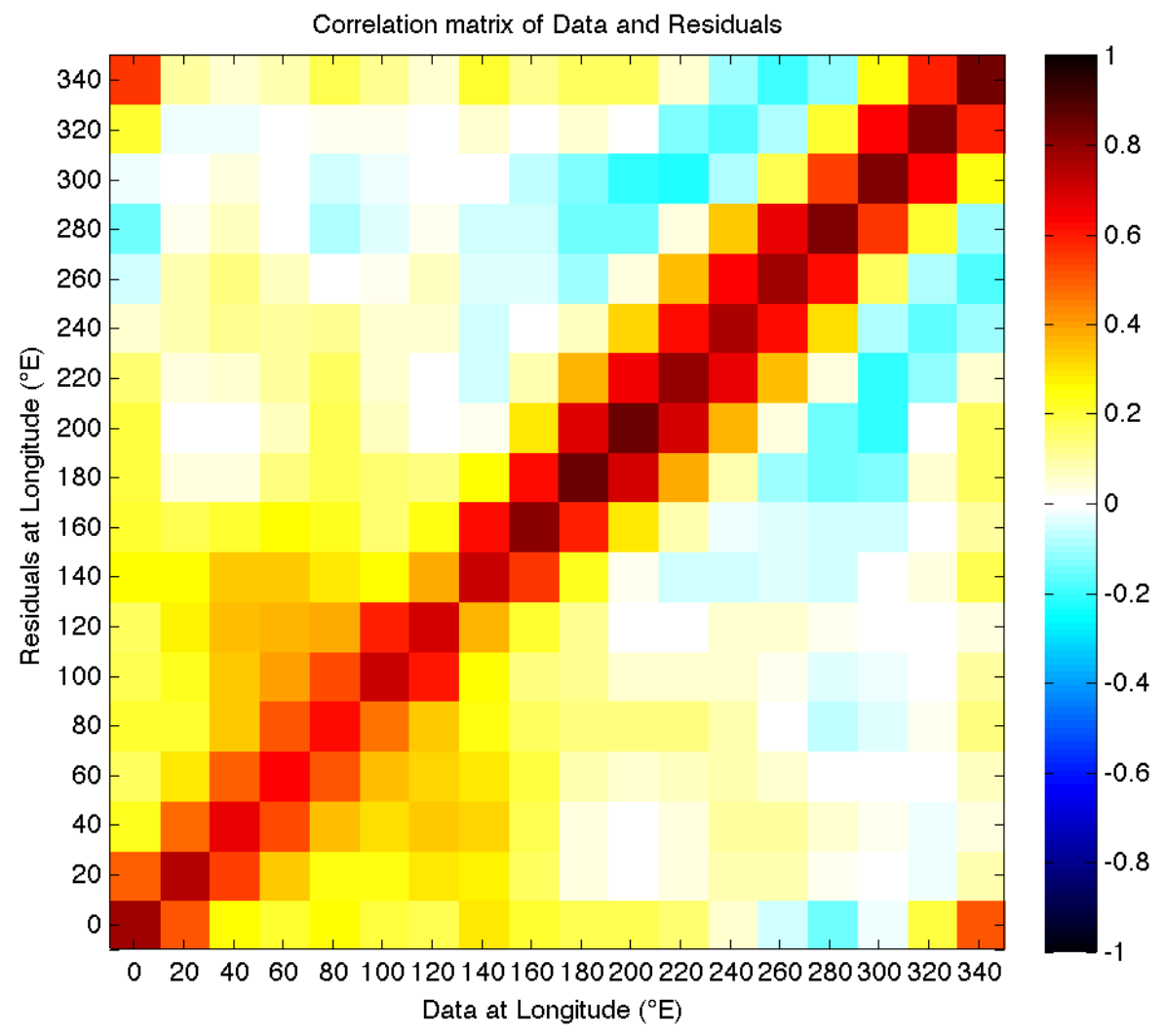

Figure 3.13 Cross correlation matrix of regression model residuals and the $850 \mathrm{mb}$ geopotential anomalies along $65^{\circ} \mathrm{S}$.

Our regression results are consistent with the known spatial influence of both oscillations. The importance of ENSO exclusively in the Pacific sector of the Southern Ocean can be related to the terminus of the PSA pattern, ENSO's teleconnection mechanism to the Antarctic. The spatial variability we find in $b^{\mathrm{SOI}}$ is in agreement with the $2^{\text {nd }}$ leading mode of EOF analysis reported by Mo [2000]. We find that the influence of SAM is more zonally symmetric and decreases northward also in agreement with the pattern expected from the EOF loading pattern of the SAM [Arblaster and Meehl, 2006; Marshall, 2003; Mo, 2000]. Furthermore, the ratio of percent variance explained by Mo's [2000] second leading mode (which is well 
correlated to SOI) and the first leading mode (the AAO) is $0.13 / 0.22=0.65$. This is consistent with the relative influence of SOI to SAM $\left(b^{\text {SOI }} / c^{\text {SAM }}\right)$ calculated from our regression model, which varies from approximately 0.4 to 0.8 in the AS region, depending on latitude and choice of smoothing.

To confirm the consistency of the SOI-SAM model, the regression analysis was applied to additional indices. The Nino 3 index (derived from tropical SST) and the BEST index (derived from a combination of the SOI and SSTs) were used as alternate representations of ENSO. Similarly the AAO (derived from the EOF of the NNR data itself) was used in place of SAM (all indices are available from NOAA at http://www.esrl.noaa.gov/psd/data/climateindices/list/). Results from these analyses (not shown) were spatially consistent with those presented above, with maximum ENSO influence in the Amundsen Sea region. This increases our confidence that the results obtained are not dependant on the index or data sets used but reflect the interactions of the physical phenomena they represent.

We examine wavelet analysis of the 30 -year regression model and its residuals from $240^{\circ} \mathrm{E}, 65^{\circ} \mathrm{S}$ in comparison with the SOI, SAM and NNR data to explore the time-dependant variation in the relationship between these climate oscillations and the Southern Ocean pressure fields. Our regression model shows a remarkable similarity to the pattern of variability in the NNR data, each exhibiting the full range of variability associated with both the SOI and SAM, though some distinct differences are evident, which are discussed below 
Wavelet analysis of the model residuals reveals the nature of this divergence (Figure 3.5e), which is predominantly at periods less than two years. High power in the residuals is observed around 1986-87 as well as in the mid 2000's at periods between 0.5 and 1.5 years. Short instances of higher frequency divergence are seen throughout the record.

So far we have examined the SOI, SAM and geopotential relationship averaged over the 30-year period from 1980 through 2009. To investigate how this relationship may have changed over time, regression analysis was conducted on the individual decades of the 1980s, 1990s, and 2000s. Results show qualitatively similar patterns in each decade as in the 30-year period as a whole; a dominant and anti-correlated SAM and a peak influence of SOI in the AS region (see Figure 3.14a). The peak of relative SOI influence $\left(b^{\mathrm{SOI}} / c^{\mathrm{SAM}}\right)$ shifts from decade to decade, with it significantly east of average in the $1990^{\prime} \mathrm{s}$ at $280^{\circ} \mathrm{E}$ (from $260^{\circ} \mathrm{E}$ for 1980 through 2009 ) and west during the $2000^{\prime}$ s at $220^{\circ}$ E. The $1980^{\prime}$ s are qualitatively similar to the whole 1980 through 2009 period average for all coefficients. Changes in $\mathrm{R}^{2}$ (Figure 3.14b) are also evident between decades, with a general peak in the 1990's. For example, $\mathrm{R}^{2}$ at $65^{\circ} \mathrm{S}, 240^{\circ} \mathrm{E}$ varies from 0.33 in the 1980 's, to 0.64 in the $1990^{\prime}$ s, to 0.33 in the 2000 's. There is a significant drop in $\mathrm{R}^{2}$ during the 2000 's centered on $200^{\circ} \mathrm{E}$, suggesting a breakdown of the model in this sector. From close inspection of the 30-year model and the NNR data in Figure 3.4, it is apparent that the model poorly represents the amplitude of peaks in the NNR data through this decade, particularly between 2003 and 2005, consistent with the wavelet results above. 

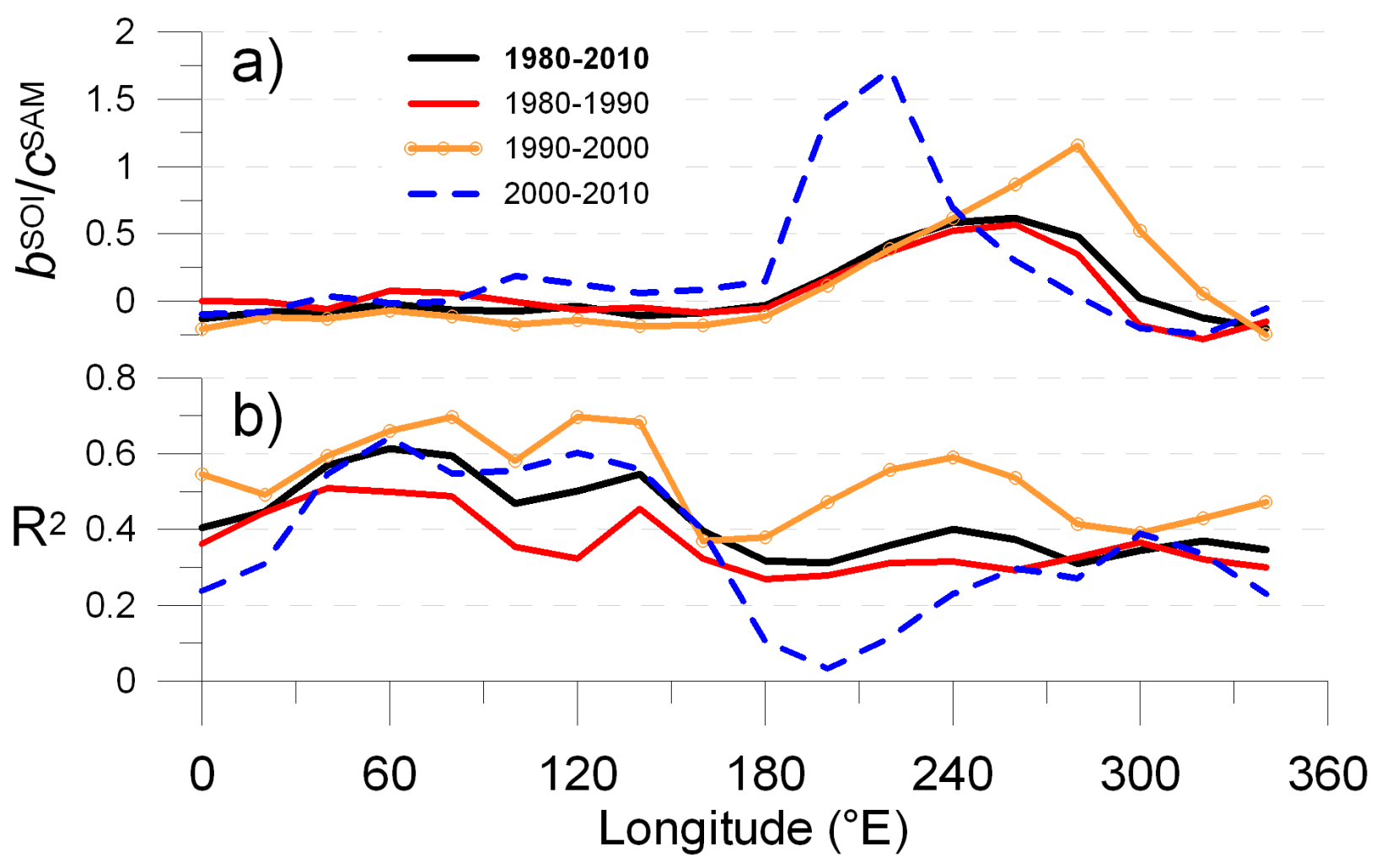

Figure 3.14 The combined SOI-SAM model for 1980 through 2009 (bold black) is compared to the individual decades: the 1980s (thin red line), 1990s (orange with open circles), and 2000s (dashed blue). a) The ratio $b^{\mathrm{SOI}} / c^{\mathrm{SAM}}$ represents the relative influence of SOI to SAM; b) and $\mathrm{R}^{2}$ represents the percent variance in NNR geopotential explained by the combined model. The results shown are for $65^{\circ} \mathrm{S}$ with a 3-month mav. Note the difference in scales. 


\subsubsection{Higher Term Regression Models}

To further investigate complexities in the SOI-SAM relationship and in an attempt to address the divergence of the combined SOI-SAM model from the NNR data, additional, higher order terms were added to the regression analysis. In general these additional terms were incorporated into the model such that Equation 1 becomes

$$
\mathbf{P}_{j}=a^{c o n s t}+b^{S O I} F\left(\mathbf{S O I}_{j}\right)+c^{S A M} G\left(\mathbf{S A M}_{j}\right)+d \mathbf{X}_{j}
$$

where $F$ or $G$ may be be filters acting on SOI or SAM, respectively, and/or where $\mathbf{X}_{\mathrm{j}}$ is a time series of an additional term. These terms were added to simulate possible complexities in the interaction of SOI and SAM or in their teleconnection processes, and include decompositions of the individual indices, quadratic terms, threshold filters, and phase-shift terms. These regression analyses were run using the SOI and SAM indices and $65^{\circ} \mathrm{S}$ NNR data with a 3-month mav smoothing. The results are discussed and summarized in Table 3-2. 
Table 3-2 Terms used in each regression model, the corresponding $\mathrm{R}^{2}$ value at $65^{\circ} \mathrm{S}, 240^{\circ} \mathrm{E}$ (the peak in the AS region), and the percent significance level. All models use time series with 3-month mav smoothing and include a constant term, $a^{\text {const }}$, not shown.

\begin{tabular}{|c|c|c|c|c|}
\hline & $\begin{array}{l}\text { Model } \\
\text { Description }\end{array}$ & Model Terms & $\mathbf{R}^{2}$ & $\begin{array}{l}\text { Significance } \\
\text { Level }\end{array}$ \\
\hline $\begin{array}{l}\text { Standard } \\
\text { Combined } \\
\text { Model }\end{array}$ & $\begin{array}{l}\text { Simple SOI- } \\
\text { SAM model }\end{array}$ & $\mathbf{S O I}_{j}, \mathbf{S A M}_{j}$ & 0.435 & $93 \%$ \\
\hline \multirow{2}{*}{$\begin{array}{l}\text { Index } \\
\text { Decomposition } \\
\text { Models }\end{array}$} & $\begin{array}{l}\text { Split SOI and } \\
\text { SAM }\end{array}$ & $\mathbf{S O I}_{j}^{+}, \mathbf{S O I}_{j}^{-}, \mathbf{S A M}_{j}$ & 0.436 & $93 \%$ \\
\hline & $\begin{array}{l}\text { Split SOI and } \\
\text { split SAM }\end{array}$ & $\begin{array}{l}\mathbf{S O I}_{j}^{+}, \mathbf{S O I}_{j}^{-}, \mathbf{S A M}_{j}^{+}, \\
\mathbf{S A M}_{j}^{-}\end{array}$ & 0.436 & $91 \%$ \\
\hline \multirow[t]{4}{*}{$\begin{array}{l}\text { Quadratic } \\
\text { Term Models }\end{array}$} & $\begin{array}{l}\text { Squared SOI } \\
\text { and SAM }\end{array}$ & $\begin{array}{l}\left(\mathbf{S O I}_{j} \times\left|\mathbf{S O I}_{j}\right|\right) \\
\mathbf{S A M}_{j}\end{array}$ & 0.382 & $79 \%$ \\
\hline & $\begin{array}{l}\text { Cubed SOI } \\
\text { and SAM }\end{array}$ & $\left(\mathbf{S O I}_{j}\right)^{3}, \mathbf{S A M}_{j}$ & 0.347 & $63 \%$ \\
\hline & $\begin{array}{l}\text { Squared SAM } \\
\text { and SOI }\end{array}$ & $\begin{array}{l}\mathbf{S O I}_{j} \\
\left(\mathbf{S A M}_{j} \times\left|\mathbf{S A M}_{j}\right|\right)\end{array}$ & 0.384 & $77 \%$ \\
\hline & $\begin{array}{l}\text { SOI, SAM and } \\
\text { SOI-SAM } \\
\text { product }\end{array}$ & $\begin{array}{l}\mathbf{S O I}_{j}, \mathbf{S A M}_{j}, \\
\left(\mathbf{S O I}_{j} \times \mathbf{S A M}_{j}\right)\end{array}$ & 0.435 & $92 \%$ \\
\hline \multirow[t]{3}{*}{$\begin{array}{l}\text { Threshold } \\
\text { Term Models }\end{array}$} & $\begin{array}{l}1 \sigma \text { threshold } \\
\text { filtered SOI } \\
\text { and SAM }\end{array}$ & $F_{1}^{\text {threshold }}\left(\mathbf{S O I}_{j}\right), \mathbf{S A M}_{j}$ & 0.375 & $75 \%$ \\
\hline & $\begin{array}{l}1.5 \sigma \\
\text { threshold } \\
\text { filtered SOI } \\
\text { and SAM } \\
\end{array}$ & $F_{1.5}^{\text {threshold }}\left(\mathbf{S O I}_{j}\right), \mathbf{S A M}_{j}$ & 0.337 & $58 \%$ \\
\hline & $\begin{array}{l}1 \sigma \text { threshold } \\
\text { filtered, split } \\
\text { SOI and SAM }\end{array}$ & $\begin{array}{l}F_{1}^{\text {threshold }}\left(\mathbf{S O I}_{j}^{+}\right), \\
F_{1}^{\text {threshold }}\left(\mathbf{S O I}_{j}^{-}\right), \mathbf{S A M}_{j}\end{array}$ & 0.375 & $75 \%$ \\
\hline \multirow[t]{2}{*}{$\begin{array}{l}\text { In-Phase } \\
\text { filtered Models }\end{array}$} & $\begin{array}{l}\text { In-phase } \\
\text { filtered SOI } \\
\text { and SAM } \\
\end{array}$ & $F^{\text {phase }}\left(\mathbf{S O I}_{j}\right), \mathbf{S A M}_{j}$ & 0.395 & $85 \%$ \\
\hline & $\begin{array}{l}\text { SOI and in- } \\
\text { phase filtered } \\
\text { SAM }\end{array}$ & $\mathbf{S O I}_{j}, F^{\text {phase }}\left(\mathbf{S A M}_{j}\right)$ & 0.337 & $42 \%$ \\
\hline \multirow[t]{2}{*}{$\begin{array}{l}\text { Decadal Shift } \\
\text { Term Models }\end{array}$} & $\begin{array}{l}\text { SOI, SAM and } \\
1989 / 90 \text { step } \\
\text { function term }\end{array}$ & $\mathbf{S O I}_{j}, \mathbf{S A M}_{j}, \mathbf{X}_{j}^{s h i f t}$ & 0.436 & $92 \%$ \\
\hline & $\begin{array}{l}\text { Pre and post } \\
1990 \text { split SOI } \\
\text { and SAM }\end{array}$ & $\begin{array}{l}\mathbf{S O I}_{j}^{1980-1989}, \\
\mathbf{S O I}_{j}^{1990-2000}, \mathbf{S A M}_{j}\end{array}$ & 0.440 & $92 \%$ \\
\hline
\end{tabular}

60 


\subsubsection{Index Decomposition}

By splitting the SOI into its positive (La Niña, SOI+) and negative (El Niño, SOI-) phases, we explore their independent influence on the model. This analysis reveals some weak asymetry in the influence of the SOI's phases as the regression assigns somewhat different values to the coefficients of each phase (see Figure 3.15b). The addition of the split-SOI term only slightly improves the $\mathrm{R}^{2}$ value $(+0.001)$ and increased the level of significance by $1 \%$ (Table 3-2). Decomposition of the SAM index shows a more symmetric response of both phases. A model incorporating the split SOI and split SAM indices shows a marginal increase in $\mathrm{R}^{2}$ and a decrease in the level of significance (Table 3-2). Taking the individual phases into account, the overall picture of hemispherical symmetric SAM importance and SOI importance solely in the AS region, is very similar to the simple SOI-SAM model. All models incorporating a split SOI and/or SAM term show non-zero $a^{\text {const }}$ values at certain longitudes (Figure 3.15b). These non-zero values lack physical interpretation and undermine the utility of this model to reliably capture ENSO and SAM influence. 


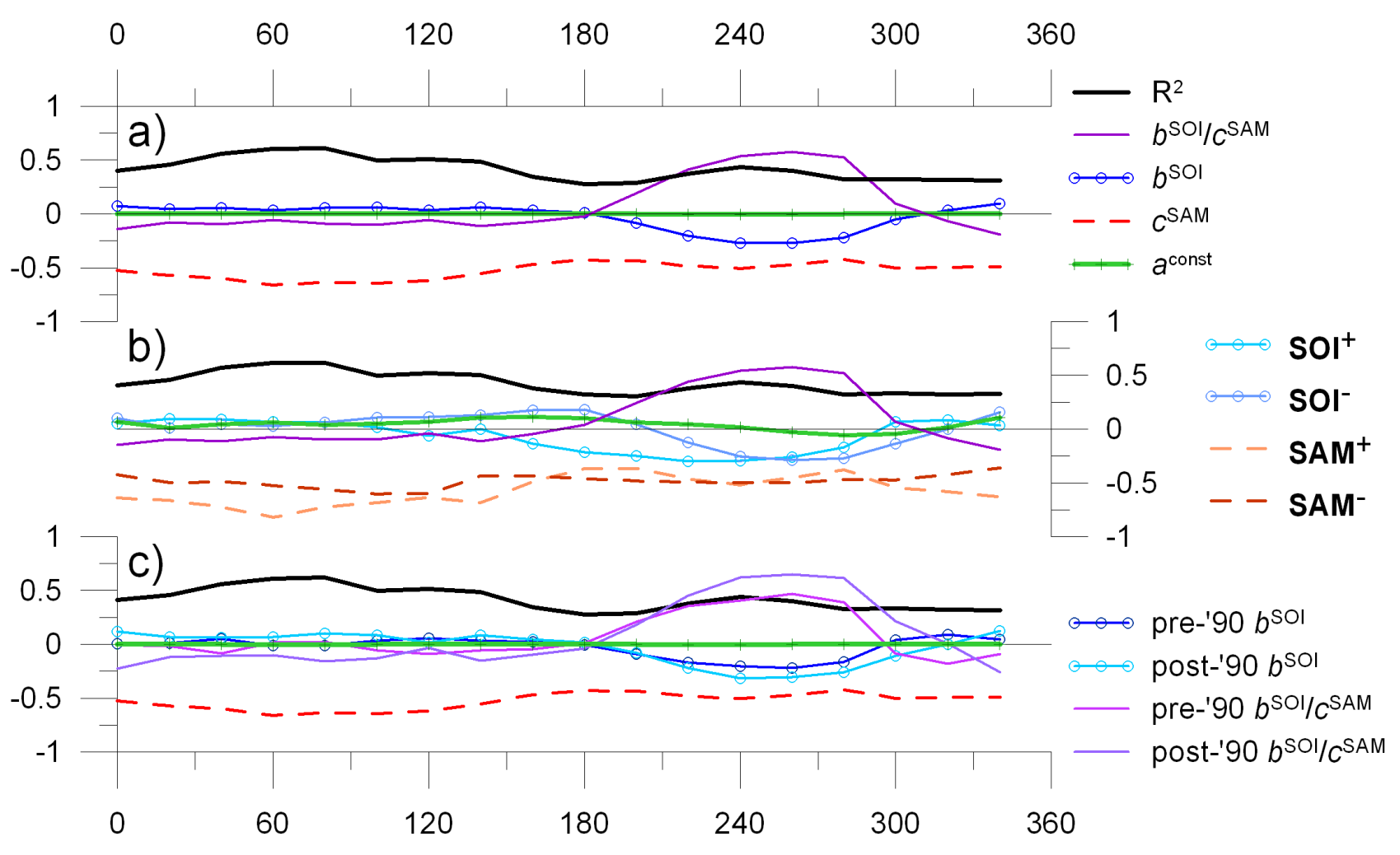

Figure 3.15 Here we compare a) the simple combined SOI-SAM model, with b) a model splitting the SOI and SAM into their positive and negative phases, and c) a model splitting the SOI into pre- and post-1990 indices. Where applicable, $\mathrm{R}^{2}$ values are shown in black, $a^{\text {const }}$ in green with crosses, $b^{\text {SOI }}$ in blue with open circles, $c^{\mathrm{SAM}}$ in dashed red, and $b^{\mathrm{SOI}} / c^{\mathrm{SAM}}$ in purple. Note the non-zero values of $a^{\text {const }}$ in b) centered at $150^{\circ} \mathrm{E}$ and $300^{\circ} \mathrm{E}$. Note also the overall spatial similarity of $\mathrm{R}^{2}$ and $b^{\mathrm{SOI}} / c^{\mathrm{SAM}}$ between models. 


\subsubsection{Quadratic Terms}

The addition of single quadratic terms $\left(\mathbf{S O I}_{j} \times\left|\mathbf{S O I}{ }_{j}\right|\right),\left(\mathbf{S A M}_{j} \times\left|\mathbf{S A M}_{j}\right|\right)$, $\left(\mathbf{S O I}{ }_{j} \times \mathbf{S A M}_{j}\right)$, or $(\mathbf{S O I})_{j}^{3}$, were used to simulate the possible affect that larger ENSO (or SAM) events may be disproportionally more important in either the ENSOSAM interaction, teleconnection, or physical expression in the AS region. The quadratic term coefficients were found in all cases to be small while the standard term coefficients were spatially similar to the simple SOI-SAM model. These models resulted in decreased $R^{2}$ values and significance levels (Table 3-2).

\subsubsection{Threshold Filter}

To test the assertion that ENSO must be significantly strong in the tropics to propagate its signal pole-ward [Fogt and Bromwich, 2006], a threshold filter was applied to the SOI using threshold values of 1 and 1.5 standard deviations of the renormalized SOI. Thus weight is given only to particularly strong El Niño/La Niña events (or either phase individually) in the regression model. A decrease in $\mathrm{R}^{2}$ values was observed in models incorporating a SAM term and a threshold-filtered SOI term $\left(F_{\sigma}^{\text {threshold }}\left(\mathbf{S O I}_{j}\right)=\mathbf{S O I}_{j}\right.$, if $\left|\mathbf{S O I}_{j}\right| \geq \sigma$, where $\sigma=1$ or 1.5 standard deviations of re-normalized SOI, else $F_{\sigma}^{\text {threshold }}\left(\mathbf{S O I}_{j}\right)=0$ ). At $65^{\circ} \mathrm{S}, 240^{\circ} \mathrm{E}, \mathrm{R}^{2}=0.375$ for a $\sigma=1$ model, and $\mathrm{R}^{2}=0.337$ for $\sigma=1.5$ (Table $3-2$ ). Regression of threshold-filtered SOI ${ }^{-}$ and $\mathrm{SOI}^{+}$terms reveals the same spatial pattern as the non-filtered split SOI but with a reduction in $\mathrm{R}^{2}\left(\mathrm{R}^{2}=0.375\right.$ at $\left.65^{\circ} \mathrm{S}, 240^{\circ} \mathrm{E}\right)$ (Table 3-2). As a whole these results suggest that the response to large SOI or SAM events in the Antarctic is not 
fundamentally different to smaller events but rather that the response simply scales with the magnitude of the event.

\subsubsection{In-phase Filter}

To test the idea that the Antarctic ENSO response requires that the ENSO and SAM be in-phase, a sign dependant filter was applied to the SOI and SAM time series, i.e. $F^{\text {phase }}\left(\mathbf{S O I}_{j}\right)=\mathbf{S O I}_{j}$ if the sign of $\mathbf{S O I}_{j}$ and $\mathbf{S A M}_{j}$ are equal, else $F^{\text {phase }}\left(\mathbf{S O I}_{j}\right)=0$. Again, a decrease in $\mathrm{R}^{2}\left(\right.$ at $65^{\circ} \mathrm{S}, 240^{\circ} \mathrm{E}: \mathrm{R}^{2}=0.395$ ) was observed in models incorporating a SAM term and an in-phase filtered SOI term. A similar decrease in $\mathrm{R}^{2}$ is observed for an analogous in-phase filtered SAM and SOI model (at $65^{\circ} \mathrm{S}, 240^{\circ} \mathrm{E}$ : $\mathrm{R}^{2}=0.337$ ) (Table 3-2). Our results suggest that the Antarctic response is best modeled as a simple linear reinforcement / interference relationship between the two oscillations without taking a phase dependant relationship into account.

\subsubsection{Decadal Shift}

We also investigate the observed shift in the ENSO-SAM relationship around 1989 [Bertler et al., 2006a; Bertler et al., 2004; Fogt and Bromwich, 2006]. We use two approaches: a) a step function term is added to the combined model, $\mathbf{X}_{j}^{\text {shift }}$, with a shift at 1990; and b) we separate the SOI into pre and post-1990 indices, allowing their coefficients to vary independently. The latter reveals a coefficient pattern (Figure 3.15c) in which the post-1990 SOI is given marginally more weight than the pre-1990 SOI in the AS Region, consistent with results shown in Figure 3.14. 
Although this model has a marginally improved $\mathrm{R}^{2}$ value, we observe a reduction in significance associated with the reduction in degrees of freedom (Table 3-2). 


\subsection{Conclusions}

The findings summarized in Figure 3.3 depicting the NNR geopotential 850 mb height anomalies associated with the phases of ENSO and SAM show that both oscillations have similar effects on the Amundsen Sea region. These findings are consistent with studies reporting a deepening of the ASL during La Niña events [Bertler et al., 2004; Chen et al., 1996; John Turner, 2004; Yuan, 2004].

Our regression model shows that a simple linear combination of the SOI and SAM indices can explain a large percentage of the variance in geopotential height around the Southern Hemisphere. Their combined influence can explain up to 44\% of this variance in the AS region while maintaining seasonal resolution (3-month mav smoothing) and up to $71 \%$ at annual resolution (12-month av smoothing). The qualitative similarity of the simple SOI-SAM model to the NNR data is remarkable (Figure 3.4 and Figure 3.5).

We show that SAM's influence on the geopotential height anomalies in the SH is uniformly dominant across longitude. Additionally, we show that ENSO has very little importance in the SH except in the AS region of the Pacific where its influence approaches that of SAM. We are able to quantify this relative influence of ENSO and SAM (Figure 3.8c), which peaks in the AS region $\left(60^{\circ} \mathrm{S}, 270^{\circ} \mathrm{E}\right)$ at $b^{\mathrm{SOI}} / c^{\mathrm{SAM}}=0.885$ for a seasonal resolution—suggesting that ENSO is up to 89\% as influential as SAM in governing the geopotential heights in the region at this time scale.

We primarily use independent station-based indices of ENSO and SAM to avoid potential statistical issues associated with EOF-based indices in this context. 
However, the amount of variance our model attributes to the joint ENSO-SAM interaction is in good agreement with results obtained by EOF analysis [Mo, 2000]. Furthermore, the loading centers of the leading EOF modes are generally consistent with the spatial variability found in our regression coefficients.

Increased smoothing of the indices and NNR data is shown to increase the $\mathrm{R}^{2}$ of our model as well as its level of significance and does not greatly change the overall spatial relationship between the terms. This suggests that higher frequency oscillations in the data or indices may cause divergence of the model from the NNR data. Comparison of the time series shows that the model under-represents higher frequencies (e.g. during the period between 2003 and 2006 in Figure 3.4c). Wavelet analysis confirms that high frequency variation dominates the model residuals. Further research into the factors governing the misfit of the model is needed.

Because our model generalizes the ENSO-SAM interaction over the 30-year period, we also examine decade-to-decade changes in this relationship. The relative influence of ENSO and SAM, as well as the variance explained by the model, change from decade to decade. The shift between the 1980's and the 1990's is considerably less dramatic than the shift between the 1990's and 2000's. This supports earlier studies that have identified a strengthening of the ENSO teleconnection in the AS region around this period [Bertler et al., 2004; Fogt and Bromwich, 2006].

Finally, we show that a simple linear combination of the SOI and SAM indices represents the influence of these two oscillations on the ASL at least as well as or better than models incorporating more complex interactions. Models using additional terms or filters did not significantly increase the variance explained and 
generally gave spatially similar results to the simple SOI-SAM model. We conclude that when in-phase, the effects of the ENSO and SAM linearly reinforce, when out of phase they linearly interfere. These results do not seem to support the idea that the ENSO-Antarctic teleconnection requires a sufficiently strong ENSO event but rather that the strength of the high latitude ENSO response is simply proportional to the magnitude of ENSO. Our findings therefore suggest that the linear regression model might have some skill forecasting geopotential variability of the ASL on seasonal to inter-annual time scales.

The ASL is an important meteorological feature and has been linked to a range of environmental changes in the Antarctic. The ASL is an effective mechanism for transporting warm marine air into West Antarctica and the Antarctic Peninsula, which contributes to significant warming in the Antarctic Peninsula [J. Turner et al., 2009] and has led to changes in snow precipitation in Marie Byrd Land [Bromwich et al., 2000]. In addition, the onshore winds cause a decrease in sea-ice extent in the Bellingshausen Sea, while the resulting katabatic flow in the Ross Sea [Bertler et al., 2004] causes an increase in sea-ice extent, in particular during autumn [J. Turner et al., 2009]. Moreover, it has been suggested that a strong ASL could enhance upwelling of warm subsurface water in the Pine Island embayment with implications for the stability of the West Antarctic Ice Sheet [Hellmer et al., 1998]. Because of its meteorological significance, understanding what drives the strength and position of the ASL is important to predicting future environmental change in Antarctica [Mayewski et al., 2009; J. Turner et al., 2009]. We have shown that changes in the occurrence rate of one phase of either the SAM or ENSO will have a 68 
predictable, quantifiable effect on the ASL. For example a further increase in El Nino events is likely to cause a further weakening of the ASL with associated changes in sea-ice extent (increase in the Ross Sea, decrease in the Bellingshausen Sea), decreased meridional wind strength, and increased upwelling of warm subsurface ocean currents at the continental margin. 


\section{Chapter 4 Synoptic variability in the Ross Sea region, Antarctica as seen from back-trajectory modeling and ice core analysis}

This manuscript has been published in the Journal of Geophysical ResearchAtmospheres. A few minor revisions and changes to formatting have been incorporated into this thesis version.

Markle, B. R., N. A. N. Bertler, K. E. Sinclair, and S. B. Sneed (2012), Synoptic variability in the Ross Sea region, Antarctica, as seen from back-trajectory modeling and ice core analysis, J. Geophys. Res., 117, D02113, doi:10.1029/2011JD016437.

\subsection{Abstract}

Synoptic variability in the Ross Sea region, Antarctica over the last thirty years is investigated using back-trajectory modeling and cluster analysis. We identify two dominant air-mass trajectory clusters: oceanic/West Antarctic and continental/East Antarctic. Our analysis shows that the oceanic/West Antarctic trajectories have an annual cycle similar to the Semiannual Oscillation and on average peak in frequency during April, while continental/East Antarctic trajectories reach their annual maximum during December. We demonstrate a causal association between the El Niño Southern Oscillation (ENSO) and the frequency of oceanic/West Antarctic trajectories originating from the Ross Sea and Amundsen Sea regions. In contrast, we find that the Southern Annular Mode (SAM) has little influence on the trajectory cluster frequencies. We then develop proxy records for synoptic variability using a 
shallow firn core from Gawn Ice Piedmont in Southern Victoria Land. Continental/East Antarctic trajectory frequency correlates with concentrations of nitrate $\left(\mathrm{NO}_{3}\right)$, which is sourced from stratospheric air-masses descending over the Antarctic interior. At seasonal to inter-annual scales, the frequency of oceanic/West Antarctic trajectory clusters strongly correlate with deuterium excess, which is sensitive to changes in relative humidity and sea surface temperature in the Ross and Amundsen Seas. Inter-annual variability in the frequency of oceanic/West Antarctic trajectories is discussed with respect to ENSO and changes in SST and sea ice extent. 


\subsection{Introduction}

The Antarctic is a key component of the global climate system [Mayewski et al., 2009]. Ice cores can provide invaluable records of past climate variability, particularly from remote regions like Antarctica where instrumental records are sparse and short in duration [Jouzel et al., 2007; Mayewski et al., 2005]. Due to high accumulation rates, ice cores from coastal sites can provide high-resolution records of near instrumental quality and help to constrain recent climate variability, including the influence of dominant climate oscillations such as the El Niño Southern Oscillation (ENSO) and the Southern Annular Mode (SAM) [Mayewski et al., 2005]. Understanding the past variability and influence of these oscillations on Antarctic climate is essential to understanding future environmental change. To achieve this, it is important to establish how synoptic conditions are modulated by these oscillations and how these histories are captured in the geochemical records of ice cores.

The aim of this study is to understand the synoptic variability at the Gawn Ice Piedmont (GIP), an ice core site in the Ross Sea region of Antarctica, and examine the influence of inter-annual climate oscillations in driving that history. Further we investigate how this synoptic variability may be recorded in the geochemical record of a firn core from the site and demonstrate how this type of analysis could be used to extend our knowledge of synoptic variability beyond the instrumental record.

The GIP site (Figure 4.1a) is located near the Byrd Glacier outlet at the boundary of the Ross Ice Shelf and the Transantarctic Mountains $\left(80.1^{\circ} \mathrm{S}, 159.3^{\circ} \mathrm{E}\right)$ 
in Southern Victoria Land, Antarctica. Due to a high accumulation rate and position at the continent-ice shelf boundary, we propose that GIP is an ideal site to investigate the interplay of competing oceanic and terrestrial climatic influences as well as the role of dominant climate oscillations in driving the climate of the region.

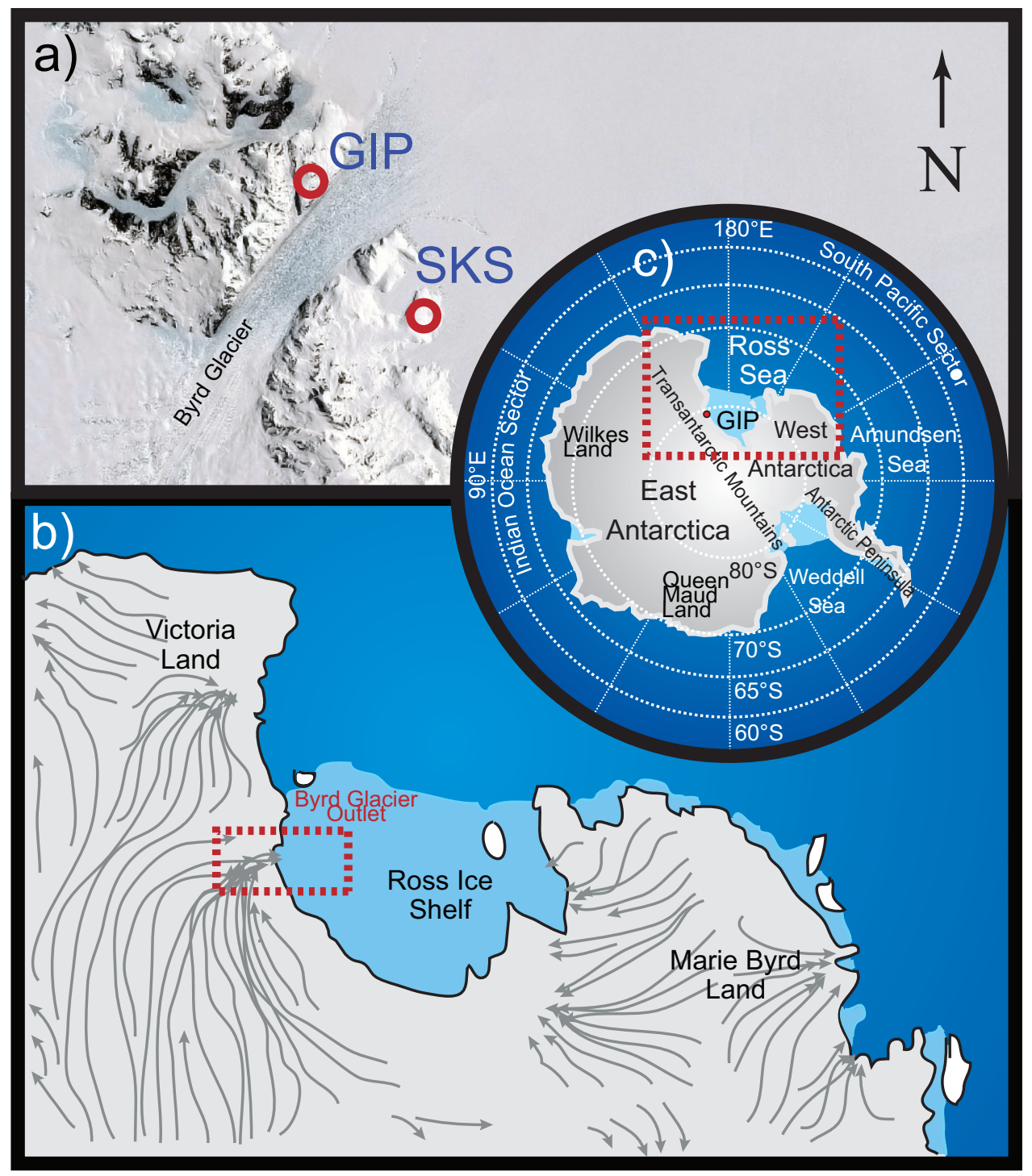

Figure 4.1 a) The Byrd Glacier drains from the East Antarctic Ice Sheet to the left, through the Transantarctic Mountains, to the Ross Ice Shelf on the right. The locations of the Gawn Ice Piedmont (GIP) and Skinner Saddle (SKS) ice core sites are shown in red. Image courtesy of NASA's Landsat Image Mosaic of Antarctica Project. North arrow indicates the grid north reference for the Landsat imagery; b) The Ross Sea region with surface wind fields plotted after Carrasco and Bromwich 
[1994]. The Byrd Glacier area is boxed in red; c) An overview of Antarctica with important features labeled with the Ross Sea area boxed in red.

In Section 4.2 we describe the climatological setting and significance of the region under study. In Section 4.3 we employ the Hybrid Single-Particle Lagrangian Integrated Trajectory (HySPLIT) model [Draxler and Hess, 1998] in conjunction with the National Centers for Environmental Protection and Atmospheric Research (NCEP/NCAR) reanalysis data set from 1980 to 2010 [Kalnay et al., 1996] to create a high-resolution back-trajectory history of the site. We then identify characteristic air-mass trajectory clusters and explore their seasonality and relationship to climate drivers such as ENSO and SAM.

In Section 4.4 we interpret the geochemical record of the GIP firn core with respect to our synoptic reconstruction to develop proxies for the seasonality and frequency of oceanic and continental air-mass influences in the region. In Section 4.5 we give a concluding summary and remark on future work.

\subsubsection{Antarctic Meteorology and Climate}

The meteorology of Antarctica is characterized by competing influences. The dry continental interior is dominated by a weak, relatively high-pressure anticyclone and gravity-driven drainage of cold katabatic winds (Figure 4.1b) [King and Turner, 1997; Parish and Bromwich, 1987]. In contrast, a low-pressure belt, the Antarctic Circumpolar Trough (CPT), surrounds the Antarctic continent (at $66^{\circ} \mathrm{S}$ on average) and is a zone of intense cyclonic activity. Asymmetry in the CPT gives rise 
to three distinct low pressure centers including the Amundsen Sea Low (ASL), which brings synoptic-scale cyclones to the Ross Sea region (Figure 4.1b) and West Antarctica (Figure 4.1c) [King and Turner, 1997; Simmonds et al., 2003].

In addition, the Ross Sea region is a center of mesocyclogenesis [Bromwich, 1991; Carrasco and Bromwich, 1994; Carrasco et al., 2003]. Bromwich [1991] found that mesoscale cyclone formation is linked to katabatic wind outflow and in particular identified the area around the Byrd Glacier outlet as an important center for mesocyclogenesis. Generally, mesocyclones form in coastal Antarctic regions through vortex stretching as air-masses descend off the steep ice sheet [Carleton, 2003]. The Byrd Glacier (Figure 4.1a and $\mathrm{b}$ ) is one of the primary drainages of surface winds from East Antarctica. Although mesocyclones form at an average rate of one per week in the area, there is a distinct seasonal cycle of summer maxima and winter minima in mesocyclonic frequency [Carrasco and Bromwich, 1994]. In an analysis of the ice-free regions of the Southern Ocean from 1999 to 2008, Irving et al. [2010] show maxima in mesocyclone density in the Amundsen-Bellingshausen Sea region during summer and autumn. Additionally they show some correlation between mesocyclone density and the phase of the Southern Annular Mode, a zonally symmetric oscillation in the strength and position of the circumpolar westerly winds related to the contraction and expansion of the polar vortex [Jones et al., 2009; Thompson and Solomon, 2002].

Scarchilli et al. [2010] analyzed the moisture source regions of precipitation to ice core sites in East Antarctica using back-trajectory analysis and the ERA-40 
reanalysis dataset. Two of the four sites examined by Scarchilli et al. are relatively close to the GIP site and along the Ross Sea coast; Taylor Dome ( $240 \mathrm{~km}$ N-NW of GIP) and Talos Dome (a further $550 \mathrm{~km}$ north of Taylor Dome). Scarchilli et al. [2010] demonstrate that $60 \%$ of annual precipitation at these coastal sites is associated with air-mass trajectories from the Pacific Ocean and Ross Sea, while $40 \%$ is associated with pathways over the Antarctic continent. These percentages are reversed for winter-only accumulation [c.f. Figure 3 of Scarchilli et al., 2010]. The authors also note a peculiarity of the circulation in the Ross Sea region; although the dominant moisture provenance is displaced zonally $10-60^{\circ}$ east of precipitation sites on the western Ross Sea coast, other coastal Antarctic sites receive moisture from sources displaced $60^{\circ}$ to their west [Scarchilli et al., 2010]. Employing automatic weather station data to identify snowfall events, Sinclair et al. [2010] investigate the synoptic drivers of snow accumulation at the Skinner Saddle ice core site (SKS), located adjacent to the GIP site ( 70km SSE; Figure 4.1a) between November 2007 and September 2008. Overall the site is characterized by high snow accumulation with $>1.85 \mathrm{~m}$ during the study. This snowfall occurred year-round with a minor decrease during April and May. Precipitation events are generally related to large synoptic-scale cyclones that are constrained by the topography of the Ross Sea coast and cross the Ross Ice Shelf from the southeast. Single storm events contributed substantially to the accumulation record, including a low-pressure system that delivered $7 \%$ of the total accumulation in one day. However, while $>60 \%$ of accumulation was associated 
with synoptic-scale systems, mesocyclones, forming locally over the Ross Ice Shelf were also identified as important contributors to the accumulation budget [Sinclair et al., 2010]. 


\subsubsection{Inter-annual Climate Oscillations}

ENSO is a principal driver of inter-annual to decadal-scale climate variability globally [Diaz and Markgraf, 1992; Trenberth, 1997] and although it originates in the tropical Pacific, it has been shown to exert significant influence in the high southern latitudes [John Turner, 2004]. It is linked to fluctuations in Antarctic sea ice extent [Simmonds and Jacka, 1995; Yuan, 2004], precipitation [Bromwich et al., 2000], sea surface temperature [Kwok and Comiso, 2002], changes in pressure fields and circulation patterns [Chen et al., 1996; John Turner, 2004], and to the suppression of other-wise expected warming trends in the Ross Sea region [Bertler et al., 2004]. The ENSO signal is propagated from the tropics to the Antarctic via the Pacific South American (PSA) pattern, a wave train of positive/negative geopotential height anomalies extending across the Pacific [Fogt and Bromwich, 2006; Houseago et al., 1998; Mo and Higgins, 1998; Mo et al., 1987; Thompson and Solomon, 2002].

The SAM is the dominant mode of climate variability in the Southern Hemisphere [Thompson and Solomon, 2002] often identified as the leading empirical orthogonal function (EOF) of Southern Hemisphere pressure fields [Gong and Wang, 1999] and operates at a range of time scales from sub-seasonal to decadal [Fogt et al., 2009b; Thompson and Solomon, 2002]. Feedbacks associated with the SAM have been connected to observed climatic changes in Antarctica such as warming in the Peninsula and cooling over the continent [Marshall, 2003; Thompson and Solomon, 2002]. 
Both the ENSO and SAM have strong expression in the Pacific Sector of the Southern Ocean and influence the strength and position of the ASL. This area is the terminus of the PSA pattern, ENSO's teleconnection mechanism to the Antarctic, as well as a center of high loading of the leading EOF defining SAM [Bertler et al., 2006b; Fogt and Bromwich, 2006; Mo and Higgins, 1998]. Several studies have investigated the interaction of ENSO and SAM and their combined forcing on Antarctic climate [Bertler et al., 2006a; Bertler et al., 2006b; Fogt and Bromwich, 2006]. Fogt and Bromwich [2006] suggest that the SAM modulates the strength of the ENSO teleconnection to the high southern latitudes such that when the two oscillations are in-phase (out of phase), ENSO's influence in the Antarctic is strengthened (weakened), due to the reinforcing/interfering nature of SAM and the PSA patterns.

Similarly, Pezza et al. [2011] found that sea ice extent responds to this joint influence such that the response is again strongest when the two oscillations are in phase, although their record was too short to draw definitive conclusions about the effect of each oscillation over time. The authors explain the spatial pattern of the ENSO-SAM influence on sea ice through the resonance of stationary waves and the resulting effect on cyclonic strength. 


\subsection{HySPLIT Back-Trajectory Modeling and Cluster Analysis}

Back-trajectory modeling, particularly in conjunction with cluster analysis, can be used to understand the synoptic controls on precipitation or the transport of chemical species to a study site [Dixon et al., 2011; Dorling and Davies, 1995; Helsen et al., 2006; Helsen et al., 2004; Schlosser et al., 2004; Sinclair et al., 2010]. Cluster analysis is a statistical method of grouping related sub-sets within a larger data set and is used here to identify characteristic atmospheric trajectory groups, which can represent distinct synoptic patterns [Dorling et al., 1992].

\subsubsection{Back-Trajectory Modeling}

Three-dimensional back-trajectories are constructed using the HySPLIT model from the National Oceanic and Atmospheric Administration's (NOAA) Air Research Laboratory [Draxler and Hess, 1998] in conjunction with NCEP/NCAR reanalysis data [Kalnay et al., 1996]. The 2.5 degree grid spacing of the reanalysis data is suitable for this application with respect to modeling synoptic scale backtrajectories [Sinclair et al., 2010] though it is unlikely to be able to resolve conditions on the scale of mesocyclones or katabatic winds. Although the NCEP/NCAR reanalysis performs well in the Southern Hemisphere after the start of the modern satellite era in 1979, it does have limitations [Bromwich et al., 2007].

In comparison to the European Center for Medium Range Weather Forecast 40-year reanalysis (ERA-40), NCEP/NCAR does better at reproducing station records at the mid southern latitudes while ERA- 40 performs better at the high 
latitude stations, though both show high correlations, greater than 0.9 , to the station data after 1979 [Bromwich and Fogt, 2004]. Both reanalyses perform best during the austral summer when more data are available for assimilation and worse during winter, especially before 1979 when biases in NCEP/NCAR in particular make it unreliable, [Bromwich and Fogt, 2004; Bromwich et al., 2007]. Although winter biases persist in NCEP/NCAR to the mid 1990s, a comparison of several reanalysis products including NCEP/NCAR and ERA-40 show that all the products examined capture the same multi-year to decadal variability in pressure fields at points over the Antarctic interior and Southern Ocean [Bromwich et al., 2007]. Trends in precipitation-evaporation over the Antarctic continent are thought to be exaggerated in the NCEP/NCAR data set, and although the ERA-Interim reanalysis product is thought to perform better for this variable, it too has problems, notably excessive dryness in the Antarctic interior [Bromwich et al., 2011].

Another known issue with the NCEP/NCAR data set is an erroneous $180^{\circ}$ rotation in the assimilation of the Australian PAOBS data between 1979 and 1992 (for details see

\section{http://www.cpc.ncep.noaa.gov/products/wesley/paobs/paobs.html). This problem} affects the region between $40^{\circ}$ and $60^{\circ} \mathrm{S}$ at daily to weekly time scales [Bromwich et al., 2007]. The error doubles the inherent model uncertainty, though this effect decreases at higher altitudes (see above link). This issue likely has little effect on the analysis presented here as only a small percent of the 5-day back-trajectories examined cross north of $60^{\circ} \mathrm{S}$ (see below). Further, this study addresses variability 
at the monthly to inter-annual time scale at which the PAOBS issue it not noticeable [Bromwich et al., 2007].

Bromwich et al. [2007] compare the performance of cyclone tracking algorithms based on several different reanalysis products, including NCEP/NCAR and ERA-40. These authors find discrepancies between the products' ability to match systems in the Southern Hemisphere especially during winter, though they find the reanalyses are in better agreement for larger, stronger systems. Bromwich et al. find no objective way to determine which reanalysis performs more "realistically" due to a lack of observational data.

Despite the above limitations, the NCEP/NCAR data set represents a useful tool for understanding the climate of the southern latitudes since 1979 [Bromwich and Fogt, 2004] and has been used with success in conjunction with Antarctic backtrajectory modeling [e.g. Dixon et al., 2011; Sinclair et al., 2010]. At the time of this analysis it represents the most consistent available reanalysis product to cover the entire time period under study.

Five-day (120 hr) 3-D back-trajectories were created from the GIP site at 12:00 UTC, daily from October 1979 through March 2010, a total of 11,131 trajectories. We use a starting point $1500 \mathrm{~m}$ above ground level at the closest reanalysis grid point to the GIP ice core site. Following Sinclair et al. [2010], initial heights of $500 \mathrm{~m}, 1000 \mathrm{~m}$, and $1500 \mathrm{~m}$ were tested for trajectories arriving at the GIP site using a trajectory matrix. Spatially consistent flow paths were generally observed for all initial heights, though $1500 \mathrm{~m}$ was chosen as it best captured 
synoptic-scale conditions, being above the katabatic layer, while minimizing the obscuring influence of underlying terrain. We employ a model upper boundary height of $20 \mathrm{~km}$ and a data-based vertical motion method.

Scarchilli et al. [2010] found spatial uncertainties in 5-day Antarctic trajectories of $15-30 \%$ of the total path distance, and attributed these to numerical truncations within the model as well as limited resolution in the reanalysis data. Similarly, Schlosser et al. [2008] suggest that mean errors of $20 \%$ may be typical of 5-day back-trajectories due largely to errors in the input wind data fields. It is reasonable to anticipate uncertainties on the same order as the above studies, though we do not quantify these as our analysis concerns the broad classification of trajectories rather than precise starting points.

Harris et al. [2005] examine the impact of different reanalysis data on a trajectory model at several locations including the high northern latitudes. They found that the choice of NCEP/NCAR versus ERA-40 resulted in relative horizontal transport deviations (RHTD) of 30-40\% of the trajectory length. By comparison, the choice of vertical motion method within the trajectory model (a 3-D data-based method versus an isentropic method) results in RHTD of 18-34\%. Thus while the uncertainty due to choice in reanalysis product is large, it is comparable to that due to other inherent aspects of the method. Harris et al. [2005] note that due to a lack of ground truth data, there is no reason to suspect either of these choices as more "correct" than the other. We inter-compare the results of our back-trajectory and 
cluster analysis method using the NCEP/NCAR, ERA-40, and ERA-Interim reanalysis, below.

\subsubsection{Cluster Analysis}

The HySPLIT model's clustering algorithm uses a $k$-means approach to group trajectories by minimizing the spatial variability between trajectories within some number of clusters, $k$, defined a priori [Draxler, 1999]. The choice of $k$ is non-trivial and several methods exist to extract some "correct" number from the statistics of the data. For example, the HySPLIT model parameterizes the total spatial variance between all clusters to suggest a $k$ that maximizes intra-cluster variability while minimizing inter-cluster variability [Draxler, 1999]. Although studies have used cluster analysis to indentify inherent states of atmospheric circulation [e.g. Michelangeli et al., 1995], much care must be taken in interpreting these results. Christiansen [2007] showed that cluster analysis can identify false positives; that is suggesting a $k$ greater than one, representing supposedly inherent regimes in contrived, unimodal data, and that different clustering methods will suggest different $k$ values from the same data. Fereday et al. [2008] conclude from an analysis of cluster stability that there is no truly objective choice for the cluster number, $k$.

In this study, rather than attempting to identify a "correct" number of inherent regimes, we employ cluster analysis to reduce the dimensionality of our data set and, as in Fereday et al. [2008], create a set of patterns that represent the 
range of circulation types experienced at the site. Though the choice of $k$ is arbitrary, it must still balance intra-cluster variability and interpretability with respect to synoptic conditions. Empirical tests of the effect of $k$ on the GIP trajectories showed that too few clusters resulted in the grouping of spatially-similar yet meteorologically-distinct paths (e.g. slow-moving cyclonic and anti-cyclonic trajectories originating from opposite sides of the Transantarctic Mountains). Thus, by retaining a larger than typical number of clusters (approximately 20 was found desirable), we balance the separation of local trajectories into distinct groups; yet still reduce the dataset to a manageable size which can then be subjectively classified as discussed below.

Cluster analysis was performed on subsets of the entire data set $(11,131$ daily trajectories) to test the consistency of the results and classification scheme. Decades (1980s, 1990s, and 2000s) were individually clustered at daily resolution using points at 4-hr intervals along each trajectory. Due to computational limitations, the entire 1980-2010 set was clustered at 2-day resolution $(5,565$ trajectories) using points at 12 -hr intervals. Time series of the two primary synoptic groups (see below) as classified from the entire 30-year set (at 2-day resolution) and the decade-long sub-sets (at daily resolution) are correlated at $r>0.9$, suggesting little information is lost in a reduction to 2-day resolution. By employing a single cluster analysis for the entire period rather than more highly resolved but discrete decade-long subsets, we are able to make unambiguous comparisons of the relative frequencies of cluster types over time. 


\subsubsection{Back-Trajectory Results}

A total of 19 trajectory clusters for 1980-2010 are segregated into two broad groups comprised of nine synoptically related classes (Table 4-1). These

classifications are defined by characteristics identified from the mean trajectories of each cluster (Figure 4.2) and within-cluster variability (not shown), including flow tendency (cyclonic versus anticyclonic), mean altitude, speed (proportional to trajectory length), source region, and pathway. 


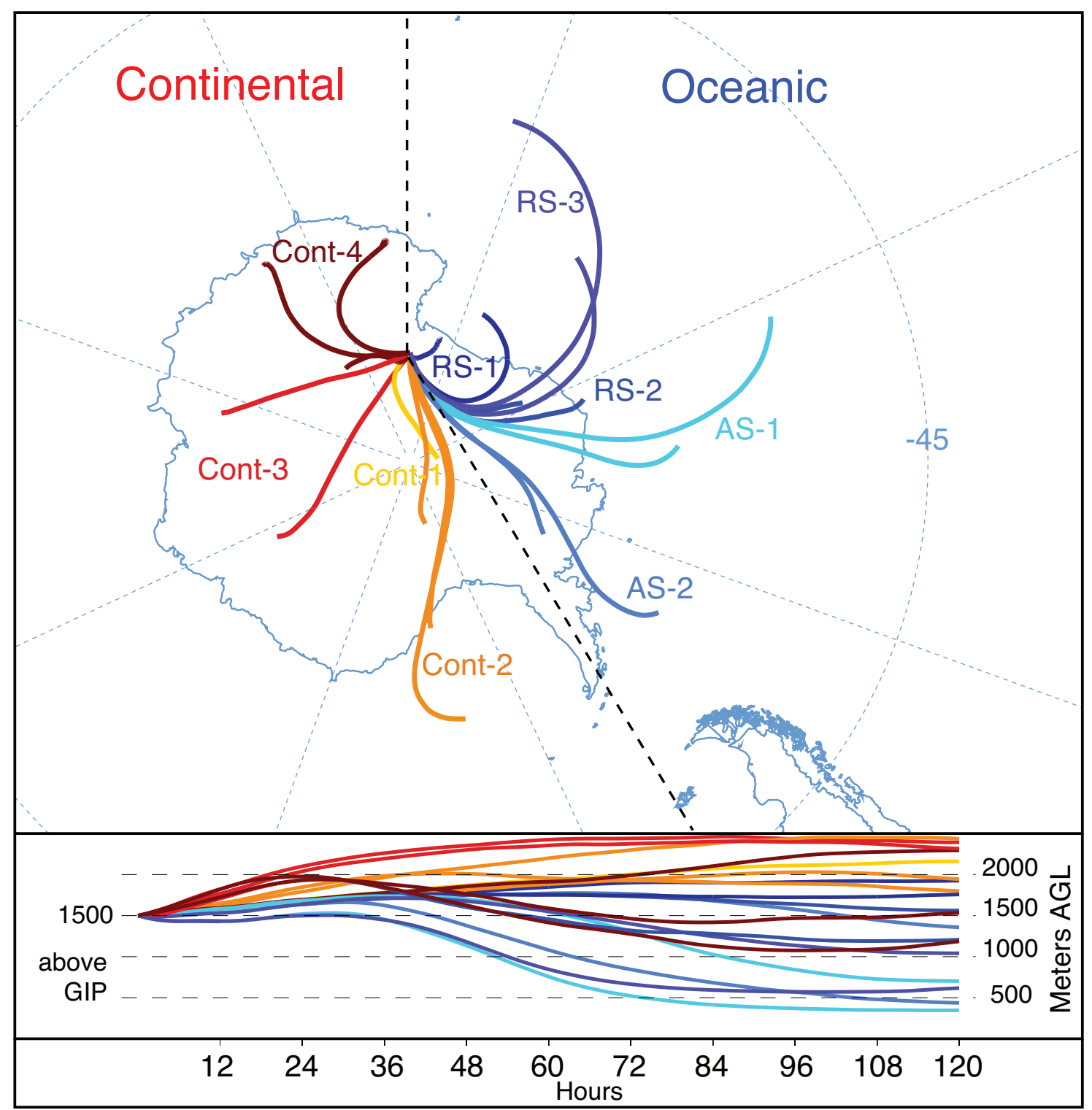

Figure 4.2 Cluster mean trajectories for the 1980-2010 cluster analysis (top) color-coded by class and group. Blue shades represent Oceanic group clusters, while red shades show the Continental group. Mean trajectory altitudes over time are shown below.

We note that the clusters, and indeed the trajectories they represent, form a semi-continuous spectrum of pathways from around the continent and Southern Ocean. However, we observe a natural break in this continuum between East and West Antarctica along the natural boundary of the Transantarctic Mountains, from 
Victoria Land to the Antarctic Peninsula (Figure 4.2). This division is present in the cluster analysis at annual to multi-decade time-scales. Those clusters over West Antarctica originate in the Ross and Amundsen Sea regions and exhibit a distinctly cyclonic flow at lower altitudes, with recently over-ocean pathways. Those over East Antarctica are predominantly trans-continental, have a tendency towards anticyclonic flow (though not uniformly), and travel at higher mean altitudes due to their transit over the polar plateau. This Victoria Land-Peninsula axis thus distinguishes two distinct, broad groups of clusters: a West Antarctic/oceanic (hereafter "Oceanic") and an East Antarctic/continental ("Continental") group. Although the resolution of the input NNR data likely limits the ability of the HySPLIT model to resolve conditions such as katabatic winds we do note that all backtrajectories arriving at the GIP site from the higher plateau do not cross the Transantarctic Mountain range anywhere except at the Byrd Glacier outlet. The Oceanic group (57.4\% of all trajectories) contains two obvious subgroups; cyclonic flow originating from i) the Ross Ice Shelf and Ross Sea (RS), and ii) from the Amundsen Sea (AS) region (Figure 4.2). Within the RS sub-group (38.2\% of all trajectories) there are three distinct classes, RS-1, 2, and 3 containing two clusters each. The AS sub-group contains two distinct classes, AS-1 and 2, originating from the western and eastern Amundsen Sea, respectively, and are comprised of two clusters each. We note that our results reveal the same eastward shift in cyclonic trajectories arriving at the western Ross Sea coast described by Scarchilli et al. [2010]. 
The Continental group makes up $42.6 \%$ of all trajectories and is divided into four distinct classes, Cont-1, 2, 3, and 4, with one, three, two, and three clusters respectively (Table 4-1). The Cont-1 class represents a broad group of trajectories originating over the polar plateau while the Cont- 3 and 4 classes show a spectrum of generally anticyclonic pathways from over East Antarctica (Figure 4.2). Trajectories within the Cont- 2 class generally originate in the Weddell Sea Region and spend significant time over the Antarctic continent. The distal ends of some trajectories within this class show cyclonic motion over the Weddell Sea before crossing the continent, though the majority of the flow is broadly similar to the rest of the Continental group. 


\begin{tabular}{|c|c|c|c|c|c|}
\hline Group & $\underline{\text { Sub }}$ & $\underline{\text { Class }}$ & $\underline{\frac{\%}{0}}$ & Pathway & $\begin{array}{l}\text { Relative } \\
\text { Speed }\end{array}$ \\
\hline \multirow{5}{*}{ 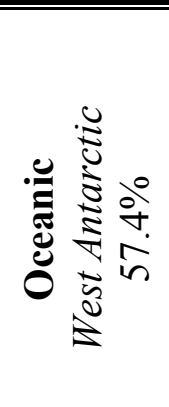 } & \multirow{3}{*}{ 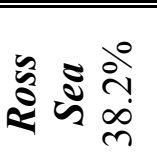 } & 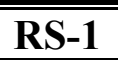 & $14.2 \%$ & Ross Sea, Ross Ice Shelf & Slow \\
\hline & & RS-2 & $17.1 \%$ & Ross Sea, WAIS & Var. \\
\hline & & RS-3 & $7.0 \%$ & Ross Sea, Pacific & Fast \\
\hline & \multirow{2}{*}{ క气 } & AS-1 & $6.8 \%$ & Amundsen Sea West, WAIS & Fast \\
\hline & & AS-2 & $12.3 \%$ & Amundsen Sea East, WAIS & Fast \\
\hline \multirow{4}{*}{ 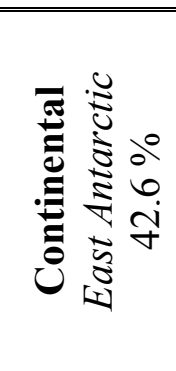 } & \multicolumn{2}{|c|}{ Cont-1 } & $8.9 \%$ & Plateau, EAIS, WAIS & Slow \\
\hline & \multicolumn{2}{|c|}{ Cont-2 } & $13.1 \%$ & Weddell Sea, EAIS, Plateau & $\begin{array}{l}\text { Fast } \\
\text { (var.) }\end{array}$ \\
\hline & \multicolumn{2}{|c|}{ Cont-3 } & $10.2 \%$ & EAIS & Fast \\
\hline & \multicolumn{2}{|c|}{ Cont-4 } & $10.5 \%$ & EAIS (WKL to VCL) & $\begin{array}{l}\text { Fast } \\
\text { (var.) }\end{array}$ \\
\hline
\end{tabular}

Table 4-1 Cluster Classification 1980-2010. Cluster groups and classes for the 1980-2010 classification arranged approximately clockwise from the GIP site. The approximate source region and/or general pathway is given (WKL=Wilkes Land and VCL=Victoria Land), along with a qualitative indication of relative speed. "Var." is used to denote classes containing trajectories with variable lengths.

To reconstruct the history of trajectory types arriving at the GIP site, monthly percentages for all synoptic classes were calculated. Additionally, Figure 4.3a shows a smoothed 91-day running frequency of synoptic classes arriving at the site for the period 1980-2010. The value for each class on a given day represents the ratio of trajectories of that class to the total number of trajectories in a 91-day window, centered on that day. We note that the frequencies presented here do not directly reflect numbers of individual storm events nor are they necessarily related to precipitation. Indeed, the connection of back-trajectories from a stationary point to individual synoptic features such as cyclones is difficult as the latter are non- 
stationary (in time and space) pressure centers. Rather, the frequencies presented here represent the percent of time (days) that daily back-trajectories are of a particular class or group, and thus the relative time that a synoptic condition persists at the site.

We test the effect of different reanalysis products on our analysis by clustering daily back-trajectories based on the NCEP/NCAR, ERA-40, and EARInterim reanalysis for the years 1990 and 2000. Comparison of cluster means from each reanalysis product (not shown) reveals results spatially consistent with Figure 4.2. The differences in cluster class and group frequencies between the reanalysis products are summarized in Table 4-2. We find good agreement between the reanalysis products in the annual frequencies of Oceanic and Continental groups (all differences less than 11\%) as well as cluster class frequencies (only three differences greater than $10 \%$ and all less than $15 \%$ ). Generally among the tests, the NCEP/NCAR and ERA-Interim products are in best agreement. Similar monthly variability in cluster class frequencies (not shown) were also observed for all reanalysis products for both years, with NCEP/NCAR and ERA-Interim again showing the most correspondence. A full, multi-year inter-comparison between the reanalysis products is beyond the scope of this study but will be a focus of future work. The above results suggest that the choice of reanalysis product has relatively small effects on the present study and likely comparable to other choices within the method. Interestingly, the NCEP/NCAR reconstructions seem more comparable to 
either the ERA-40 or ERA-Interim reconstruction than the ERA reconstructions are to each other. 


\begin{tabular}{|c|c|c|c|}
\hline & $\begin{array}{l}\text { NCEP/NCAR- } \\
\text { ERA-40 }\end{array}$ & $\begin{array}{l}\text { NCEP/NCAR- } \\
\text { ERA-Interim }\end{array}$ & $\begin{array}{l}\text { ERA-40- } \\
\text { ERA-Interim }\end{array}$ \\
\hline$\underline{1990}$ & $(\%)$ & $(\%)$ & $(\%)$ \\
\hline Oceanic & 4.1 & -6.8 & -11.0 \\
\hline$-R S$ & 10.1 & -3.6 & -13.7 \\
\hline$-A S$ & -6.0 & -3.3 & 2.7 \\
\hline Continental & -4.1 & 6.8 & 11.0 \\
\hline -Cont 1,2 & -1.4 & 1.4 & 2.7 \\
\hline- Cont 3,4 & -2.7 & 5.5 & 8.2 \\
\hline \multicolumn{4}{|l|}{2000} \\
\hline Oceanic & -8.5 & 0.3 & 8.7 \\
\hline$-R S$ & -13.1 & -7.1 & 6.0 \\
\hline$-A S$ & 4.6 & 7.4 & 2.7 \\
\hline Continental & 8.5 & -0.3 & -8.7 \\
\hline -Cont 1,2 & 7.1 & 0.8 & -6.3 \\
\hline -Cont 3,4 & 1.4 & -1.1 & -2.5 \\
\hline
\end{tabular}

Table 4-2 Reanalysis Inter-comparison. Percent differences in annual cluster class or group frequency between three reanalysis products, NCEP/NCAR, ERA-40, and ERA-Interim. Bold italic numbers indicate differences greater than $10 \%$.

\subsubsection{Trajectory Seasonality and Climate Drivers}

The frequency distribution of cluster classes for the 1980-2010 period shows distinct seasonality (Figure 4.3a and 4.4). The Oceanic group frequencies peak on average in April with an additional local maximum in October (note that the Oceanic and Continental group frequencies sum to 1 at any point in time, thus the Continental group is shown to peak in December in Figure 4.4). The Amundsen Sea class shows strong bi-modal peaks (April and October) with a February minimum while the Ross Sea class has a single peak in April and a minimum in December (Figure 4.4). This average monthly variability in cluster frequency matches the signal of the Semiannual Oscillation (SAO), a prominent half-yearly mode of 
variability in the mid to high-latitude pressure systems of the Southern Hemisphere caused by the differing annual temperature cycles over the Antarctic continent and the mid-latitude ocean [Simmonds and Jones, 1998; van Loon, 1967]. The SAO exhibits two distinct average low pressure states between $60^{\circ}$ and $75^{\circ} \mathrm{S}$, from February to April and from September to November, and is strongest in the Ross Sea region [Simmonds, 2003; Simmonds and Jones, 1998] coinciding with peaks in Oceanic trajectories from our analysis. 


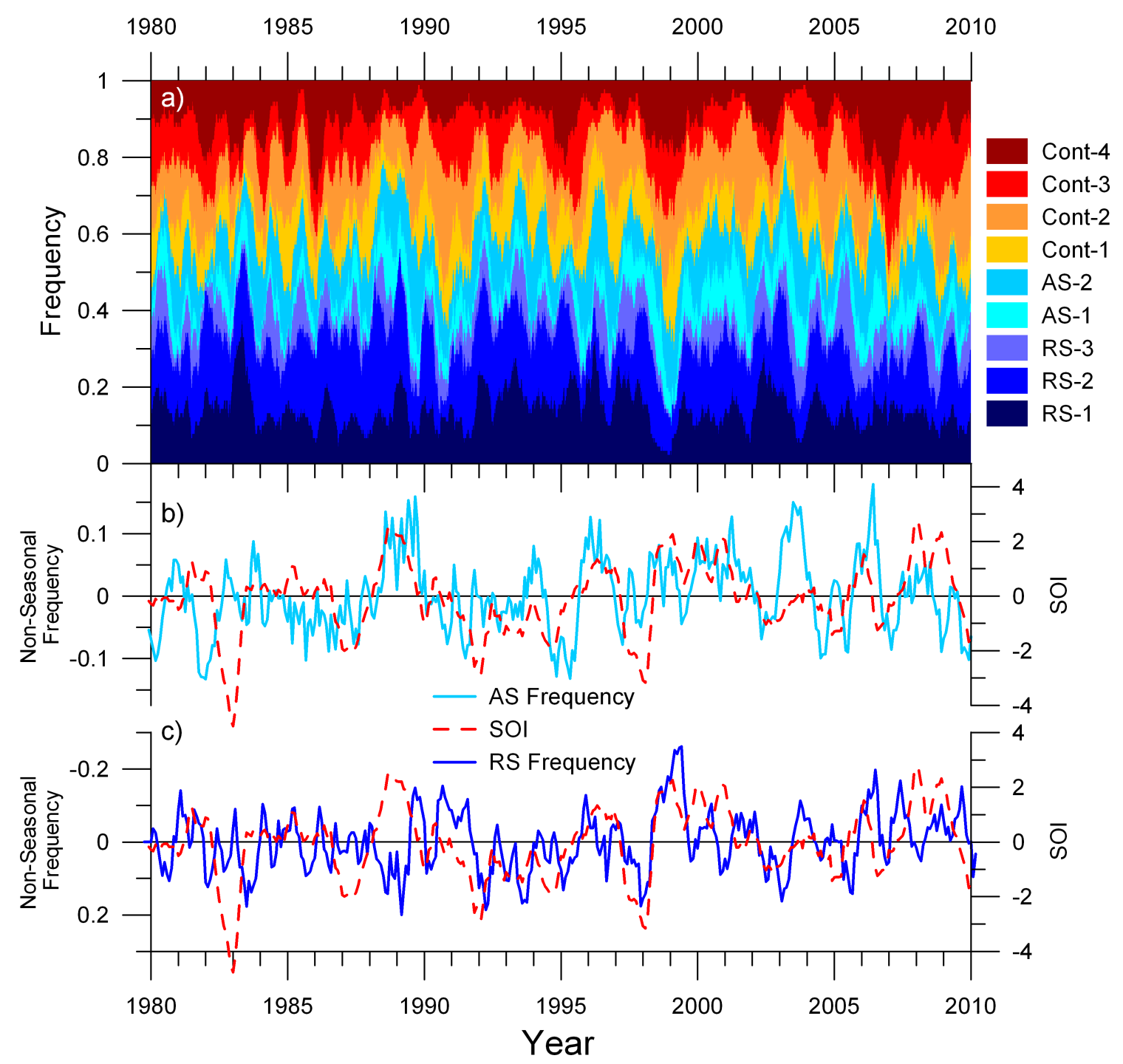

Figure 4.3a) The 91-day moving average frequencies of cluster classes for the 1980 to 2010 period. Each color represents an individual cluster class as shown in Figure 4.2. Blue shades correspond to oceanic/West Antarctic group frequencies while red and orange shades correspond to continental/East Antarctic group frequencies. They are stacked from bottom, approximately clockwise (east) from the GIP site. Frequencies are shown in fractions of 1, i.e. a class with a frequency of 0.5 occurred on $50 \%$ of the days within a 91-day window centered on that day; b) The 5-month moving average time series of the SOI (red) and the non-seasonal AS sub-group (light blue); c) The 5-month moving average time series of the SOI (red) and the non-seasonal RS sub-group (dark blue). Note the reverse orientation of the RS frequency axis. 


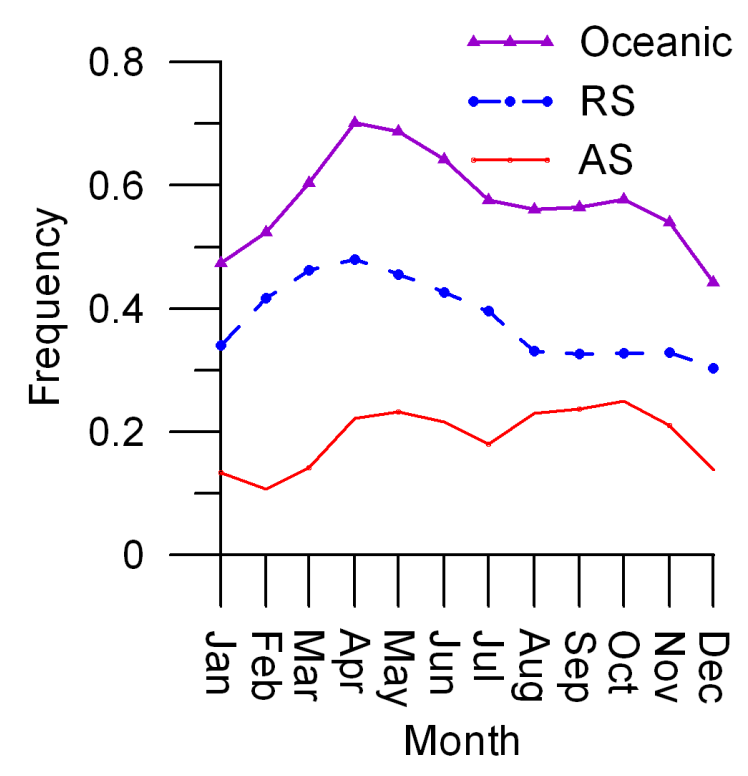

Figure 4.4 The seasonality of the Oceanic group frequency is shown (purple) as well as the constituent sub-groups: the Ross Sea (RS) sub-group (blue) and the Amundsen Sea (AS) sub-group (red). Note that the Continental group seasonality is simply opposite that of the Oceanic group, since at any point in time the sum of the two groups comprises all trajectories.

In addition to mean annual variability, we observe multi-year variability in the frequency distribution of classes, which is accentuated by the removal of the mean annual cycle from the data. Hereafter "non-seasonal" refers to a time series with the monthly mean value of all years removed from each monthly value. We compare the monthly, non-seasonal time series of all cluster classes and groups to the Southern Oscillation Index (SOI) and the Marshall [2003] SAM index, standard indices of ENSO and SAM variability, respectively. To examine the possible influence of the joint ENSO-SAM forcing discussed above, we create a joint index by simple linear combination of renormalized SOI and SAM to account for a reinforced response when the two oscillations are in-phase, as suggested above.

Trenberth [1997] suggests that some smoothing is appropriate for analysis of the SOI due to local high frequency variability obscuring decadal-scale signals and a 
5-month running average is commonly used. We test a range of smoothing factors $(1,3,5$, and 7 month moving averages), finding a consistent trend of increased correlation with increased smoothing. We use a 5-month moving average for all time series in this analysis unless otherwise noted. The level of significance ( $p$ value) is calculated using a two-tailed test and we use $\geq 95 \%$ confidence level to discern significant correlation. To account for lag-1 autocorrelation within the data sets, we adjust the degrees of freedom following Bretherton et al. [1999].

When applied to the entire 1980-2010 record, the smoothed, non-seasonal Oceanic group frequency exhibits no statistically significant correlation with the SOI $(\mathrm{r}=-0.12, \mathrm{p}=0.44)$ or with SAM $(\mathrm{r}=-0.07, \mathrm{p}=0.58)$. However, some synchrony between the SOI and Oceanic group frequency is apparent at intervals within the 30year record. For example, the correlation is stronger after January 1990, though still not statistically significant $(r=-0.30, p=0.13)$.

As noted above, RS and AS classes within the Oceanic group behave differently on a seasonal timescale. By decoupling the Ross and Amundsen Sea classes, we find a stronger SOI signal (Figure 4.3b and c). The non-seasonal RS frequency has a significant negative correlation $(r=-0.33, p=0.03)$ with the SOI (Figure 4.3c), while the non-seasonal Amundsen Sea sub-group exhibits a positive correlation $(\mathrm{r}=0.28, \mathrm{p}=0.07)$ (Figure $4.3 \mathrm{~b}$ ). These relationships are stronger at intervals within the 30-year period, for example after 1990, the non-seasonal RS group shows significant correlation with the SOI at $r=-0.53, p<0.01$, (for the AS group, $r=0.32, p=0.1$ ). The nature of the misfit between the SOI, RS, and AS time 
series can be examined in Figure 4.3. Some strong ENSO events appear to be better captured by either AS or RS variability. For example, the strong 1988-89 La Niña event closely matches variability in the AS frequency while the 1997-99 ENSO cycle is more closely matched by the RS frequency. Most major ENSO events over the thirty-year period are accompanied by similar variability in either the RS or AS frequencies or both. One notable exception to this is the exceptionally strong 198283 El Niño.

The relationship between the RS and AS frequencies and the SOI is readily explained in the context of ENSO's influence on the pressures systems of the Southern Ocean [e.g. Carleton, 2003; Fogt and Bromwich, 2006]. In Figure 4.5 we show the characteristic average annual geopotential height anomalies around Antarctica from NCEP/NCAR reanalysis data for a) positive ENSO (La Niña) and b) negative ENSO (El Niño) years between 1980 and 2010 with respect to the 19812010 climatological mean. During La Niña years the ASL strengthens significantly off the Amundsen Sea coast, while during El Niño years the ASL substantially weakens in the same region. We note that similar patterns have been shown to be associated with sea ice extent in the region [Carleton and Fitch, 1993]. 


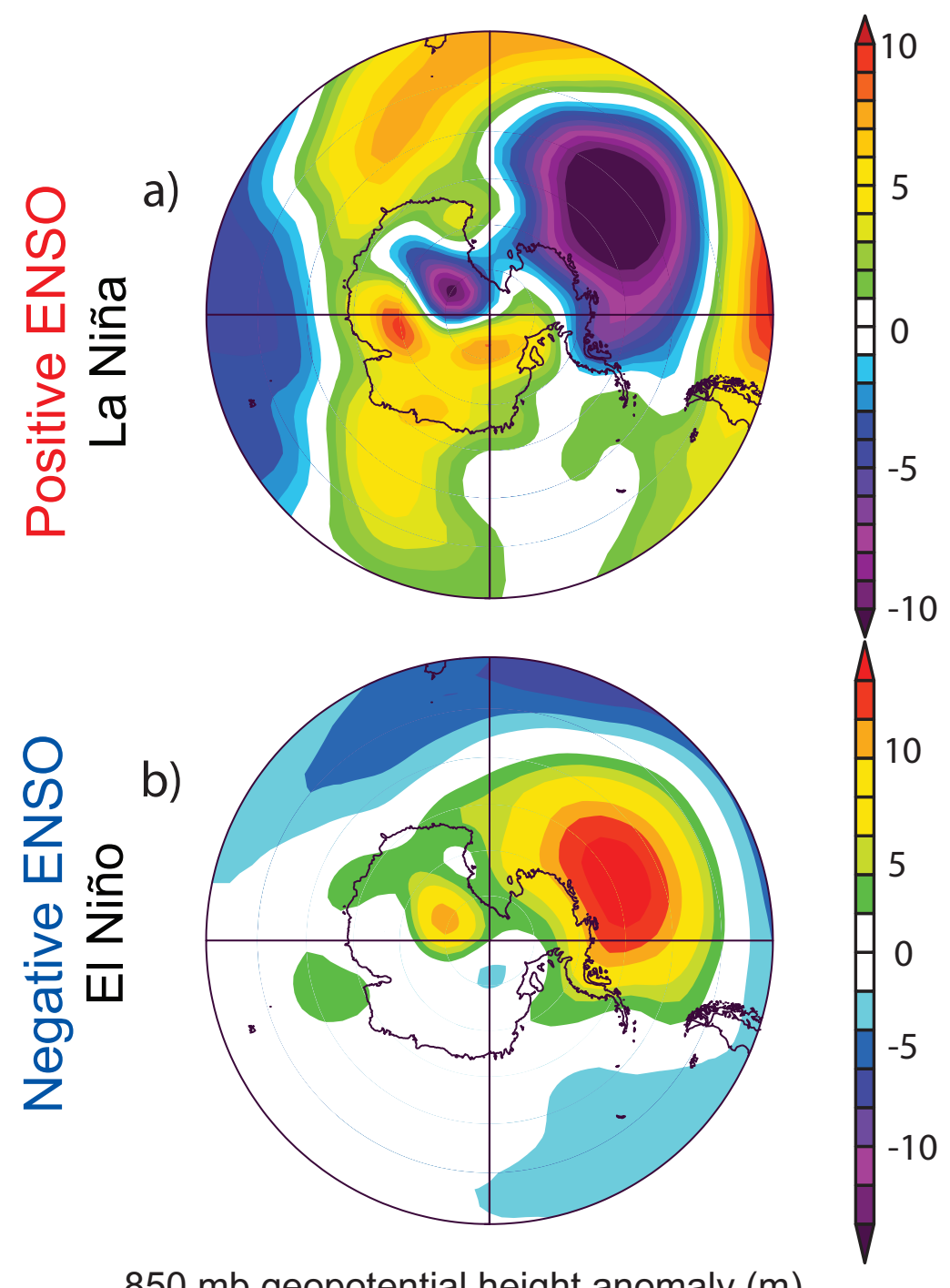

$850 \mathrm{mb}$ geopotential height anomaly $(\mathrm{m})$

Figure 4.5 $850 \mathrm{mb}$ geopotential height anomalies associated with ENSO's a) positive phase (La Niña) and b) negative phase (El Niño). Anomalies are shown in meters from the 1981-2010 climatological mean. Positive ENSO (a) is associated with negative anomalies off West Antarctica and a deepening of the ASL which leads to increased frequency of trajectories sourced from the AS reaching the GIP site. Negative ENSO (b) is associated with positive anomalies off West Antarctica, a relative weakening of the ASL and a relative increase in RS sourced trajectories. Annual (Jan. to Dec.) $850 \mathrm{mb}$ geopotential height anomalies are plotted from the NCEP/NCAR reanalysis data (available at http://www.esrl.noaa.gov/psd/cgi-bin/data/composites/). Positive/negative ENSO years were determined by the sign of annual (Jan. to Dec.) sums of monthly SOI values. Positive SOI years: 1981, '85, '88, '96, '99, '00, '01, '07, '08. Negative years: 1980, '82, '83, '84, '86, '87, '90, '91, '92, '93, '94, '95, '97, '98, '02, '03, '04, '05, '09.

It is important to keep in mind that Figure 4.5 is a plot of anomalies and that the Ross and Amundsen Seas are still a climatological low-pressure center even 
during El Niño years. We can interpret these anomalies then as a relative weakening/strengthening of the ASL and shifts in its average position. During La Niña events, in conjunction with a stronger ASL off West Antarctica, we see an increase in the frequency of trajectories from the AS region that cross West Antarctica toward the ice core site (Figure 4.5a). Conversely during El Niño events, we observe a decrease in AS frequency in association with the weaker center in the Amundsen Sea, concurrent with an increase in the RS frequency accompanying a shift in the low's average position (Figure 4.5b).

In this context we can more closely examine periods of misfit between the SOI and RS or AS frequencies. For example, the 1988-89 La Niña event is accompanied by a strong increase in AS frequency, as expected, as well as an increase in RS frequency, which is unexpected, given the above average model. Examining the geopotential anomalies of 1988 and 1989 reveal deviations from the average La Niña effect (see Carleton and Fitch [1993], for example). Specifically the characteristic negative anomalies extend across the entire Pacific Sector rather than being confined off West Antarctica, consistent with an increase in both RS and AS frequencies to the GIP site. As another example, the 1982-83 El Niño event, which does not correlate well with either AS or RS frequency, shows atypically weak anomalies with a spatially inconsistent pattern. We propose then that, on average, ENSO events will be accompanied by changes in the frequency of RS and AS trajectories as described above, but that the dynamics of individual events may alter this picture. 
To further examine the relationship between ENSO variability and our synoptic reconstruction we compare cluster class frequencies to the Nino3 index, another index of ENSO variability based on Eastern Pacific tropical SSTs (available from NOAA at http://www.esrl.noaa.gov/psd/data/climateindices/list/J. We observe strong correlation between the Nino3 index and RS frequency $(r=0.47, p<$ $0.01)$ and some correlation to AS frequency $(r=-0.27, p=0.06)$ in the expected pattern. This correlation is in part driven by the strong synchronous seasonality of the Nino3 index and cluster class frequencies though multi-year correspondence is also apparent.

Interestingly, although correlations with the SOI are strong, the Oceanic, RS, and AS cluster frequencies are not strongly nor significantly correlated with the Marshall SAM index. Furthermore, a linear combination of the SOI and SAM index, which accentuates the signal when the two oscillations are in-phase, gives weaker correlations than the SOI by itself. Some correspondence between the SAM and cluster class frequencies is observed at intervals over the thirty-year period particularly at higher frequencies, yet on average the effect is insignificant when compared to that of ENSO.

This surprising result is explained by the geopotential height anomalies associated with SAM. Although, anomalies in the ASL associated with both the SAM and ENSO are similar (Figures 4.5 and 4.6), we note that those associated with the SAM are far more zonally symmetric around the continent than those associated with ENSO, which exhibit a focused anomaly in the Pacific Sector. This is not 
surprising given the underlying dynamics driving each oscillation. The SAM is a hemispheric phenomenon defined by the nearly symmetric leading EOF of SH geopotential height [Simmonds and King, 2004]. On the other hand, ENSO is fundamentally a Pacific phenomenon and the EOF associated with the PSA pattern is centered strongly in the Amundsen Sea [e.g. Carleton, 2003]. This focused zonal asymmetry in ENSO's teleconnection to the Antarctic allows for stronger differential expression between the RS and AS source regions. For these reasons we do not expect the SAM to exert a similar influence to ENSO on the frequency of cluster classes. 


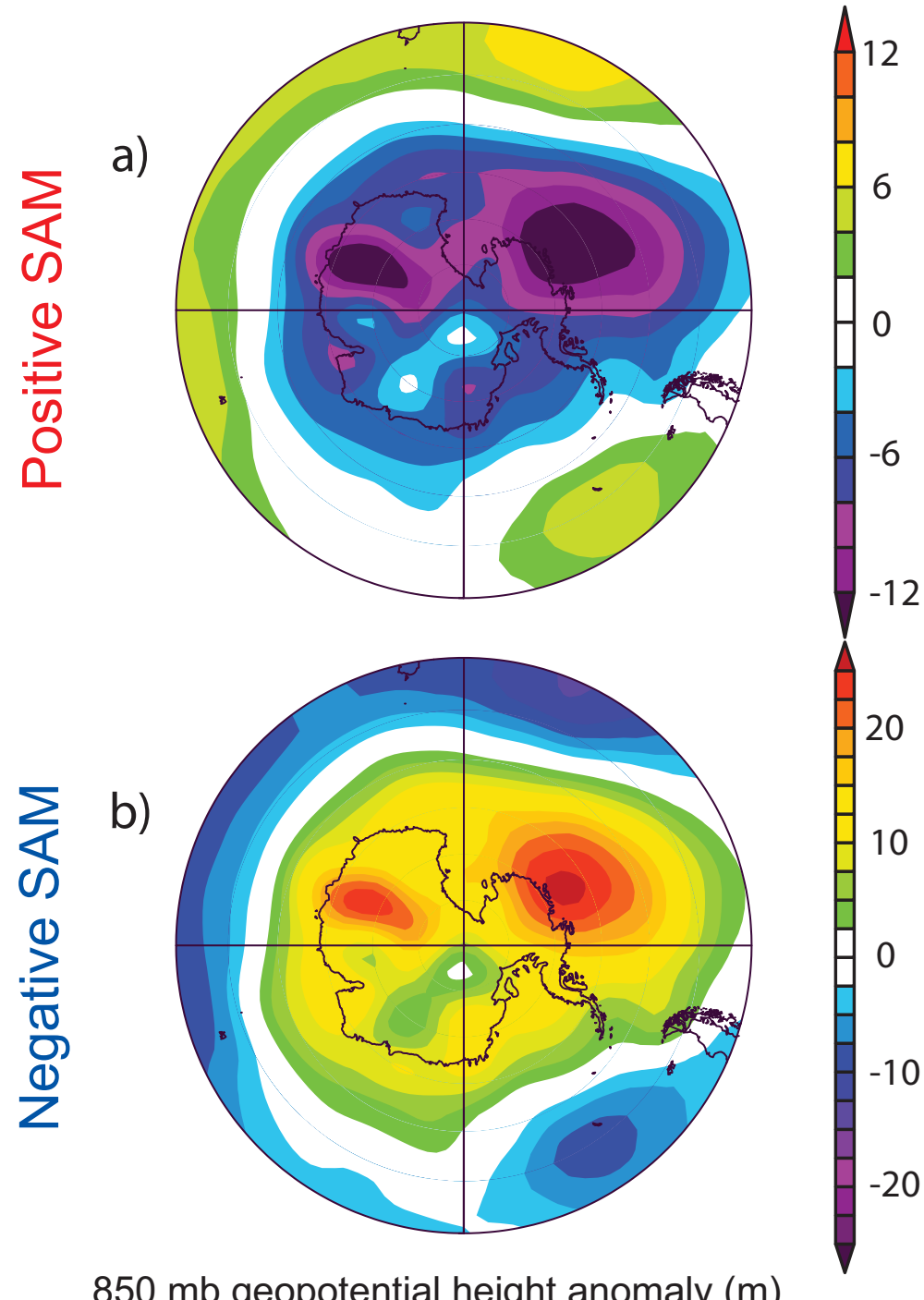

Figure 4.6 Annual (Jan. to Dec.) $850 \mathrm{mb}$ geopotential height anomalies associated with the a) positive and b) negative phase of SAM, shown in meters from the 1981-2010 climatological mean. Geopotential height anomalies are obtained from the NCEP/NCAR reanalysis data (available at http://www.esrl.noaa.gov/psd/cgi-bin/data/composites/). Positive/negative SAM years were determined from annual (Jan. to Dec.) sums of monthly Marshall [2003] SAM index values. Positive SAM years: 1982, '83, '85, '89, '93, '95, '97, '98, '99, '00, '01, '03, '04, '05, '06, '08, '09, '10. Negative years: 1980, '81, '84, '86, '87, '88, '90, '91, '92, '94, '96, '02, '07. 


\subsection{Proxy Development from the GIP Firn Core}

In this section we present the geochemical record from a $12 \mathrm{~m}$ reconnaissance firn core recovered from the Gawn Ice Piedmont in 2007-08 as part of the New Zealand International Trans-Antarctic Scientific Expedition (ITASE). We use the method of synoptic reconstruction through back-trajectory analysis presented above to interpret the geochemistry of the GIP core.

\subsubsection{Ice Core Processing, Analysis, and Age Model}

The GIP core was processed in a class 100 clean room at the GNS Science Ice Core Research Laboratory. Each $1 \mathrm{~m}$ section of core was logged, weighed and cut in preparation for further analysis. The core was discretely sampled with an average resolution of $1.8 \mathrm{~cm}$ using a continuous melter system designed by the University of Maine [Osterberg et al., 2006].

In total, 495 samples were measured for stable isotopic ratios $\left(\delta^{18} 0\right.$ and $\left.\delta D\right)$ at the National Isotope Centre, GNS Science. Oxygen stable isotopes were analyzed on a GVI AquaPrep attached to a GVI IsoPrime mass spectrometer by the equilibration method. $400 \mu \mathrm{l}$ of water is equilibrated with $3 \mathrm{ml}$ of headspace flushed with $\mathrm{CO}_{2}$ for 24 hours at $25.5{ }^{\circ} \mathrm{C}$. The $\mathrm{CO}_{2}$ is extracted and analyzed by dual inlet on the IsoPrime. All oxygen results are reported with respect to VSMOW, normalized to our internal standards: INS11, INS9 and MM1 with reported values of $-0.3 \% 0,-17.3$ $\%$, and $-29.4 \%$ respectively. The analytical precision for these measurements is $0.1 \%$. 
Hydrogen stable isotopes were analysed on a GVI PyrOH attached to a GVI IsoPrime mass spectrometer by direct injection over hot chromium. $5 \mu$ of water is injected into a helium stream through a quartz reactor filled with chromium granules and quartz chips held at $1050^{\circ} \mathrm{C}$, where it is reduced to $\mathrm{H}_{2}$ gas. The $\mathrm{H}_{2}$ is then analyzed by continuous flow mode on the IsoPrime. All hydrogen results are reported with respect to VSMOW, normalized to our internal standards: INS11, INS9 and MM1 with reported values of $-3.3 \%$, $-136.5 \%$, and $-231.5 \%$ respectively. The analytical precision for these measurements is $1.0 \%$.

Every $5^{\text {th }}$ sample (99 in total) of the GIP core was measured for major and trace element concentrations. Ion chromatography analyses of major ion concentrations $\left(\mathrm{Na}^{+}, \mathrm{K}^{+}, \mathrm{Mg}^{2+}, \mathrm{Ca}^{2+}, \mathrm{MS}^{-}, \mathrm{Cl}^{-}, \mathrm{NO}_{3}{ }^{-}, \mathrm{SO}_{4}{ }^{2-}\right)$ were carried out at the Climate Change Institute, University of Maine. Major cation concentrations were measured using ion chromatography with a Dionex IonPac CS12 column and a 20 mM methanesulphonic acid eluent. Major anion concentrations were measured with a Dionex AS11 column and 6.0 mM NaOH eluent. External quality control samples were run approximately every tenth sample. Control samples of frozen ultrapure water (18 M $\Omega$ MilliQ) were measured and show that no significant contamination occurred during the sampling and processing stages.

An age model was constructed for the GIP record employing a multi-proxy approach using maxima in methylsulphonate (MS) concentrations and $\delta^{18} 0$ to identify annual cycles. Because of high and continuous accumulation rate observed at the nearby SKS site [Sinclair et al., 2010], particular care was taken to discern 
annual temperature oscillations from variation due to sub-seasonal or event-driven cycles. The stable isotope ratios of water, $\delta^{18} 0$ and $\delta \mathrm{D}$, are linearly related to precipitation site temperature [Dansgaard, 1964; Jouzel et al., 1997] enabling their use in ice core records as a paleothermometer. MS is a secondary bi-product of primary production by marine phytoplankton and diatoms and is produced locally in the Ross Sea Region during the summer months [Legrand and Mayewski, 1997; Saltzman et al., 1983]. Rhodes et al. [2009] demonstrate a causal link between the MS record in precipitation and the seasonal cycle of sea ice cover and primary production in the Ross Sea Region. MS has strong cyclicity in the GIP record, and cross-correlation and principal component analysis (PCA) shows strong independence of the MS record from other measurements, making its use in this context appropriate. The MS record does show strong correlation with $\mathrm{SO}_{4}(\mathrm{r}=0.87$, $\mathrm{p}<0.001$ ), which is expected since like $\mathrm{MS}, \mathrm{SO}_{4}$ is a product of the oxidation of dimethylsulphide produced by marine primary production [Saltzman et al., 1983]. Although other sources of Antarctic $\mathrm{SO}_{4}$ exist (e.g. anthropogenic or volcanic [Legrand and Mayewski, 1997]), the strong correlation with MS suggest these are insignificant at the GIP site.

Maxima in $\delta^{18} 0$ were assigned to the 1 st of January of each year, which reanalysis data suggest is consistently the month of peak annual temperature as described in Chapter 2. In years when a single $\delta^{18} 0$ minimum was unambiguous (2001, 2003, and 2004), these sample depths were tied to August $1^{\text {st }}$, August $1^{\text {st }}$, and July $1^{\text {st }}$, respectively, based on temperature minima from reanalysis data. Ages for 
all samples were then linearly interpolated between tie points, giving an average of 41 samples per year and no less than 12 samples per year. For the purpose of correlation with trajectory classes and meteorological fields, all ice core data were also re-sampled to monthly resolution using a linear interpolation.

Based on our age model, the GIP record spans almost 8 years, from early 2000 to recovery in November 2007. The average accumulation is 1.12 meters of water equivalent per year, an exceptionally high rate for Antarctica, but in agreement with AWS data from the nearby SKS site [Sinclair et al., 2010].

An independent tie point is provided by a large, local-origin dust storm event that affected the Ross Sea region in the spring of 2004 [Steinhoff et al., 2008]. A cyclonic system propagated across the Ross Ice Shelf from the SE towards McMurdo Sound and initiated a barrier jet along the Transantarctic Mountains. The lowest annual accumulation of the record occurs during this year $\left(73 \mathrm{~cm} \mathrm{yr}^{-1}\right)$, suggesting that some wind scour may have occurred at the site in association with this event. Interestingly, the core also shows the largest $\mathrm{SO}_{4}$ and $\mathrm{MS}$ spikes of the record in the summer after the storm (2004-05). This suggests that an unusually large algae bloom was present, possibly due to enhanced iron fertilization from the dust delivered into the Ross Sea during the event.

\subsubsection{Back-Trajectory Reconstruction}

Following the method in Section 4.2.3, a back-trajectory history was reconstructed to span the GIP ice-core record. Daily back trajectories from October 
1999 to March 2008 (3105 trajectories) were clustered at daily resolution using points along each trajectory at 3-hr intervals. The 2000-2008 reconstruction was classified following the same criteria as the 1980-2010 dataset and is shown in Table 4-3. Trajectory cluster means are shown in Figure 4.7 and the stacked cluster class frequencies are shown in Figure 4.8. 


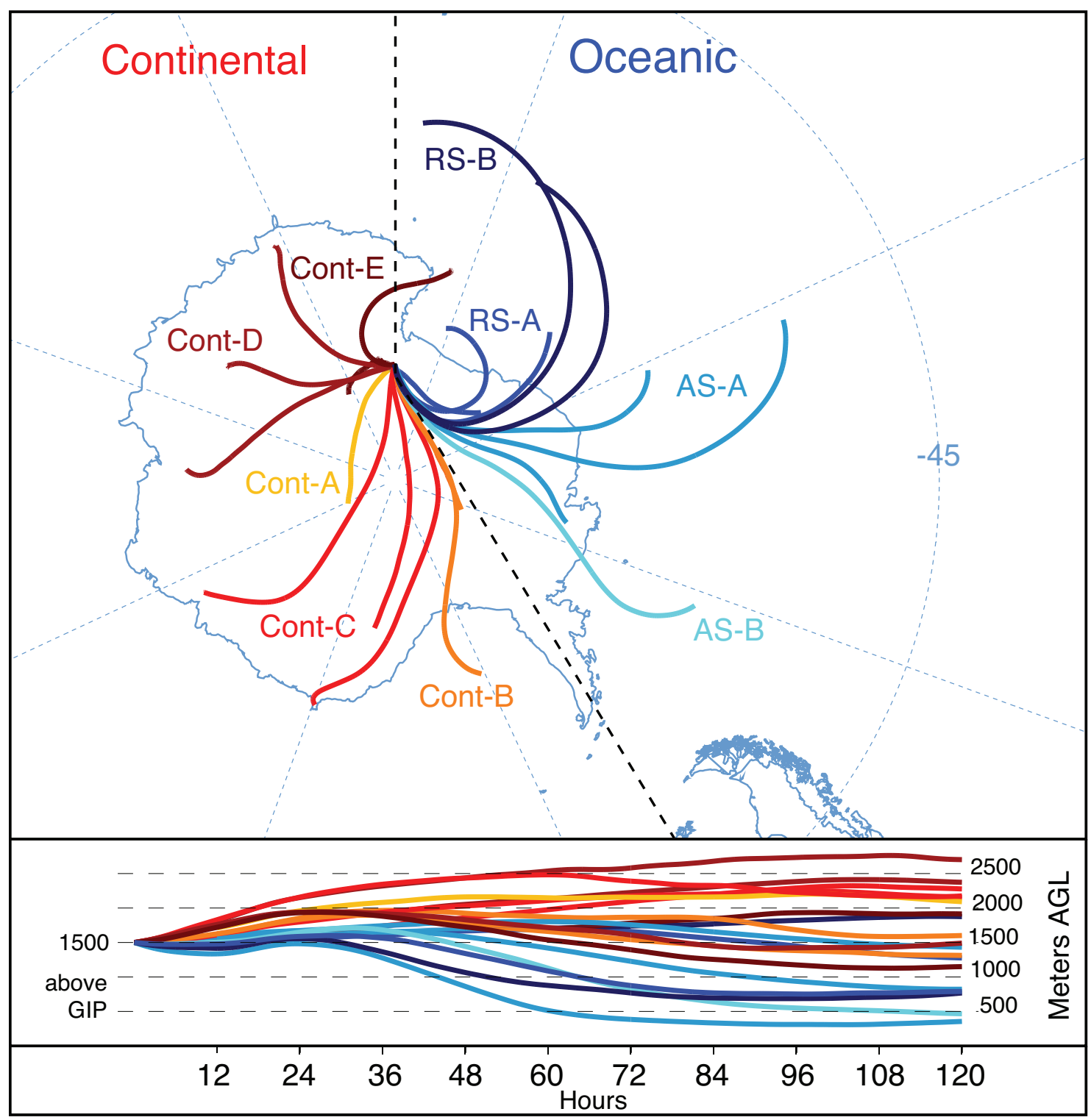

Figure 4.7 Cluster mean trajectories for the 2000-2008 cluster analysis (top) color-coded by class and group. Blue shades represent Oceanic group clusters, while red shades show the Continental group. Mean trajectory altitudes over time are shown below. 


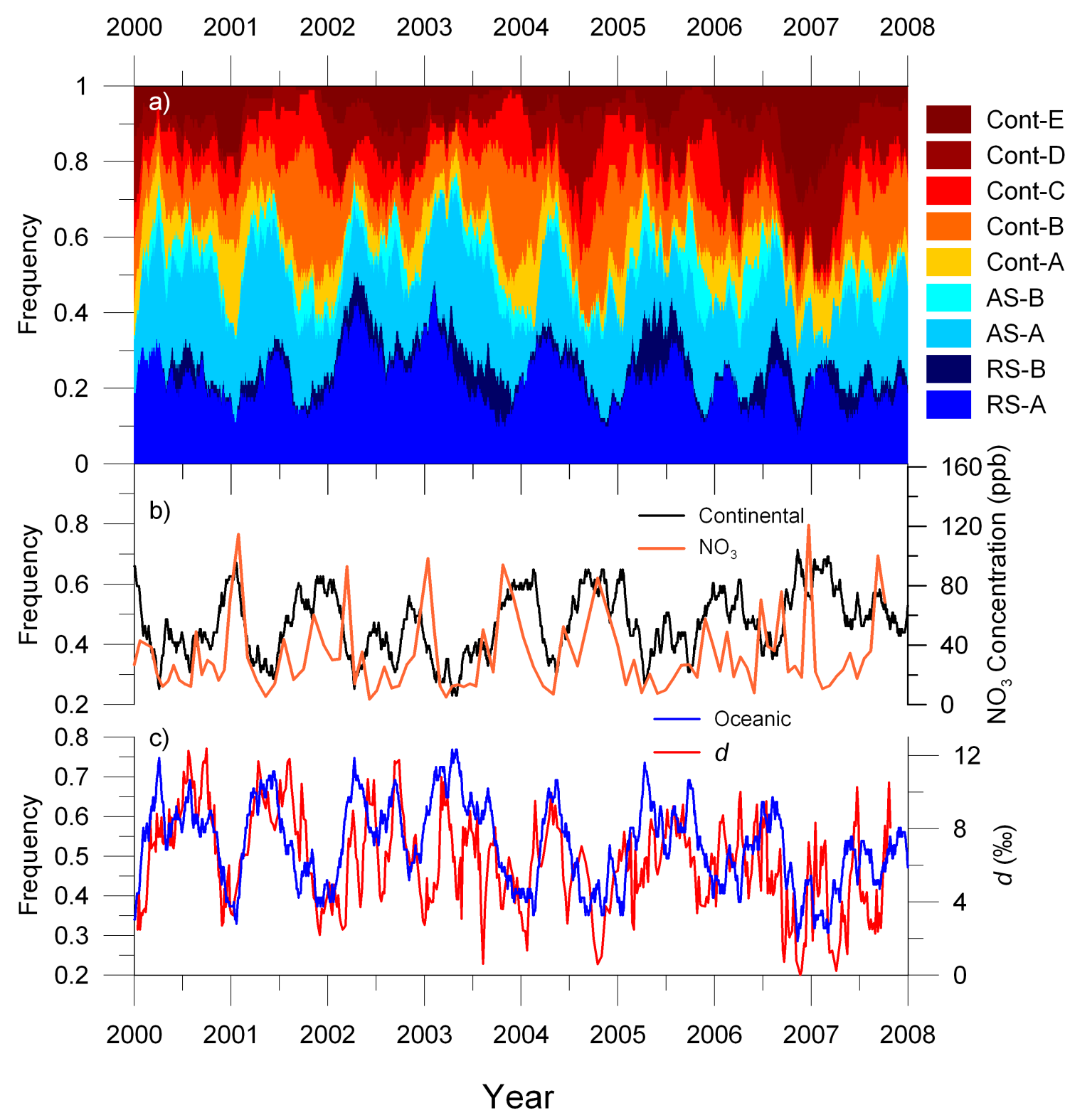

Figure 4.8 a) The 91-day moving average frequencies of cluster classes, 2000-2008. Each color represents an individual cluster class as in Figure 4.7. Blue shades correspond to Oceanic group frequencies while red and orange shades correspond to Continental group frequencies. They are stacked, from bottom, clockwise (east) from the GIP site; b) Raw NO3 (orange) data are shown against the 91-day smoothed Continental group frequency (black). c) Raw d data (red) are shown against the 91-day smoothed Oceanic group frequency (blue). 


\begin{tabular}{|c|c|c|c|c|c|}
\hline Group & $\frac{\text { Sub }}{\text { Group }}$ & $\underline{\text { Class }}$ & $\stackrel{\frac{\%}{0}}{\text { of total }}$ & Pathway & $\frac{\text { Relative }}{\text { Speed }}$ \\
\hline \multirow{4}{*}{ 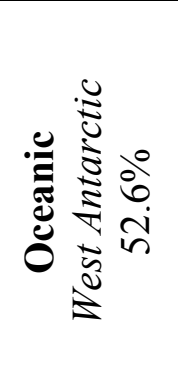 } & \multirow{2}{*}{ 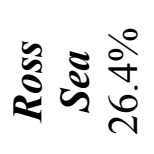 } & RS-A & $22.2 \%$ & Ross Sea, Ross Ice Shelf & Slow \\
\hline & & RS-B & $4.3 \%$ & Ross Sea, WAIS & Fast \\
\hline & \multirow{2}{*}{ 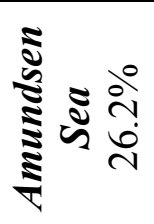 } & AS-A & $21.4 \%$ & $\begin{array}{l}\text { Amundsen Sea West, } \\
\text { WAIS }\end{array}$ & $\begin{array}{l}\text { Fast } \\
\text { (var.) }\end{array}$ \\
\hline & & AS-B & $4.8 \%$ & $\begin{array}{l}\text { Amundsen Sea East, } \\
\text { WAIS }\end{array}$ & Fast \\
\hline \multirow{5}{*}{ 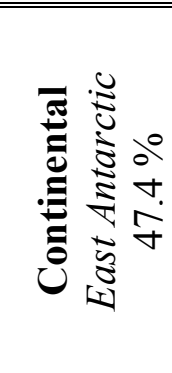 } & \multicolumn{2}{|c|}{ Cont-A } & $7.3 \%$ & Plateau, EAIS & $\begin{array}{l}\text { Slow } \\
\text { (var.) }\end{array}$ \\
\hline & \multicolumn{2}{|c|}{ Cont-B } & $13.3 \%$ & Plateau, EAIS, WAIS & (var.) \\
\hline & \multicolumn{2}{|c|}{ Cont-C } & $8.5 \%$ & Plateau, EAIS, QML & Fast \\
\hline & \multicolumn{2}{|c|}{ Cont-D } & $10.4 \%$ & EAIS, WKL, VCL & Fast \\
\hline & \multicolumn{2}{|c|}{ Cont-E } & $7.9 \%$ & EAIS, VCL & Slow \\
\hline
\end{tabular}

Table 4-3 Cluster Classification 2000-2008. Cluster groups and classes for the 2000-2008 classification arranged approximately clockwise from the GIP site. The approximate source region and/or general pathway is given $(\mathrm{QML}=$ Queen Maud Land, WKL= Wilkes Land, and VCL= Victoria Land), along with a qualitative indication of relative speed. "Var." is used to denote classes containing trajectories with variable lengths.

On average, the Oceanic group has a maximum monthly frequency in April while the Continental group peaks in December, as in the 30-year reconstruction. Likewise, AS and RS sub-groups also show seasonality nearly identical to that in Figure 4.4. We note again that this variability matches that of the SAO which is most pronounced in the Ross Sea region [Simmonds, 2003; Simmonds and Jones, 1998]. We interpret the seasonal variability of the Oceanic group as SAO driven changes in pressure anomalies that govern the cyclone activity in the area. The average ratio of RS to AS trajectories is nearly 1:1 for the length of the GIP record in contrast to 2:1 for the 1980 to 2010 period. 
Figure 4.8a demonstrates the inter-annual variability between cluster classes. As above, variability is evident between the frequencies of the AS and RS subgroups comprising the Oceanic group. Within the Continental group, we observe variability in the importance of Queen Maud Land (QML) and Wilkes Land (WKL) as trajectory sources. Classes Cont B and C, which cross QML, dominate during 2001, '03, and '04, while classes Cont D and E, which cross WKL, significantly spike in frequency in 2006 and 2007. By comparison to Figure 4.3a we see that this variability is irregular over the last 30 years. While the implications of this variation within the Continental group is beyond the scope of this study, it illustrates the detail of information possible from this method of synoptic reconstruction.

A snow accumulation record was calculated using firn density measurements from the mass of each $1 \mathrm{~m}$ section of core. For this reason, the accumulation record is limited by the coarseness of available density data, with an average of 1.5 data points per year. The annual accumulation history of GIP shows some similarity to the Oceanic group frequency, however the shortness of the record makes this a purely qualitative relationship (Figure 4.9). 


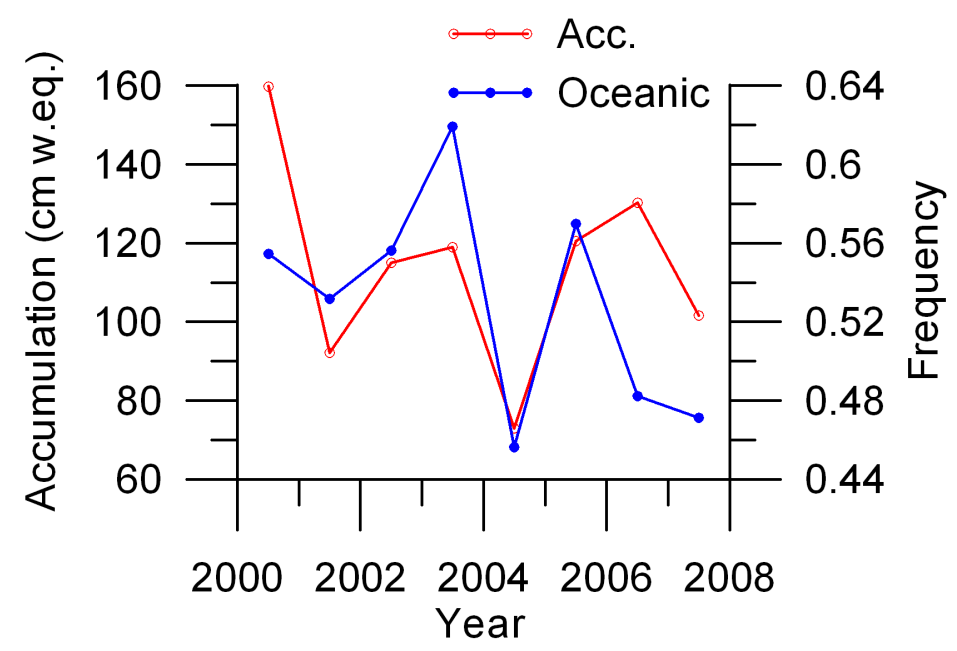

Figure 4.9 Annual snow accumulation in $\mathrm{cm}$ of water equivalent (red) and average annual Oceanic group frequency (blue) for 2000-2008.

\subsubsection{Proxy Development for Continental Trajectories}

Methylsulfonate (MS), sulfate $\left(\mathrm{SO}_{4}\right)$, and nitrate $\left(\mathrm{NO}_{3}\right)$ concentrations show summer maxima (Figure 4.10a) as reported at other Antarctic sites [Legrand and Mayewski, 1997]. The summer peaks in $\mathrm{MS}$ and $\mathrm{SO}_{4}$ are well-understood and related to summer primary production in the Ross Sea [R. H. Rhodes et al., 2009]. In contrast, $\mathrm{NO}_{3}$ is thought to form in lightning-related processes in the tropics, reaching the Antarctic primarily from the stratosphere [Legrand and Delmas, 1986; Legrand and Mayewski, 1997; Michalski et al., 2005]. After gaseous deposition on the ice cap, $\mathrm{NO}_{3}$ can be transported to coastal sites via drainage from the upper plateau (such as katabatic winds) [Legrand and Mayewski, 1997; Michalski et al., 2005]. Thus we associate $\mathrm{NO}_{3}$ with air-masses draining from the upper plateau through the Transantarctic Mountains. Indeed, we find good agreement in both seasonality and 
magnitude of smoothed, resampled $\mathrm{NO}_{3}$ concentrations with Continental group frequencies (Figure 4.8b), yielding a correlation coefficient of $r=0.55(p=0.02)$.

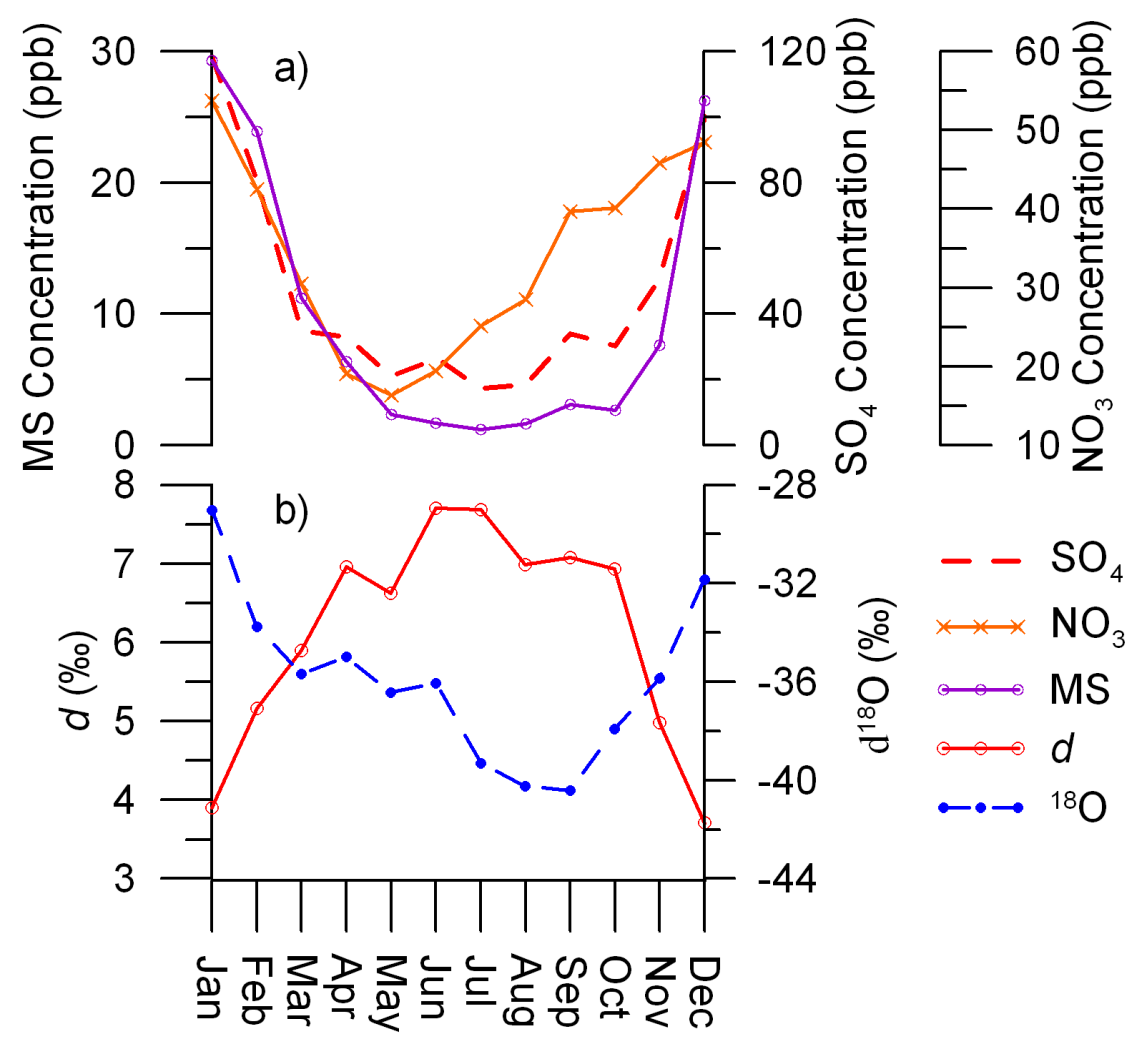

Figure 4.10 a) The mean resampled monthly values of NO3 (orange), SO4 (red), and MS (purple) concentrations from the GIP core; b) Seasonality of the mean resampled d (red) and $\partial 180$ (blue) values. 


\subsubsection{Proxy Development for Oceanic Trajectories}

\subsubsection{Deuterium Excess}

Stable isotope ratios $\delta^{18} 0$ and $\delta D$ are driven by Rayleigh-type distillation processes, that is the progressive fractionation of vapor by removal of equilibrated precipitation during moisture transport [Merlivat and Jouzel, 1979]. The deuterium excess parameter $\left(d=\delta D-8 \delta^{18} 0\right)$, however, is primarily driven by kinetic, nonequilibrium fractionation processes during evaporation and is thought to record integrative information about the moisture source region, particularly SST, relative humidity (h), and surface winds [Dansgaard, 1964; Merlivat and Jouzel, 1979]. In addition to the initial source region imprint, in-cloud processes related to the supersaturation of water vapor influence the $d$ value during moisture transport [Ciais and Jouzel, 1994; Fisher, 1991; Helsen et al., 2006]. There is also evidence of post-depositional influences on $d$, related to surface sublimation in cold arid regions [Masson-Delmotte et al., 2008], but these influences are not likely to be important at high-accumulation sites such as GIP.

The physical parameterization of processes that drive kinetic fractionation at ocean source regions, and hence $d$, are well-understood and modeled [Merlivat and Jouzel, 1979]. Relative humidity in the boundary layer above the ocean surface is the primary driver of kinetic fractionation but this, in turn, has a dependence on SST. Through sensitivity studies of isotopic models, Vimeux et al. [2001] show that for the Taylor Dome site in coastal Victoria Land, changes in source region SST are 
positively correlated to changes in the $d$ imprint and are more than twice as influential as changes in $h$, which are negatively correlated with $d$. Furthermore, they show that the $h$ imprint decreases as air-masses move inland, such that $\Delta \mathrm{SST}$ is nearly ten-times as important as $\Delta \mathrm{h}$ at central sites [Vimeux et al., 2001]. Similarly, Masson-Delmotte et al. [2003] found that, in contrast to $\delta^{18} 0$ and $\delta D$ which are primarily controlled by site temperature, $d$ is largely controlled by source region SST, which accounts for 76\% of the variance in $d$.

Over the Antarctic continent as a whole there is a positive correlation between $d$ and site elevation as well as distance from the coast; that is higher sites that are farther from the coast generally have higher $d$ values [Masson-Delmotte et al., 2008]. The $d$ of vapor within the atmosphere increases toward the equator and trajectories advected from lower-latitude moisture source regions (more distant from the pole) are associated with higher $d$ values in precipitation [Helsen et al., 2006; Schlosser et al., 2008].

These influences are reflected in the seasonality of $d$ in Antarctic precipitation, which (out of phase with $\delta^{18} 0$ and $\delta D$ ) is greatest in winter when, due to sea ice cover, source regions are more distant from the continent with relatively warmer SSTs and lower relative humidity [Delmotte et al., 2000; Fujita and Osamu, 2006; Masson-Delmotte et al., 2003; Schlosser et al., 2008]. However, during summer when high-latitude oceans are ice free, the contributions of these colder, proximal moisture sources with higher relative humidity are thought to lower $d$ values in vapor and thus precipitation [Delmotte et al., 2000; Fujita and Osamu, 2006; Helsen 
et al., 2006; Masson-Delmotte et al., 2003; Masson-Delmotte et al., 2008; Schlosser et al., 2008].

\subsubsection{The GIP d Record and Oceanic Group Frequency}

The $d$ excess record at the GIP site shows winter maximum (Figure 4.10b), suggesting that the site experiences similar fluctuations in moisture source regions as seen elsewhere in the Antarctic [Delmotte et al., 2000; Fujita and Osamu, 2006; Helsen et al., 2006; Masson-Delmotte et al., 2003; Masson-Delmotte et al., 2008; Schlosser et al., 2008]. During summer, local cold moisture sources (lower $d$ ) play a larger role in the moisture budget, while more distant, warmer ocean sources (higher $d$ ) are dominant in winter.

We note a similar seasonality in both the $d$ record and cyclonic activity at the GIP site, and find a high degree of synchrony between the 91-day running mean Oceanic group frequency and the raw $d$ record (Figure 4.8c). It is of note that the timing of the $d$ record is linearly interpolated between only one or two tie points per year. While snow accumulation at the site is likely consistent and high year-round, any heterogeneity in that accumulation history has the potential to introduce age uncertainty in the $d$ record, particularly at steep changes between seasons. We apply a 5-month moving average to both the resampled $d$ and Oceanic group frequency to reduce the high degree of noise in both signals and the influence of any event-driven punctuation in the $d$ record. We find a strong correlation between the smoothed records with $r=0.62(p<0.02)$. 
Although the correlation between $\mathrm{NO}_{3}$ and the Continental group frequency appears in large part seasonally driven, there is strong correspondence between the multi-year variability in both $d$ and Oceanic group frequency (Figure 4.8c). To further explore the extra-annual relationship, we remove the average annual cycle from each monthly time series and again apply a 5-month moving average (Figure 4.11a). A strong correlation in multi-year variability is observed $(r=0.55, p<0.04)$ such that higher $d$ values are associated with increased Oceanic group frequency, beyond their seasonal relationship. This result suggests that, in comparison to all other trajectory classes, the Oceanic group is sourced from more distant regions with higher SSTs and lower relative humidity yielding higher $d$ values in vapor. 


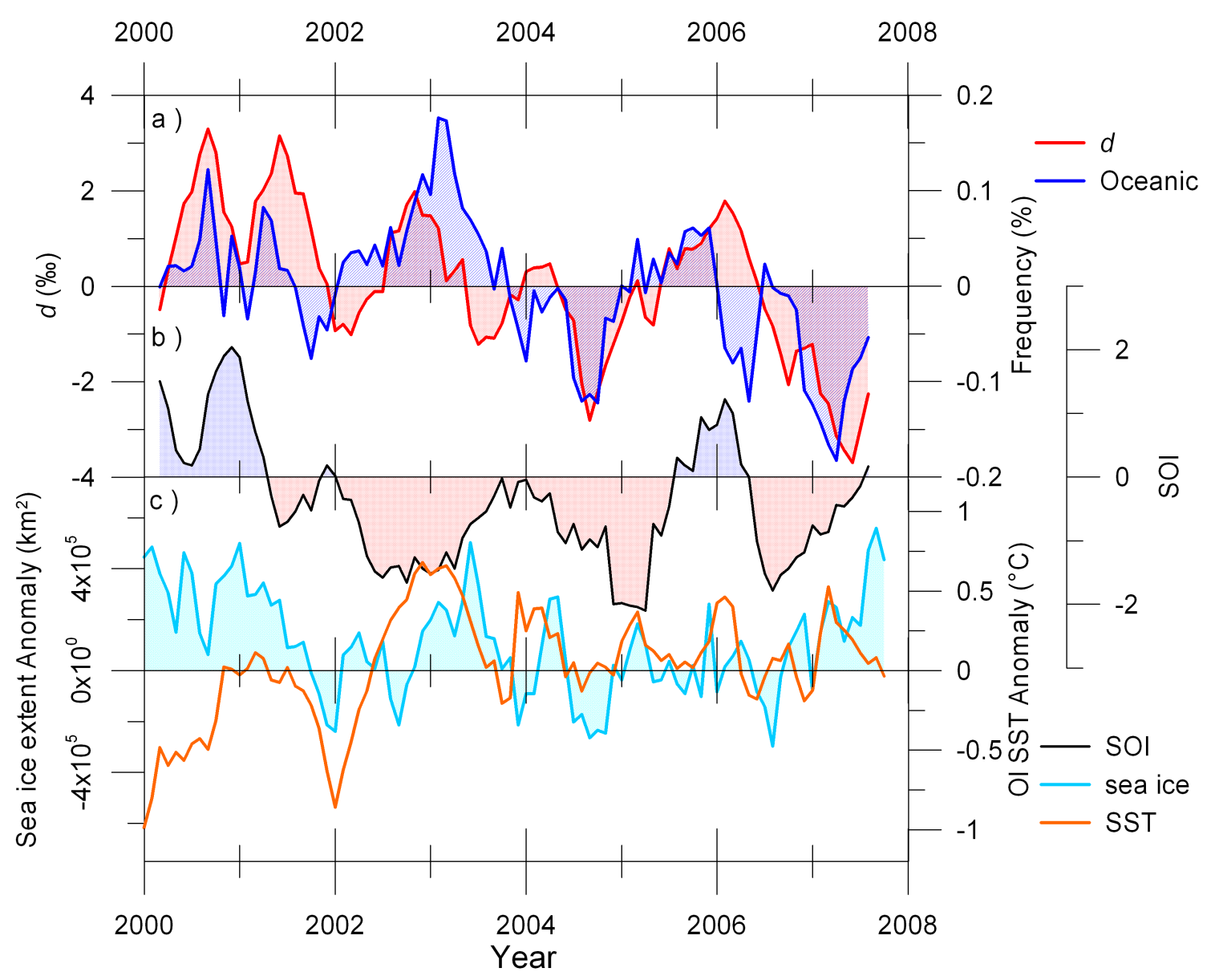

Figure 4.11 a) The non-seasonal, 5-month moving average Oceanic group frequency and resampled d record; b) the SOI; and c) NOAA's OI SST anomalies for the Ross and Amundsen Seas (orange) as well as the NSIDC sea Ice index for the Amundsen Sea (blue) (SST and SOI data available from http://www.esrl.noaa.gov/psd/data/climateindices/; and sea ice data is available from http://nsidc.colorado.edu/data/seaice_index/).

While $d$ is shown to be a strong proxy for air-mass trajectories of more Oceanic origin, it does not appear sensitive to changes between source regions within the Pacific Sector (i.e. the RS and AS regions). We propose that the contrast of the relatively warm Oceanic group source region as a whole against all other cluster classes (those comprising the Continental Group) is the primary driver of the $d$ record at a variety of time scales. Any effects associated with subtleties of source region within the Oceanic group are comparatively insignificant. 


\subsubsection{Possible Inter-annual Drivers of $d$ Variability}

To investigate potential additional drivers of inter-annual variability we compare the smoothed, non-seasonal time series of $d$ and Oceanic group frequency to ENSO, SST, and sea ice variability (Figure 4.11). As seen in Section 4.2.4, the SOI shows some in-phase correlation to the non-seasonal Oceanic group frequency. However, over the timeframe of the GIP record, the relationship is inconsistent and notably out-of-phase in 2002 and 2003 (Figure 4.11b). Because the GIP record spans just one to two average ENSO cycles of 2-7 years [Trenberth, 1997] any statistical correlation to the SOI is not particularly meaningful. Furthermore, a variety of factors may complicate any ENSO signal in the $d$ record. In particular, the combination of geopotential height and SST anomalies associated with either phase of ENSO could be self-dampening. During a La Niña phase, the deepened ASL may on average tend to increase input to GIP from more distant (relatively warmer) moisture sources in the AS (Figure 4.5a). However the average SST anomalies associated with La Niña suggest that those waters in the AS will be anomalously cooler than average (Figure 4.12a). Thus the net affect on $d$ may tend to cancel and, at the least, ENSO is likely to show a complicated relationship to the $d$ record. 

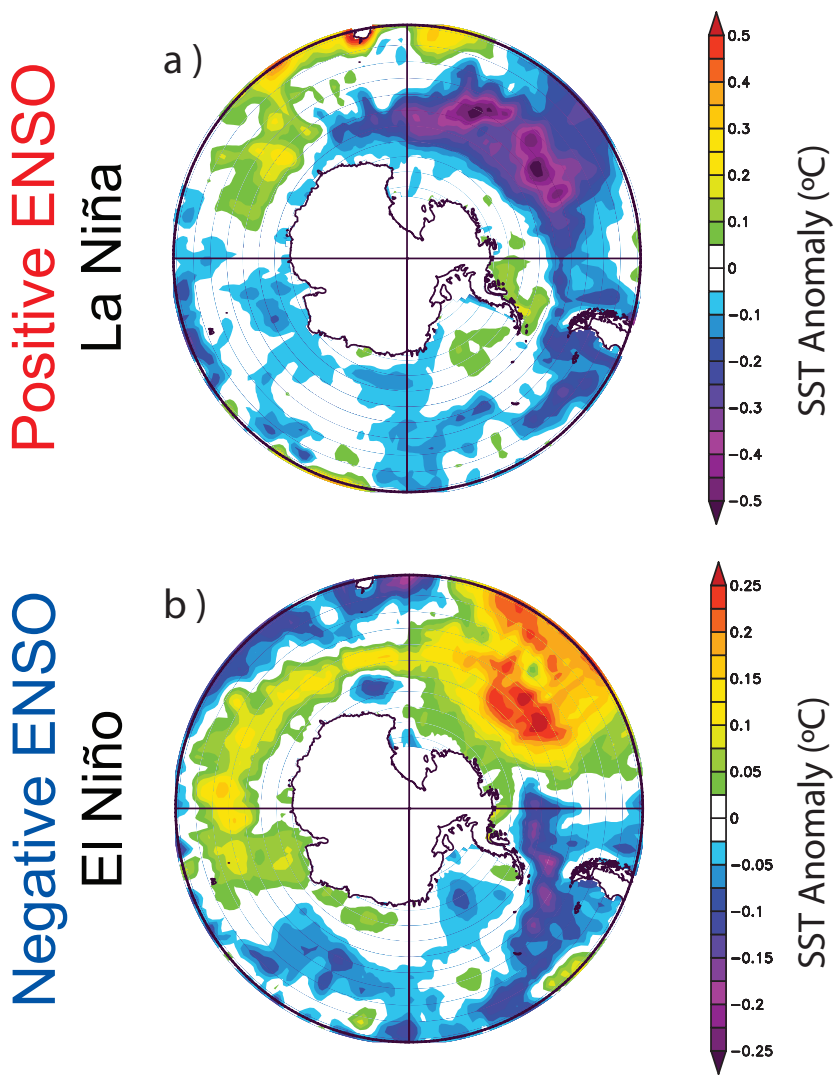

Figure 4.12 SST anomalies associated with a) positive ENSO years and b) negative ENSO years. Positive/negative ENSO years are identical to those described in Figure 4.5. Images created from NOAA's web plotting tool (available at http://www.esrl.noaa.gov/psd/cgibin/data/composites/printpage.pl).

Non-seasonal SST anomalies for the Ross and Amundsen Sea region (obtained from NOAA's Optimum Interpolation Sea Surface Temperature Analysis [Reynolds et al., 2002]) do not show a strong relationship to the GIP $d$ record (Figure 4.11c). We do observe a period of particularly high SST anomalies in 2003, during the notable misfit with the SOI, with concomitant high $d$ values, possibly supporting the idea of ENSO's self-moderation in influencing the $d$ signal. However, aside from this strong event, there is little multi-year correspondence between the SST anomaly and the $d$ record. While seasonal and latitudinal changes in SST likely influence the seasonal $d$ signal, the above comparison suggests that local multi-year 
SST variability is not a dominant driver of inter-annual $d$ variability in the GIP record.

The annual cycle of sea ice extent in the Ross and Amundsen Seas (summer minima and winter maxima, obtained from the National Snow and Ice Data Center [Fetterer et al., 2002]) supports the interpretation that sea ice extent influences the proximity of moisture source regions. However, non-seasonal, sea ice anomalies in the Ross and Amundsen Seas regions do not exhibit significant correlation with $d$ or Oceanic group frequency (AS region anomalies shown in Figure 4.11c). Through GCM modeling Noone and Simmonds [2004] showed the complex relationship between zonal mean sea ice extent and $\delta^{18} 0$ and $d$ in Antarctic precipitation. Coastal regions showed stronger sensitivity to changes in sea ice extent than did interior locations, though their analysis did not account for zonal asymmetries in sea ice extent, which are known to coincide with ENSO and SAM cycles. While the authors demonstrated a positive relationship between $d$ and sea ice extent, their results indicate that sea ice may only account for $2 \%$ variability in $d$. Thus inter-annual changes in sea-ice extent are unlikely to be a dominant driver of the GIP $d$ variability.

The interrelatedness of, and feedbacks between inter-annual variability in SSTs, sea ice, and ENSO make it difficult to parse their distinct influences on interannual $d$ variability. The lack of sensitivity of the $d$ record to source region changes within the Pacific Sector and the shortness of the GIP record further limits this investigation. However, as shown above, the frequency of Oceanic trajectories does 
show a strong and consistent correlation with $d$. We suggest that the total frequency of oceanic air-masses to the GIP site is the dominant driver of the seasonal and inter-annual $d$ record.

\subsection{Conclusions}

We have presented here a new method for reconstructing and interpreting the synoptic history of an Antarctic ice core site, the Gawn Ice Piedmont, using backtrajectory modeling to create time series of characteristic synoptic conditions. Through clustering and classification of these trajectories, this method enables the analysis of meteorological relationships from seasonal to decadal time scales. The data allow us to differentiate between continental/East Antarctic and oceanic/West Antarctic influences at the site and to identify likely precipitation source regions and transport pathways.

Through this reconstruction we demonstrate the distinct seasonality in synoptic conditions of the Ross Sea region. Air-mass trajectories of more oceanic origin occur $\sim 60 \%$ of the time at the GIP site and peak in frequency in the autumn and spring in synchrony with the SAO, while Continental trajectory frequencies $(\sim 40 \%)$ peak in summer. Within the Oceanic trajectory group we describe interannual oscillations in the relative frequency of RS and AS-sourced trajectories and demonstrate a correlation between their frequency and ENSO variability. During the negative phase of ENSO, a weakened ASL off West Antarctica diminishes the 
influence of the Amundsen Sea as a source region and increases the relative influence of the Ross Sea. Alternatively, during positive ENSO events, a significantly deepened ASL increases the frequency of trajectories originating from the AS and passing over West Antarctica. In contrast, we find little to no signal from the SAM in the back-trajectory reconstruction. We suggest that this is a result of the zonally symmetric nature of the geopotential anomalies associated with SAM, which do not show the differential influence across the Pacific Sector that drives the ENSO signal.

We also demonstrate the utility of trajectory cluster analysis in the interpretation of the GIP firn core geochemistry record. We find correlation between continental/Eat Antarctic-sourced trajectories and $\mathrm{NO}_{3}$ concentrations in the core at a seasonal scale. Sourced from the upper atmosphere, $\mathrm{NO}_{3}$ is transported to the site in association with air-masses descending from the high continental plateau through the Transantarctic Mountains, and thus serves as a proxy for continental air-mass input to the GIP site.

Finally, we establish the use of the $d$ excess parameter as a robust proxy for the frequency of air-mass trajectories of more oceanic origin to the ice core site. In comparison to all other trajectory classes, the Oceanic group represents more distant moisture source regions with warmer SSTs, lower relative humidity, and thus higher $d$ values. Because the Oceanic group and $d$ time series are highly correlated at seasonal and inter-annual scales, we suggest that the frequency of these oceanic-sourced air-masses is the dominant influence on the $d$ record at the site. 
Our data demonstrate the utility of back-trajectory modeling to ice core interpretation as well as the potential for using geochemical proxies to reconstruct synoptic conditions at coastal Antarctic sites. Similar synoptic reconstructions for sites of longer high-resolution ice cores could be used to develop proxies to extend our knowledge of synoptic variability in Antarctic beyond the instrumental record. There also exists tremendous potential in tying back-trajectory models to isotope models to aid the interpretation of climate records. Finally, a complete intercomparison of all available reanalysis products in conjunction with longer ice core records from several sites will provide constraint on the utility of this method and will be a focus of future work. 


\section{Chapter 5 Correlations in Trajectory Frequencies and Pressure Fields}

In this section I examine the relationship between the Oceanic group trajectory frequencies and the pressure systems of the Antarctic to provide a more in-depth exploration of ideas raised in Chapter 4. Correlations are plotted for the southern hemisphere NNR geopotential heights (between $50^{\circ}$ and $90^{\circ} \mathrm{S}$ ) and the trajectory frequencies of the Oceanic group, the Amundsen Sea (AS) subgroup, and the Ross Sea (RS) subgroup calculated in Chapter 4, using NOAA's online reanalysis plotting tool (available at http://www.esrl.noaa.gov/psd/data/correlation/). These NNR fields are a part of the same data set used as the basis for the trajectory modeling discussed above. Annual correlations (January through December) for the 1980 through 2009 period are shown in Figure 5.1. 

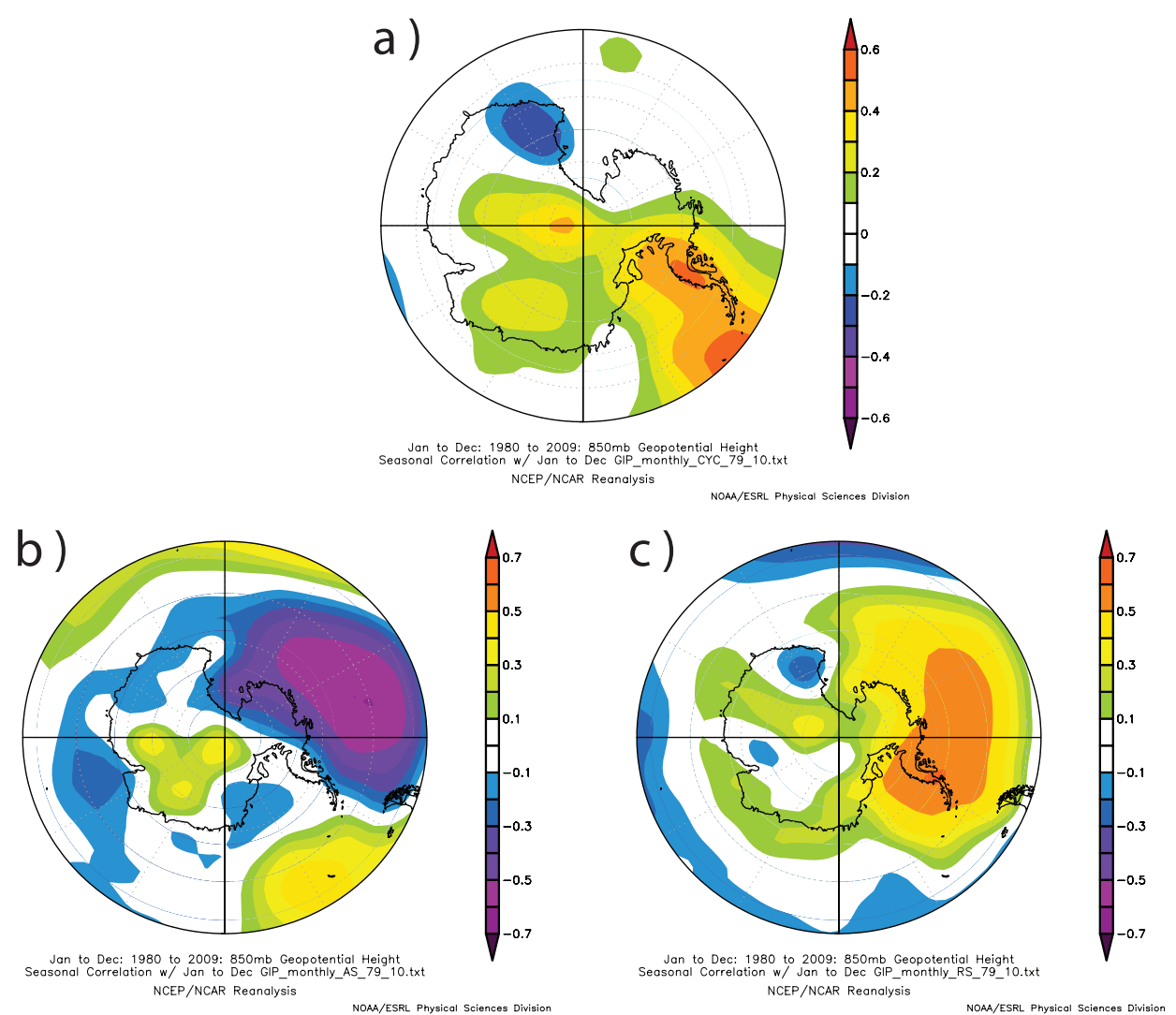

Figure 5.1 Correlations between annual (Jan-Dec) NNR $850 \mathrm{mb}$ geopotential height from 1980 through 2009 are shown for monthly a) Oceanic group, b) Amundsen Sea sub group, and c) Ross Sea sub group trajectories frequencies. Data are available at http://www.esrl.noaa.gov/psd/data/correlation/. Note the difference in scales.

The Oceanic group trajectory frequencies show little correlation to the 850 mb geopotential heights in the Ross and Amundsen Seas (Figure 5.1a). Some negative correlation is observed over northern Victoria Land, which is expected as lower geopotential height (low pressure) in this region should increase the frequency of cyclonic trajectories to the GIP site. Yet the lack of strong correlation throughout the RS and AS region is surprising. However, this result is explained by 
examining the correlations of the constituent AS and RS subgroup trajectory frequencies independently. The AS subgroup (Figure 5.1b) shows strong negative correlation throughout the Amundsen Sea, just as expected, while the RS sub group shows strong positive correlation over the ASL and negative correlation over northern Victoria Land (Figure 5.1c). Low pressures in the AS (a deeper ASL) will increase the frequency of trajectories sourced from this region arriving at the GIP site, while decreasing the frequency of RS sourced trajectories. On the other hand, high pressures in the AS will reduce the AS sourced trajectory frequency while increasing the frequency of RS sourced trajectories (possibly through a blockinghigh mechanism). This result confirms the out of phase nature of these two regions as trajectory sources to the GIP site described in Chapter 4. Additionally it explains the insignificant correlation the total Oceanic group exhibits in the region, as the total group is simply the sum of these two, out of phase sub groups.

Although the average annual correlation of the Oceanic group frequency and geopotential fields is weak, seasonal correlations over the period reveal more pronounced relationships. During summer (Figure 5.2a) strong negative correlation is observed over the Ross Sea and off northern Victoria Land. Winter (Figure 5.2c) shows a broader field of anti-correlation across the Ross Sea, the western Amundsen Sea and the New Zealand sector of the Southern Ocean. All seasons show some degree of positive correlation around the Antarctic Peninsula and the eastern Amundsen Sea. 
a)

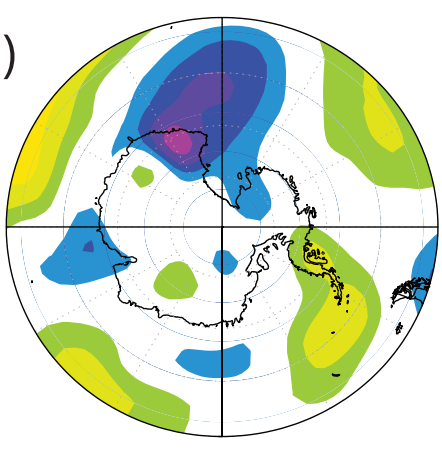

Dec to Feb: 1980 to 2009: $850 \mathrm{mb}$ Geopotentiol Height NCEP/NCAR Reanalysis NOAM/ESPL Physical Sciences Division

c)
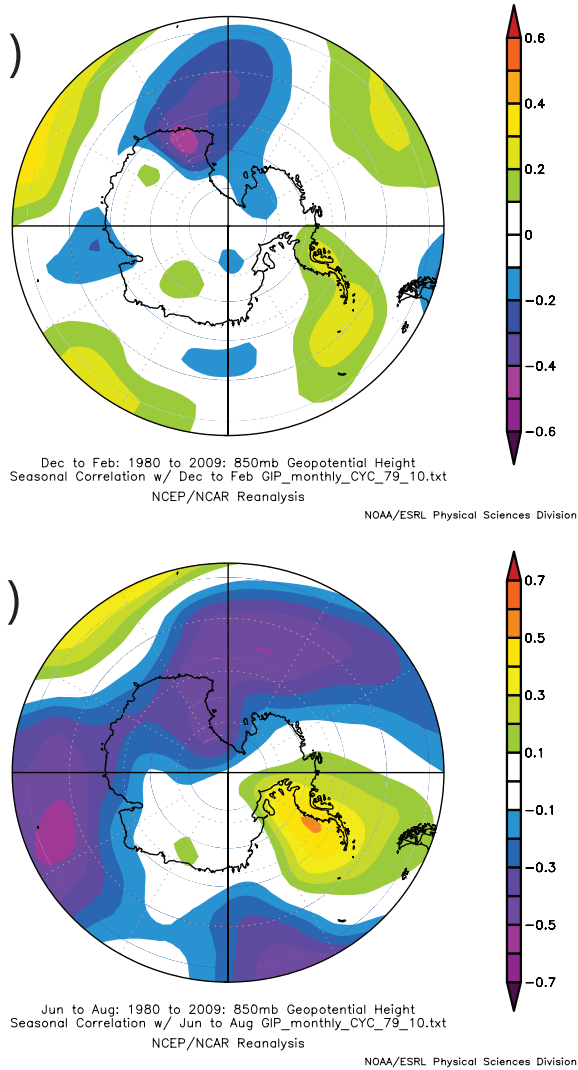

b)

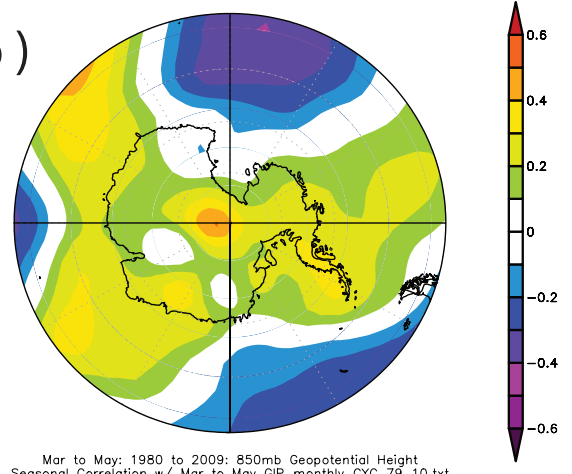

Mar to May: 1980 to 2009: $850 \mathrm{mb}$ Geopotential Height
Seasonal Correlation w/ Mar to Moy GIP_monthly_CYC_79_10.txt NOAA/ESRL Physical Sciences Division

d)

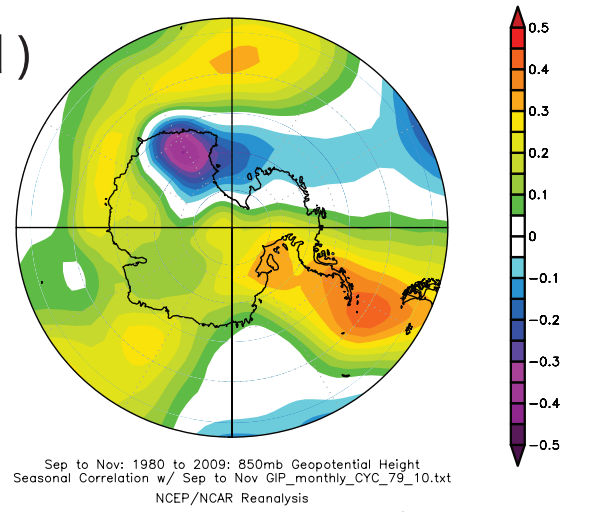

Figure 5.2 Oceanic group frequency correlations with NNR $850 \mathrm{mb}$ geopotential height from 1980 through 2009 are shown for a) summer (D J F), b) fall (M A M), c) winter (J J A), and d) spring (S O N) Data are available at http://www.esrl.noaa.gov/psd/data/correlation/. Note the difference in scales.

The dichotomy of the AS and RS source regions of GIP trajectories is further apparent in their seasonal correlations (Figures 5.3 and 5.4, respectively). The geopotential heights of the Amundsen Sea show strong negative correlation with the AS sub group frequencies (Figure 5.3) during most seasons; lower geopotential heights (pressures) in the region of the ASL are associated with increased AS sub group frequencies. This affect is least evident during summer, when AS frequencies 
are at an annual minimum, and strongest during spring, summer, and fall when AS trajectories show a broad maximum (see Figure 4.4).

a)

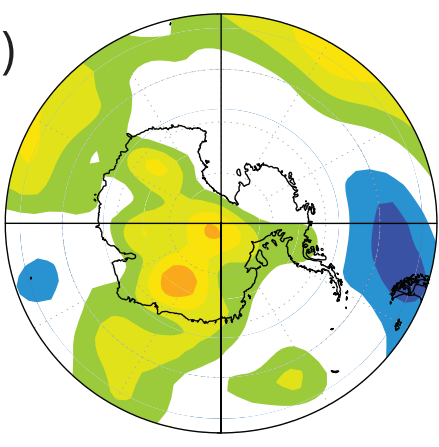

Dec to Feb: 1980 to 2009: $850 \mathrm{mb}$ Geopotentiol Height
Seasonal Correlation NCEP/NCAR Reanalysis

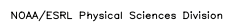

c)

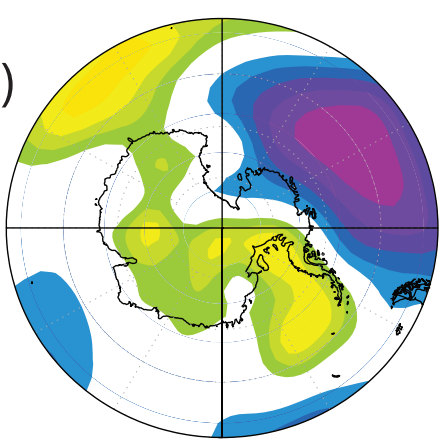

Jun to Aug: 1980 to $2009: 850 \mathrm{mb}$ Geopotential Height
Seosonal Correlation w/ Jun to Aug GIP_monthly_AS_79_10,tx

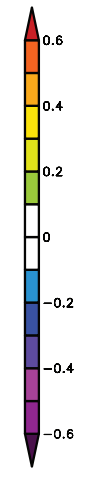

b)

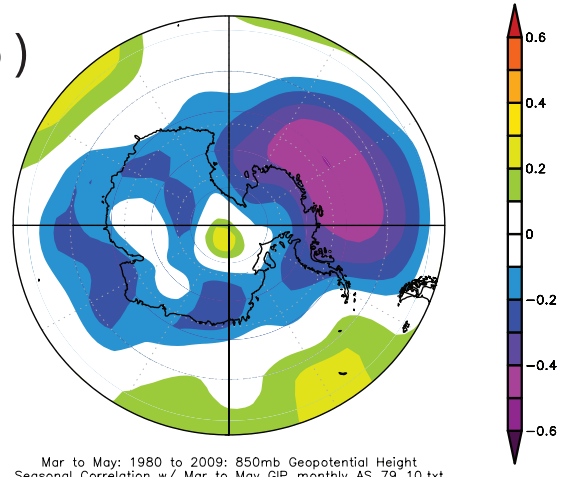

Mar to May: 1980 to $2009: 850 \mathrm{mb}$ Geopotential Height
Seasonal Correlation w/ Mar to May GIP_monthly_AS_79_10.tx NOAA/ESRL Physical Scie

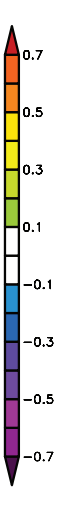

d)

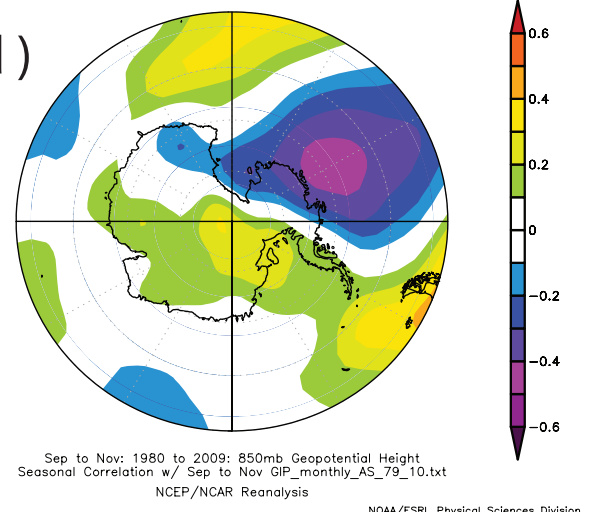

Figure 5.3 AS subgroup frequency correlations with NNR $850 \mathrm{mb}$ geopotential height from 1980 through 2009 are shown for a) summer (D J F), b) fall (M A M), c) winter (J J A), and d) spring (S ON ) Data are available at http://www.esrl.noaa.gov/psd/data/correlation/. Note the difference in scales

In contrast, the RS subgroup generally shows strong negative correlation in the Ross Sea and northern Victoria Land while exhibiting strong positive correlation in the Amundsen Sea during all seasons (Figure 5.4). The negative correlations over the Ross Sea are strongest in winter (Figure 5.4c) while the positive correlations over the Amundsen Sea peak in fall (Figure 5.4b). The RS sub groups show the weakest correlations in summer and spring (Figure 5.4a, d) when the frequency 
exhibits an annual minimum. In comparing Figures 5.3 and 5.4, it is shown that the inverse relationship between the RS and AS frequencies described above largely holds on a seasonal scale.

a)

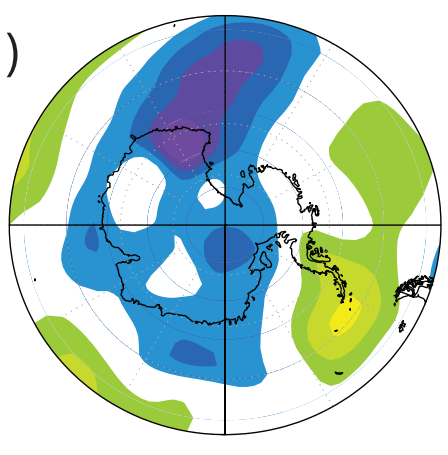

Dec to Feb: 1980 to $2009: 850 \mathrm{mb}$ Geopotentiol Height
Seosonal Correlotion w/ Dec to Feb GIP_monthly_RS_79_10.tx NCEP/NCAR Reanalysis

NOAA/ESRL Physic

c)

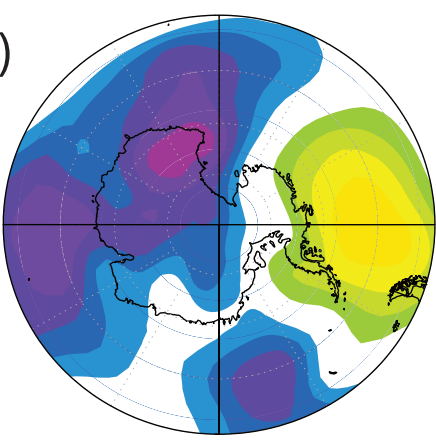

Jun to Aug: 1980 to $2009: 850 \mathrm{mb}$ Geopotential Height
Seasonal Correlation w/ Jun to Aug GIP_monthly_RS 79 - 10.txt NCEP/NCAR Reanalysis

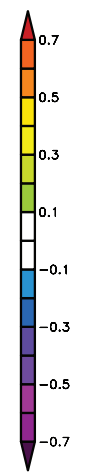

b)

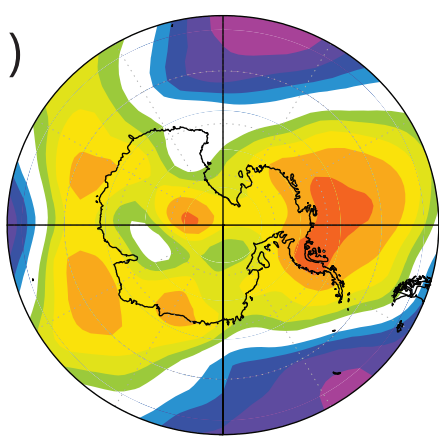

Mor to May: 1980 to $2009: 850 \mathrm{mb}$ Geopotential Height
Seosonol Correlotion w/ Mor to May GII_monthly_RS__9_ 10.tx NOAA/ESRL Physical Sciences Division

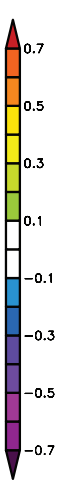

d)

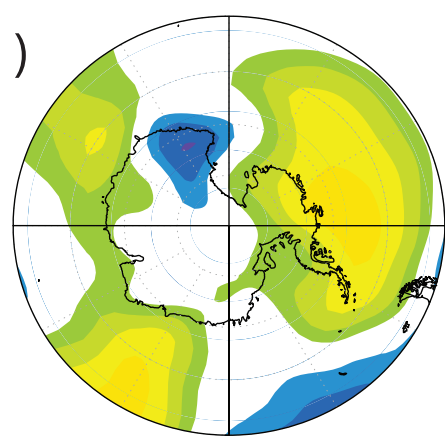

Sep to Nov: 1980 to $2009: 850 \mathrm{mb}$ Geopotentiol Height
Seasonal Correlation w/ Sep to Nov GIP_monthly_RS_79_10.txt

Figure 5.4 RS subgroup frequency correlations with NNR $850 \mathrm{mb}$ geopotential height from 1980 through 2009 are shown for a) summer (D J F), b) fall (M A M), c) winter (J J A), and d) spring (S O N) Data are available at http://www.esrl.noaa.gov/psd/data/correlation/. Note the difference in scales

This analysis illustrates a link between the pressure systems of the southern hemisphere and the trajectory source regions modeled in the synoptic reconstruction presented in Chapter 4, and confirms the robustness of this method. Additionally we see the distinctly different influence of the Amundsen and Ross Seas on the types and frequencies of trajectories arriving at the GIP site. As discussed in 
Chapter 4, it is these differing influences that may complicate the ENSO signal at the site. However, I propose here that the method of synoptic reconstruction described in Chapter 4 could be used to select and assess sites that may record a desired signal such as ENSO.

\section{Chapter 6 Conclusions}

In this thesis I have identified dominant characteristics of synoptic variability in the Ross Sea region of Antarctica and examined the influences of ENSO and SAM in modulating that variability. I have reconstructed the synoptic history of an ice core site in the region through back-trajectory analysis and examined its relationship to decadal climate oscillaitons. Finally, I analyzed a shallow firn core from the Gawn Ice Piedmont to develop proxy records for this synoptic variability.

The Amundsen Sea Low is an important climatological feature in the Antarctic. Because of its dominant control on the cyclonic activity of the region, variability in the ASL can be recorded in ice cores from the Pacific Sector. Greater understanding of the influence of decadal climate oscillations such as ENSO and SAM on the ASL could lead to extended records of these powerful oscillations. In Chapter 3, I show that a simple linear combination of ENSO and SAM indices can explain a large amount of the variance in the ASL between 1980 and 2010. The SAM is shown to be generally dominant around the Southern Hemisphere, as expected, while ENSO is solely influential in the Pacific sector, peaking in importance in the Amundsen and 
Ross Sea regions. At annual timescales, those potentially resolvable in ice core records, the amount of variance in the ASL explained by ENSO approaches that explained by SAM.

The phases of ENSO and SAM are shown to have similar impact on the strength of the ASL. The negative phases of each oscillation cause significant deepening of the ASL off West Antarctica, while the positive phases show a weakening of the low. Additionally, the positive phase of ENSO is associated with negative pressure anomalies in the Ross Sea, representing a westward shift of the low.

Through back-trajectory and cluster analysis of the last 30 years (Chapter 4), the GIP site is shown to exemplify the competing climatic influences that characterize Antarctica as a whole; oceanic cyclones and continental katabatic drainage. I identify these two dominant groups within the 11,131 back-trajectories modeled to the GIP site, and distinguish several important sub-groups and classes within those broader groups. Distinct seasonal and decadal variability at the site is shown; oceanic frequency peaks in April while trajectories from continental sources are greatest in frequency during December.

The Ross and Amundsen Sea source regions are shown to have distinctly different behavior and variability. The frequencies of trajectories originating from these two source regions are directly linked to their pressure systems, which, as shown above, are strongly influenced by decadal oscillations. ENSO in particular is demonstrated to modulate the relative frequencies of cyclones from the Ross and 
Amundsen Seas. This influence is explained through ENSO's impact on the position and intensity of the ASL and pressure anomalies in the Ross Sea investigated in Chapter 3. During La Niña events, a deeper ASL causes more frequent AS sourced cyclones, while during El Niño events, a weaker ASL and low-pressure anomalies over the Ross Sea cause more frequent RS sourced cyclones. Thus these two source regions show opposite signs of correlation with the ENSO (Chapter 5).

It is interesting that the joint ENSO-SAM forcing of the ASL described in Chapter 3 does not appear to significantly modulate the frequency of trajectory types at the GIP site. ENSO is shown to be associated with an oscillation of lowpressure centers between the Amundsen Sea (positive phase) and Ross Sea (negative phase). While the pressure anomalies associated with SAM are similar to that of ENSO around the ASL, they are different and indistinct within the Ross Sea. I suggest that the ENSO-driven oscillation between these two source regions dominates the cyclonic signal at the GIP site and overrides any affects of SAM's modulation of the ASL. Sites more directly connected to the ASL, beyond the influence of Ross Sea pressure systems may better record the ENSO-SAM interaction.

The GIP reconnaissance firn core is interpreted in association with the backtrajectory reconstruction to establish geochemical proxies of synoptic activity at the site. High correlation is shown between the frequency of Continental trajectories and the timing of $\mathrm{NO}_{3}, \mathrm{SO}_{4}$, and MS peaks within the core. On the other hand, the correlation of Continental trajectories with $\mathrm{MS}$ and $\mathrm{SO}_{4}$ represents the very strong 
seasonal cycle of these species rather than a relationship to transport. In contrast, the correlation with $\mathrm{NO}_{3}$ is suggested to be a direct result of direct transport to the site from upper atmosphere sources. Thus we suggest the use of $\mathrm{NO}_{3}$ as a proxy for the seasonal influence of continental air-mass input to sites along the Southern Victoria Land Coast.

The $d$ excess record is established as a robust and consistent proxy for total oceanic cyclone influence at seasonal and decadal scales. The frequency of cyclonic events, in contrast to other synoptic controls and moisture sources, is the dominant control on $d$ values in the record, representing an integration of seasonal and multiyear changes in source region SSTs and $h$.

Several promising courses for future research are proposed from this study. Firstly, the GIP record suggests that the 2004 dust storm event in the McMurdo Sound area may represent an opportunity to investigate relationships between biogeochemical processes in the Ross Sea and regional atmospheric dynamics (Appendix 5).

Secondly, although the GIP record is of insufficient length to establish robust geochemical proxies of decadal climate oscillations, a clear ENSO signal is indentified in the 30-year synoptic reconstruction. The method of trajectory and reconstruction established here, in combination with ice core analysis, can be used to identify and assess other ice core sites for their ability to record decadal climate oscillations or other desired signals. The application of a precipitation-weighted filter based on reanalysis precipitation fields could improve its utility at lower 
accumulation sites and is also a promising course for further research. Furthermore, the establishment of the $d$ excess/cyclone frequency proxy is likely extendable to other coastal Antarctic ice core sites with sufficiently high accumulation. I suggest that sites in West Antarctica may exhibit an unfiltered dependence of cyclonic frequency on the strength of the ASL due to their removal from the compounding influences of the Ross Sea described above. Thus they may provide unique records of ENSO and SAM variability and interaction. 


\section{Chapter 7 Appendices}

\subsection{Appendix 1. ICP-MS Data and Analysis}

In this appendix I present a brief discussion of data obtained from ICP-MS analysis not addressed elsewhere. All data are shown in Table 7-1 (attached CDROM: Appendix 1/ICPMS_IC_Data/All Data). Detection limits and melter blank background concentrations are shown in Tables 7-2 and 7-3 (attached CD-ROM: Appendix 1/ICPMS_IC_Data/Detection Limits, Melter Blanks), respectively. As discussed in Chapter 2, Mg concentrations are plotted against $\mathrm{Na}$ concentrations and shown in Figure 7.1. Four samples, GIP_025, 030, 215, and 400) were found to plot strongly off the mean ocean line of $\mathrm{Mg} / \mathrm{Na}=0.1198 \mathrm{~g} \mathrm{~g}^{-1}$ [Wilson, 1975]. These samples showed anomalously high, single-point spikes in the concentration of many species. Neighboring archived samples, GIP_024, 029, 214, and 399, were measured to assess the continuity of these peaks. The new data do not show these anomalous concentrations or $\mathrm{Mg} / \mathrm{Na}$ values as seen in Figure 6.1, confirming the single-point nature of these peaks. This suggests either contamination or the presence of particles not fully dissolved during acidification. These data were removed from further analysis. 


\section{Mg vs Na \\ ICP-MS}

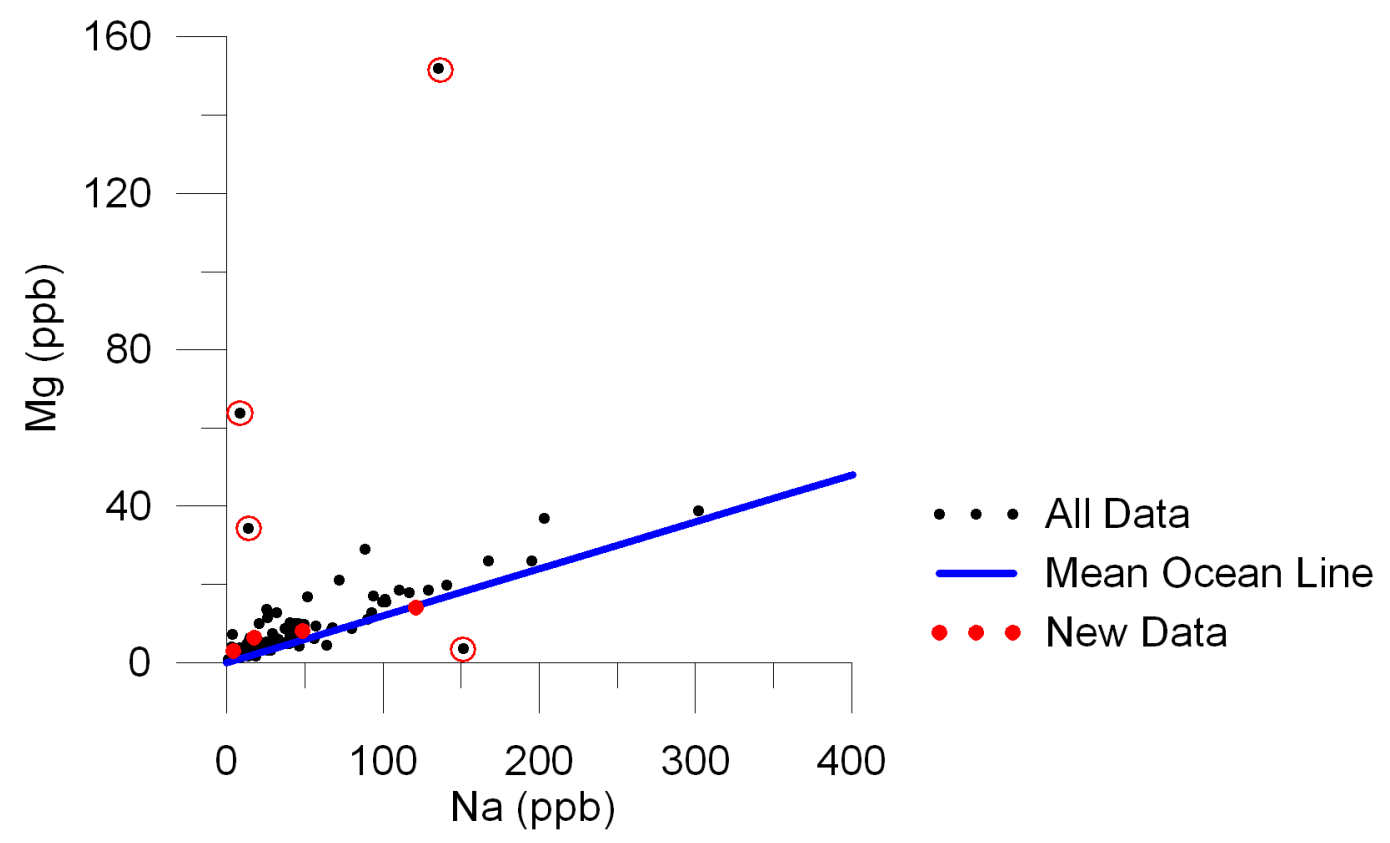

Figure 7.1 Concentrations of Mg are plotted against $\mathrm{Na}$, as measured by ICP-MS, for all data. The blue line indicates the mean seawater ratio of $\mathrm{Mg}$ to $\mathrm{Na}$. Data samples suspected of contamination are shown as black dots surrounded by red circles, plotting well off the mean seawater line. Samples neighboring the suspected samples were then measured ("New Data", shown in red dots) and are shown to plot closer to the mean water line, similar to the rest of the data.

Comparison of ICP-MS and IC results for $\mathrm{Ca}, \mathrm{Mg}$, and $\mathrm{Na}$ are shown in Figure 7.2. Concentrations of $\mathrm{Mg}$ and $\mathrm{Na}$ measured on both systems show very consistent variability and values, with the exception of the four samples mentioned above and two samples, GIP_170 and 485, that show anomalously high values in the IC measurement. With these data removed the $\mathrm{Na}$ and $\mathrm{Mg}$ data between the two measurement techniques show correlation coefficients of 0.995 and 0.897 , respectively. The mean differences between concentrations for each sample were $1.02 \mathrm{ppb}$ for $\mathrm{Na}$ and $0.80 \mathrm{ppb}$ for $\mathrm{Mg}$. 


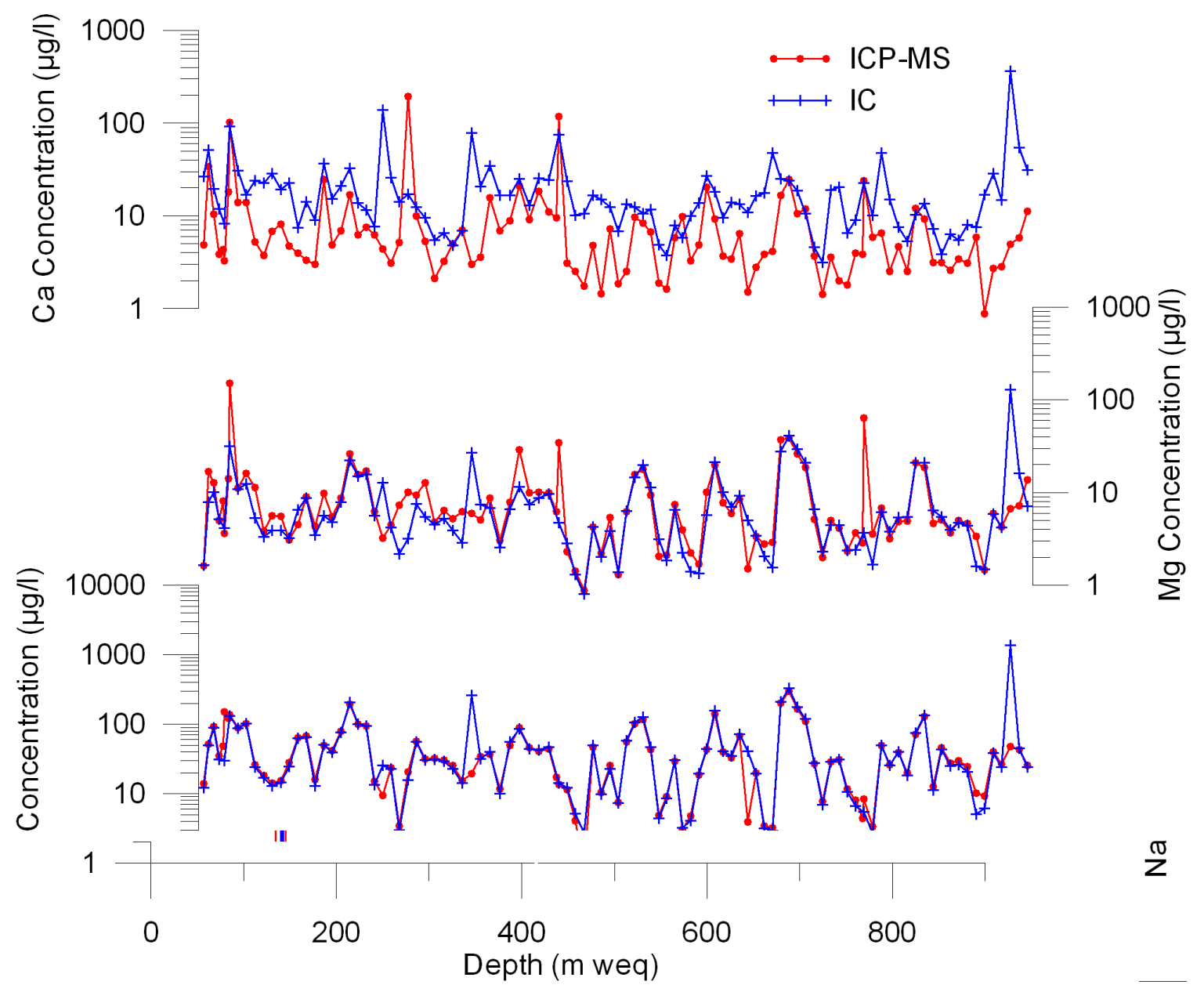

Figure 7.2 Values of Ca, Mg, and Na measured by both ICP-MS (red) and IC (blue) for identical samples are plotted against core depth (meters of water equivalent). Concentrations are plotted on a log scale, to highlight outliers.

Concentrations of Ca from the two measurement techniques differ considerably with a mean difference between concentrations for each sample of $25.1 \mathrm{ppb}$ and a correlation coefficient of 0.08. MilliQ blanks were run through the continuous melter system during core sampling and show especially high background Ca values with a mean of $4.33 \mathrm{ppb}$, or $\sim 40 \%$ of the mean concentration measured in all samples, an order of magnitude larger than for Mg or Na (see Table 7-3). This may indicate some Ca contamination in the melter line. Yet the difference 
between the two measurement methods is surprising, as Ca detection limits for the ICP-MS were comparable to those of other species (Table 7-3). Additional tests are necessary to identify the cause of the anomalously high background values and the difference between measurement techniques. However, since Ca data were not an important data set for this study, and in light of the time constraints of the laboratory, I excluded the values from the interpretation and suggest that future studies using the continuous melter line should test for Ca contamination before commencing the processing of samples.

A cross correlation matrix for all ICP-MS and IC data is shown in Figure 7.3. The strong relationship between Mg and Na values of the two measurement techniques is evident. Furthermore distinct groups of correlation are seen, for example $\mathrm{Mg}, \mathrm{Na}, \mathrm{Cl}$, and $\mathrm{Sr}$ are all well correlated. These relationships are further examined through principle component analysis (PCA). The first PC (Figure 7.4), which represents $43.6 \%$ of the total variance, has strong loading for many species while the second PC (15.6\% of the variance) shows loading of dominant marine species, $\mathrm{Mg}, \mathrm{Na}, \mathrm{Cl}, \mathrm{Sr}$, and $\mathrm{Tl}$. The next two principle components make up 10.2 and 7.5\% of total variance, respectively. By plotting the loadings of PC 1 against PC 2 (Figure 7.5) the relationship between the species is readily visible. Marine species $(\mathrm{Cl}, \mathrm{Mg}, \mathrm{Na}, \mathrm{Sr}$, and $\mathrm{Tl})$ plot in the upper right quadrant, with strong loadings of both PC 1 and 2. MS is seen to plot independently, the only species showing negative loadings in both components. Trace elements plot cohesively in high first component, and negative in the second component loads. A sub-group of species, 
$\mathrm{SO}_{4}, \mathrm{NO}_{3}, \mathrm{Zr}, \mathrm{Ca}, \mathrm{Bi}$, and $\mathrm{Pb}$, plot cohesively with weak first component, negative second component loadings. As described in Chapter $4, \mathrm{SO}_{4}$ and $\mathrm{NO}_{3}$ are associated with Continental trajectory classes. It is reasonable to expect elements characteristic of terrestrial rocks to be associated with Continental trajectories at the core site. However, the relationship is inconsistent as evidenced by the low correlation coefficients of, for example, $\mathrm{NO}_{3}$ and $\mathrm{Pb}$. We find little correspondence between our trajectory cluster frequencies and the times series of PCs or geochemical concentrations other than those discussed in Chapter 4. For example, the total Cyclonic frequency and PC 2 (associated with marine species) show no significant correlation. This may point to event-driven signals in the chemistry data, the importance of dry deposition for some species, or other factors. 


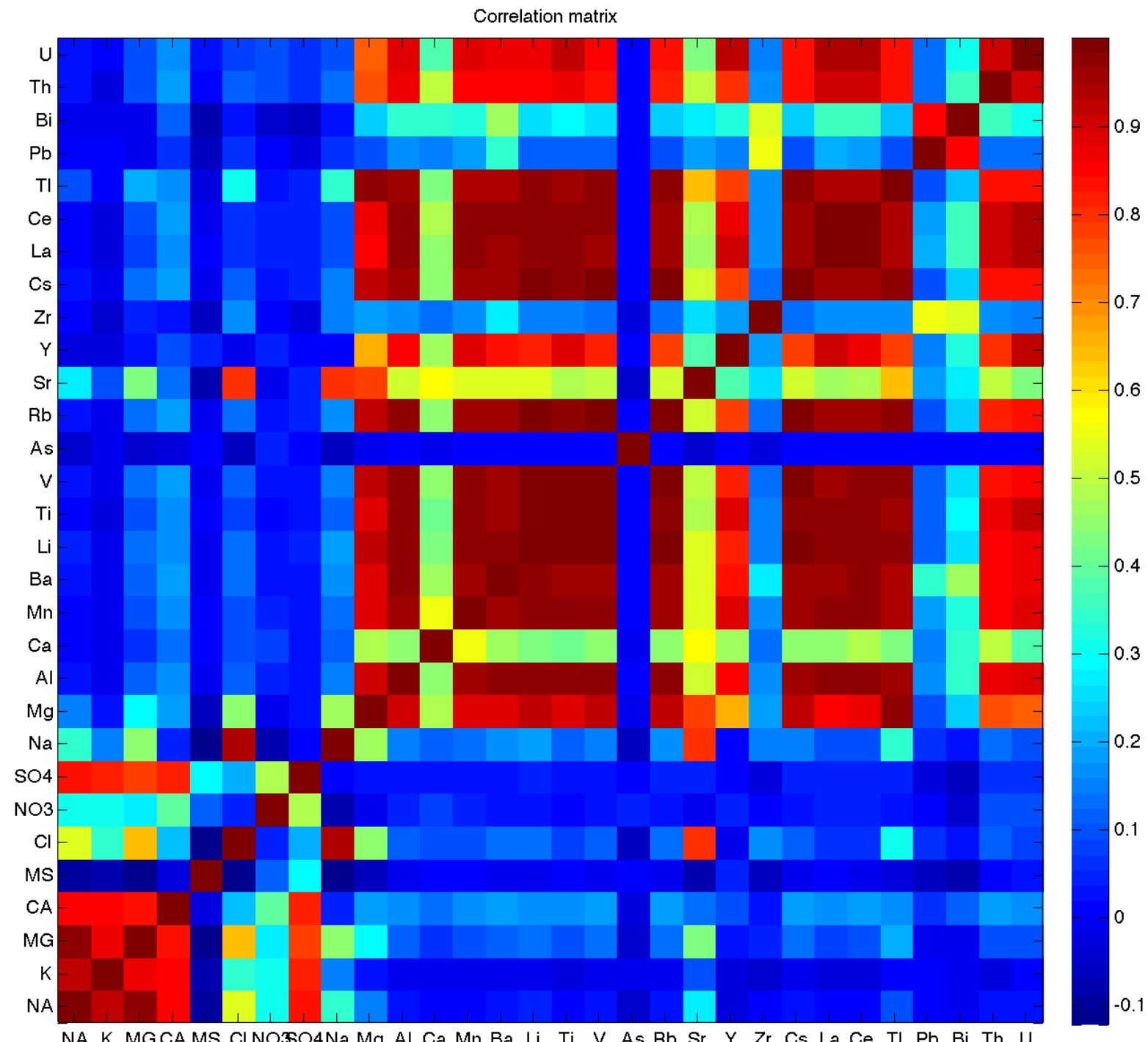

Figure 7.3 A cross correlation matrix is shown of all geochemistry concentrations. "NA", "MG", "CA" are concentrations measured by IC, as opposed to "Na" "Mg" and "Ca" measured by ICP-MS. Correlations along the $\mathrm{Y}$-axis are read in the rows below the labels, $\mathrm{X}$-axis correlations in the column to the right of the labels. 

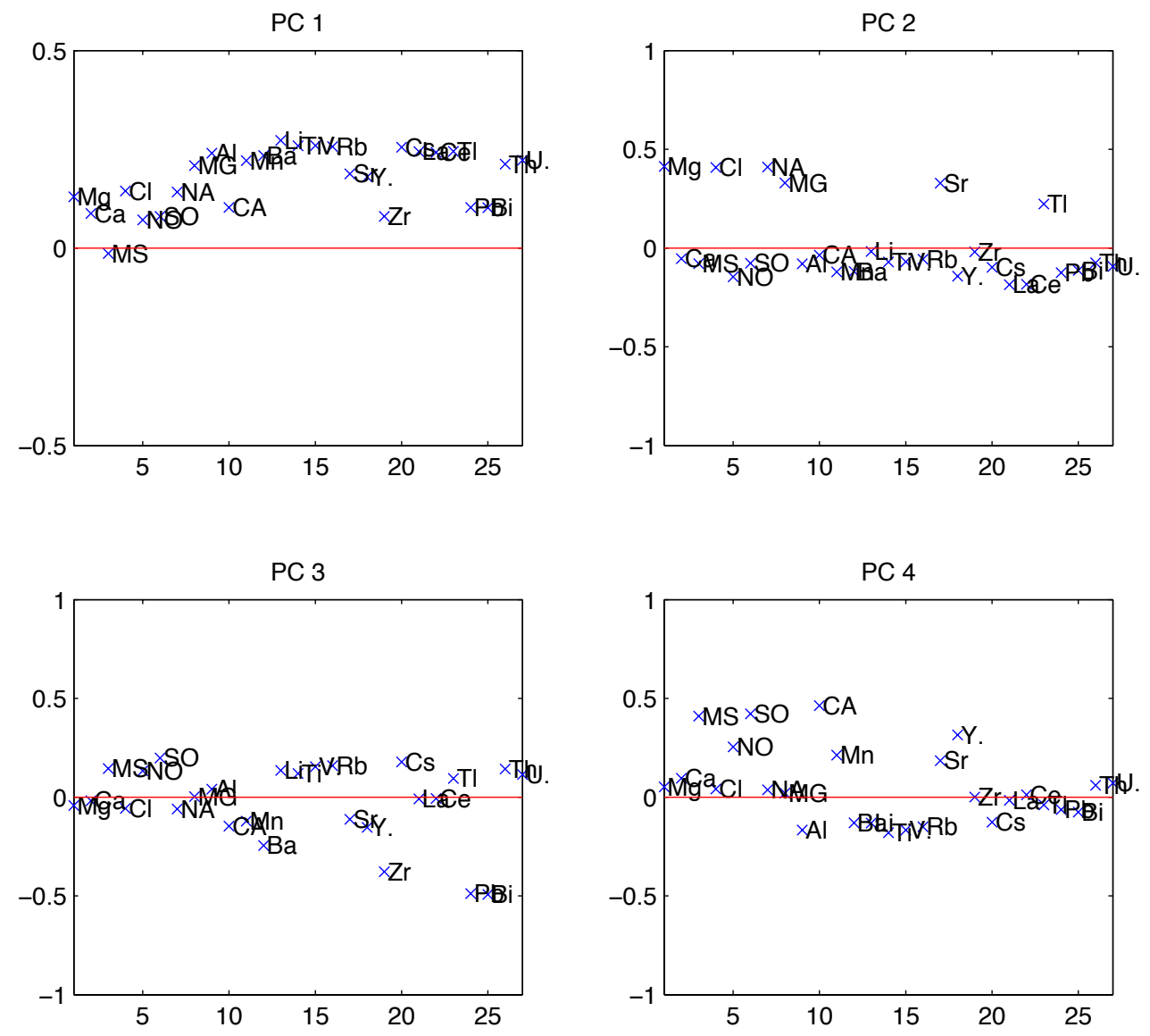

Figure 7.4 Loadings, by element, are shown for the first four principle components, representing in total $77 \%$ of the total variance. 


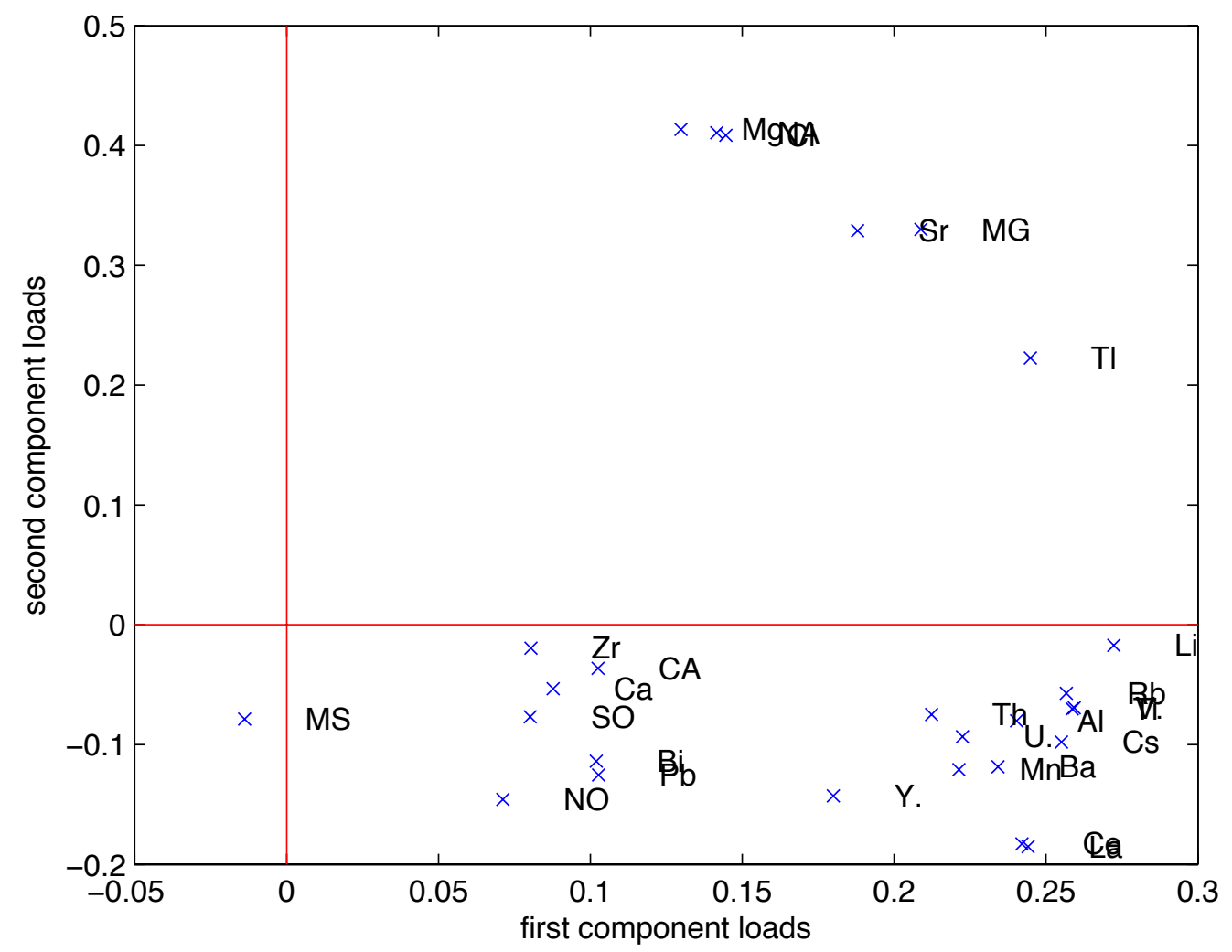

Figure 7.5 The loadings of PC 2 against PC 1 are shown for all elements. Note the distinct clustering of species into coherent groups.

\section{Appendix 1 Tables}

Due to file size, all data are made available in attached CD-ROM.

Table 7-1 Geochemistry data. All chemistry data is shown by sample. Age is based on the age model described in Chapter 2.

Table 7-2 Detection Limits. ICP-MS detection limits are shown for all species in all samples.

Table 7-3 Melter Blanks. Background concentrations are presented for MilliQ blanks that were passed through the entire core sampling process and melter system. 


\subsection{Appendix 2. Comparison of Weather Station and Reanalysis Data in the Ross Sea Region}

In this section a brief comparison is presented of NCEP/NCAR reanalysis data (NCEP) and available AWS data for the Skinner Saddle (SKS, $\left.80.9^{\circ} \mathrm{S}, 159.5^{\circ} \mathrm{E}\right)$ and Evans Piedmont Glacier (EPG, $76.7^{\circ} \mathrm{S}, 162.6^{\circ} \mathrm{E}$ ) ice core sites, both in the Ross Sea Region of Antarctica. In Figure 7.6 the monthly NCEP and AWS temperatures for both sites from October 2007 to December 2008 are shown. Both sites show similar month-to-month variability, which is well captured by the NCEP data although the NCEP data underestimates the absolute temperatures. This is likely due to the fact that surface NCEP reanalysis fields are for approximately $5 \mathrm{mb}$ above the surface, which is generally above than the standard $3 \mathrm{~m}$ height of AWS stations. However, we conclude that the NCEP data perform satisfactorily in representing local variability in the region over the time period studied.

Although no transfer functions for $\delta^{18} 0$ to temperature were developed due to the lack of a local, multi-year weather station record, $\delta^{18} 0$ are plotted along side NCEP temperature for the GIP and SKS [Bertler, pers. comm., 2011] ice core sites between 2000 and 2008 (Figure 7.7). Also shown is a comparison of NCEP temperature for EPG and the available AWS temperature records for both the SKS and EPG sites. Time series are arranged North (top) to South (bottom) from EPG to SKS. Both the SKS and GIP oxygen records show muted signals before 2004, and the GIP site shows consistently lower $\delta^{18} 0$ values in winter than the SKS site. All sites show similar variability in NCEP records. 

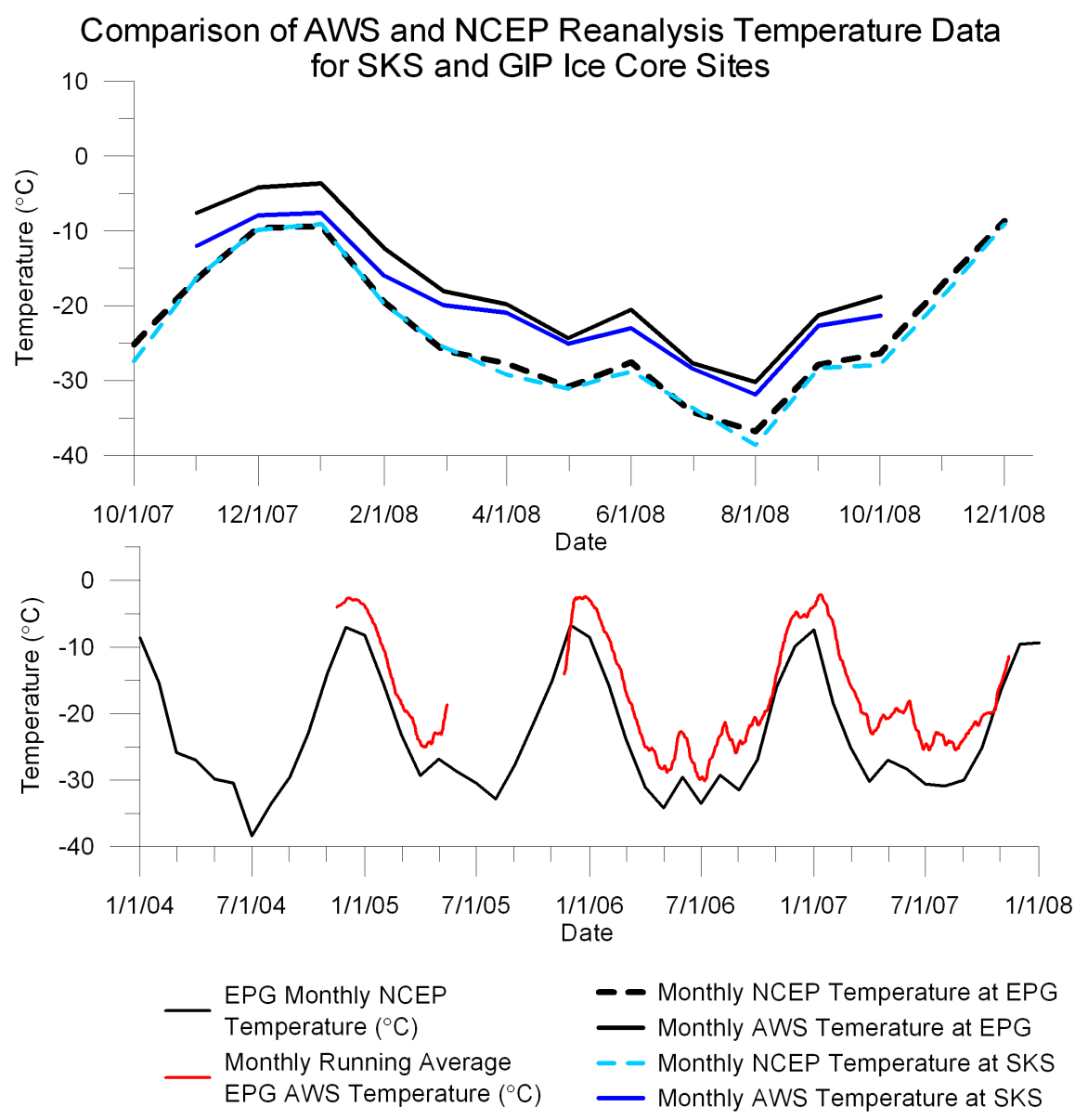

Figure 7.6 Comparison of AWS and NCEP temperature for the SKS and EPG ice core sites. NCEP data are available from NASA's Earth System Research Laboratory, Physical Sciences Division (http://www.esrl.noaa.gov/psd/data). 

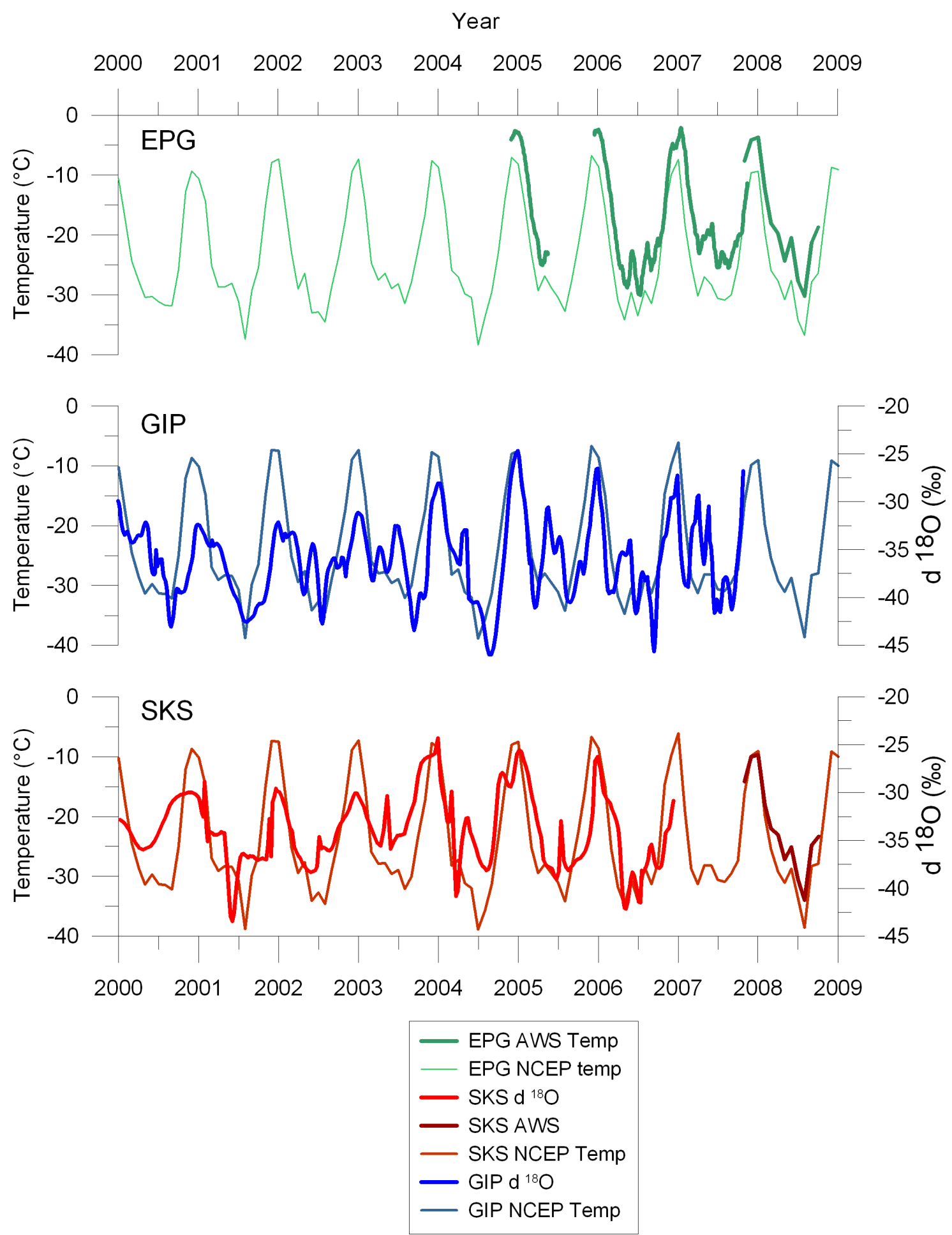

Figure 7.7 Comparison of $\delta^{18} 0$, NCEP temperature, and AWS temperature (where applicable) between the EPG, GIP, and SKS ice core site in the Ross Sea Region Antarctica. The data show an acceptable agreement between recorded temperature and $\delta^{18} 0$, suggestive that a longer record from GIP could be used to reconstruct the temperature history of the region. 


\subsection{Appendix 3. Complete Trajectory and Cluster Analysis Plots}

Due to file size limitations all plots and data are made available in the attached CD_ROM.

Plots are provided showing all trajectories within each cluster for the 19802010 reconstruction [see attached data cd: Appendix_3/1980-2010) and the 20002008 reconstruction [see attached data cd: Appendix_3/2000-2008). Clusters are labeled by class as described in Chapter 4 .

\subsection{Appendix 4. Intercomparison of HySPLIT Results from Different Reanalysis Products}

Work for this section was completed with the help of Dr. Kate Sinclair and assistance from Dr. Dan Zwartz at GNS Science and Victoria University of Wellington, respectively.

In this appendix I give additional information regarding the intercomparison of NCEP/NCAR , ERA-40, and ERA-Interim (ERA-Int) reanalysis products as input meteorology for the NOAA HySPLIT back-trajectory model, that was not possible to include in the published manuscript comprising Chapter 4. At the time of this analysis NCEP/NCAR represented the only reanalysis product to consistently cover the entire period under study. Although biases do exist in the NCEP/NCAR reanalysis, correlations to station pressure records are above 0.9 after 1979 [Bromwich et al., 2007]. Further more, in comparing pressure records of several reanalysis products at points over the Southern Ocean and the Antarctic interior, Bromwich et al. [2007] found them all to capture the same inter-annual to decadal 
variability. Bromwich et al. [2011] do show differences in cyclone tracking results between the reanalysis products, though I interpret these as difference between reanalyses rather than errors within just one product, as all of them suffer from a lack of data in the region with which to ground-truth their "correctness".

While a full comparison of NCEP/NCAR and ERA Interim-based trajectory reconstructions is beyond the scope of this thesis, I have conducted case studies of two individual years, 1990 and 2000, comparing NCEP/NCAR, ERA-Interim, and ERA-40 as described in the text in Chapter 4. In general I find good agreement between the different reanalysis products. At the Group scale, I find difference in the total annual frequencies of less than $10 \%$ between NCEP/NCAR and either of the other two products and similar results at the sub-group scale as shown in Table 4-2. In general better agreement is seen between NCEP/NCAR and ERA-Int than between NCEP/NCAR and ERA-40 or ERA-40 and ERA-Int (See Table 4-2). Additionally I found consistent cluster means between all reanalyses and all years (Figure 7.8). I also find consistent monthly frequencies across the reanalyses, again with NCEP/NCAR and ERA-Int showing the strongest similarity (Figure 7.9 and 7.10). 

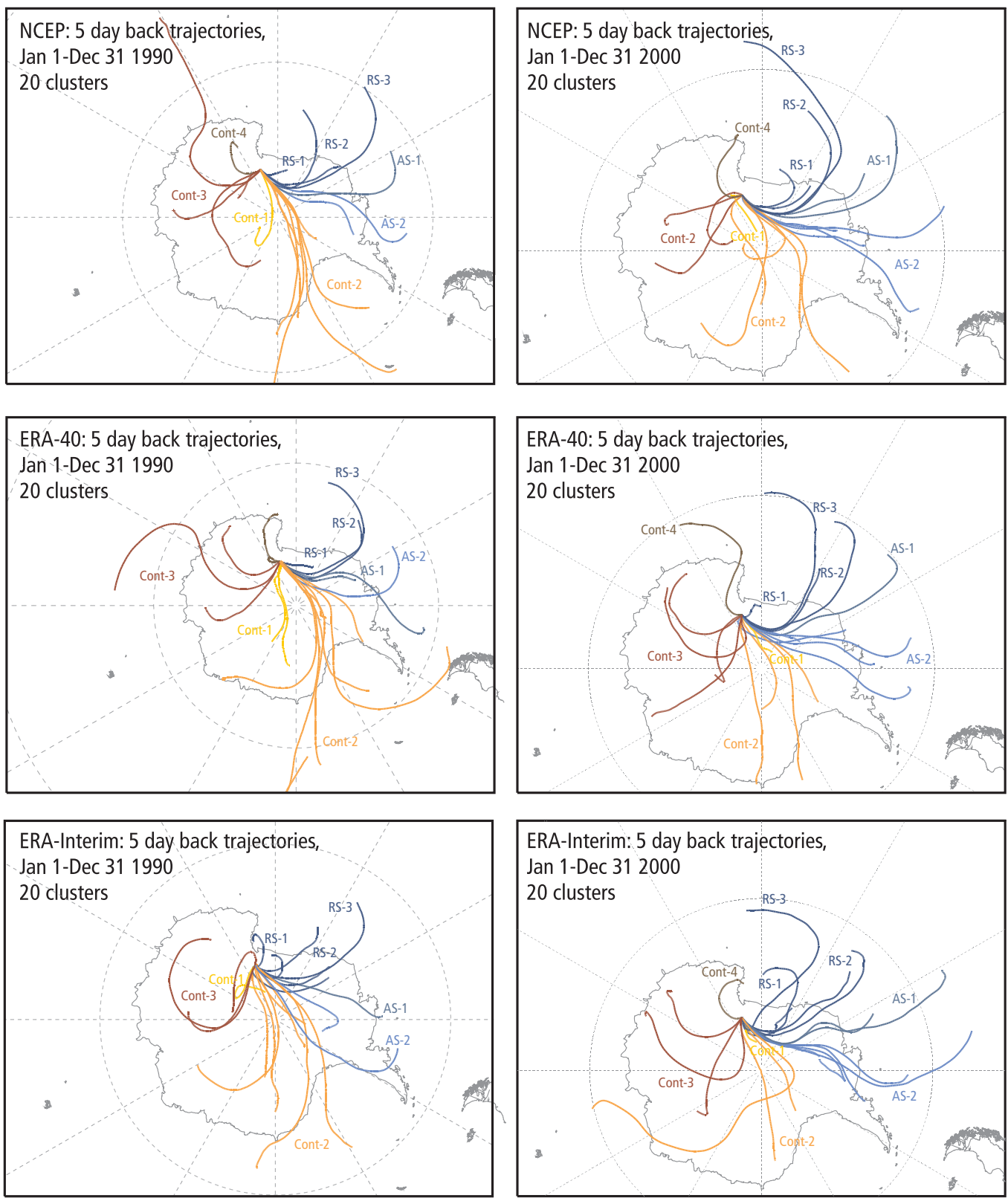

Figure 7.8 Comparison of cluster means for cluster analysis of daily back-trajectories for 1990 and 2000 based on NCEP/NCAR, ERA-40, and ERA-Interim reanalysis data. 

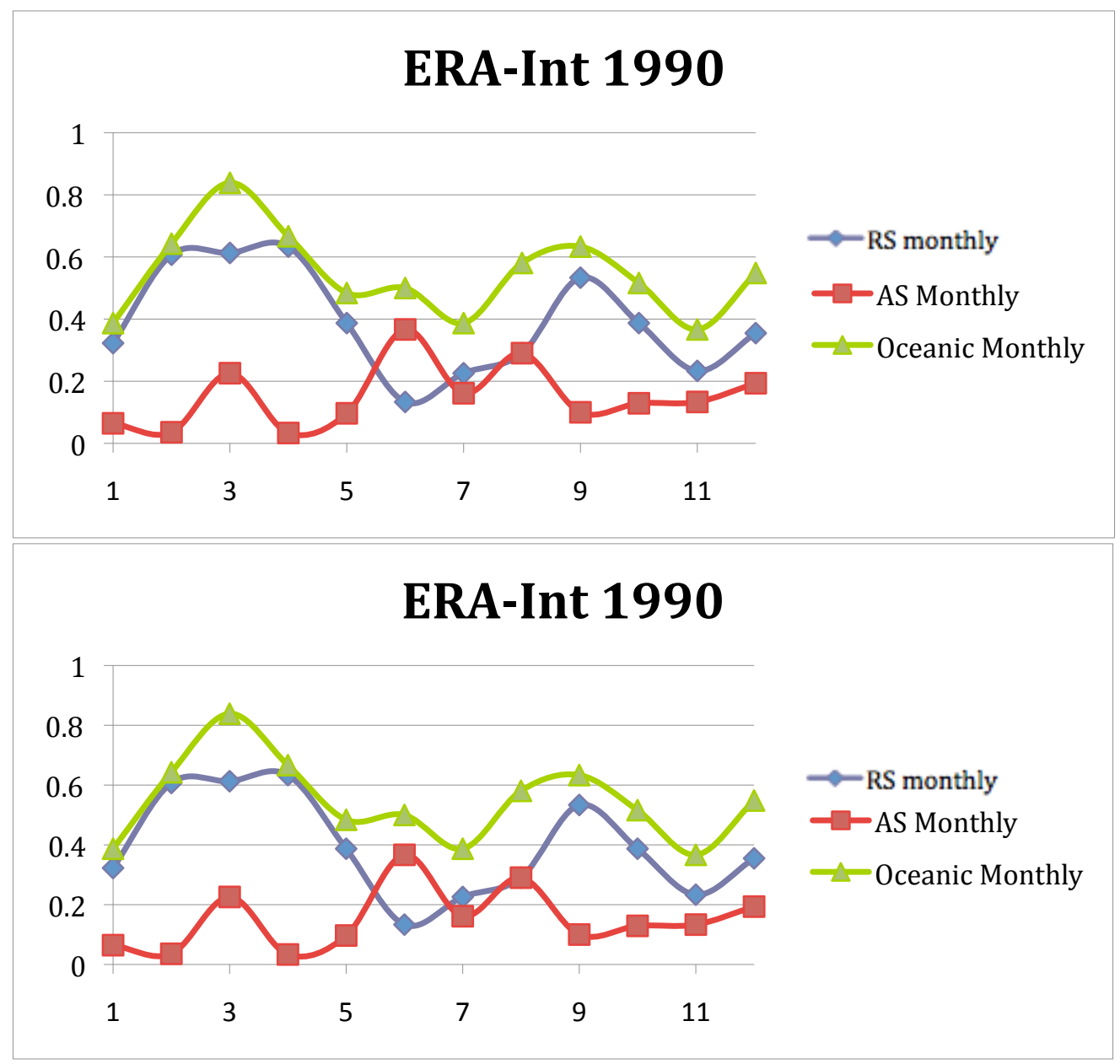


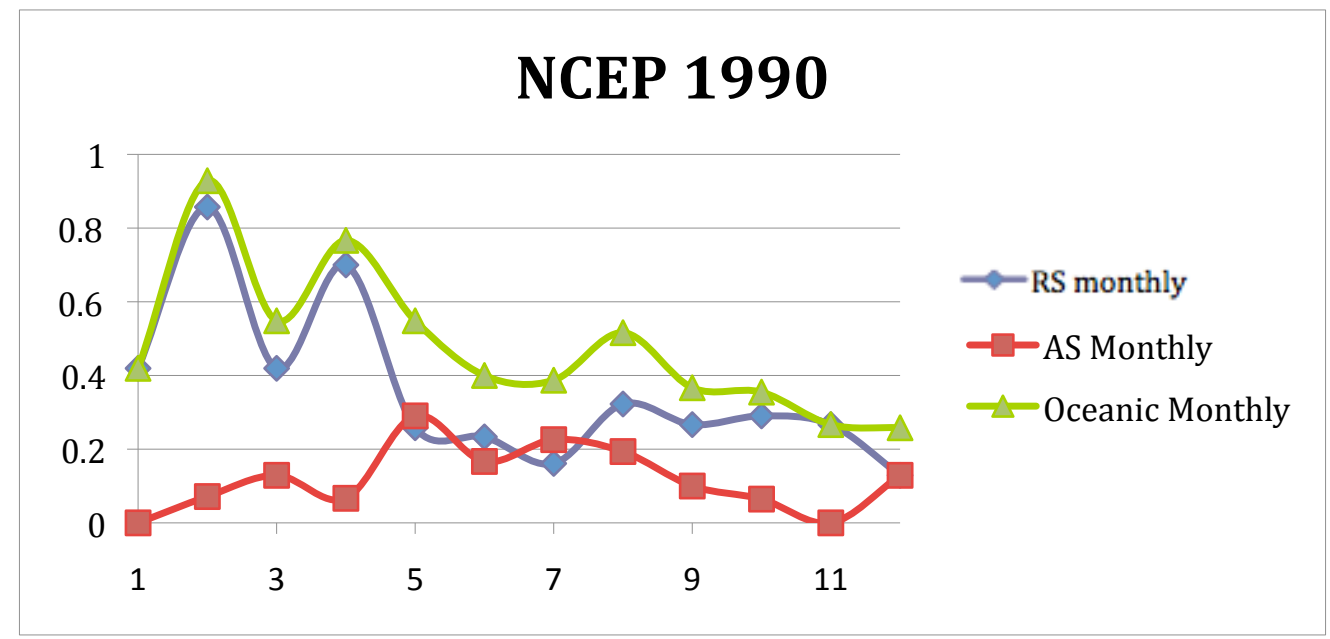

Figure 7.9 Graphs showing the Oceanic Group (green), and RS (blue) and AS (red) sub-group monthly frequencies for each reanalysis product for 2000 . Y-axis shows frequency from 0 to $100 \%$, and $\mathrm{X}$-axis shows the numerical month (i.e. January $=1$ ).

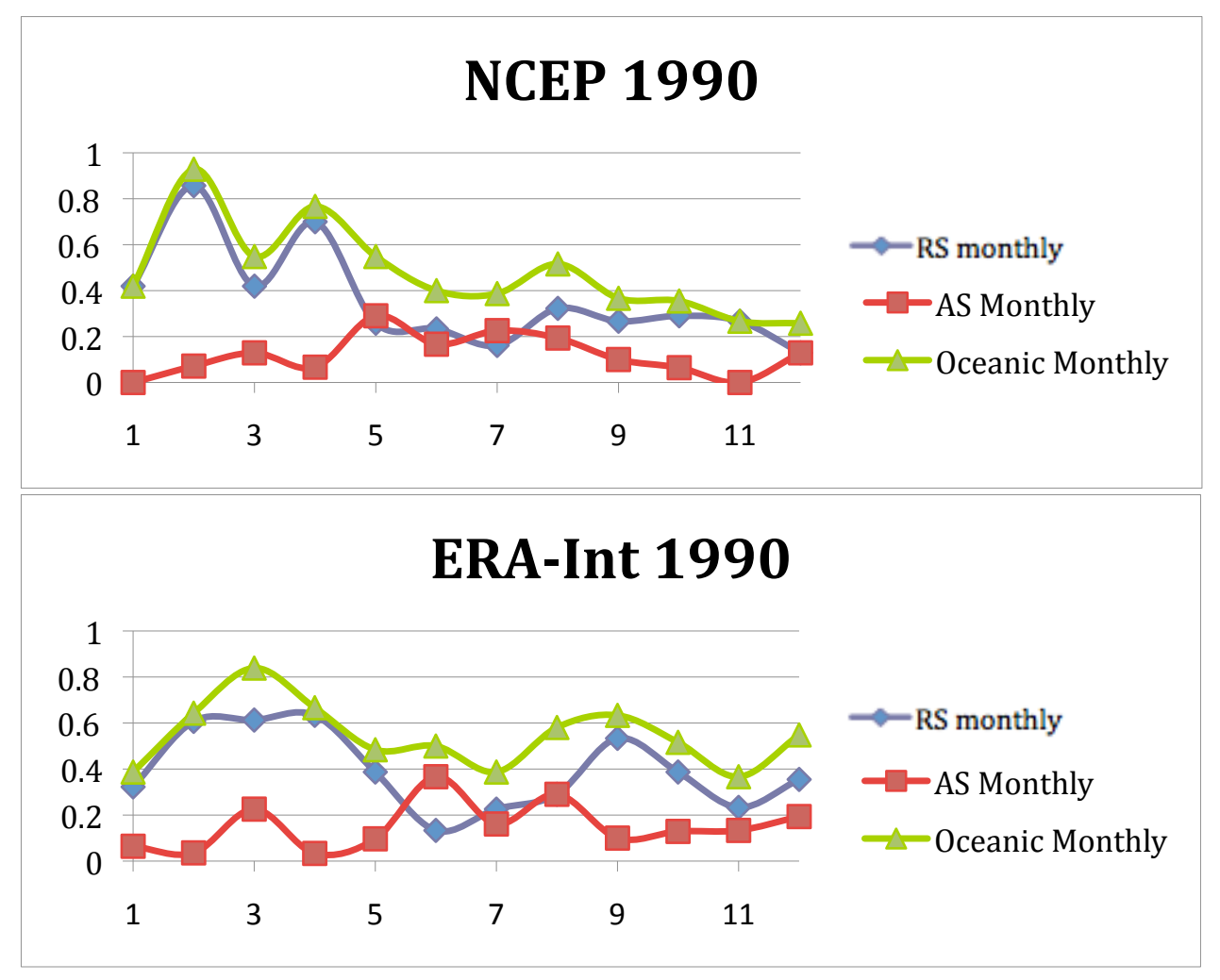



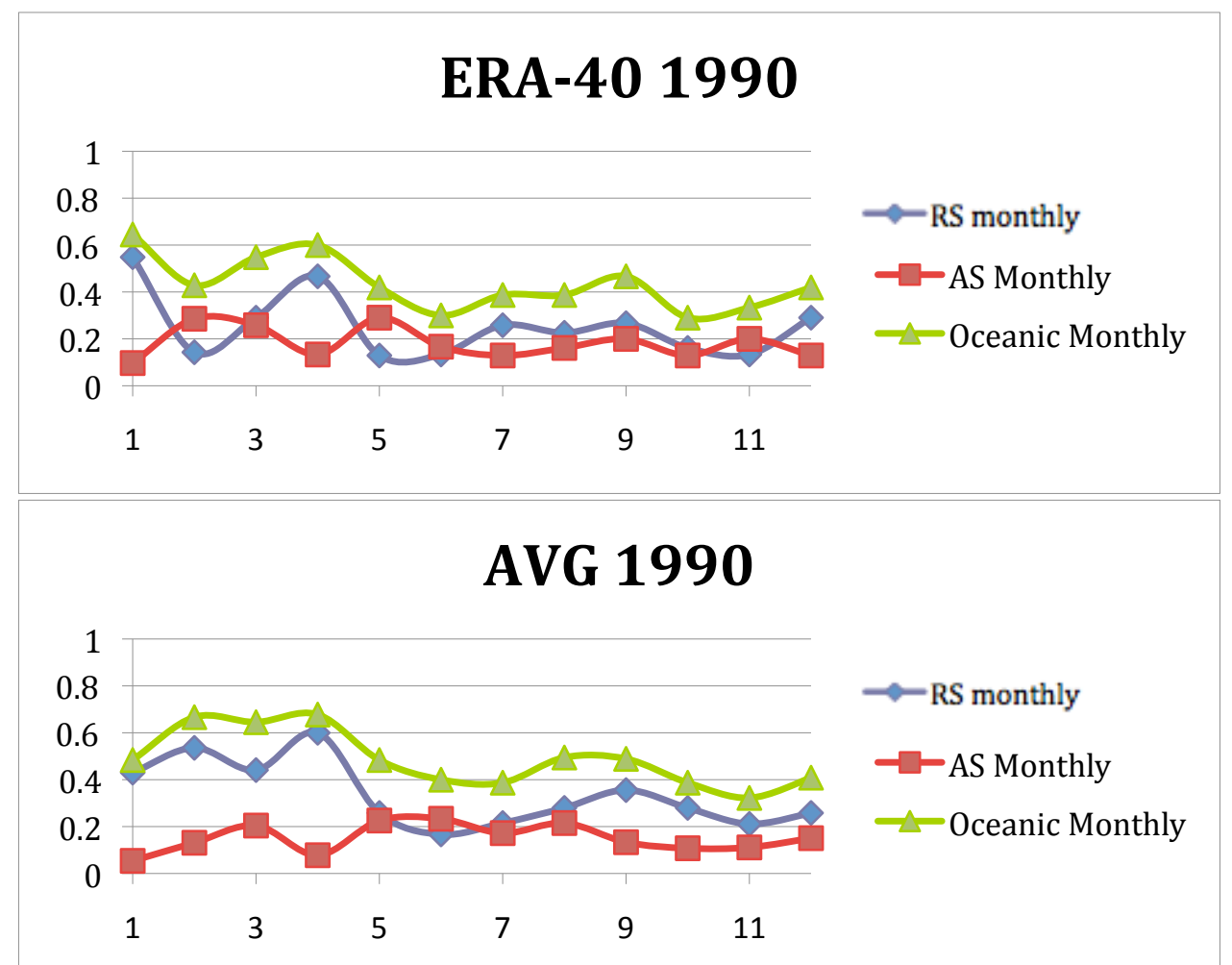

Figure 7.10 Graphs showing the Oceanic Group, and RS and AS sub-group monthly frequencies for each reanalysis product for the year 1990 The average of all three reanalyses for 1990 is also shown. $\mathrm{Y}$-axis shows frequency from 0 to $100 \%$, and $\mathrm{X}$-axis shows the numerical month (i.e. January $=1$ ).

The results of these case studies suggest that back-trajectory and cluster analysis results obtained form NCEP/NCAR are consistent with both those from ERA-reanalysis products, and ERA-Interim in particular. I do not think that the error introduced by the choice of reanalysis product, less than $10 \%$ of total annual group frequency, would substantially change the analysis presented here or the overall conclusions of Chapter 4. Thus as NCEP/NCAR represents the most consistent reanalysis product available for the time period of study, it is confidently employed in this study. Again, while a full comparison of the different reanalyses is beyond the scope of this thesis, such a study would be extremely interesting and will be a focus of future work. 


\subsection{Appendix 5. McMurdo Sound Dust Storm Event and Potential Biogeochemical Links to the GIP Record}

As noted in Section 4.2.5, a strong storm event affected the McMurdo Sound regions in May 2004 [Steinhoff et al., 2008] and was responsible for a higher than average dust flux in the area [Dunbar et al., 2009]. The following summer (2004/05), anomalously large spikes in $\mathrm{MS}$ and $\mathrm{nssSO}_{4}$ concentrations are observed in the GIP ice core record. Both of these records show striking similarity to a record of dust flux in the McMurdo Sound area, as shown in Figure 7.11, with large, simultaneous peaks in 2005 and 2007 (dust flux data provided by Holly Winton, personal communication). A barrier wind, with speeds in excess of $30 \mathrm{~m} \mathrm{~s}^{-1}$ formed in association with the 2004 event along the boundary of Transantarctic Mountains and the Ross Ice Shelf. It is possible that wind scour in association with this event is responsible for the lowest annual accumulation observed in the GIP record during 2004 (Figure 4.9).

Both MS and $\mathrm{nsSO}_{4}$ are products of oxidation of dimethylsulphide which is produced by marine algae and phytoplankton [Saltzman et al., 1983]. Additionally, while MS has a single source in the Antarctic, $\mathrm{SO}_{4}$ can be sourced from continental lithhologies (e.g. $\mathrm{CaSO}_{4}$ ) or from the atmospheric oxidation of $\mathrm{SO}_{2}$ which may either be volcanic or anthropogenic in origin [Legrand and Mayewski, 1997]. The strong correlation of the GIP MS and nssSO 4 records $(r=0.87, \mathrm{p}<0.001)$ suggests that biogenic processes dominate the nssSO4 signal, although some continental input 
associated with katabatic flow through the Transantarctic Mountains cannot be ruled out.

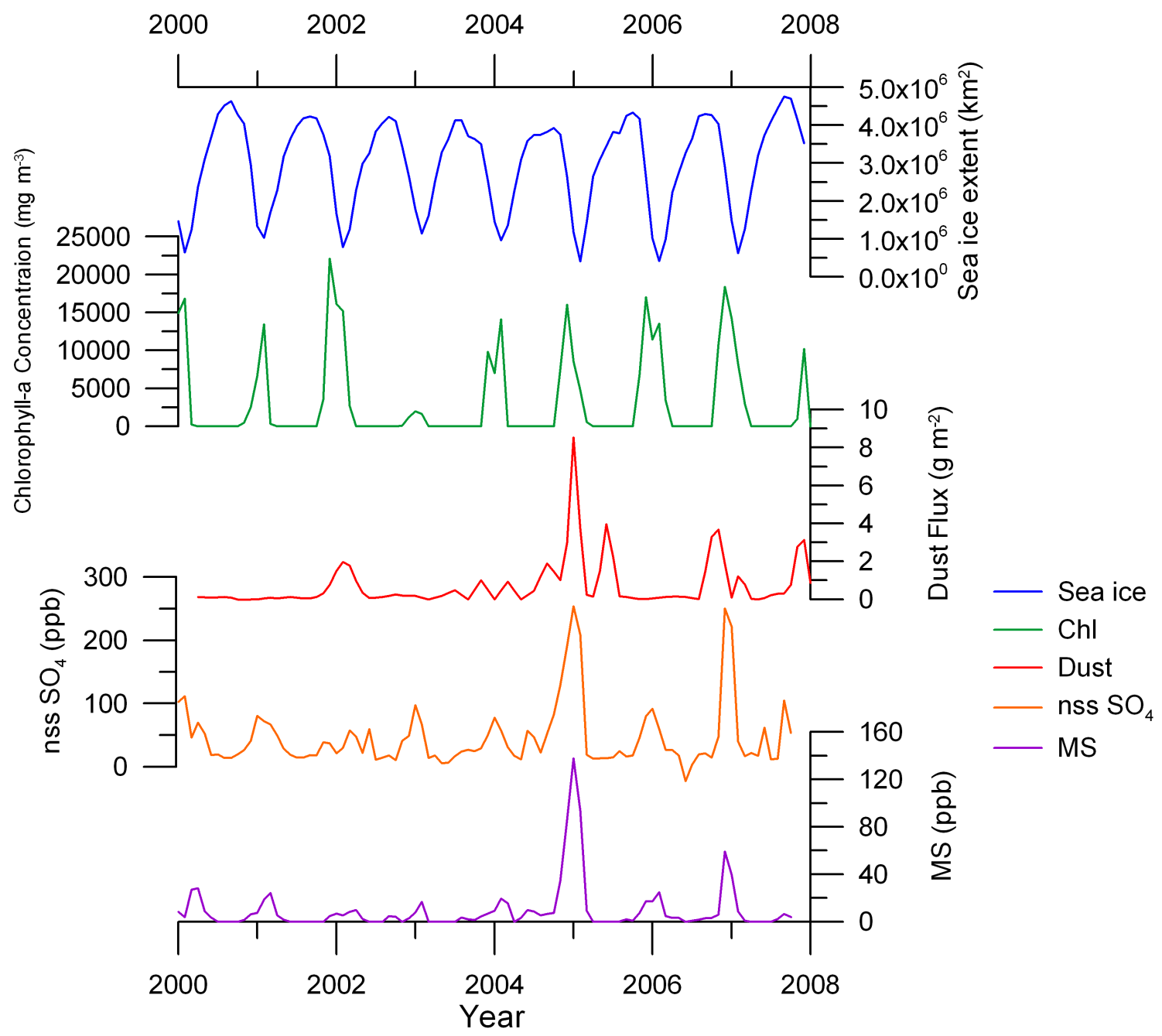

Figure 7.11 From top to bottom: A comparison of Ross Sea sea ice extent (from the NSIDC sea ice index data base), Chlorophyll- $\alpha$ concentration from the McMurdo Sound polynya region from the SEA-WiFS program, McMurdo Sound dust flux concentration [Winton, personal communication], GIP nss $\mathrm{SO}_{4}$, and GIP MS records.

Available open water in the Ross Sea limits primary production during the austral summer and for this reason MS and $\mathrm{nsSSO}_{4}$ have been used as proxies for sea ice extent in Antarctica [Abram et al., 2007; Dixon et al., 2004; R. H. Rhodes et al., 
2009]. In Figure 7.11, I compare sea ice extent of the Ross Sea (data available from the National Snow and Ice Data Center,

http://nsidc.colorado.edu/data/seaice index/), Chlorophyll- $\alpha$ concentration from the McMurdo Sound polynya area, an indicator of primary production (data from the SeaWiFS program, provided by Holly Winton, personal communication), and the GIP MS and nssSO 4 records. All records show the expected seasonal cycle of summer minima in sea ice extent and maxima in Chlorophyll, MS, and $\mathrm{nssSO}_{4}$ concentrations.

However the strong correlation between the MS (and nssSO ${ }_{4}$ ) and dust flux records $(r=0.68, p<0.001)$ are not exclusively seasonally driven. I propose that enhanced iron fertilization associated with large dust fluxes (exemplified by the 2004 event) increases primary production in the Ross Sea, and thus MS and nssSO ${ }_{4}$ production. The fact that affects of the 2004 event can be seen at GIP, some $600 \mathrm{~km}$ south of McMurdo Sound suggests that this storm could provide an excellent opportunity to study iron fertilization in the Ross Sea, in particular with a highresolution ice core record closer to the edge of the Ross Ice Shelf. Chlorophyll- $\alpha$ concentrations for the McMurdo Sound polynya area (Figure 7.11) do not show abnormal values for this time, however trajectory analysis (see Chapter 4) suggests that Chlorophyll- $\alpha$ concentrations from the whole Ross Sea may be more influential at the GIP site than just from the McMurdo polynya. Additionally, other factors may influence the relationship between Chlorophyll, MS, and primary production and are beyond the scope of this study. However, this connection represents a promising 
avenue for further research and could provide insights to the biogeochemical

processes of the Ross Sea region and their connection to atmospheric dynamics. 


\section{References}

Abram, N. J., R. Mulvaney, E. W. Wolff, and M. Mudelsee (2007), Ice core records as sea ice proxies: an evaluation from the Weddell Sea region of Antarctica, Journal of Geophysical Research, 112, doi:10.1029/2006JD008139.

Arblaster, J. M., and G. A. Meehl (2006), Contributions of External Forcings to Southern Annular Mode Trends, Journal of Climate, 19, 2896-2904,

Basher, R. (1998), The 1997/98 El Nino event : Impacts, responses and outlook for New Zealand, edited by S. a. T. N.Z. Ministry of Research, Ministry of Research, Science and Technology, Wellington.

Bertler, N. A. N. (2008), Intermediate Science Report to Antarctica New ZealandRep., $12 \mathrm{pp}$, Antarctica New Zealand.

Bertler, N. A. N. (2011), Cold conditions in Antarctica during the Little Ice Age Implications for abrupt climate change mechanisms, Earth Planet Sc Lett, doi:doi:10.1016/j.epsl.2011.05.021.

Bertler, N. A. N., T. R. Naish, P. A. Mayewski, and P. J. Barrett (2006a), Opposing oceanic and atmospheric ENSO influences on the Ross Sea Region, Antarctica, Advances in Geosciences, 6, 83-86,

Bertler, N. A. N., P. J. Barrett, P. A. Mayewski, R. L. Fogt, K. J. Kreutz, and J. Shulmeister (2004), El Nino suppresses Aantarctic warming, Geophys Res Lett, 31(15),

Bertler, N. A. N., T. R. Naish, H. Oerter, S. Kipfstuhl, P. J. Barrett, P. A. Mayewski, and K. Kreutz (2006b), The effects of joint ENSO-Antarctic Oscillation forcing on the McMurdo Dry Valleys, Antarctica, Antarct Sci, 18(4), 507-514, doi:0.1017/S0954102006000551.

Bertler, N. A. N., et al. (2005), Snow chemistry across Antarctica, Annals of Glaciology, 41, 167-179,

Boning, C. W., A. Dispert, M. Visbeck, S. R. Rintoul, and F. U. Schwarzkopf (2008), The response of the Antarctic Circumpolar Current to recent climate change, Nature Geosci, 1(12), 864-869, doi:http://www.nature.com/ngeo/journal/v1/n12/suppinfo/ngeo362 S1.ht $\underline{\mathrm{ml}}$.

Bretherton, C. S., M. Widmann, V. P. Dymnikov, J. M. Wallace, and I. Blad $\sqrt{ }\left({ }^{1}\right.$ (1999), The Effective Number of Spatial Degrees of Freedom of a Time-Varying Field, Journal Of Climate, 12(7), 1990-2009, doi:10.1175/15200442(1999)012<1990:tenosd>2.0.co;2.

Breusch, T. S., and A. R. Pagan (1979), A Simple Test for Heteroscedasticity and Random Coefficient Variation, Econometrica, 47(5), 1287-1294,

Broecker, W. S. (1997), Thermohaline Circulation, the Achilles Heel of Our Climate System: Will Man-Made CO2 Upset the Current Balance?, Science, 278(5343), 1582-1588, doi:10.1126/science.278.5343.1582. 
Bromwich, D. H. (1991), Mesoscale Cyclogenesis over the Southwestern Ross Sea Linked to Strong Katabatic Winds, Mon Weather Rev, 119(7), 1736-1752,

Bromwich, D. H., and R. L. Fogt (2004), Strong Trends In The Skill Of The Era-40 And Ncep/ Ncar Reanalyses In The High And Middle Latitudes Of The Southern Hemisphere, 1958-2001, Journal of Climate, 17(23), 4603-4619, doi:10.1175/3241.1.

Bromwich, D. H., J. P. Nicolas, and A. J. Monaghan (2011), An Assessment of Precipitation Changes over Antarctica and the Southern Ocean since 1989 in Contemporary Global Reanalyses, Journal Of Climate, 24(16), 4189-4209, doi:10.1175/2011jcli4074.1.

Bromwich, D. H., R. L. Fogt, K. I. Hodges, and J. E. Walsh (2007), A tropospheric assessment of the ERA-40, NCEP, and JRA-25 global reanalyses in the polar regions, J. Geophys. Res., 112(D10), D10111, doi:10.1029/2006jd007859.

Bromwich, D. H., A. N. Rogers, P. Kallberg, R. I. Cullather, J. W. C. White, and K. J. Kreutz (2000), ECMWF analyses and reanalyses depiction of ENSO signal in antarctic precipitation, Journal of Climate, 13(8), 1406-1420,

Cai, W. J., and I. G. Watterson (2002), Modes of interannual variability of the southern hemisphere circulation simulated by the CSIRO climate model, Journal of Climate, 15(10), 1159-1174,

Carleton, A. M. (2003), Atmospheric teleconnections involving the Southern Ocean, J Geophys Res-Atmos, 108(C4), doi:10.1029/2000JC000379.

Carleton, A. M., and M. Fitch (1993), Synoptic Aspects of Antarctic Mesocyclones, J. Geophys. Res., 98(D7), 12997-13018, doi:10.1029/92jd02132.

Carrasco, J. F., and D. H. Bromwich (1994), Climatological Aspects of Mesoscale Cyclogenesis over the Ross Sea and Ross Ice Shelf Regions of Antarctica, Mon Weather Rev, 122(11), 2405-2425,

Carrasco, J. F., D. H. Bromwich, and A. J. Monaghan (2003), Distribution and characteristics of mesoscale cyclones in the Antarctic: Ross Sea eastward to the Weddell Sea, Mon Weather Rev, 131(2), 289-301,

Chen, B., S. R. Smith, and D. H. Bromwich (1996), Evolution of the Tropospheric Split Jet over the South Pacific Ocean during the 1986,Äìg ENSO Cycle, Mon Weather Rev, 124(8), 1711-1731, doi:doi:10.1175/1520-0493(1996)124.

Christiansen, B. (2007), Atmospheric circulation regimes: Can cluster analysis provide the number?, Journal of Climate, 20, 2229-2250,

Ciais, P., and J. Jouzel (1994), Deuterium and Oxygen-18 in Precipitation - Isotopic Model, Including Mixed Cloud Processes, J Geophys Res-Atmos, 99(D8), 16793-16803,

Dansgaard, W. (1964), Stable Isotopes in Precipitation, Tellus, 16(4), 436-468,

Delmotte, M., V. Masson, J. Jouzel, and V. I. Morgan (2000), A seasonal deuterium excess signal at Law Dome, coastal eastern Antarctica: A southern ocean signature, J. Geophys. Res., 105(D6), 7187-7197, doi:10.1029/1999jd901085.

Diaz, H., and V. Markgraf (Eds.) (1992), El Niño: Historical and Palaeoclimatic Aspects of the Southern Oscillation, Cambridge University Press, Cambridge. 
Dixon, D., P. A. Mayewski, S. Kaspari, and M. Handley (2004), A 200 year sub--annual record of sulfate in West Antarctica, from 16 ice cores, Annals of Glaciology, 39, 545-556,

Dixon, D., P. A. Mayewski, I. Goodwin, G. J. Marshall, K. A. Freeman, K. A. Maasch, and S. Sneed (2011), An ice-core proxy for northerly air mass incursions into West Antarctica, International Journal of Climatology, doi:10.1002/joc.2371.

Doran, P. T., et al. (2002), Antarctic climate cooling and terrestrial ecosystem response, Nature, 415(6871), 517-520,

Dorling, S. R., and T. D. Davies (1995), Extending Cluster-Analysis - Synoptic Meteorology Links to Characterize Chemical Climates at 6 Northwest European Monitoring Stations, Atmos Environ, 29(2), 145-167,

Dorling, S. R., T. D. Davies, and C. E. Pierce (1992), Cluster-Analysis - a Technique for Estimating the Synoptic Meteorological Controls on Air and Precipitation Chemistry - Method and Applications, Atmos Environ a-Gen, 26(14), 25752581,

Draxler, R. R. (1999), HYSPLIT4 user's guide, edited by NOAA, NOAA Technical Memo, Silver Spring, MD.

Draxler, R. R., and G. D. Hess (1998), An overview of the HYSPLIT_4 modeling system of trajectories, dispersion, and deposition, Australian Meteorology Magazine, 47, 295-208,

Dunbar, G. B., N. A. N. Bertler, and R. M. Mackay (2009), Sediment flux through the Mcmurdo Ice Shelf in Windless Bight, Antarctica. Global and Planetary Change, Global Planet Change, 69(3), doi:doi:10.1016/j.gloplacha.2009.05.007.

Fereday, D. R., J. R. Knight, A. A. Scaife, C. K. Folland, and A. Philipp (2008), Cluster Analysis of North Atlantic-European Circulation Types and Links with Tropical Pacific Sea Surface Temperatures, Journal of Climate, 21, 3687-3703, doi:10.1175/2007JCLI1875.1.

Fetterer, F., K. Knowles, W. Meier, and M. Savoie (2002), Sea Ice Index, edited, National Snow and Ice Data Center, Boulder, Colorado.

Fisher, D. A. (1991), Remarks on the deuterium excess in precipitation in cold regions, Tellus $B$, 43(5), 401-407, doi:10.1034/j.1600-0889.1991.t01-400006.x.

Fogt, R. L., and D. H. Bromwich (2006), Decadal variability of the ENSO teleconnection to the high-latitude South Pacific governed by coupling with the southern annular mode, Journal of Climate, 19(6), 979-997,

Fogt, R. L., J. Perlwitz, S. Pawson, and M. A. Olsen (2009a), Intra-annual relationships between polar ozone and the SAM, Geophys. Res. Lett., 36(4), L04707, doi:10.1029/2008gl036627.

Fogt, R. L., J. Perlwitz, A. J. Monaghan, D. H. Bromwich, J. M. Jones, and G. J. Marshall (2009b), Historical SAM Variability. Part II: Twentieth-Century Variability and Trends from Reconstructions, Observations, and the IPCC AR4 Models, Journal of Climate, 22(20), 5346-5365, 
Fujita, K., and A. Osamu (2006), Stable isotopes in daily precipitation at Dome Fuji, East Antarctica, American Geophysical Union, Washington, DC, ETATS-UNIS.

Gillett, N. P., T. D. Kell, and P. D. Jones (2006), Regional climate impacts of the Southern Annular Mode, Geophys Res Lett, 33(23), -,

Gong, D., and S. Wang (1999), Definition of Antarctic Oscillation index, Geophys. Res. Lett., 26(4), 459-462, doi:10.1029/1999gl900003.

Grove, R. H. (1998), Global impact of the 1789-93 El Nino, Nature, 393(6683), 318319 ,

Harris, J. M., R. R. Draxler, and S. J. Oltmans (2005), Trajectory model sensitivity to differences in input data and vertical transport method, J. Geophys. Res., 110(D14), D14109, doi:10.1029/2004jd005750.

Hellmer, H. H., S. S. Jacobs, and A. Jenkins (1998), Oceanic erosion of a floating Antarctic glacier in the Amundsen Sea, Antarctic Research Series(75), 83-99,

Helsen, M. M., R. S. W. van de Wal, M. R. van den Broeke, V. Masson-Delmotte, H. A. J. Meijer, M. P. Scheele, and M. Werner (2006), Modeling the isotopic composition of Antarctic snow using backward trajectories: Simulation of snow pit records, J Geophys Res-Atmos, 111(D15),

Helsen, M. M., R. S. W. Van de Wal, M. R. Van den Broeke, E. R. T. Kerstel, V. MassonDelmotte, H. A. J. Meijer, C. H. Reijmer, and M. P. Scheele (2004), Modelling the isotopic composition of snow using backward trajectories: a particular precipitation event in Dronning Maud Land, Antarctica, Ann Glaciol, 39, 293299,

Houseago, R. E., G. R. McGregor, J. C. King, and S. A. Harangozo (1998), Climate anomaly wave-train patterns linking southern low and high latitudes during South Pacific warm and cold events, International Journal of Climatology, 18(11), 1181-1193, doi:10.1002/(sici)1097-0088(199809)18:11.

IPCC (2007), Summary for policymakers Rep, Cambridge University Press, Cambridge, United Kingdom and New York, USA.

Irving, D., I. Simmonds, and K. Keay (2010), Mesoscale Cyclone Activity over the IceFree Southern Ocean:1999-2008, 17 pp., American Meteorological Society, Boston, MA, United States.

Jacobs, S. S., A. F. Amos, and Bruchhau.Pm (1970), Ross-Sea Oceanography and Antarctic Bottom Water Formation, Deep-Sea Res, 17(6), 935-\&,

Jones, J. M., R. L. Fogt, M. Widmann, G. J. Marshall, P. D. Jones, and M. Visbeck (2009), Historical SAM Variability. Part I: Century-Length Seasonal Reconstructions, Journal of Climate, 22(20), 5319-5345,

Jouzel, J., et al. (1997), Validity of the temperature reconstruction from water isotopes in ice cores, J Geophys Res-Oceans, 102(C12), 26471-26487,

Jouzel, J., et al. (2007), Orbital and millennial Antarctic climate variability over the past 800,000 years, Science, 317(5839), 793-796,

Kalnay, E., et al. (1996), The NCEP/NCAR 40-Year Reanalysis Project, $B$ Am Meteorol Soc, 77(3), 437-471, doi:10.1175/1520-0477(1996)077. 
Kidston, J., J. A. Renwick, and J. McGregor (2009), Hemispheric-Scale Seasonality of the Southern Annular Mode and Impacts on the Climate of New Zealand, Journal of Climate, 22(18), 4759-4770,

King, J. C., and J. Turner (1997), Antarctic Meteorology and Climatology, Cambridge University Press, Cambridge.

Koenker, R. (1981), A note on studentizing a test for heteroscedasticity, Journal of Econometrics, 17(1), 107-112,

Kwok, R., and J. C. Comiso (2002), Spatial patterns of variability in antarctic surface temperature: Connections to the Southern Hemisphere Annular Mode and the Southern Oscillation, Geophys Res Lett, 29(14),

Legrand, M. R., and R. J. Delmas (1986), Relative contributions of tropospheric and stratospheric sources to nitrate in Antarctic snow, Tellus B, 38B(3-4), 236249, doi:10.1111/j.1600-0889.1986.tb00190.x.

Legrand, M. R., and P. Mayewski (1997), Glaciochemistry of polar ice cores: A review, Rev Geophys, 35(3), 219-243,

Lythe, M. B., D. G. Vaughan, and B. C. the (2001), BEDMAP: A new ice thickness and subglacial topographic model of Antarctica, J. Geophys. Res., 106(B6), 1133511351, doi:10.1029/2000jb900449.

Marshall, G. J. (2003), Trends in the southern annular mode from observations and reanalyses, Journal of Climate, 16(24), 4134-4143,

Marshall, G. J. (2007), Half-century seasonal relationships between the Southern Annular mode and Antarctic temperatures, International Journal of Climatology, 27(3), 373-383, doi:10.1002/joc.1407.

Masson-Delmotte, V., M. Delmotte, V. Morgan, D. Etheridge, T. van Ommen, S. Tartarin, and G. Hoffmann (2003), Recent southern Indian Ocean climate variability inferred from a Law Dome ice core: new insights for the interpretation of coastal Antarctic isotopic records, Clim Dynam, 21(2), 153166, doi:10.1007/s00382-003-0321-9.

Masson-Delmotte, V., et al. (2008), A review of Antarctic surface snow isotopic composition: Observations, atmospheric circulation, and isotopic modeling, Journal of Climate, 21(13), 3359-3387,

Mayewski, P. A., and F. White (2002), The Ice Chronicles, University Press of New Englan, Hanover and London.

Mayewski, P. A., et al. (2009), State of the Antarctic and Southern Ocean Climate System (SASOCS), Rev Geophys, 47, 1-38, doi:10.1029/2007RG000231.

Mayewski, P. A., et al. (2005), The International Trans-Antarctic Scientific Expedition (ITASE): an overview, Annals of Glaciology, 41, 180-185,

Merlivat, L., and J. Jouzel (1979), Global Climatic Interpretation of the DeuteriumOxygen 18 Relationship for Precipitation, J. Geophys. Res., 84(C8), 5029-5033, doi:10.1029/JC084iC08p05029.

Michalski, G., J. G. Bockheim, C. Kendall, and M. Thiemens (2005), Isotopic composition of Antarctic Dry Valley nitrate: Implications for NO sources and 
cycling in Antarctica, Geophys. Res. Lett., 32(13), L13817, doi:10.1029/2004gl022121.

Michelangeli, P.-A., R. Vautard, and B. Legras (1995), Weather regimes: Recurrence and quasi stationarity, Journal of the Amosphereic Sciences, 52, 1237-1256,

Mo, K. C. (2000), Relationships between low-frequency variability in the Southern Hemisphere and sea surface temperature anomalies, Journal of Climate, 13(20), 3599-3610,

Mo, K. C., and R. W. Higgins (1998), The Pacific-South American modes and tropical convection during the Southern Hemisphere winter, Mon Weather Rev, 126(6), 1581-1596,

Mo, K. C., J. Pfaendtner, and E. Kalnay (1987), A GCM Study on the Maintenance of the June 1982 Blocking in the Southern Hemisphere, Journal of the Atmospheric Sciences, 44(8), 1123-1142,

Monahan, A. H., J. C. Fyfe, M. H. P. Ambaum, D. B. Stephenson, and G. R. North (2009), Empirical Orthogonal Functions: The Medium is the Message, Journal of Climate, 22(24), 6501-6514,

Neelin, J. D., D. S. Battisti, A. C. Hirst, F.-F. Jin, Y. Wakata, T. Yamagata, and S. E. Zebiak (1998), ENSO theory, J. Geophys. Res., 103(C7), 14261-14290, doi:10.1029/97jc03424.

Noone, D., and I. Simmonds (2004), Sea ice control of water isotope transport to Antarctica

and implications for ice core interpretation, Journal of Geophysical Research, 109, doi:10.1029/2003JD00422.

O'Donnell, R., N. Lewis, S. McIntyre, and J. Condon (2010), Improved Methods for PCA-Based Reconstructions: Case Study Using the Steig et al. (2009) Antarctic Temperature Reconstruction, Journal Of Climate, 24(8), 2099-2115, doi:10.1175/2010jcli3656.1.

Osterberg, E. C., M. J. Handley, S. B. Sneed, P. A. Mayewski, and K. J. Kreutz (2006), Continuous ice core melter system with discrete sampling for major ion, trace element, and stable isotope analyses, Environ Sci Technol, 40(10), 33553361 ,

Parish, T. R., and D. H. Bromwich (1987), The Surface Windfield over the Antarctic Ice Sheets, Nature, 328(6125), 51-54,

Pezza, A., H. Rashid, and I. Simmonds (2011), Climate links and recent extremes in antarctic sea ice, high-latitude cyclones, Southern Annular Mode and ENSO, Clim Dynam, 1-17, doi:10.1007/s00382-011-1044-y.

Pielke, R. A., and C. N. Landsea (1999), La Nina, El Nino, and Atlantic hurricane damages in the United States, B Am Meteorol Soc, 80(10), 2027-2033,

Reynolds, R. W., N. A. Rayner, T. M. Smith, D. C. Stokes, and W. Q. Wang (2002), An improved in situ and satellite SST analysis for climate, Journal of Climate, 15(13), 1609-1625, 
Rhodes, R. H. (2011), Insights into Late Holocene climate of the Ross Sea region, Antarctica, from high resolution ice core chemistry, Victoria University of Wellington, Wellington.

Rhodes, R. H., N. A. N. Bertler, J. A. Baker, S. B. Sneed, H. Oerter, and K. R. Arrigo (2009), Sea ice variability and primary productivity in the Ross Sea, Antarctica, from methylsulphonate snow record, Geophys Res Lett, 36,

Rignot, E., J. L. Bamber, M. R. Van Den Broeke, C. Davis, Y. H. Li, W. J. Van De Berg, and E. Van Meijgaard (2008), Recent Antarctic ice mass loss from radar interferometry and regional climate modelling, Nat Geosci, 1(2), 106-110,

Saltzman, E. S., G. W. Brass, and D. A. Price (1983), Mechanism of sulfate aerosol formation: chemical and sulfur isotopic evidence, Geophysical Research Letters, 10, 513-516,

Scarchilli, C., M. Frezzotti, and P. M. Ruti (2010), Snow precipitation at four ice core sites in East Antarctica: provenance, seasonality and blocking factors, Clim Dynam, doi:10.1007/s00382-010-0946-4.

Schlosser, E., C. Reijmer, H. Oerter, and W. Graf (2004), The influence of precipitation origin on the 180T relationship at Neumayer station, Ekstromisen, Antarctica, Annals of Glaciology, 39, 41-48,

Schlosser, E., H. Oerter, V. Masson-Delmotte, and C. Reijmer (2008), Atmospheric influence on the deuterium excess signal in polar firn: implications for icecore interpretation, J Glaciol, 54(184), 117-124,

Simmonds, I. (2003), Modes of atmospheric variability over the Southern Ocean, Journal of Geophysical Research, 108(C4), doi:10.1029/2000JC000542.

Simmonds, I., and T. H. Jacka (1995), Relationships between the Interannual Variability of Antarctic Sea Ice and the Southern Oscillation., Journal of Climate, 8(3), 637-648, doi:10.1175/15200442(1995)008<0637:RBTIVO>2.0.C0;2.

Simmonds, I., and D. A. Jones (1998), The mean structure and temporal variability of the semiannual oscillation in the southern extratropics, International Journal of Climatology, 18(5), 473-504, doi:10.1002/(sici)1097-0088(199804)18:5.

Simmonds, I., and J. C. King (2004), Global and hemispheric climate variations affecting the Southern Ocea, Antarctic Sceince, 16(4), 401-413, doi:10.1017/S0954102004002226.

Simmonds, I., K. Keay, and E. P. Lim (2003), Synoptic activity in the seas around Antarctica, Mon Weather Rev, 131(2), 272-288,

Sinclair, K. E., N. A. N. Bertler, and W. J. Trompetter (2010), Synoptic controls on precipitation pathways and snow delivery to high-accumulation ice core sites in the Ross Sea region, Antarctica, J Geophys Res-Atmos, 115, D22112,

Smith, C. A., and P. D. Sardeshmukh (2000), The effect of ENSO on the intraseasonal variance of surface temperatures in winter, International Journal of Climatology, 20(13), 1543-1557, doi:10.1002/10970088(20001115)20:13<1543::aid-joc579>3.0.co;2-a. 
Steig, E. J., D. P. Schneider, S. D. Rutherford, M. E. Mann, J. C. Comiso, and D. T. Shindell (2009), Warming of the Antarctic ice-sheet surface since the 1957 International Geophysical Year (vol 457, pg 459, 2009), Nature, 460(7256), 766-766,

Steinhoff, D. F., D. H. Bromwich, M. Lambertson, S. L. Knuth, and M. A. Lazzara (2008), A dynamical investigation of the May 2004 McMurdo Antarctica severe wind event using AMPS, Mon Weather Rev, 136(1), 7-26,

Thompson, D. W., and S. Solomon (2002), Interpretation of recent Southern Hemisphere climate change, Science, 296(5569), 895-899, doi:10.1126/science.1069270296/5569/895 [pii].

Torrence, C., and G. P. Compo (1998), A Practical Guide to Wavelet Analysis, B Am Meteorol Soc, 79(1), 61-78, doi:doi:10.1175/15200477(1998)079<0061:APGTWA>2.0.CO;2.

Trenberth, K. E. (1997), The definition of El Nino, B Am Meteorol Soc, 78(12), 27712777 ,

Turner, J. (2004), Review: The El Niño-Southern Oscillation and Antarctica, International Journal of Climatology, 24, 1-31, doi:10.1002/joc.965.

Turner, J., R. Bindschandler, P. Convey, G. di Prisco, E. Fahrbach, J. Gutt, D. Hodgson, P. A. Mayewski, and C. P. Summerhayes (Eds.) (2009), Antarctic Climate Change and the Environment, 526 pp., UK, Scientific Committee on Antarctic Research, Cambridge.

van Loon, H. (1967), The half-yearly oscillations in middle and high southern latitudes and the coreless winter. ,Journal of the Amosphereic Sciences, 24, 472-486,

Vimeux, F., V. Masson, J. Jouzel, J. R. Petit, E. J. Steig, M. Stievenard, R. Vaikmae, and J. W. C. White (2001), Holocene hydrological cycle changes in the Southern Hemisphere documented in East Antarctic deuterium excess records, Clim Dynam, 17(7), 503-513, doi:10.1007/pl00007928.

Wilson, T. R. S. (1975), Salinity and the major elements of sea water, in Chemical Oceanography, edited by J. P. Riley and G. Skirrow, pp. 365-413, Academic, London.

Yuan, X. J. (2004), ENSO-related impacts on Antarctic sea ice: a synthesis of phenomenon and mechanisms, Antarct Sci, 16(4), 415-425, 
Facing Page: Clear skies and storms, Roosevelt Island, Ross Sea region, Antarctica Photo: Bradley Markle, 2010 


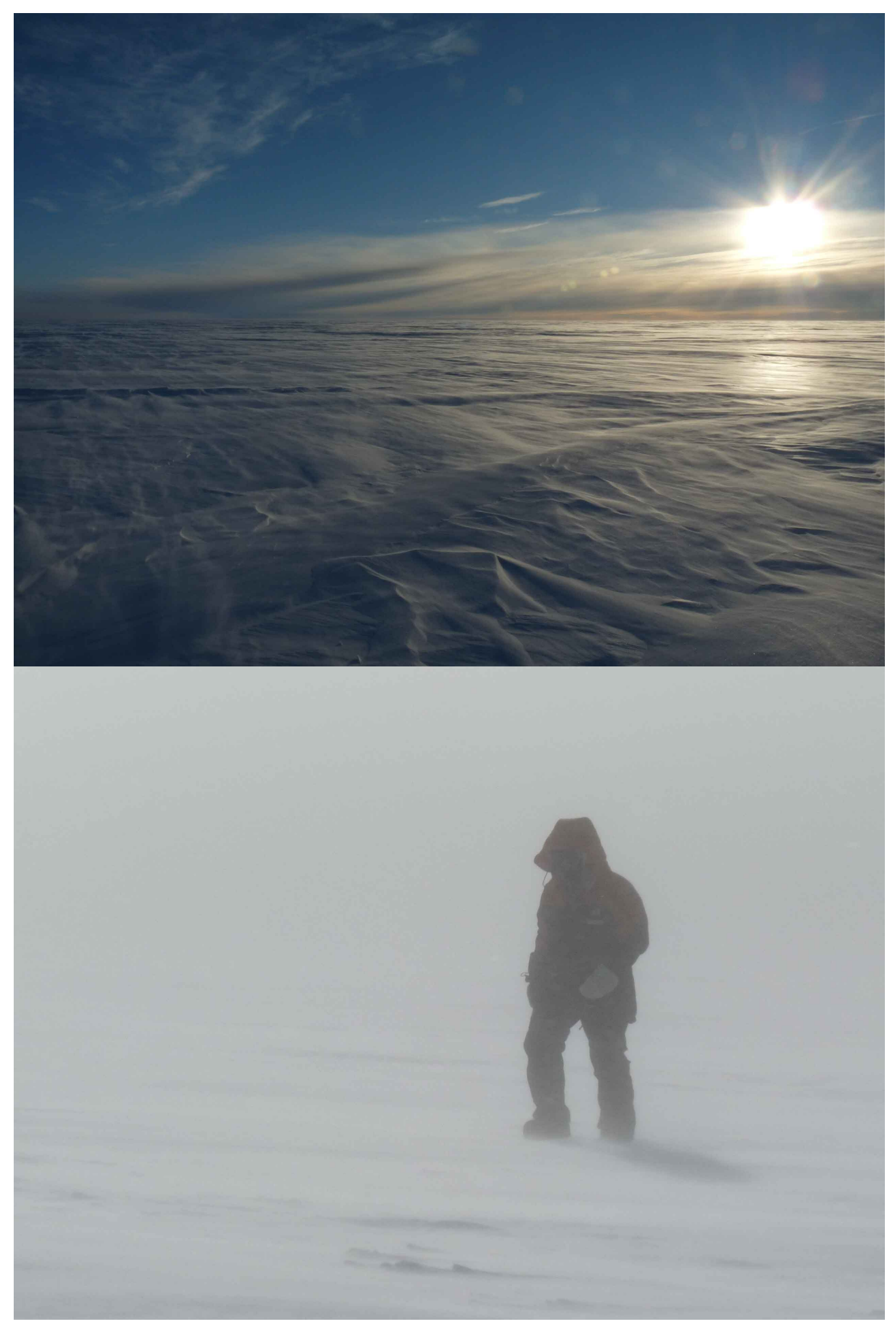

